\title{
Exposition von Proteinen \\ auf der Oberfläche von Escherichia coli Zellen: \\ mechanistische Betrachtung \\ und biotechnologische Anwendung
}

\author{
Dissertation \\ zur Erlangung des Doktorgrades \\ der Mathematisch-Naturwissenschaftlichen Fakultäten \\ der Georg-August-Universität zu Göttingen
}

vorgelegt von

Alexander Wentzel

aus Hamburg 
Referent:

Korreferent:

Tag der mündlichen Prüfung:
PD Dr. Harald Kolmar

PD Dr. Wilfried Kramer

7. Mai 2003 
Meinen Eltern 


\section{Inhaltsverzeichnis}

1. Einführung und Zielsetzung 1

1.1 Die prokaryotische Zelle 2

1.2 Die Bakterienhülle 3

1.3 Gram-negative Bakterien ___ 3

1.3.1 Aufbau der Bakterienhülle Gram-negativer Bakterien ___ 3

1.3.2 Proteine der äußeren Membran___ 4

1.3.3 Export von Proteinen durch die äußere Membran __ 5

1.3.3.1 Enterohaemorrhagische Escherichia coli (EHEC)___ 5

1.3.3.2 Das EHEC Intimin EaeA 6

\subsection{Oberflächenpräsentation von Proteinen und biotechnologische Anwendungen 8}

1.4.1 Präsentation von Peptiden und Proteinen auf Bakteriophagen (phage display) 10

1.4.2 Zelloberflächenpräsentation auf der Hefe Saccharomyces cerevisiae (yeast surface display) 11

1.4.3 Ausschließliche in vitro Methoden der Genotyp-Phänotyp-Kopplung (ribosome display und mRNA display) 12

1.4.4 Verfahren zur Oberflächenpräsentation von Peptiden und Proteinen auf Bakterienzellen (bacterial surface display)

1.4.4.1 Porin vermittelte Exposition auf der Zelloberfläche 13

1.4.4.2 Exposition auf Flagellen/Fimbrien___ 14

1.4.4.3 Durch Autotransport-Proteine vermittelte Oberflächenexposition 14

1.4.4.4 Ice nucleation protein (INP) vermittelte Präsentation ___ 15

1.4.4.5 Zelloberflächenpräsentation auf Gram-positiven Bakterien ___ 15

1.5 Zielsetzung 16

2. Ergebnisse 17

2.1 Aufbau eines EHEC-Intimin basierten Präsentationsverfahrens 19

2.1.1 Konstruktion des Plasmids pASKInt100 20

2.1.2 Oberflächenexposition von Fusionsproteinen über das EHEC Intimin EaeA auf Zellen von $E$. coli $\mathrm{K}-12$

2.1.3 Einfluss der Intimin-Produktion auf das klonale Wachstum und das individuelle Überleben der Zellen

2.1.4 Bestimmung und Regulation der Anzahl Oberflächen-exponierter Moleküle 25

2.1.5 Regulation der Nettoakkumulation von Intimin'-Fusionsprotein in der äußeren Membran von E. coli

2.1.5.1 Konstruktion des Plasmids pREP4-supE

2.1.5.2 Graduelle Induktion der Genexpression und Oberflächenpräsentation des Intimins 29

\subsection{Zelloberflächenpräsentation strukturell unterschiedlicher Domänen durch}

EaeA' 30

2.2.1 Präsentation von $R E I_{v}$ auf Zellen von E. coli 30

2.2.1.1 Das Bence-Jones Protein $R E I_{v}$ 
2.2.1.2 Klonierung des $R E I_{v}$ Gens in pASKInt100 31

2.2.1.3 Präsentation von $R E I_{v}$ durch Fusion an EaeA' 32

2.2.2 Präsentation von Interleukin 4 auf Zellen von E. coli 34

2.2.2.1 Homo sapiens Interleukin 4

2.2.2.2 Klonierung des Interleukin 4 Gens in pASKInt100__ 35

2.2.2.3 Präsentation von $\mathrm{Il}-4$ durch Fusion an EaeA' ___ 36

2.2.3 Vergleich der Präsentation von EETI-CK ${ }^{\text {send }}, R E I_{v}$ und Il-4 über das EaeA'-basierte Zelloberflächenpräsentationssystem 37

2.2.4 Präsentation von Calmodulin auf Zellen von E. coli 71-18P' ___ 39

2.2.4.1 Calmodulin 39

2.2.4.2 Klonierung des Calmodulin-Gens in pASKInt100 40

2.2.4.3 Präsentation von Calmodulin durch Fusion mit EaeA' 41

2.2.5 Präsentation von Streptomyces clavuligerus $\beta$-Laktamase Inhibitor Protein $(B L I P)$ auf Zellen von E. coli 71-18P' 43

2.2.5.1 Das Streptomyces clavuligerus $\beta$-Laktamase Inhibitor Protein (BLIP) 43

2.2.5.2 Klonierung des BLIP-Gens in pASKInt100__ 44

2.2.5.3 Präsentation von BLIP durch Fusion mit EaeA' 44

2.2.6 Präsentation von E. coli TEM-1 $\beta$-Laktamase auf Zellen von 71-18___ 46

2.2.6.1 Die TEM-1 $\beta$-Laktamase von Escherichia coli ___ 46

2.2.6.2 Klonierung des TEM-1 $\beta$-Laktamase-Gens in pASKInt100 _ 47

2.2.6.3 Präsentation von TEM-1 $\beta$-Laktamase durch Fusion mit EaeA' ___ 47

2.2.6.4 Zufallsmutagenese zur Erzeugung und Präsentation von $\beta$-Laktamase-Varianten _48

2.2.7 Zur biotechnologischen Anwendung: Anreicherung das Sendai-Epitop präsentierender Zellen aus einem Klongemisch 50

3. Diskussion 53

4. Material 61

4.1 Stämme von Escherichia coli 61

4.2 Plasmide 62

4.3 Oligodesoxyribonukleotide _ 63

4.3.1 Oligodesoxyribonukleotide für die Sequenzierung ___ 63

4.3.2 Oligodesoxyribonukleotide für die Amplifikation mittels PCR 64

4.4 DNA-Längenstandards und Protein-Molekulargewichtsmarker___ 64

4.4.1 DNA-Längenstandards ___ 64

4.4.2 Molekulargewichtsmarker für Proteine __ 65

4.5 Chemikalien __ 65

4.6 Enzyme und Proteine___ 67

4.7 Sonstige Materialien und Geräte ___ 67

4.8 Zusammensetzung der Nährmedien ___ 70

4.9 Lösungen und Puffer _ 
4.10 Verwendete Computer-Software 74

5. Methoden 75

5.1 Handhabung von Bakterien 75

5.1.1 Lagerung von Escherichia coli___ 75

5.1.2 Vermehrung von Escherichia coli __ 75

5.1.3 Transformation von Escherichia coli___ 75

5.2 Molekularbiologische Arbeitsmethoden _ 76

5.2.1 Vorbereitung von Geräten und Lösungen____ 76

5.2.2 Reinigung und Präzipitation von Nukleinsäuren ___ 76

5.2.2.1 Alkoholische Präzipitation von DNA _ 76

5.2.2.2 Extraktion von DNA in wässrigen Lösungen mit Phenol, Phenol/Chloroform oder Chloroform__ 76

5.2.3 Agarosegelelektrophorese von Nukleinsäuren ___ 77

5.2.4 Reinigung von DNA aus Agarosegelen ___ 77

5.2.5 Abtrennung von Oligonukleotiden und kurzen DNA-Fragmenten mit Hilfe des NucleotraPCR-Kits (Macherey \& Nagel)___ 77

5.2.6 Isolierung von Plasmid-DNA___ 78

5.2.7 Bestimmung der Konzentration von DNA in wässrigen Lösungen ___ 78

5.3 Enzymatische Manipulation von DNA___ 78

5.3.1 Klonierung von DNA-Fragmenten in Escherichia coli __ 78

5.3.2 Spaltung von DNA mit Restriktionsendonukleasen ___ 79

5.3.3 Auffüllen überhängender DNA-Enden___ 80

5.3.4 Ligation von DNA-Fragmenten __ 80

5.3.5 Polymerase-Kettenreaktion (PCR) __ 80

5.3.6 DNA-Sequenzbestimmung___ 81

5.4 Proteinchemische Arbeitsmethoden ___ 82

5.4.1 Bestimmung der Konzentration von Proteinen in einer wässrigen Lösung ___ 82

5.4.2 Präparation von Proteinen der äußeren Membran von Escherichia coli-Zellen____ 83

5.4.3 Denaturierende Polyacrylamidgelelektrophorese (SDS-PAGE) __ 83

5.4.3.1 Herstellung 12,5\% iger (v/v) Polyacrylamidgele ___ 83

5.4.3.2 Durchführung der SDS-Polyacrylamidgelelektrophorese ___ 84

5.4.3.3 Entwicklung eines SDS-Polyacrylamidgels____ 84

5.4.4 Biochemischer Nachweis von $\beta$-Laktamase____ 84

5.4.5 Nachweis von Proteinen auf Nitrozellulose-Membranen (Western Blot)____ 84

\subsection{Zellbiologische Arbeitsmethoden ___ 85}

5.5.1 Induktion der Expression in Bakterienkulturen ___ 85

5.5.2 Fluoreszenzmarkierung von Escherichia coli Zellen ___ 85

5.5.3 Durchflusszytometrie und Fluoreszenz-aktivierte Zellsortierung von Escherichia coli Zellen _ 86

6. Zusammenfassung _ 87

7. Literatur 289 
8. Anhang 107

8.1 Abkürzungen ___ 107

8.2 Sequenzen __ 110

8.2.1 pASKInt100-P 110

8.2.2 pREP4-supE _ 119

8.3 Danksagung ___ 121

8.4 Lebenslauf___ 122 


\section{Einführung und Zielsetzung}

Wasser in seiner flüssigen Form, eine Quelle freier Energie und organische Substanzen, die zur Selbst-Assemblierung befähigt waren, stellten drei wichtige Grundvoraussetzungen für die Entstehung des Lebens auf der Erde dar (Monnard \& Deamer, 2002). Flüssiges Wasser ist essentiell für alles heutige Leben, und es ist kaum vorstellbar, dass Leben ohne dessen Anwesenheit existieren kann. Die Sonne oder chemische Reaktionen unter der Erde oder unter Wasser kommen als mögliche Lieferanten freier Energie in Betracht, je nachdem ob das Leben auf oder unterhalb der Erdoberfläche entstanden ist. Zur spontanen Assemblierung befähigte Substanzen waren die notwendigen Bausteine für die Synthese von Polymeren und die Entstehung von Grenzstrukturen.

Der Kompartimentierung, der Eingrenzung chemischer Verbindungen hoher Konzentration und komplexer Struktur in einem abgeschlossenen Raum, kommt bei der Entstehung zellulären Lebens neben der Anwesenheit auf Katalyse basierter Stoffwechselund Polymerisationsreaktionen und der Befähigung zur Selbstreproduktion eine Schlüsselstellung zu (Fleischaker, 1990, Deamer et al., 1994, Lazcano, 1994a,b, Deamer, 1997, Tawfik \& Griffiths, 1998, Luisi et al., 1999, Szostak et al., 2001). Die damit verbundene Einschränkung der Bewegungsfreiheit von Molekülen entgegen dem allgegenwärtigen Bestreben nach Erhöhung des Entropiegehalts ist in sogenannten Biomembranen verwirklicht (Abb. 1).

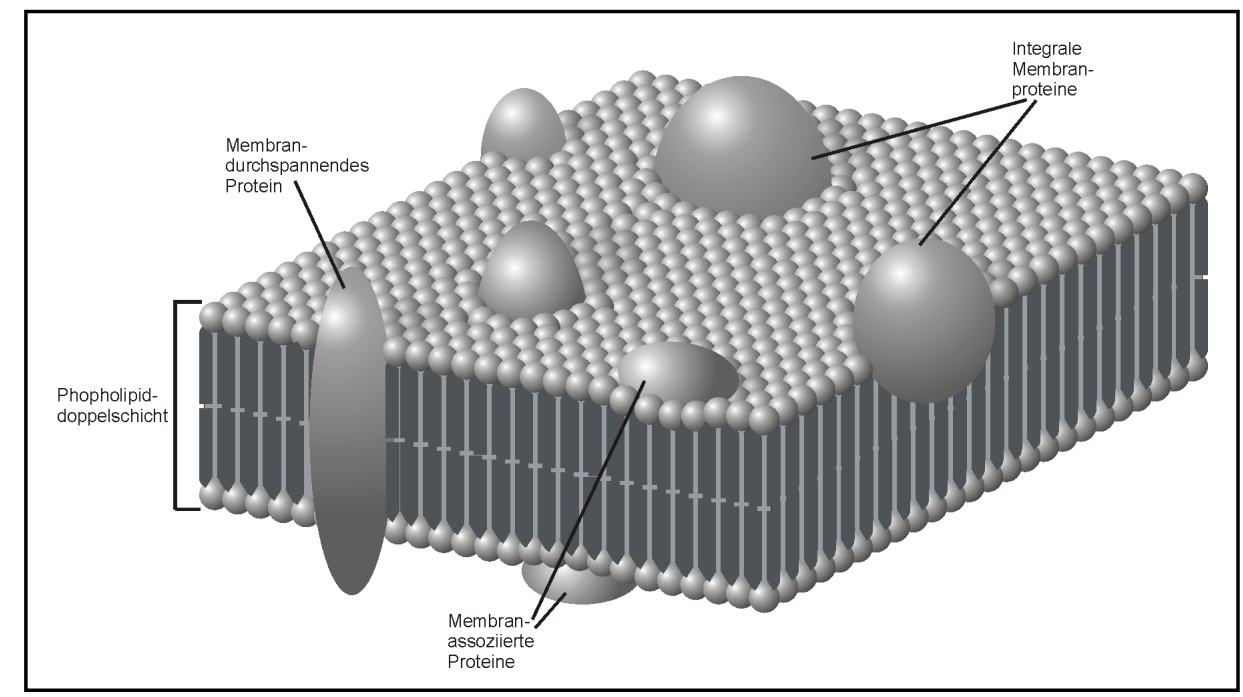

Abbildung 1: Schematische Darstellung einer Biomembran.

Biomembranen bestehen hauptsächlich aus einer von Phospholipiden gebildeten Doppelschicht mit hydrophiler Oberfläche und hydrophobem Inneren. Ihr Anteil an Proteinen kann in Abhängigkeit von der Funktion der Membran stark variieren. Man kann Membranproteine unterteilen in membranassoziierte und membrandurchspannende Einheiten, die nach dem von Singer und Nicholson vorgeschlagenen "fluid-mosaic" Modell in der Ebene der Membran frei beweglich sind (Singer \& Nicholson, 1972, Saffman \& Delbrück, 1975). Die Anwesenheit membrandurchspannender Proteine gewährleistet einen kontrollierten Stoffaustausch mit der umgebenden Umwelt zur Versorgung des eingeschlossenen, komplexen Netzwerkes katalytisch aktiver Komponenten im Inneren des 
Kompartiments mit Substraten und Energie. Heute nehmen hochentwickelte Biomembranen selbst entscheidende Aufgaben in der Bindung und Transduktion von Energie sowie der Beherbergung komplexer Netzwerke katalytischer Reaktionen des zellulären Stoffwechsels wahr, als Ergebnis einer Entwicklung, die mit der Entstehung der Erde ihren Anfang nahm.

Das Alter der Erde wird auf etwa 4,5 Milliarden Jahre geschätzt und die Kondensation des ersten Ozeans liegt etwa 4,4 Milliarden Jahre zurück (Wilde et al., 2001). Aus Daten der Bestimmung von Kohlenstoffisotopen in Schichten von Sedimentgestein mit einem Alter von ca. 3,8 Milliarden Jahren kann abgeleitet werden, dass das Leben auf dem Planeten und die biologische Fixierung von Kohlenstoffdioxid an diesem Ort und zu dieser Zeit seinen Anfang nahm (Mojzsis et al., 1996, Rosing, 1999, Nisbet \& Sleep, 2001, Ueno et al., 2002). Die ältesten Stromatolite lassen sich auf eine Zeit vor 3,5 Milliarden Jahren datieren, erbaut aus Ablagerungen photosynthetisch aktiver Mikroorganismen, die den heutigen Prokaryonten ähnlich waren (Walter 1983, Nisbet \& Sleep, 2001). Die Erfolgsgeschichte dieses Organismenreichs seit dieser Zeit sucht aus heutiger Sicht in der Geschichte der Natur ihresgleichen. Zu dem Zeitpunkt, als die erste eukaryotisch organisierte Zelle vor etwa 1,5 Milliarden Jahren entstand (Javaux et al., 2001), war die Entwicklung der Prokaryoten schon so weit fortgeschritten, dass bereits eine Aufspaltung des Reichs Monera in die Unterreiche der Eubakterien und Archaeen stattgefunden hatte (Whittaker \& Margulis, 1978). Zu diesem Zeitpunkt waren zahllose Arten prokaryotischer Mikroorganismen in unterschiedlichsten Habitaten der Erde angesiedelt.

\subsection{Die prokaryotische Zelle}

Prokaryoten unterscheiden sich von allen anderen Ausprägungen organismischen Lebens vor allem durch das Fehlen eines Zellkerns und anderer Membran-basierter Organellen. Auf der Grundlage vergleichender Sequenzanalyse ribosomaler mRNAs und der Gene ribosomaler Proteine kann eine Unterteilung des Reichs der Prokaryoten in die Zweige der Eubakterien und Archaeen getroffen werden (Woese et al., 1990, Lecompte et al., 2002). Die Taxonomie der Prokaryoten ist aufgrund immer neuer Sequenzinformation bis heute im Fluss, auch der ständig stattfindende laterale Gentransfer sogar zwischen nur wenig verwandten Arten erschwert häufig eine endgültige Zuordnung (Wolf et al., 2002). Wissenschaftliche Klassifizierungen können deshalb meist nur auf der Grundlage phänotypischer Ausprägungen aber auch genetischer Analysen wie dem Vergleich ribosomaler RNAs vorgenommen werden. Zur Unterscheidung von Eubakterien und Archaeen kann zum Beispiel das Fehlen von Peptidoglycan in der Zellwand von Archaeen herangezogen werden. Weiter besitzen Archaeen verzweigte Lipidreste, die mit den Glyzerinmolekülen in der Membran verethert sind (Woese et al., 1978). Die so beschaffenen Membranen ermöglichen diesen Organismen durch die auf diese Weise erreichte Stabilität ihrer Hüllen auch unter extremen Umweltbedingungen zu überleben.

Prokaryotische Zellen haben in der Regel ein Volumen zwischen $0,02 \mu \mathrm{m}^{3}$ bei einigen Mykoplasmen, den kleinsten bekannten Bakterien, und über $400 \mu \mathrm{m}^{3}$ (Koch, 1996). Ihre Zellmorphologie kann von Art zu Art von rund über stäbchenförmig bis hin zu spiralig oder Komma-förmig variieren. Auch können Bakterien in unterschiedlich angeordneten 
Verbünden von mehreren Zellen auftreten. Zudem sind die Beweglichkeit durch Flagellen und das Vorhandensein von Fimbrien oder Pili sowie die Bildung von Glykokalyx oder Sporen wichtige bakterielle Klassifizierungsmerkmale (Schlegel, 1992). Die Varianz prokaryotischer Zellformen wird von der Vielfalt evolvierter Stoffwechselwege weit überschritten. Bakterien sind an allen Stoffkreisläufen maßgeblich beteiligt und werden vom Menschen seit jeher in den vielfältigsten Anwendungsbereichen kultiviert und eingesetzt (Schlegel, 1992).

\subsection{Die Bakterienhülle}

Ein sehr wichtiges Klassifizierungsmerkmal innerhalb des Bakterienreichs ist das Auftreten einer Zellwand sowie deren Beschaffenheit. Die Zellwand determiniert die Form einer Bakterienzelle entscheidend und bildet eine elastische Barriere gegenüber der die Zelle umgebenden Umwelt. Sie gewährleistet die Integrität der Zelle selbst bei großem osmotischen Stress und ist ferner Träger von Zellorganellen wie z.B. den Flagellen (Schlegel, 1992). Die Zellwand von Eubakterien besteht größtenteils aus Peptidoglycan, dessen Grundgerüst aus den Zuckern N-Acetylglukosamin (NAG) und N-Acetylmuraminsäure (NAM) besteht. Dieses Zucker-Rückgrat ist mit kurzen Aminosäureketten quervernetzt (Rogers, 1974, van Heijenoort, 2001). Die Anfärbung der Zellwand im Zuge der GramFärbung (Gram, 1884) macht diese Methode zu dem wichtigsten Klassifizierungsmittel innerhalb der Eubakterien. Man unterscheidet nach der Anfärbbarkeit der Zellwand mit Kristall-Violett oder Safranin Gram-positive von Gram-negativen Arten. Gram-positive Bakterien besitzen demnach eine wesentlich mächtigere Zellwand aus Peptidoglycan als Gram-negative Arten (Abbildung 2). Auch das Auftreten von Teichonsäure zur Verbindung mehrerer Peptidoglycanlagen ist charakteristisch für Gram-positive Zellen (Lambert et al., 1977, Baddiley, 1989).

\subsection{Gram-negative Bakterien}

\subsubsection{Aufbau der Bakterienhülle Gram-negativer Bakterien}

Gram-negative Bakterien wie beispielsweise Escherichia coli besitzen anstelle einer dicken Zellwand eine zweite, äußere Zellmembran. Die Hülle dieser Arten zeigt somit einen deutlich komplexeren Aufbau als die Gram-positiver Bakterien (Abb. 2). Außerhalb der das Zellinnere begrenzenden Zytoplasmamembran erstreckt sich eine offene Struktur, der periplasmatische Raum. Innerhalb dieses Bereichs befindet sich eine dünne Lage aus Peptidoglycan, der Murein-Sacculus, gefolgt von der in ihrer Ausgestaltung sich von der Zytoplasmamembran deutlich unterscheidenden äußeren Membran. Der Murein-Sacculus ist eine hochmolekulare Struktur, die durch Transpeptidierung und Transglycosylierung von Murein (Peptidoglycan) entsteht (Holtje, 1998). Mit dieser Schicht kovalent verbunden ist das Braun'sche Lipoprotein, welches diese Schicht mit der äußeren Membran fest verbindet (Braun \& Rehn, 1969, Braun, 1975). Die beiden Seiten der äußeren Membran sind deutlich voneinander zu unterscheiden. Neben Lipiden und Proteinen, welche zum Teil die Membran durchspannen, befindet sich auf der Außenseite ein von Art zu Art unterschiedlich großer Anteil verschiedener Lipopolysaccharide, welche das O-Antigen beinhalten, das im Falle 
einer Infektion mit einem Gram-negativen Bakterium Hauptangriffspunkt für die Immunantwort ist (Reeves, 1995).

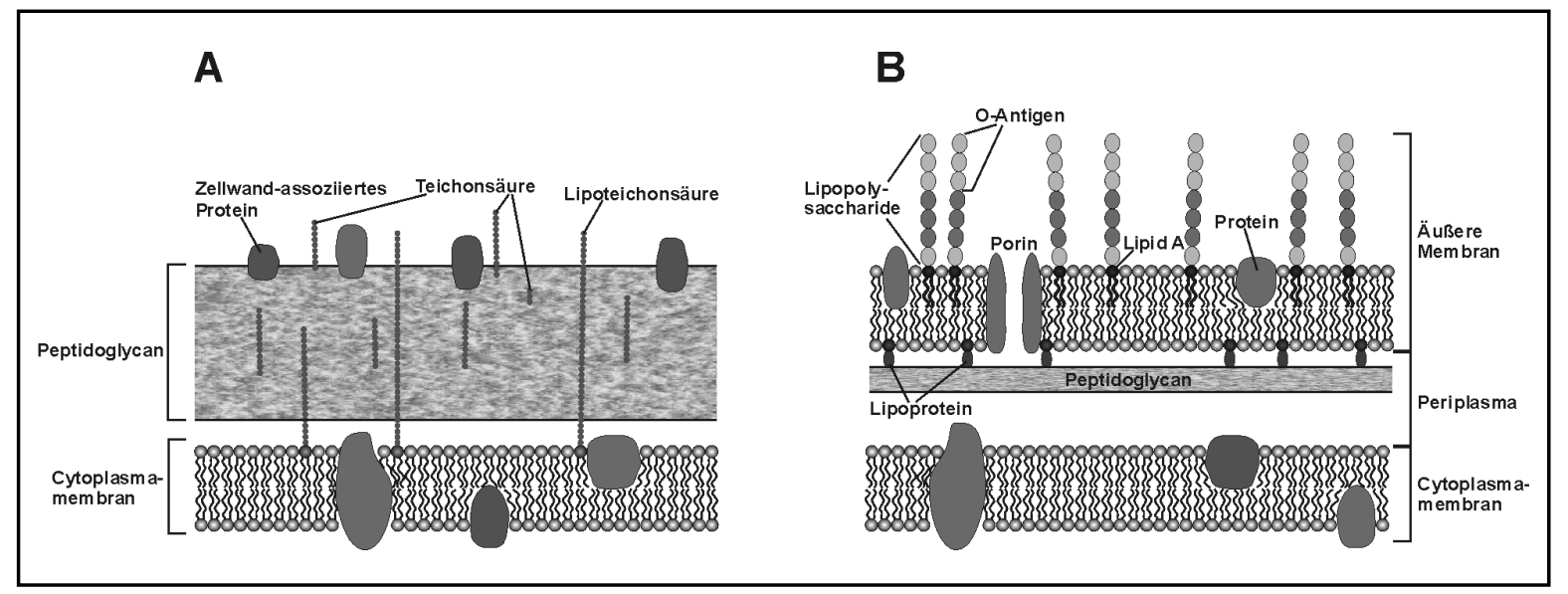

Abbildung 2: Schematische Darstellung prokaryotischer Zellhüllen. (A) Gram-positive Bakterien, (B) Gram-negative Bakterien

\subsubsection{Proteine der äußeren Membran}

Ein Anteil von etwa 50 \% der äußeren Membran Gram-negativer Bakterien besteht aus Protein, entweder in Form von Lipoproteinen, die aminoterminal mit den Membranlipiden verknüpft sind, oder als integrale Membranproteine, die die äußere Membran durchspannen. In E. coli wurden bisher mehr als ein Dutzend unterschiedliche Lipoproteine identifiziert (Blattner et al., 1997). Die Anzahl unterschiedlicher Transmembranproteine übersteigt diese Zahl noch. Einige dieser integralen Proteine wie OmpA (Chai \& Foulds, 1977) und die wichtigsten Porine (Nikaido \& Vaara, 1985, Schirmer, 1998) werden in hoher Kopienzahl auf der Oberfläche exponiert und sorgen so für eine begrenzte Durchlässigkeit der Membran. Die Synthese weiterer Membranproteine kann unter bestimmten Bedingungen stark induziert werden. Dazu zählen die Porine PhoE (Overbeeke \& Lugtenberg, 1980) und LamB Luckey \& Nikaido, 1980a,b), die TonB abhängigen Rezeptorproteine FhuA (Coulton et al., 1986) und FepA (Pugsley \& Reeves, 1976, 1977), die Komponenten vielfältiger Proteinexport Systeme, den sogenannten Autotransportern (Henderson \& Nataro, 2001), die Sekretionssyteme I, II und III [ABC Transporter (Fath \& Kolter, 1993), Komponenten des sognannten general secretion pathway (Pugsley, 1993, Sandkvist, 2001) und der Typ III Sekretionsapparat (Galan \& Collmer, 1999, Hueck, 1998)], Proteine, die an der Biogenese von Flagellen und Pili beteiligt sind und Enzyme wie die OmpT Protease (Mangel et al., 1994) und die Phospholipase A (Dekker, 2000). Viele Proteine der äußeren Membran wurden zunächst aufgrund ihrer Interaktion mit Bakteriophagen oder Bakteriozinen beschrieben, noch bevor ihre natürliche Funktion bekannt wurde. So wurde FhuA alias TonA als für die Infektion mit dem Phagen T1 notwendig beschrieben (T-one protein A), das Maltoporin $\operatorname{LamB}$ trägt seine Rezeptoreigenschaft für den Phagen $\lambda$ noch heute im Namen (Koebnik et al., 2000).

In den vergangenen Jahren wurden mehr und mehr Strukturen von Proteinen der äußeren Membran aufgeklärt (u. a. OmpA: Pautsch \& Schulz, 1998, OmpX: Vogt \& Schulz 1999, OmpF: Cowan et al., 1992, OMPLA: Snijder et al., 1999, ScrY: Forst et al., 1998, LamB: Schirmer et al., 1995, FhuA: Ferguson et al., 1998, Locher et al., 1998, FepA: Buchanan et al., 
1999, OmpT: Vandeputte-Rutten et al., 2001, OpcA: Prince et al., 2002). Demnach besteht die Faltung aller bekannten, die äußere Membran durchspannenden Proteine aus $\beta$-Fass Strukturen, während $\alpha$-Helix-Bündel Strukturen ausschließlich in Proteinen der Zytoplasmamembran vorkommen. Allgemein wird angenommen, dass dieser Befund auf die Biogenese der Proteine der äußeren Membran zurückzuführen ist. Deren Polypeptidketten müssen die Zytoplasmamembran durchqueren und würden dort inserieren, wenn sie zu hydrophobe Eigenschaften aufwiesen (Koebnik et al., 2000).

\subsubsection{Export von Proteinen durch die äußere Membran}

Alle Proteine der äußeren Membran Gram-negativer Bakterien werden im Zytoplasma synthetisiert. Der Weg, auf dem diese Proteine in die äußere Membran gelangen, ist im Vergleich zur mittlerweile gut verstandenen Translokation durch und Integration in die Zytoplasmamembran bis heute nur wenig verstanden. Insbesondere die Frage, wie bei Proteinen der äußeren Membran, die ihrerseits Domänen nach außen exponieren, diese durch die Membran transloziert werden, ist nur wenig untersucht.

Diese Arbeit soll einen Beitrag dazu leisten, die Frage des Translokationsmechnismus durch die äußere Membran Gram-negativer Bakterien am Beispiel des Intiminproteins aus pathogenen Escherichia coli paradigmatisch zu beleuchten und die daraus gewonnenen Erkenntnisse in biotechnologische Anwendungen umzusetzen.

\subsubsection{Enterohaemorrhagische Escherichia coli (EHEC)}

Escherichia coli ist das wohl am besten untersuchte Gram-negative Bakterium. Neben seiner natürlichen endosymbiontischen Funktion beim Menschen besitzt es ein vielfältiges Anwendungsspektrum in der molekular- und mikrobiologischen sowie medizinischen Forschung. Während die hier vorkommenden und verwendeten Stämme von E. coli keine krankheitserregenden Eigenschaften aufweisen, gibt es solche, deren Infektion schwere pathologische Effekte hervorrufen kann. Man unterscheidet hier nach ihren Eigenschaften und hevorgerufenen Krankheitsbildern u.a. EPEC (enteropathogenic E.coli), EHEC (enterohemorhagic E. coli), ETEC (enterotoxigenic E. coli), EAEC (enteroaggregative E. coli), DAEC (diffuse adherent E. coli), EIEC (enteroinvasive E. coli), CDEC (cell-detaching E. coli) [alle Auslöser von Durchfallerkrankungen, Nataro \& Kaper, 1998] sowie auch NMEC (neonatal meningitis E. coli, Bingen et al., 1997) und UPEC (uropathogenic E. coli, Foxman et al., 1995; Johnson et al., 1998; Zhang et al., 2000).

Enterohaemorrhagische E. coli (EHEC) sind eine der wichtigsten Arten in der Nahrung vorkommender Krankheitserreger mit sporadischer aber auch teilweise epidemischer Verbreitung und mindestens 20.000 Infektionen jährlich allein in den USA (Nataro \& Kaper, 1998). Das Bakterium besiedelt und schädigt im Verlauf der Infektion das Dickdarmepithel mit systemischem Krankheitsbild wie dem einer hämolytischen Urämie (HUS), hämolytischer Anämie, Thrombozytopänie und Nierenversagen (Karmali, 1989). Der am häufigsten auftretende Serotyp O157:H7 wird allgemein als der virulenteste angesehen.

Der initiale Schritt der EHEC Infektion ist die Anheftung des Pathogens an das Darmepithel. Im weiteren Verlauf exprimiert das Bakterium Shiga-ähnliche Toxine (Stx- 
Toxine), welche die genannten Krankheitsbilder hervorrufen. Die Anheftung von EHEC Zellen an das Epithel geht mit drastischen Veränderungen der Morphologie der Wirtszellen einher. Die Mikrovilli werden lokal zurückgebildet und es kommt zur Ausbildung filamentösen Actins, dessen Polymer einen quasi Sockel unter der Bakterienzelle formt, auf diesem die Zelle emporgehoben wird. Die so gebildete Struktur wird als A/E Lesion bezeichnet (attaching and effacing lesion; Staley et al., 1969, Ulshen \& Rollo, 1980, Moon et al., 1983) und wird auch von anderen Pathogenen hervorgerufen (EPEC: Frankel et al., 1998; Citrobacter rodentium: Schauer \& Falkow, 1993). Die Bildung der A/E Lesion ist das Ergebnis einer komplexen Interaktion zwischen dem Bakterium und der befallenen Zelle. Wie viele andere pathogene Bakterien kodieren EHEC für eine Typ III Sekretions-Maschinerie, mit der eine Reihe bakterieller Effektormoleküle in letztere eingeschleust werden und dort eine spezifische Antwort auslösen (Hueck, 1998). Es wird von einem Drei-Schritt-Mechanismus ausgegangen (Donnenberg \& Kaper, 1992): Nach einer lockeren Anheftung des Bakteriums werden über die Typ III Maschinerie Effektormoleküle in die Wirtszelle injiziert, und auf diesem Wege wird dort die soeben beschriebene Veränderung der Epithelzelle hervorgerufen (Donnenberg \& Kaper, 1991, Foubister et al., 1994a,b, Ismaili et al., 1995, Kenny \& Finlay 1995, Jarvis \& Kaper 1996, Wolff et al., 1998). Letztendlich kommt es zur dichten und festen Anheftung des Pathogens an die Epithelzellmembran (Knutton et al., 1989). Sowohl die sezernierten Effektormoleküle als auch die Proteine des Typ III Sekretionsapparates sind auf einer $35 \mathrm{~kb}$ umfassenden Pathogenitätsinsel zusammengefasst (Jarvis et al., 1995, Kenny \& Finlay, 1995, McDaniel \& Kaper, 1997, Perna et al., 1998).

\subsubsection{Das EHEC Intimin EaeA}

Ebenfalls ausgehend von dieser Pathogenitätsinsel wird das für die Virulenz der EHEC Zellen notwendige äußere Membranprotein Intimin, kodiert durch das eaeA Gen, exprimiert (Jerse et al., 1990, Beebakhee et al., 1992, Yu \& Kaper, 1992, Tzipori et al., 1995). EHEC Mutanten, die kein Intimin exprimieren, sind nach wie vor in der Lage, in den Stoffwechsel der Wirtszelle einzugreifen. Die Fähigkeit der festen Anheftung an das Epithel und die Auslösung der Actin-Kondensation haben diese Zellen jedoch verloren (Donnenberg \& Kaper, 1991, Rosenshine et al., 1992, 1996a,b, Louie et al. 1993). Die feste Anheftung der EPEC Bakterienzellen an die Wirtszelle basiert auf der Interaktion von Intimin mit dem Tir (translocated intimin receptor) Protein. Tir ist wie Intimin ein bakteriell kodiertes Protein, welches nach dem initialen Kontakt zwischen Pathogen und Wirt auf dem Wege der Typ III Sekretion transloziert wird (Kenny et al., 1997). In EHEC wird dem EspE Protein eine mit dem Tir aus EPEC vergleichbare Rolle zugesprochen. In den Wirtszellen vorgelegtes Tir führt zur festen Anhefung von Zellen sowohl von EPEC als auch von EHEC (Rosenshine et al., 1996b, Liu et al., 1999a). Tir ist sowohl carboxyterminal als auch aminoterminal in der Wirtsmembran verankert (Hartland et al., 1999).

Die Struktur von Iniminen ist am besten am Beispiel der EPEC Intimins untersucht. Intimin besitzt eine aminoterminale bakterielle Membranankerdomäne und carboxyterminale Domänen, welche für dessen Bindung von Tir nötig sind (Liu et al., 1999b). Im Jahr 2000 ist es Strynadka und Mitarbeiter gelungen, die Struktur des Intimin-Tir Komplexes zu lösen (Luo et al., 2000). 


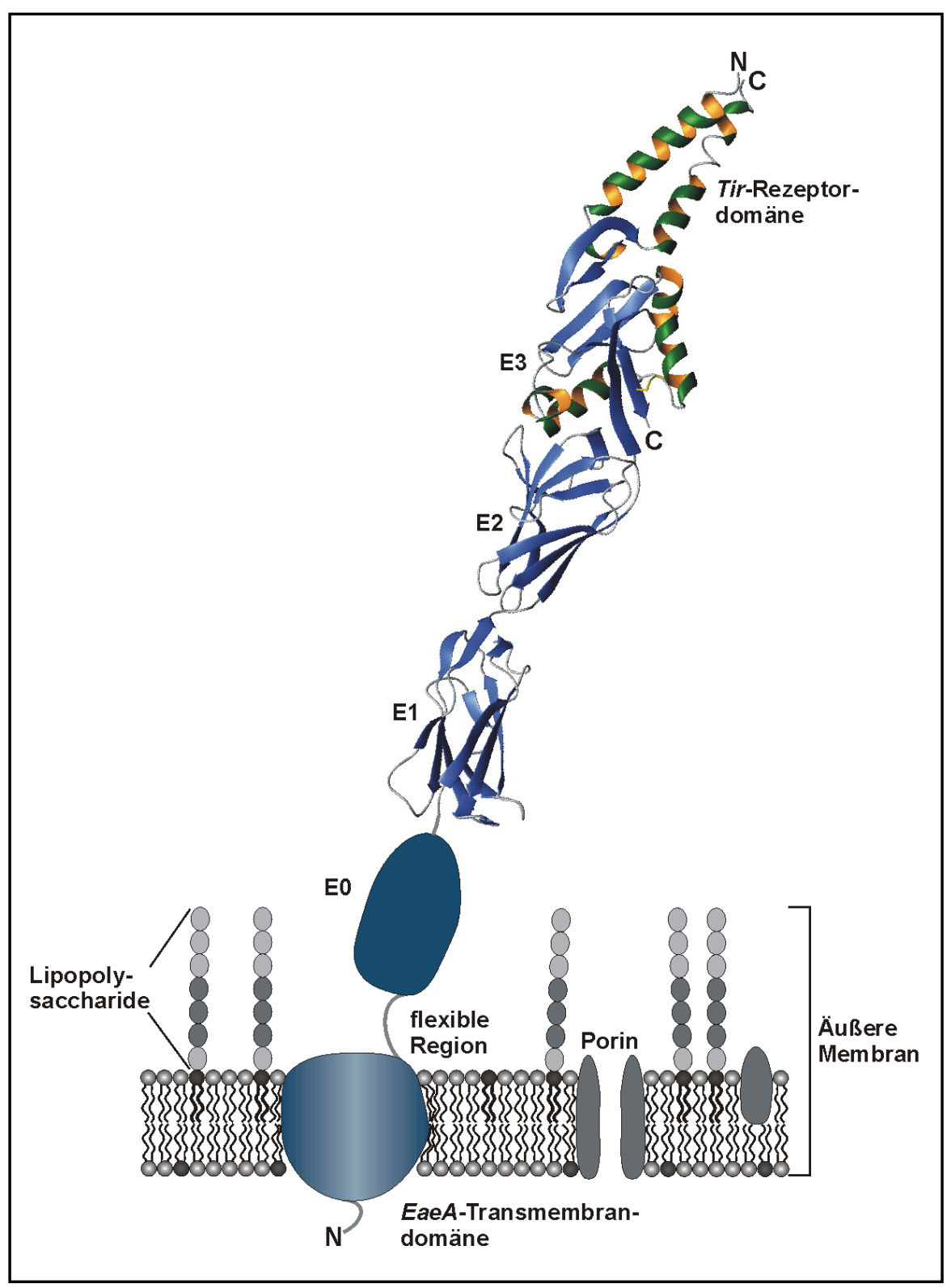

\begin{abstract}
Abbildung 3: Membraninsertion des EaeA-Proteins (Intimin) enteropathogener Escherichia coli (EPEC) und dessen Interaktion mit dem relevanten Bereich des Tir-Rezeptors. Dargestellt ist die äußere Bakterienmembran. Die vier extrazellulären Domänen E0, E1, E2 und E3 sind über eine flexible Region mit der aminoterminalen Transmembrandomäne verbunden, die in der äußeren Membran inseriert (Luo et al., 2000). Die schematische Darstellung der Struktur der Domänen E1, E2 und E3 sowie des Tir-Bereichs wurde erzeugt unter Verwendung von Molmol, Version 2K.2, Reto Konradi, PDB: 1F02, Luo et al., 2000.
\end{abstract}

Die Struktur bei 1,9 $\AA$ Auflösung umfasst die drei carboxyterminalen Domänen des Moleküls (E1: Aminosäuren \#658 bis \#751, E2: Aminosäuren \#752 bis \#841, E3: Aminosäuren \#842 bis \#939). Die Domänen E1 und E2 zeigen eine Immunglobulin-ähnliche Struktur ausschließlich aus $\beta$-Strängen bestehend, E3 weist eine Typ C Lektin-ähnliche Struktur auf. Von den Autoren wird auf der Basis von Sequenzvergleichen und der bekannten Struktur des $\beta_{1}$ Integrin bindenden Invasins aus Yersinia pseudotuberculosis (Hamburger et al., 1999) eine weitere Immunglobulin-ähnliche Domäne aminoterminal der drei benannten postuliert. Diese Domäne E0 umfasst demnach die Aminosäuren \#559 bis 
\#657, die Aminosäuren \#1 bis \#539 bilden den Membrananker, welcher $33 \%$ Sequenzidentität zu den aminoterminalen 489 Aminosäuren von Invasin aufweist. Die vier carboxyterminalen Domänen bilden nach den Strukturen von Invasin und Intimin eine gestreckte, relativ unflexible Anordnung. Den Übergang zur Transmembrandomäne bildet ein acht Aminosäuren umfassendes Segment flankiert von zwei konservierten GlycinResten. Diese Region bildet somit möglicherweise einen flexiblen Übergang zwischen der Transmembrandomäne und der gestreckten Anordnung der extrazellulären Domänen E0 bis E3, der mechanische Bewegung der letzteren zulässt (Luo et al., 2000).

\subsection{Oberflächenpräsentation von Proteinen und biotechnologische Anwendungen}

Ein Hauptziel der Molekularen Biotechnologie ist es, Proteine mit spezifischer und auf das jeweilige Bedürfnis abgestimmter Funktion zu erzeugen, die dann ihren Einsatz beispielsweise als Wirkstoffe in Medikamenten gegen Krankheiten des Menschen oder als Biokatalysatoren unterschiedlichster Funktion finden. Trotz der großen Diversität heute bekannter und charakterisierter Proteine können diese für eine Vielzahl an Anwendungen nicht unmittelbar genutzt werden. Grund dafür ist zum einen, dass Proteine mit einer relativen Molmasse von über 10.000 bis heute nicht auf chemischem Wege synthetisiert werden können. Desweiteren sind evolutiv entstandene Proteine auf maximale Funktion in zellulärer oder physiologischer Umgebung optimiert, was unter Bedingungen, in denen sie als Reagenzien eingesetzt würden, zu einem Funktionsverlust führte. Auch die Spezifität zu einem bestimmten Substrat, mit welcher evolutiv entstandene Proteine in der Regel ausgestattet sind, ist hoch und zumeist auf die Interaktion mit einem definierten zweiten Protein oder die Katalyse einer einzigen chemischen Reaktion beschränkt. Diese hohe Spezifität zeigt sich bereits daran, dass die Effizienz des Umsatzes stark absinkt, wenn einem Enzym homologe anstelle identischer Substrate angeboten werden. Besonders aufgrund dieser Spezifität ist die Optimierung eines Proteins auf einen bestimmten Verwendungszweck hin häufig indiziert.

Mit Hilfe molekularbiologischer Methoden besteht heutzutage die Möglichkeit, ausgehend von natürlichen Proteinen solche zu generieren, die einer bestimmten, gewünschten Funktion genügen. Dabei wird versucht, durch Modifikation von Proteinen eine bestimmte Funktionalität zu verändern, eine bereits vorhandene Funktionalität den jeweiligen Bedürfnissen anzupassen oder gänzlich neuartige Proteineigenschaften zu erzeugen. Disziplinen die diese Ziele verfolgen sind das rationale Protein Design oder Engineering, das de novo Protein Design und die molekulare Evolution.

Ein leistungsfähiger und heutzutage sich immer mehr durchsetzender Ansatz der Erzeugung von Proteinen mit vorgegebener, neuer Funktion beruht auf der Anwendung evolutiver Methoden. Mittels dieser ist es möglich, basierend auf der Einführung der gewünschten funktionellen Eigenschaften durch zufällige Modifikation innerhalb eines Proteins, gefolgt von Detektion und Selektion eine angestrebte, neue Funktion zu erhalten. Auf diesem Weg werden Probleme, wie sie im rationalen Protein Design auftreten, umgangen. Dort besteht das Hauptproblem darin, dass der komplexe Vorgang der Proteinfaltung nach wie vor nur wenig verstanden ist. 
Experimente zur molekularen Evolution von Nukleinsäuren gehen auf in vitro Untersuchungen zur Replikation des Phagen $Q \beta$ zurück (Mills et al., 1967). Durch in vivo durchgeführte evolutive Modifikation von katalytisch aktiven RNA-Molekülen konnte eine Veränderung der katalytischen Aktivität und Substratspezifität der Ribozyme bewirkt werden (Chapman und Szostak, 1994). Auch Aptamere, RNA-Moleküle mit einer definierten Bindungsspezifität, konnten angereichert werden (Ellington und Szostak, 1990, Sassanfar und Szostak, 1993, Lorsch und Szostak, 1994a,b, Ekland et al., 1995). Der größte Vorteil bei der Veränderung und Selektion von Nukleinsäure-Molekülen bestimmter Aktivität ist, dass im amplifizierten Molekül selbst die genetische Information innewohnt, welche nach jedem Selektionsvorgang, reverser Transkription und Amplifikation mittels PCR sofort entschlüsselbar ist. Wird hingegen ein Protein molekular evolviert, so kann dies nur durch physikalische Kopplung des selektierbaren Phänotyps an den jeweiligen Genotyp geschehen.

Es gibt heutzutage vielgestaltige Verfahren, um den Phänotyp eines Proteins mit der der Funktion zugrundeliegenden genetischen Information zu verbinden (Abb. 4). Namentlich sind dies die unterschiedlichen Methoden der Präsentation auf Bakteriophagen (phage display), auf der Oberfläche von Bakterienzellen (bacterial surface display) und Hefezellen (yeast surface display) sowie eine Reihe reiner in vitro Verfahren, bei denen die Kopplung über die Bildung von mRNA-Proteinkonjugaten ternär über das translatierende Ribosom oder kovalent über eine Puromyzin-Gruppe erfolgt.

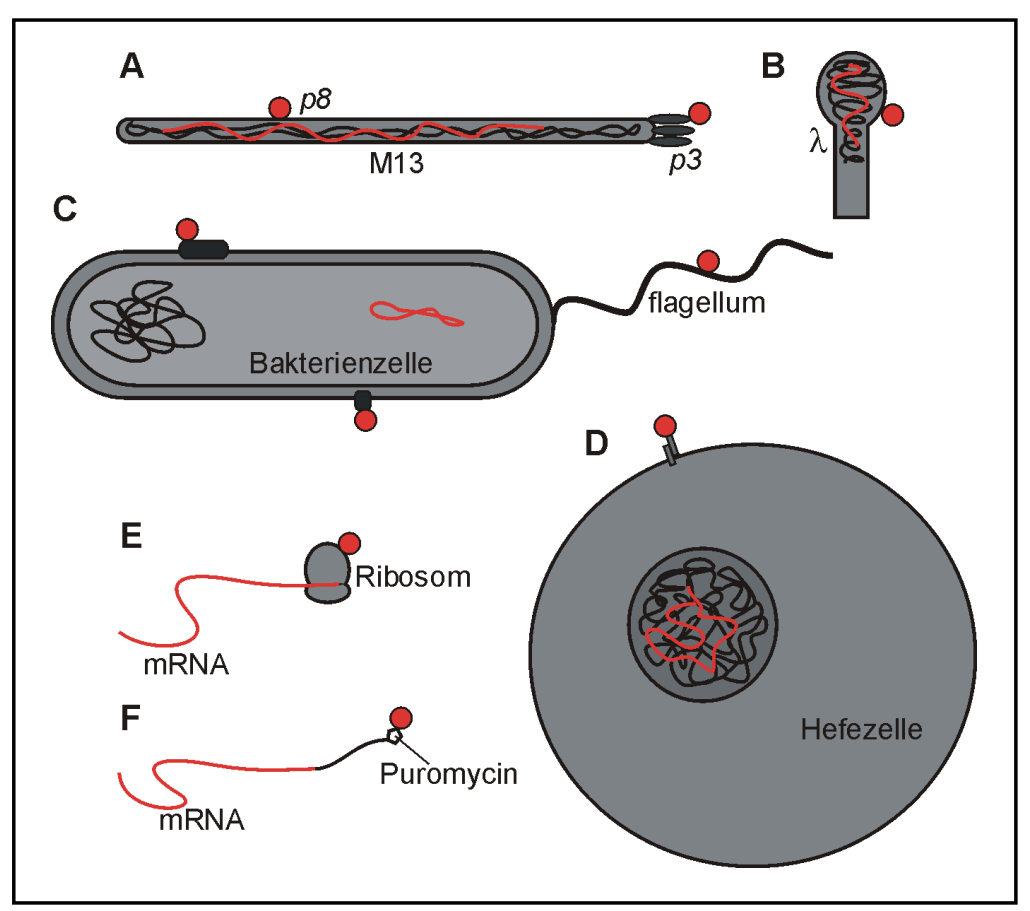

Abbildung 4: Schematische Darstellung unterschiedlicher Verfahren zur GenotypPhänotyp-Kopplung. (A) M13 phage display über p3 oder p8, (B) Lambda ( $\lambda$ ) phage display, (C) bacterial surface display über Zelloberflächenproteine (unterschiedliche Verfahren) oder Flagellenproteine, (D) yeast surface display, (E) ribosome display, (F) mRNA display. Das präsentierte Protein und die zugrundeliegende Nukleinsäure sind in rot dargestellt. 


\subsubsection{Präsentation von Peptiden und Proteinen auf Bakteriophagen (phage display)}

Die zur Zeit am weitesten verbreitete Methode, eine Genotyp-Phänotyp-Kopplung zu gewährleisten, ist mit der Technik des phage displays gegeben (Clackson \& Wells, 1994, Winter et al., 1994). Hierbei werden zur molekularen Evolution die betreffenden Proteine, welche bestimmte Bindungseigenschaften besitzen oder erlangen sollen, auf der Oberfläche vorzugsweise filamentöser E. coli Phagen wie M13, f1 oder fd präsentiert. Diese Phagenklasse eignet sich deshalb so gut für diese Art der Anwendung, weil sie ein relativ kleines Genom besitzt, in dem es leicht möglich ist, aufgrund des filamentösen Baus der Phagen Repertoires von Proteinen mit einer langen kodierenden DNA-Sequenz zu konstruieren. Außerdem sind ihre viralen Partikel (Virionen) relativ stabil, und sie können zu Titern bis zu $10^{12} / \mathrm{ml}$ akkumulieren, so dass die Möglichkeit besteht, von einem sehr großen Pool an varianten Peptiden oder Proteinen auszugehen (Hoess et al., 1993). Die zufallsmäßige Erzeugung eines Repertoires von Proteinvarianten und deren Durchmusterung auf die angestrebte Funktion erfordert ein Maximum an möglichen Varianten als Ausgangsbasis, was durch das phage display auf filamentösen Phagen gewährleistet ist. Die Größe der initialen Bibliothek ist hier wie auch beim bacterial surface display lediglich durch die Transformationseffizienz von E. coli Zellen beschränkt. Phage display ist demnach eine gemischte in vivo/in vitro Methode zur Genotyp-Phänotyp-Kopplung.

Die Präsentation von varianten Proteinen auf der Oberfläche filamentöser Phagen erfolgt zum Beispiel durch Kopplung des betreffenden varianten Gens an das für das Phagenprotein p3 kodierende Gen 3 und Produktion des Fusionsproteins. Die Phagen behalten dabei ihre Infektiösität (Smith, 1985). Die Anreicherung von Klonen mit erhöhter Affinität aus einer Bibliothek an M13 Phagen erfolgt beispielsweise durch sogenanntes biopanning, wobei eine Bindung an einer Matrix immobilisierter oder markierter Liganden (z.B. biotinyliert) erfolgt. In jeder Runde des biopanning können Binder von Nicht-Bindern mit einer Selektivität von bis zu $10^{3}$ angereichert werden. Die weitere Anreicherung besonders seltener Klone wird durch iterative Runden des pannings erreicht (Bass et al., 1990, McCafferty et al., 1990, 1994, Garrard et al., 1991). Auf diesem Wege konnten Immunglobulinfragmente $\left(s c F_{v}, F_{a b}\right)$ mit Bindungskonstanten von $10^{5}-10^{7} \mathrm{M}^{-1}$ aus Phagenbibliotheken isoliert werden (Griffiths et al., 1993, 1994, Marks et al., 1993). Auch die Affinitätsreifung der natürlichen Immunantwort konnte invitro durch ungerichtete Mutagenese der Phagen nachgestellt werden (Hawkins et al., 1992). Durch Nutzung des Zwei-Ketten-Charakters von Immunglobulinen in sogenannten kombinatorischen Infekten konnte die aufgrund der Transformationseffizienz der primären Wirtszellen begrenzte Repertoiregröße weiter erhöht werden (Waterhouse et al., 1993). Wirkliche evolutive Bedingungen wurden durch direkte Kopplung der Ligandenbindung an einen Selektionsvorteil, die Infektiösität der Phagenpartikel, erreicht. Durch Fragmentierung des p3-Proteins in eine amino- und eine carboxyterminale Domäne und die Fusion der zu untersuchenden Interaktionspartner an jeweils eine der beiden $p 3$-Domänen, vermittelt eine Assoziation die Rekonstruktion des vollständigen p3-Proteins und damit das Wiedererlangen der Infektiösität (Duenas \& Borrebaeck, 1994, Gramatikoff et al., 1994, Krebber et al., 1995). Neben der Präsentation über 33 ist auch die Präsentation über das Hüllprotein $p 8$ des Phagen M13 dokumentiert (Markland et al., 1991). Die Fusion dieses häufigsten Proteins von M13 
mit einem zu präsentierenden Protein, in angegebenem Fall dem menschlichen Wachstumshormon ( $\mathrm{hGH}$ ), führt zu einer vielfachen Exposition des Proteins, verbunden mit Aviditätseffekten, die zu Bindemoleküle mit meist nur sehr schwachen Bindeeigenschaften führen (z.B. K(d) $>1 \mu \mathrm{M}$, Sidhu et al., 2000).

Neben den filametösen Phagen wurden auch $\lambda$-Phagen zur Oberflächenpräsentation von Proteinen verwendet (Sternberg und Hoess, 1995). Durch die Verwendung des lytischen Phagen Lambda ist anders als beim auf M13 basierten Verfahren die dort nötige Sekretion über die Bakterienmembran nicht nötig, eine Einschränkung, die für Zell-basierte Verfahren in jedem Fall gegeben ist.

\subsubsection{Zelloberflächenpräsentation auf der Hefe Saccharomyces cerevisiae (yeast surface display)}

Neben den anderen Methoden zur Genotyp-Phänotyp-Kopplung kann auch die Hefe Saccharomyces cerevisiae für die Isolierung von Proteinen mit verbesserten Bindeeigenschaften verwendet werden (Shusta et al., 1999). In diesem Fall ist es möglich, auch eukaryotische Proteine in ihrer nativen, funktionalen Konformation auf der Oberfläche von Hefezellen zu präsentieren (Boder \& Wittrup, 1997). Die Proteine werden mit dem Carboxyterminus der Aga2 Untereinheit des $\alpha$-Agglutinins der Hefe fusioniert, dem Rezeptor für die Adhäsion der Zellen bei der Kreuzung. Die Aga2-Fusion wird über Disulfidbrücken mit dem Aga1-Peptid kovalent verknüpft, welches wiederum kovalent mit der Zellwand der Hefezelle über Phosphatidyl-Inositol-Glykan verbunden ist. Auf diese Weise präsentiert jede Zelle einer molekularen DNA-Bibliothek das korrespondierende Protein auf der Zelloberfläche, fest verankert in der Zellwand. Dort besteht die Möglichkeit der Funktionsabfrage beispielsweise bezüglich der Liganden-Bindung. Ein Nachweis kann hier durch Durchflusszytometrie erfolgen, eine Anreicherung durch Fluoreszenz-aktivierte oder andere Methoden der Zellsortierung bewerkstelligt werden.

Anfänglich wurde das Verfahren zur Selektion bezüglich der Ligandenbindung verbesserter, gegen Fluorescein gerichteten Ein-Ketten $F_{v}$ Antikörperfragmenten aus zufallsmäßig erzeugten molekularen Bibliotheken verwendet. Nach Einführung zufälliger Mutationen in einem Mutatorstamm von E. coli konnten Varianten mit um das Dreifache verringerter Dissoziiationsrate angereichert werden (Boder \& Wittrup, 1997). In einem anderen Ansatz konnten $s c F_{v}$ Varianten mit erhöhter Affinität zu einer löslichen T-Zell Rezeptor-Domäne erhalten werden (Kieke et al., 1997). Mit diesem Verfahren sollte es möglich sein, eine Vielzahl unterschiedlicher Rezeptoren antagonistisch zu adressieren (Cereghino \& Cregg, 1999). Das Hauptproblem eines auf der Hefe beruhenden Verfahrens zur Selektion von Proteinvarianten liegt in der Limitierung der Größe zu erzeugender Bibliotheken. Es ist bis heute nicht gelungen, die Transformationseffizienz der Zellen bis in einen Bereich zu steigern, der die Erzeugung komplexer Repertoires, die mehr als einige Millionen individuelle Klone umfassen, erlaubt. 


\subsubsection{Ausschließliche in vitro Methoden der Genotyp-Phänotyp-Kopplung (ribosome display und mRNA display)}

Von einer Limitierung aufgrund zellulärer Transformationseffizienzen frei sind Methoden zur Genotyp-Phänotyp-Kopplung in vitro, zu denen unter anderem das ribosome display und das mRNA display zählen. Mit ihnen ist es möglich, Bibliotheken mit bis zu $10^{14}$ Varianten zu erzeugen und zu handhaben. Außerdem lassen diese Ansätze den Zusatz bestimmter Reagenzien während eines Selektionsexperimentes zu, was in Zell-basierten Verfahren nur schwer möglich ist. Technologien zur in vitro Selektion lassen sich in zwei Gruppen unterteilen. Die erste Gruppe umfasst solche Ansätze, die auf der Translation und Selektion in einer Wasser-in-Öl Emulsion, also auf Mikrokompartimentierung beruhen (Tawfik \& Griffiths, 1998, Doi \& Yanagawa, 1999, Griffiths \& Tawfik, 2000, Ghadessy et al., 2001), der Imitierung lebender Zellen. Die zweite Gruppe sind die invitro Präsentationstechnologien, die eine Genotyp-Phänotyp-Kopplung durch physikalische Verknüpfung von mRNA und der auf deren Grundlage entstehenden Polypeptidkette während der Translation bewerkstelligt. Die beiden bekanntesten Verfahren, das ribosome display und das $m R N A$ display sollen im Folgenden näher erläutert werden. Das ribosome display wurde zunächst für die Selektion von Peptiden entwickelt (Mattheakis et al., 1994). Es folgte eine Ausweitung des Anwendungsspektrums auf gefaltete Proteine (Hanes \& Plückthun, 1997, He \& Taussig, 1997). Die Methode beruht auf der Bildung eines ternären Komplexes aus einer mRNA, dem Ribosom und der durch die Translation der erstgenannten entstandenen Polypeptidkette. Das erzeugte Fusionsprotein ist mit einem carboxyterminalen Linkerpeptid gekoppelt, das im Ribosom verbleibt, während die zu präsentierende Domäne in der Lage ist zu falten. Die translatierte mRNA besitzt kein Stop-Kodon, so dass diese nicht von dem Ribosom freigesetzt werden kann. Eine hohe Magnesiumkonzentration und geringe Temperaturen stabilisieren den ternären Komplex weiter. Das auf diesem Wege mit seiner kodierenden mRNA verbundene Protein kann direkt für die Selektion auf gewünschte Eigenschaften eingesetzt werden (Amstutz et al., 2001). Das mRNA display ist konzeptionell mit dem ribosome display verwandt und wird auch als "mRNA-protein fusions" (Roberts \& Szostak, 1997) oder "in vitro virus" (Nemoto et al., 1997) bezeichnet. Dieses Verfahren beruht auf der kovalenten Verknüpfung der mRNA mit der durch Translation entstandenen Peptidkette. Die mRNA wird kovalent mit einer kurzen Linker-DNA verbunden, die eine Puromyzin-Gruppe enthält. Wenn im Rahmen der in vitro Translation das Ribosom den Übergang von der mRNA zur DNA erreicht, hält es inne, während die Puromyzin-Gruppe in der Peptidyltransferase-Stelle des Ribosoms bindet und dort mit der Peptidkette kovalent verknüpft wird. Das mRNA-Protein Konstrukt wird isoliert und vom Ribosom befreit. An dieser Stelle wird meist eine reverse Transkription angeschlossen, um einen cDNA-Strang als Komplement zur mRNA zu generieren, bevor das RNA-DNA Hybrid für eine Selektion Verwendung findet (Roberts \& Szostak, 1997). Wie auch das ribosome display wurde das $m R N A$ display zunächst im Rahmen der Selektion von kurzen Peptiden eingesetzt, in optimierter Form aber schon bald auch für Proteine (Cho et al., 2000). Der aufwendige Schritt der Ligation des DNA-Linkers mit der mRNA wurde ersetzt durch eine photochemische Reaktion. Der DNA-Linker trägt in verbesserten Protokollen eine Psoralen Gruppe, die nach Hybridisierung mit der mRNA aktiviert wird und zu einer kovalenten Verknüpfung von DNA und mRNA führt (Kurz et al., 2000). Die Optimierung dieses 
Verfahren bildet die Grundlage für den Einsatz des mRNA displays in Selektionsexperimenten aus komplexen Bibliotheken. Mittels ribosome display wurden bereits zahlreiche Anreicherungsexperimente von bevorzugt Antikörperfragmenten mit verbesserten Bindungseigenschaften aus komplexen Bibliotheken durchgeführt (He \& Taussig, 1997, Hanes et al., 1998, 2000, Schaffitzel et al., 1999, He et al., 1999, Jermutus et al., 2001, Irving et al., 2001). Das mRNA display wurde erfolgreich zur Anreicherung von StreptavidinBindeproteinen aus einer Bibliothek von $\alpha$-helikalen und $\beta$-Strang Segmenten eingesetzt (Cho et al., 2000). In einem weiteren Experiment wurden aus einer 80 Aminosäuren umfassenden, vollständig randomisierten Polypeptid-Bibliothek Varianten isoliert, die Affinitäten bis zu 100 nM gegenüber ATP aufwiesen (Keefe \& Szostak, 2001). Die isolierten, vermutlich eine dreidimensionale Struktur besitzenden Bindemoleküle konnten in mehrere Sequenzklassen unterteilt werden, eine besaß sogar eine Faltungs-stabilisierende ZinkionBindestelle.

Die Verwendung von mRNA in den beschriebenen Methoden der Genotyp-PhänotypKopplung ist aufgrund der Hydrolyse- und Nukleaseempfindlichkeit ein entscheidender Nachteil, dem durch die reverse Transkription in cDNA begegnet werden kann (Kurz et al., 2000). Der ternäre Komplex aus mRNA, Ribosom und Polypeptid beim ribosome display hingegen wird mit einer Stabilität von mindestens 15 Tagen beschrieben (Amstutz et al., 2001).

\subsubsection{Verfahren zur Oberflächenpräsentation von Peptiden und Proteinen auf Bakterienzellen (bacterial surface display)}

Die Oberflächenpräsentation von Peptiden und Proteinen auf Bakterienzellen wurde in zahlreichen Ansätzen und sowohl auf Stämmen Gram-positiver als auch vor allem Gramnegativer Arten erfolgreich bewerkstelligt. Besonders die Präsentation auf der Oberfläche von Escherichia coli wurde unter Verwendung zahlreicher Expressionssysteme beschrieben. Escherichia coli ist besonders aufgrund der Möglichkeit zur Erzeugung und Vermehrung umfangreicher molekularer Repertoires, abgeleitet von mehr als $10^{10}$ unabhängigen Transformanten, der bevorzugte Organismus der evolutiven Biotechnologie. Für die meisten anderen Mikroorganismen ist aufgrund geringerer Tranformationseffizienzen die maximale Repertoiregröße auf mehrere Größenordnungen niedriger begrenzt. Ein Protein oder Peptid, welches auf der Oberfläche von Escherichia coli präsentiert werden soll, muss zu diesem Zweck sowohl die Zytoplasma- als auch die äußere Membran der Bakterienhülle durchqueren. Aus diesem Grund basieren nahezu alle Präsentationssysteme in E. coli auf der genetischen Fusion oder Insertion des zu präsentierenden Passagierproteins oder -peptids mit einem Translokatorprotein, welches vollständig oder in Teilen auf der Außenseite der Bakterienzelle lokalisiert ist (Lang, 2000).

\subsubsection{Porin vermittelte Exposition auf der Zelloberfläche}

Den Porinen kommt im Zusammenhang mit der bakteriellen Oberflächenpräsentation eine wichtige Rolle zu. Porine kommen in großer Anzahl in der äußeren Membran Gramnegativer Bakterienzellen vor und dienen dem Stoffaustausch zwischen der Zelle und der sie umgebenden Umwelt. In ihrem Aufbau bestehen sie aus $\beta$-Fass Strukturen, gebildet aus antiparallelen $\beta$-Strängen, welche die äußere Membran durchspannen, verbunden durch 
Schleifen, die einerseits in das Periplasma und andererseits in Richtung des umgebenden Mediums weisen (Cowan et al., 1992). Durch genetische Insertion kurzer Peptide mit Längen von maximal 50-60 Aminosäuren in Oberflächen-exponierte Schleifen von OmpC und $\operatorname{LamB}$ konnten diese auf der Zelloberfläche exponiert nachgewiesen werden (Lang, 2000). Sowohl die Länge des eingefügten Peptids als auch die Auswahl der Schleife für die Insertion spielen dabei für die effiziente Präsentation eine wichtige Rolle, längere Peptide scheinen die korrekte Faltung und Membraninsertion des Porins zu verhindern. Der Weg der Insertion in Schleifenregionen von Porinmolekülen ist nicht der einzige beschrittene Weg zur Nutzung von Porinen als Ankerdomänen für die bakterielle Oberflächenpräsentation. Da die Termini aller bekannten Porine in Richtung des Periplasmas weisen, ist eine terminale Fusion zur Exposition in das umgebende Medium nicht möglich. Georgiou und Mitarbeiter haben daraufhin Präsentationssysteme entwickelt, welche nur kleine Teile des Porins OmpA umfassen und für eine Fusion freie Carboxytermini bereithalten. Die Lpp-OmpA-Systeme bestehen aus einem die ersten neun Aminosäuren umfassenden Abschnitt des major outer membrane lipoprotein LPP und davon C-terminal drei bzw. lediglich einem die Membran durchspannenden $\beta$-Strang des OmpA $\beta$-Fasses, woran wiederum C-terminal das zu präsentierende Protein oder Peptid fusioniert werden kann (Francisco et al., 1992). Das aminoterminale Cystein des Lpp-Anteils wird in E.coli mit einem drei Fettsäurereste tragenden Glyzerinrest modifiziert und wirkt so als Anker in der äußeren Membran der Zelle (Ghrayeb et al., 1984). Mit Hilfe des Lpp-OmpA Expressionssystems war es möglich, unterschiedliche, größere Proteindomänen auf E. coli zu präsentieren, darunter TEM-1 $\beta$ Laktamase (Francisco et al., 1992), Einketten-Antikörper-Fragmente ( $\left.s c F_{v}\right)$ (Daugherty et al., 1999) und Protease-Inhibitoren mit Cystin-Knoten Faltungsmotiv (Christmann, et al., 1999).

\subsubsection{Exposition auf Flagellen/Fimbrien}

Ein anderer Ansatz zur Präsentation von Peptiden auf der Oberfläche Gram-negativer Bakterien wurde durch Kopplung an Proteine von Flagellen und Fimbrien verfolgt. Diese komplexen Strukturen bestehen aus einer großen Anzahl identischer Proteine, in welche an permissiven Stellen Insertionen unterschiedlicher Länge eingefügt werden konnten, ohne dass deren Synthese oder Funktion eingeschränkt wäre. So konnten durch Insertion in die Flagellen-Untereinheit FliC Peptide mit einer Länge von bis zu 300 Aminosäuren präsentiert werden (Westerlund-Wikström et al., 1997), und in Fimbrienproteine eingefügte Metallionen-Bindemotive waren funktionell auf der bakteriellen Oberfläche nachweisbar (Schembri et al., 1999, Kjaergaard et al., 2001). Der Vorteil der Präsentation über Fimbrien und Flagellen besteht in der hohen Kopienzahl, mit der betreffende, auch längere Peptide exponiert werden können, ohne die Faltung der Passagierdomäne oder die Filamentbildung zu beeinträchtigen. Anwendungsmöglichkeiten für Flagellen- bzw. Fimbrien display sind unter anderem die Epitopkartierung und die Untersuchung von Adhesin-Rezeptor Interaktionen (Westerlund-Wikström, 2000).

\subsubsection{Durch Autotransport-Proteine vermittelte Oberflächenexposition}

Eine Klasse von Proteinen, welche für die bakterielle Oberflächenpräsentation verbreitet Anwendung findet, ist die der Autotransporter. Autotransporter sind sekretierte Proteine Gram-negativer Bakterien, die eine charakteristische Domänenstruktur aufweisen. Einer 
aminoterminalen Signalsequenz folgen die sekretierte Effektordomäne und eine carboxyterminale $\beta$-Domäne, die in der äußeren Membran eine $\beta$-Fass Struktur ausbildet (Henderson et al., 1998). Durch dieses Fass bzw. durch eine durch mehrere Untereinheiten der $\beta$-Domäne gemeinsam gebildete Pore (Veiga et al., 2002) wird nach der Membraninsertion die Effektordomäne passagiert und meist durch Autoprotolyse freigesetzt. Bekanntester Vertreter der Autotransporter ist die $\beta$-Domäne der $\operatorname{IgA-Protease~}(\operatorname{Ig} A \beta)$ von Neisseria gonorrhoeae (Pohlner et al.,1987), welche auch heterolog exprimiert in E. coli in der Lage ist, neben der IgA-Proteasedomäne auch andere Domänen durch die äußere Membran zu transportieren. Gezeigt wurde dies am Beispiel der Präsentation von Choleratoxin B (Klauser et al., 1992) und Varianten des Protease-Inhibitors EETI-II (Wentzel et al., 1999). Allerdings konnte gezeigt werden, dass die Überexpression von IgA $\beta$-Fusionsprotein in $E$. coli toxisch wirkt, was die Handhabung des Systems im Rahmen der Durchmusterung Moleklarer Repertoires erschwert (Wentzel et al., 1999). Neben $\operatorname{Ig} A \beta$ wurde auch der Autotransporter AIDA-I (adhesin involved in diffuse adherence) für die Präsentation von Choleratoxin B herangezogen, ebenso wie für die Exposition von T-Zell Epitopen (Maurer et al., 1997) und die TEM-1 $\beta$-Laktamase von E. coli (Lattemann et al., 2000). In letzterem Fall konnte die enzymatische Aktivität des Enzyms nachgewiesen werden.

\subsubsection{Ice nucleation protein (INP) vermittelte Präsentation}

Ein weiteres Protein für die Verankerung heterologer Passagierproteine in und deren Exposition auf der Oberfläche von E. coli Zellen ist das ice nucleation protein (INP) aus Pseudomonas syringae. Dieses Protein katalysiert die Bildung von Eiskristallen in unterkühltem, flüssigem Wasser und ist über einen Glykosyl-Phosphatinositol Anker (GPI) in der äußeren Membran der Bakteriums verankert (Kozloff et al., 1991). Wie die Präsentation über $\operatorname{Ig} A \beta$ ist auch eine Exposition von Passagierproteinen über INP auf Zellen von Escherichiacoli möglich. Erfolgreich präsentierte Passagierdomänen waren die Levansucrase (Jung et al., 1998), Organophosphat-Hydrolase (Shimazu et al., 2001), Carboxymethylcellulase (Kim et al., 2000), HIV gp120 (Kwak et al., 1999), das OberflächenAntigen des Hepatitis B Virus (Kim et al., 1999) sowie synthetische Phytochelatine (Bae et al., 2002).

\subsubsection{Zelloberflächenpräsentation auf Gram-positiven Bakterien}

Ansätze zur Zelloberflächenpräsentation auf Zellen Gram-positiver Bakterien verfolgt im Gegensatz zur Exposition auf Gram-negativen Bakterienzellen hauptsächlich das Ziel der Vakzinierung. In diesem Zusammenhang kamen neben Bacillus subtilis, dem wohl am besten untersuchten Gram-positiven Bakterium, attenuierte Mykobakterien, nicht-pathogene Staphylokokken, Lakto- und Streptokokken zum Einsatz (Hansson et al., 2001). Aber auch biotechnologische Ansätze sind dokumentiert. So konnten Einketten-Antikörperfragmente $\left(s c F_{v}\right)$ für diagnostische Tests und die Cellulose Bindedomäne der Cellulase aus Trichoderma reesei als mikrobieller Biokatalysator auf Staphylokokken präsentiert werden (Gunneriusson et al., 1996, Lehtio et al., 2001). 


\subsection{Zielsetzung}

Im Rahmen der vorliegenden Arbeit sollte versucht werden, auf der Basis des EHEC O157:H7 EaeA Proteins ein neues Verfahren zu entwickeln, mit dem es möglich ist, Proteine auf der Oberfläche von Escherichia coli K12 Zellen in hoher Kopienzahl zu präsentieren. Nach erfolgtem qualitativem Nachweis der Oberflächenexposition sollte das Verfahren hinsichtlich der prinzipiellen Einsetzbarkeit bei der Durchmusterung umfangreicher molekularer Repertoires bewertet werden. Entscheidende Parameter der Zelloberflächenpräsentation sind dabei eine maximale Anzahl Oberflächen-exponierter Moleküle bei minimalem Einfluss auf die Vitalität der Zellen. Gleichzeitig sollte anhand dieses Verfahrens der generelle Mechanismus der Translokation von Proteindomänen über die äußere Membran Gram-negativer Bakterien im Speziellen von Escherichia coli am Beispiel der EaeA vermittelten Translokation untersucht werden. Dabei sollte der Einfluss diverser Parameter wie Faltung, Größe, Struktur und Stabilität auf die Translokationskompetenz evaluiert werden. 


\section{Ergebnisse}

Die Isolierung von Peptiden und Proteinen mit neuen oder verbesserten Eigenschaften durch die Präsentation komplexer molekularer Bibliotheken auf der Oberfläche von E. coli Zellen hat sich als Verfahren in den vergangenen Jahren gut bewährt (Francisco et al., 1992, Daugherty et al., 1999, Wentzel et al., 1999, Christmann et al., 1999, Christmann et al., 2001, Westerlund-Wikström, 2000). Die bakterielle Oberflächenpräsentation bildet damit neben der Präsentation auf Phagen (1.4.1), dem Hefe display (1.4.2) und den auf DNA- bzw. RNABindung basierenden reinen in vitro Methoden (1.4.3) ein wirkungsvolles Instrument zur Identifizierung neuer Bindemoleküle. Mehr noch bietet das bacterial surface display gegenüber den anderen Methoden sogar deutliche Vorteile. Wichtige Parameter für die Auswahl eines Präsentationsverfahrens sind die Möglichkeit der Erzeugung umfangreicher molekularer Bibliotheken, die Stabilität der Komplexität innerhalb der Repertoires im Verlauf eines Anreicherungsexperiments sowie der experimentelle Aufwand, der mit deren Durchmusterung verbunden ist. Die Verwendung von Escherichia coli als bakterieller Wirtsorganismus stellt einen großen Vorteil mit Blick auf die Möglichkeit der Erzeugung sehr großer Bibliotheken gegenüber dem Hefe display dar, mit dem Diversitäten jenseits von $10^{7}$ unabhängigen Klonen aufgrund der geringen Transformationseffizienz der Zellen ausgeschlossen sind. Wie auch bei der wohl am weitesten verbreiteten Methode der Oberflächenpräsentation von Peptiden und Proteinen, der Präsentation auf der Oberfläche von Phagenpartikeln (phage display), ist die Komplexität der Repertoires hier lediglich durch die Effizienz der Transformation von E.coli Zellen begrenzt, die bei nahe $10^{10}$ pro Mikrogramm Plasmid-DNA liegt (Dower et al., 1988, Song et al., 1993). Von Bedeutung für die generelle Anwendbarkeit von Verfahren, die auf der biologischen Synthese von Molekülvarianten beruhen, ist der Erhalt der Diversität der von den replizierenden Einheiten produzierten Moleküle bei Vermehrung der Produzentenzellen. Beim phage display werden von den produzierenden Bakterien die Proteinvarianten in Phagenpartikel verpackt. In der Regel werden sie dabei als Fusionsprotein mit einem Hüllprotein des Phagen produziert, das für die Infektion von Bakterienzellen und damit für die Phagenvermehrung notwendig ist. Formell nicht auszuschließen und auch häufig beobachtet ist der Fall, dass die Effizienz der Infektion einer Wirtszelle von speziellen Merkmalen der Aminosäuresequenz präsentierter Proteinvarianten abhängig ist und dies bei Anwendung mehrerer Runden von Infektion und Phagenvermehrung im Laufe eines Experimentes zu einem Verlust der Varianten führt, die eine etwas geringere Infektionswahrscheinlichkeit aufweisen als andere. Der damit einhergehende Verlust an Diversität ist unerwünscht, da das Risiko besteht, dass auch Varianten mit gewünschten Bindungseigenschaften eliminiert werden. Die direkte Präsentation auf Bakterienzellen bietet eine Alternative und umgeht diese Unzulänglichkeiten.

Die Komplexität des molekularen Repertoires, wie sie bei der Präsentation auf Phagen und Bakterien möglich ist, wird lediglich von den in vitro Methoden des ribosomal display übertroffen. Wie aber auch beim phage display ist der experimentelle Ansatz der Durchmusterung der Sammlung von Varianten als eine Art, black box' Experiment anzusehen. Es besteht keinerlei Möglichkeit einer Erfolgskontrolle während einer Anreicherungsrunde. Dies ist lediglich bei Zell-basierten Methoden gegeben, die den Einsatz von beispielsweise Fluoreszenz-aktivierter Zellsortierung (FACS) erlauben. Darüber hinaus 
ist der experimentelle Aufwand, wie er bei den reinen invitro Methoden dem Experimentator abverlangt wird, bei der bakteriellen Oberflächenpräsentation deutlich geringer.

Die am häufigsten verwendete Methode zur bakteriellen Zelloberflächenpräsentation auf Escherichia coli beruht auf der von Georgiou und Mitarbeitern im Jahre 1992 veröffentlichten Produktion eines Fusionsproteins mit Lpp-OmpA (Franscisco et al., 1992, siehe auch 1.4.4.1). Dieses Konstrukt wurde in unterschiedlichen Variationen auch im Rahmen einiger Arbeiten in der Abteilung für Molekulare Genetik des Instituts für Mikrobiologie und Genetik bearbeitet und unter anderem von A. Christmann für die Isolierung von Proteaseinhibitor-Varianten aus einem komplexen Hintergrund negativer Ereignisse heraus angewandt (Christmann et al., 1999). Schon im Rahmen dieser Arbeiten wurde sehr bald deutlich, dass das hauptsächliche Problem dieser Methode in dem Einfluss der Expression des Oberflächen-exponierten Passagierproteins auf die Vitalität der Bakterienzellen lag. Eine hohe Nettoakkumulation auf der Zelloberfläche war hierbei mit dem Überleben der Zellen nur noch schwer vereinbar. Gerade dieser Aspekt stellt jedoch mit Blick auf die generelle Anwendbarkeit des Verfahrens in routinemäßigen Anreicherungsexperimenten aus umfangreichen molekularen Bibliotheken ein nahezu unüberwindbares Problem dar. Die Stabilität der Komplexität der erzeugten Repertoires wäre wie beim phage display nur begrenzt gegeben. Es bestand folglich die Notwendigkeit, alternative, verbesserte Methoden zu entwerfen und aufzubauen, die es erlauben, Proteindomänen verankert auf der E. coli Zelloberfläche zu exponieren, ohne dass dies mit Einschränkungen der Überlebensfähigkeit der produzierenden Zellen verbunden ist. Die Suche nach Alternativen zu den Lpp-OmpA Konstrukten ging von der Arbeitshypothese aus, dass ein in hoher Kopienzahl in der äußeren Membran von E. coli vorkommendes Protein, welches seinerseits Proteindomänen auf der Zelloberfläche exponiert, als Grundgerüst für die Exposition von Fremdproteinen besonders gut geeignet ist. Fündig wurde man letztendlich bei pathogenen Escherichia coli, im Speziellen bei enterohaemorrhagischen E. coli (EHEC). Das in diesen Zellen vorkommende EaeA Protein hat seinen originären Platz in der äußeren Membran der Zellen und exponiert mehrere C-terminale Domänen in das die Zelle umgebende Medium. Die natürliche Funktion des EaeA Proteins in EHEC liegt dabei in der festen Anheftung der Bakterien an die Zellen des Darmepithels des Wirtsorganismus über die Bildung eines Komplexes mit einem Rezeptormolekül (Rosenshine et al., 1996a,b, Liu et al., 1999a). Das adressierte Zielprotein ist der ebenfalls EHEC kodierte Tir Rezeptor, der in die Membranen des Darmepithels eingelagert wird (Kenny et al., 1997). Strukturell ist das EaeA Protein in mehrere Domänen untergliedert (Liu et al., 1999b, Luo et al., 2000). Nach Strukturvorhersagen folgt dem in das Periplasma zeigenden aminoterminalen Abschnitt des Proteins eine aus $\beta$-Strängen bestehende Transmembrandomäne. An deren Carboxyterminus folgt nach dem Modell nach einem flexiblen Bereich ein relativ rigides Gefüge aus drei Domänen mit Immunglobulin-ähnlicher (E0, E1, E2) und am weitesten C-terminal die Effektordomäne mit Lektin-ähnlicher Struktur (E3). Die Struktur der Domänen E1, E2 und E3 wurde im Jahr 2000 von Luo und Mitarbeitern im Komplex mit der Bindedomäne des TirRezeptors gelöst (Luo et al., 2000). Der Mechanismus der Translokation der extrazellulären Domänen hingegen ist noch nicht bekannt, die Möglichkeit eines AutotransportMechanismus wie zum Beispiel bei der Neisseria gonorrhoeae IgA-Protease (Pohlner et al., 
1987a,b, Veiga et al., 2002) oder beim E. coli AIDA-I Protein (Maurer et al., 1997) scheint jedoch wahrscheinlich. Die Tatsache, dass dieses Protein gleich mehrere Domänen membranständig auf der Bakterienoberfläche zu exponieren vermag, machte EaeA zu einem guten Kandidaten für ein neuartiges Präsentationsverfahren zur bakteriellen Oberflächenpräsentation von Peptiden und Proteinen auf Zellen von E. coli Laborstämmen.

\subsection{Aufbau eines EHEC-Intimin basierten Präsentationsverfahrens}

Als Membrananker für die bakterielle Oberflächenpräsentation heterologer Proteine auf Zellen von Escherichia coli K-12 wurde das Intimin EaeA enterohaemorrhagischer Escherichia coli ausgewählt. Wie in Kapitel 1.3.3.2 ausführlich dargelegt, fungiert die N-terminale Region mit großer Wahrscheinlichkeit als Ankerdomäne in der äußeren Membran der Bakterien und exponiert vier zum Teil strukturell bekannte carboxyterminale Domänen in das umliegende Medium (Luo et al., 2000). Dabei kommt der carboxyterminalen Domäne mit Lektinähnlicher Struktur bei der Anheftung der EHEC-Zellen an das Darmepithel eine zentrale Bedeutung zu, da diese in der Lage ist, das Tir Rezeptorprotein auf der Oberfläche von Epithelzellen zu binden (Liu et al., 1999b). Bei dem in dieser Arbeit vorgestellten Intiminbasierten Präsentationsverfahren kommt eine um die Domänen E2 und E3 verkürzte Variante des originären EHEC Intimins EaeA zum Einsatz (Abb. 5).

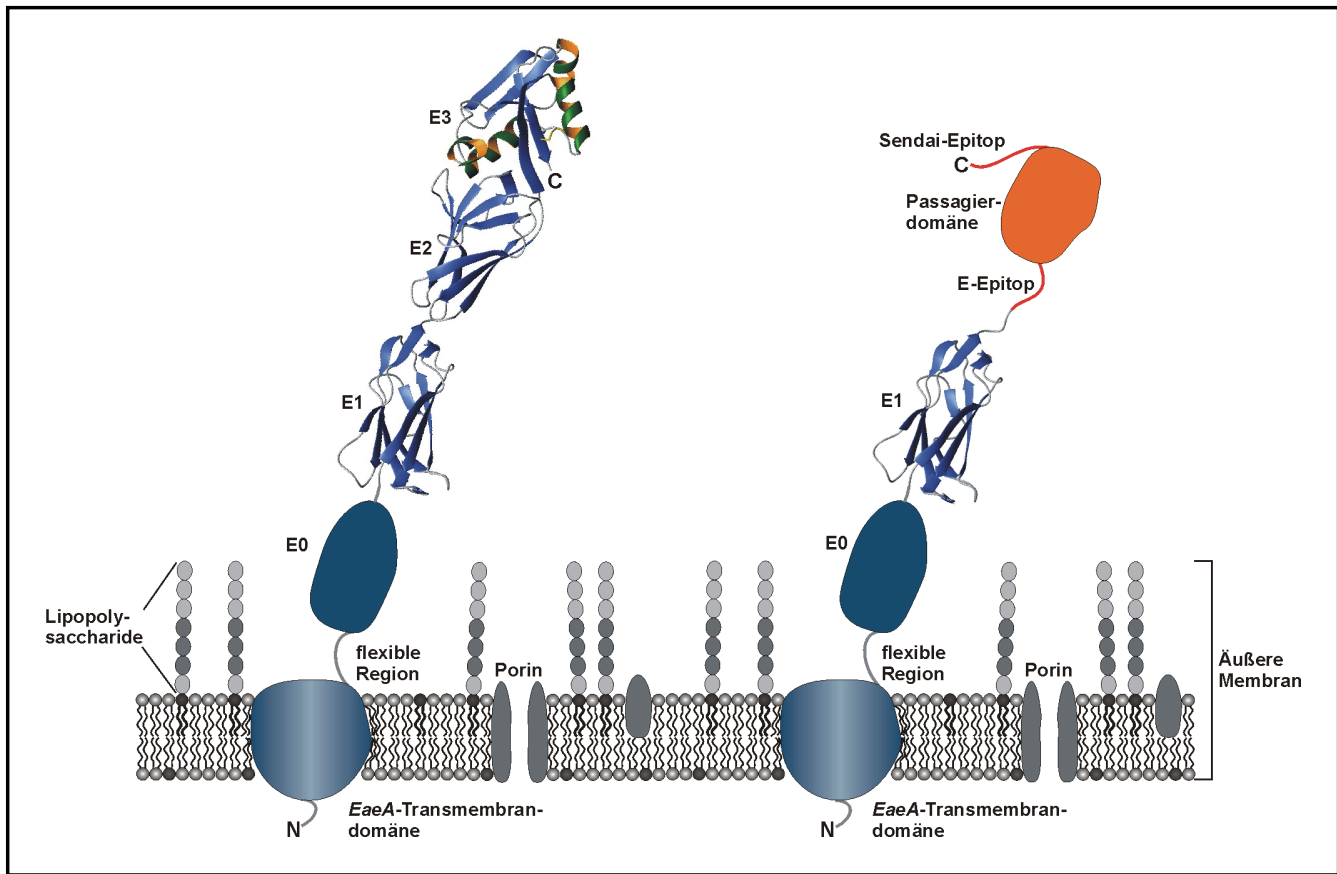

Abbildung 5. Schematische Darstellung des Intimins enteropathogener E. coli (EPEC) (links) sowie des im Rahmen dieser Arbeit verwendeten, davon abgeleiteten Intimin' Proteins (rechts). Dargestellt ist die äußere Bakterienmembran und jeweils die relative Lokalisation des Proteins in der Bakterienhülle sowie dessen postulierte Domänenstruktur. In der äußeren Membran: Transmembrandomäne unbekannter Struktur, E0: Domäne unbekannter Struktur, E1, E2: Domänen mit Immunglobulin-ähnlicher Struktur, E3: Domäne mit Lektinähnlicher Struktur, rot: Passagierdomäne. Die vier extrazellulären Domänen E0, E1, E2 und E3 sind über eine flexible Region mit der aminoterminalen Transmembrandomäne verbunden, die in der äußeren Membran inseriert (Luo et al., 2000). Die schematische Darstellung der Struktur der Domänen E1, E2 und E3 sowie des Tir-Bereichs wurde erzeugt unter Verwendung von Molmol, Version 2K.2, Reto Konradi, PDB: 1F02, Luo et al., 2000. 
Das aus den ersten 659 Aminosäuren des EaeA-Proteins bestehende Konstrukt wird zur besseren Unterscheidung vom EHEC O157:H7 (Wildtyp-) Intimin mit EaeA' bzw. Intimin' bezeichnet, das zugrundeliegende Gen als eaeA'-Gen.

\subsubsection{Konstruktion des Plasmids pASKInt100}

Die Kodone \#1 bis \#659 des Gens eaeA enterohaemorrhagischer Escherichia coli O157:H7, Stamm 933 wurden mittels PCR amplifiziert, wobei als Matrize chromosomale DNA von EHEC O157:H7 in einer Hitze-inaktivierten Gesamtzellpräparation diente. Die Präparation der Hitze-inaktiverten EHEC-Zellen wurde von Prof. Dr. J. Hacker von der Universität Würzburg dankenswerterweise bereitgestellt. Der prinzipielle Ablauf dieser sowie aller anderen im Rahmen dieser Arbeit durchgeführten Klonierungen ist im Methodenteil ausführlich dargelegt (Methode 5.3.1). Das durch die PCR mit den Oligonukleotiden Intiminup und Intilo1 amplifizierte DNA-Fragment von 2013 bp Länge wurde mit den Restriktionsenzymen XbaI und MunI gespalten und mit dem durch XbaI und EcoRI gespaltenen Vektorfragment von pASKC21-EETI-CK ${ }^{\text {send }}$ (siehe 4.2) ligiert. Das so erhaltene Plasmidkonstrukt wurde nach Transformation von Zellen des Escherichia coli Stammes 71-18 amplifiziert. Das erzeugte Plasmid trägt den Namen pASKInt1-EETI-CK ${ }^{\text {send }}$ und enthält das eaeA'-Gen unter der transkriptionellen Kontrolle des strikt regulierbaren tetA-Promotors/Operators des Ursprungsplasmids pASK75 (Skerra, 1994, siehe 4.2). Das im Rahmen dieser Klonierung als Rezipientenvektor fungierende Plasmid pASKC21-EETI-CK ${ }^{\text {send }}$ ist ein Derivat des Plasmids pASK21-EETI-CK ${ }^{\text {send }}$ (Christmann et al., 1999). Es unterscheidet sich von diesem durch die Anwesenheit der kodierenden Sequenz des mittels eines kommerziell erhältlichen monoklonalen Antikörpers leicht nachweisbaren E-Epitops (E-tag) des Gla-Proteins in menschlichen Knochen (Fa. Amersham Biosciences), welche unmittelbar vor dem 5'-Ende der kodierenden Sequenz für eine Variante des Ecballium elaterium Trypsin Inhibitors II (EETI-II) eingefügt worden war. Diese Variante von EETI-II (EETI-CK ${ }^{\text {Send }}$ ) enthält eine Epitop-Sequenz aus dem L-Protein des Sendai-Virus mit einer Länge von 13 Aminosäuren als Austausch der Aminosäuren \#3 bis \#8 des Wildtyp EETI-II-Proteins. Dieses anstelle der originalen Inhibitor-Schleife verwendete Epitop kann mittels eines monoklonalen anti-Sendai Antikörpers leicht immunochemisch nachgewiesen werden (Einberger et al., 1990). Weiter enthält das Plasmid pASKC21-EETI-CK ${ }^{\text {send }}$ anstelle der in den Kodonen \#8 bis \#281 deletierten kodierenden Sequenz für die Ampicillin-Resistenz vermittelnde $\beta$-Laktamase die kodierende Sequenz für eine Resistenz gegen Chloramphenicol vermittelnde Chloramphenicol-Acetyltransferase.

Die für die Aminosäure Glutamin kodierende Kodon-Position \#35 des eaeA'-Gens (CAG) in pASKInt1 wurde in einem weiteren Klonierungsschritt durch ein amber Stopkodon (TAG) substituiert. Dazu wurde ein Teil der kodierenden Region des eaeA'-Gens in einer PCR mit den Oligonukleotiden Intiminup und Intimin-amber-lo amplifiziert. Das auf diesem Wege erhaltene DNA-Fragment von 139 bp Länge wurden mit den Restriktionsendonukleasen XbaI und EcoRI gespalten und in das mit denselben Enzymen gespaltene, lineare Vektorfragment des Plasmids pASKInt1-EETI-CK ${ }^{\text {send }}$ ligiert. Es folgte die Amplifikation des

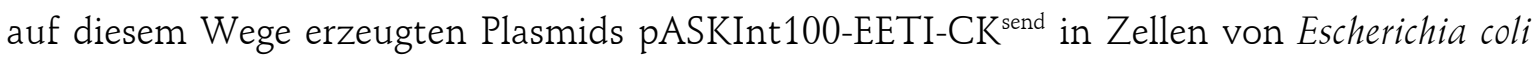
71-18. Durch die Einführung eines TAG amber Stopkodons im vordersten Abschnitt des eaeA'-Gens und die Verwendung eines Suppressor-Stammes wie 71-18 (Rüther \& Müller- 
Hill, 1983, supE) oder DH5 (Hanahan 1983, supE44) wird die Expression des Intimin'Konstruktes reduziert, da die Effizienz des Überlesens eines Stopkodons im verwendeten Stamm niedrig ist. Damit wird sichergestellt, dass die Nettoakkumulation des Intimin'Konstruktes in der äußeren Membran reduziert ist und keine unerwünschten, negativen Einflüsse auf Zellvitalität und Wachstum auftreten (siehe 2.1.3).

Die Klonierungen im Rahmen der Erstellung des Plasmids pASKInt100-EETI-CK ${ }^{\text {send }}$ sind schematisch in Abbildung 6 wiedergegeben, die vollständige DNA-Sequenz des Plasmids befindet sich im Anhang zu dieser Arbeit.

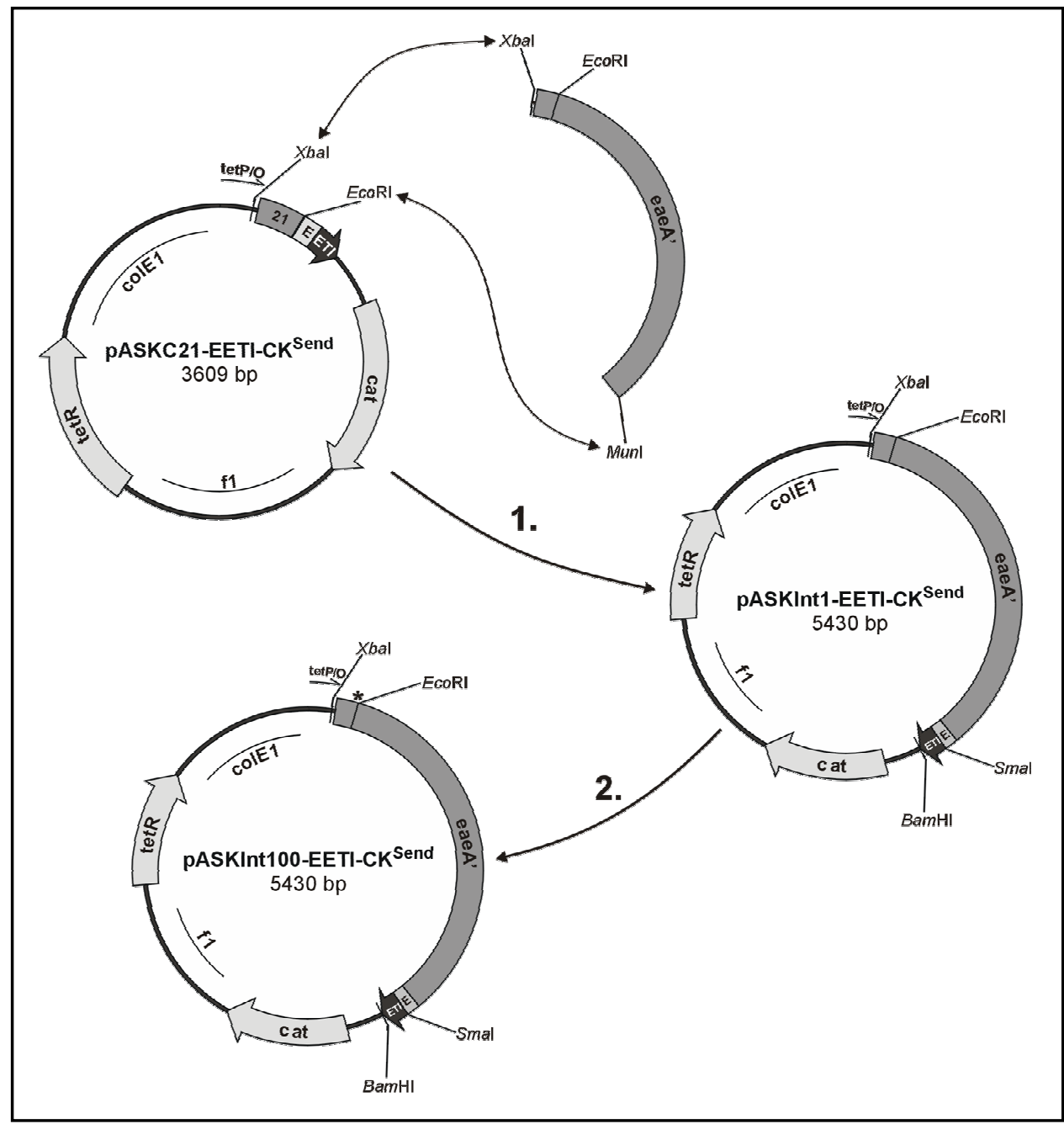

Abbildung 6. Schematische Darstellung der Erzeugung des Plasmids pASKInt100-EETI$\mathrm{CK}^{\text {Send }}$. (1.) Klonierung des das EHEC O157:H7 eaeA'-Gen enthaltenden PCR-Produkts über XbaI und EcoRI/MunI; (2.) Klonierung eines PCR-Produkts zum Austausch des CAG-Kodons an Position \#35 des eaeA'-Gens in pASKInt1-EETI-CK ${ }^{\text {send }}$ durch ein TAG amber Stopkodon über XbaI und EcoRI in pASKInt100-EETI-CK ${ }^{\text {Send }}$. Nähere Informationen im Text, komplette Sequenz des Plasmids pASKInt100-EETI-CK ${ }^{\text {send }}$ im Anhang 8.2.1 zu dieser Arbeit.

\subsubsection{Oberflächenexposition von Fusionsproteinen über das EHEC Intimin EaeA auf Zellen von $E$. coli $\mathrm{K}-12$}

Das aminoterminale Fragment des EaeA-Proteins, wie es ausgehend von dem Plasmid pASKInt100-EETI-CK ${ }^{\text {send }}$ durch Zellen von Escherichia coli produziert werden kann, soll in diesem neuen Verfahren einer bakteriellen Zelloberflächenpräsentation für die Exposition 
heterologer Passagierdomänen auf den Bakterienzellen genutzt werden. Um zu untersuchen, ob das verwendete Fragment EaeA' des EHEC O157:H7 EaeA-Proteins für die Translokation durch die äußere Membran von E. coli K-12 Zellen ausreichend ist, wurde als NachweisDomäne das Derivat EETI-CK ${ }^{\text {send }}$ des EETI-II Proteins (siehe 2.1.1) verwendet. Dieses gehört zu einer Familie von nur wenige Dutzend Aminosäuren kurzen sogenannten Mikroproteinen, welche als Familie der Cystin-Knoten Protease-Inhibitoren bezeichnet wird (Pallaghy et al., 1994). EETI-II bietet dabei ein stabiles Grundgerüst für die Verankerung konformationell eingeschränkter Peptide unterschiedlicher Länge und Aminosäuresequenz (Christmann et al., 1999; Wentzel et al., 1999) wie beispielsweise die des hier verwendeten Sendai-Epitops (DGSLGDIEPYDSS, Einberger et al., 1990). Zur Expression des ein TAG amber Stopkodon enthaltenden Fusionsgens eaeA'-eeti-ck ${ }^{\text {send }}$ wurde der amber SuppressorStamm DH5 $\alpha$ Z1 verwendet. Die Anwesenheit des Intimin'-Fragments in der äußeren Membran der pASKInt100-EETI-CK ${ }^{\text {send }}$ tragenden DH5 $\alpha Z 1-Z$ ellen wurde durch indirekte Immunfluoreszenz-Markierung der intakten Bakterienzellen mit dem anti-E Antikörper (Fa. Amersham Biosciences) nachgewiesen (Methode 5.5.2, Abb. 7). Dieser Antikörper bindet spezifisch die E-Epitop Sequenz (AGAPVPYPDPLEPRAASG) unmittelbar benachbart des Intimin' Carboxyterminus (vgl. Abbildung 5).

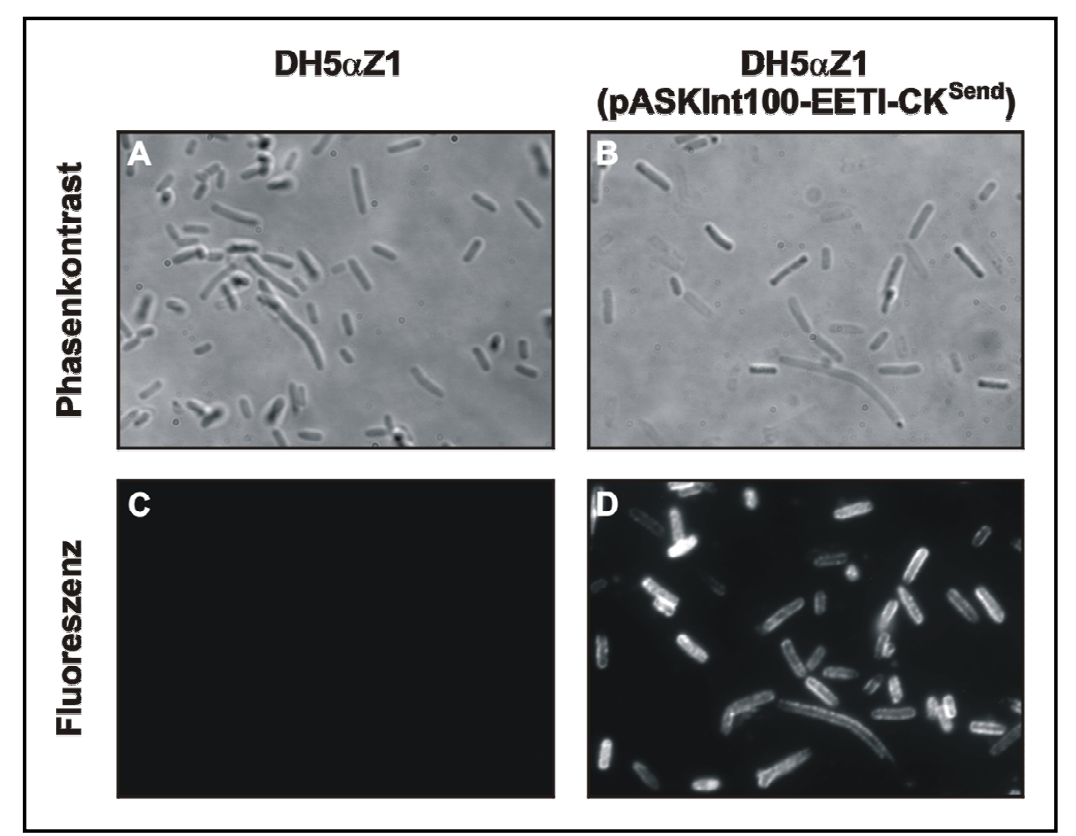

\begin{abstract}
Abbildung 7. (A, B) Phasenkontrast- und (C, D) fluoreszenzmikroskopische Aufnahmen desselben Gesichtsfeldes von untransformierten DH5aZ1-Zellen (A, C) und DH5aZ1Zellen, welche das Plasmid pASKInt100-EETI-CK ${ }^{\text {send }}$ tragen (B, D). Die Zellen wurden in Anwesenheit von Anhydrotetrazyklin wachsen gelassen und somit die Expression von eaeA'eeti-ck ${ }^{\text {send }}$ induziert. Es folgte die Inkubation der Zellen in Folge mit anti-E Antikörper, biotinyliertem anti-Maus Antikörper und Streptavidin, R-Phycoerythrin-Konjugat.
\end{abstract}

Die DH5aZ1-Zellen wurden bei $37^{\circ} \mathrm{C}$ unter Schütteln inkubiert. Bei Erreichen einer Optischen Dichte bei $600 \mathrm{~nm}$ Wellenlänge von 0,2 wurde als Induktor der Intimin'-EETI$C K^{\text {send }}$ Expression Anhydrotetrazyklin bis zu einer Endkonzentration von $0,2 \mu \mathrm{g} / \mathrm{ml}$ zugegeben. Nach einer weiteren, 60 minütigen Inkubation bei $37^{\circ} \mathrm{C}$ unter Schütteln wurde ein Aliquot der Kulturen zentrifugiert und die pelletierten Bakterienzellen wurden wie in Methode 5.5.2 ausführlich beschrieben nacheinander mit anti-E Antikörper, biotinyliertem 
anti-Maus Antikörper und Streptavidin, R-Phycoerythrin-Konjugat, inkubiert. Die anschließende fluoreszenzmikroskopische Untersuchung zeigte, dass durch diese Markierungsprozedur alle pASKInt100-EETI-CK ${ }^{\text {send }}$ tragenden DH5 $\alpha$ Z1-Zellen eine Fluoreszenzmarkierung aufwiesen. Das Ergebnis ist in Abbildung 7 dargestellt. Nicht mit pASKInt100-EETI-CK ${ }^{\text {send }}$ transformierte Zellen von DH5 $\alpha Z 1$ zeigten hingegen keinerlei Fluoreszenzmarkierung.

Die Expression von eaeA'-eeti-ckend in DH5aZ1 und dessen Exposition auf der bakteriellen Oberfläche konnte folglich spezifisch mittels der anti-E Markierung nachgewiesen werden. Das verwendete Fragment des EHEC 0157:H7 EaeA-Proteins (EaeA') ist für die Translokation von EETI-CK ${ }^{\text {send }}$ durch die äußere Membran von E. coli K-12 Zellen ausreichend.

\subsubsection{Einfluss der Intimin-Produktion auf das klonale Wachstum und das individuelle Überleben der Zellen}

Die Induktion der Expression des Intimin'-Gens in einer Kultur des Stammes DH5 $\alpha$ Z1, der das Plasmid pASKInt1-EETI-CK ${ }^{\text {send }}$ trug, führte zu einem Wachstumsstopp der Kultur infolge einer drastischen Verringerung des Überlebens der Zellen (Beobachtung H. Kolmar). Es ist weiter verschiedentlich für andere bakterielle Oberflächenpräsentationssysteme dokumentiert worden, dass die Überproduktion von Proteinen, die mit der äußeren Membran assoziiert sind, die Struktur der Membran derart stört, dass die Zellen sterben (Lpp-OmpA: Daugherty et al., 1999, Igaß: Wentzel et al., 1999). Die Rückführung der Nettoakkumulation von Fusionsprotein in der äußeren Membran auf Translationsebene durch die Einführung eines amber Stopkodons auf ein geringeres Maß führte dazu, dass entsprechende Kulturen nach Induktion der Expression von eae $A^{\prime}$ nicht oder zumindest in weit geringerem Ausmaß in ihrem Wachstum beeinträchtigt waren.

Um einen möglichen Einfluss der durch Einführung eines amber Stopkodons reduzierten eaeA'-Expression auf die Zellvitalität zu beleuchten, wurde die Überlebensrate von pASKInt100-EETI-CK ${ }^{\text {send }}$ tragenden DH5 2 Z1 Zellen im Vergleich zu untransformierten Kontrollzellen untersucht. Dazu wurde eine Kultur in Vollmedium bis zu einer O.D. bei $600 \mathrm{~nm}$ Wellenlänge von 0,2 wachsen gelassen und die Expression von eaeA'-eeti-ck ${ }^{\text {send }}$ mit $0,2 \mu \mathrm{g} / \mathrm{ml}$ Anhydrotetrazyklin induziert. Nach 0, 1, 2 und 4 Stunden wurden Aliquots der Kultur entnommen, und einzelne Zellen mit Hilfe der Einzelzellablagefunktion eines MoFlo Cell-Sorters (Fa. Cytomation) über 1024 Kanäle im 20 x 20 Raster auf Vollmediumsplatten abgelegt. Die abgelegten Zellen wurden zu Kolonien herangezogen, und deren Anzahl wurde bestimmt. Bezogen auf die jeweilige Anzahl an Kontrollzellen zu den verschiedenen Zeitpunkten wurde die prozentuale Überlebensrate bestimmt. Das Ergebnis ist in Abbildung 8 dargestellt. Die Überlebensrate präsentierender Zelle ist demnach nach einer Stunde Induktion nur geringfügig kleiner als die von Kontrollzellen. Selbst nach 4 Stunden Induktion der Genexpression beträgt die Überlebensrate noch über $60 \%$. 


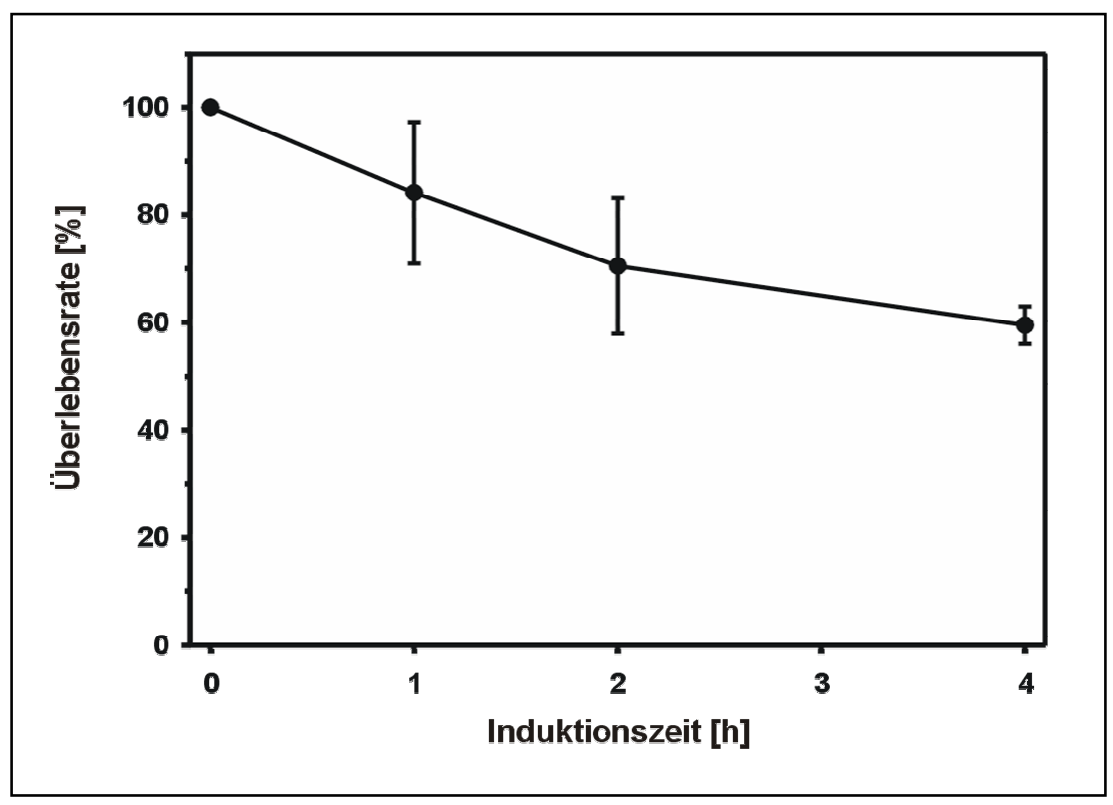

\begin{abstract}
Abbildung 8. Überleben von pASKInt100-EETI-CK ${ }^{\text {send }}$ tragenden DH5 $\alpha Z 1$ Zellen nach Induktion der intimin'-eeti-ck $k^{\text {send }}$ Expression durch Zugabe von $0,2 \mu \mathrm{g} / \mathrm{ml}$ Induktor Anhydrotetrazyklin (entspricht $0 \mathrm{~h}$ ). Zu unterschiedlichen Zeitpunkten nach Induktionsbeginn wurden Zellen mit dem FACS auf Agar-Platten abgelegt. Nach über Nacht Inkubation bei $37^{\circ} \mathrm{C}$ wurde die Anzahl der Kolonien bestimmt und diese mit der Koloniezahl gleichbehandelter Kontrollzellen (untransformierte DH5 2 Z1 Zellen, $100 \%$ gesetzt) verglichen. Drei unabhängige Experimente lieferten die Standardabweichungen.
\end{abstract}

Um zu untersuchen, ob Intimin'-präsentierende E.coli Zellen einen signifikanten Wachstumsnachteil in Flüssigkultur gegenüber nicht präsentierenden Zellen bei Dauerinduktion haben, wurde ein kompetitives Wachstumsexperiment durchgeführt. Als Expressionsstamm diente hierzu der Stamm 71-18mutS, welcher ein chromosomal integriertes Tetrazyklin-Resistenzgen trägt. Dieses bewirkt, dass die Zellen in der Lage sind, in Anwesenheit des Antibiotikums Tetrazyklin zu wachsen, so dass in dem vorliegenden Experiment auch über Nacht noch genügend Induktor zur Vollinduktion verfügbar war. Übernachtkulturen in dYT Vollmedium mit Chloramphenicol von pASKInt100-EETI-CK ${ }^{\text {send }}$ bzw. pASK75cat [ein zusätzlich das cat-Gen tragendes Derivat von pASK75 (Skerra, 1994)] tragenden 71-18mutS Zellen wurden im Verhältnis von ca. 1:1, bestimmt über die O.D.600, zu einer Mischkultur vereinigt. Mit $2 \mu \mathrm{l}$ dieses Gemisches wurden $50 \mathrm{ml}$ dYT Vollmedium mit Chloramphenicol $(25 \mu \mathrm{g} / \mathrm{ml})$ und Tetrazyklin $(12,5 \mu \mathrm{g} / \mathrm{ml})$ inokuliert. Nach Inkubation über Nacht wurde die Kultur als Starterkultur verwendet. Mit je $2 \mu \mathrm{l}$ wurden drei Kolben mit je $50 \mathrm{ml}$ Vollmedium mit Chloramphenicol $(25 \mu \mathrm{g} / \mathrm{ml})$ und Tetrazyklin $(12,5 \mu \mathrm{g} / \mathrm{ml})$ inokuliert. Nach Wachstum über Nacht wurden mit $2 \mu \mathrm{l}$ aus jeder Kultur $50 \mathrm{ml}$ frisches Vollmedium mit Chloramphenicol und Tetrazyklin inokuliert. Diese Prozedur wurde noch achtmal wiederholt. Letztendlich wurden Aliquots der einzelnen Übernachtkulturen mit dem anti-E Antikörper markiert und die Zellen durchflusszytometrisch vermessen. Abbildung 9 zeigt als Ergebnis die Auftragung des Anteils markierbarer Zellen gegen die Zeit.

Nach Kultivierung der Mischung über mehr als 100 Generationen hinweg kann man erkennen, dass der Anteil an Intimin'-EETI-CK ${ }^{\text {send }}$ präsentierenden Zellen von $40 \%$ auf 
ungefähr $5 \%$ gefallen ist, was anzeigt, dass Kontrollzellen nur einen geringen, wenn auch signifikanten Wachstumsvorteil gegenüber den präsentierenden Zellen aufweisen.

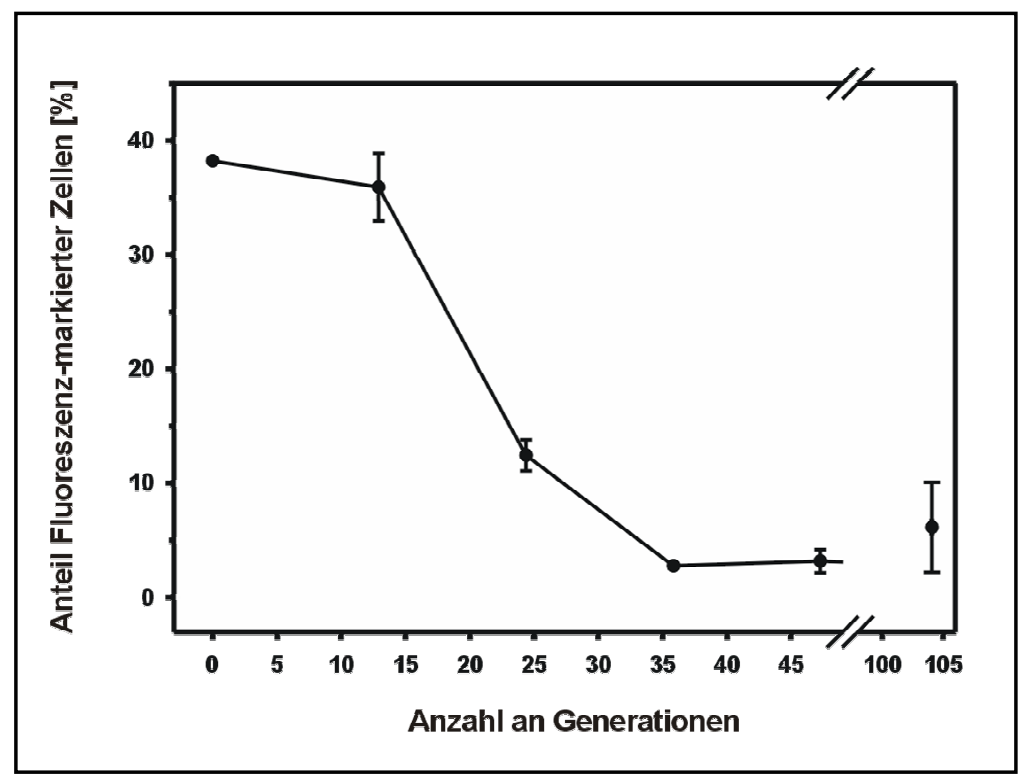

\begin{abstract}
Abbildung 9. Wachstums-Kompetitionstest Tetrazyklin-induzierter Zellen von pASKInt100-EETI-CK ${ }^{\text {send }}$ tragenden Zellen von 71-18mutS verglichen mit pASK75cat tragenden 71-18mutS Zellen. Eine 1:1 Mischkultur beider Plasmid-tragender Zellen wurden in permanenter Anwesenheit von Tetrazyklin für über 100 Generationen durch wiederholtes Überimpfen inkubiert. Der Anteil Intimin' präsentierender Zellen wurde durch Fluoreszenzmarkierung von Zellen zu bestimmten Zeitpunkten bestimmt. Drei unabhängige Experimente lieferten die Standardabweichungen.
\end{abstract}

\title{
2.1.4 Bestimmung und Regulation der Anzahl Oberflächen-exponierter Moleküle
}

Für das Konstrukt EaeA-E-tag-EETI-CK ${ }^{\text {send }}$ sollte die Anzahl Oberflächen-präsentierter Moleküle von E-tag-EETI-CK ${ }^{\text {send }}$ bestimmt werden. Dazu wurden Expressions-induzierte Zellen von DH5 $\alpha Z 1$, die das Plasmid pASKInt100-EETI-CK ${ }^{\text {send }}$ trugen, herangezogen. Es wurden 13 x $400 \mu \mathrm{l}$ Kultur geerntet und die Zellen mit steigenden Mengen anti-E Antikörper inkubiert. Es wurden Mengen von $0 \mu \mathrm{g}, 0,001 \mu \mathrm{g}, 0,003 \mu \mathrm{g}, 0,006 \mu \mathrm{g}, 0,01 \mu \mathrm{g}, 0,05 \mu \mathrm{g}, 0,1 \mu \mathrm{g}$, $0,2 \mu \mathrm{g}, 0,4 \mu \mathrm{g}, 0,6 \mu \mathrm{g}, 1 \mu \mathrm{g}$ und $2 \mu \mathrm{g}$ anti-E Antikörper in je $10 \mu \mathrm{l}$ PBS eingesetzt. Die Zellen wurden in der Antikörperlösung für 5 min bei Raumtemperatur inkubiert. Anschließend wurden $500 \mu \mathrm{l}$ PBS zugegeben und die markierten Zellen abzentrifugiert. In den beiden folgenden Schritten wurden die Zellen mit im Überschuss befindlichem zweiten, biotinylierten Antikörper und Streptavidin, R-Phycoerythrin Konjugat behandelt. Die für einen Überschuss notwendige Menge an Antikörper bzw. Streptavidin, R-Phycoerythrin war zuvor ermittelt worden und wurde entsprechend eingesetzt. Von einer mit $0 \mu \mathrm{g}$ anti-E Antikörper behandelten Probe wurde die Zellzahl bestimmt. Dazu wurde die Probe in $4 \mathrm{ml}$ PBS verdünnt und $1 \mathrm{ml}$ der Zellsuspension im cell sorter gezählt. Es wurde eine Zellzahl von $4,5 \times 10^{7}$ pro $400 \mu \mathrm{l} \mathrm{Kulturansatz} \mathrm{ermittelt.} \mathrm{Die} \mathrm{markierten} \mathrm{Proben} \mathrm{wurden} \mathrm{vollständig} \mathrm{in}$ $1 \mathrm{ml}$ PBS resuspendiert, und die durchschnittliche relative Fluoreszenz von 300.000 Zellen wurde durchflusszytometrisch bestimmt. Diese durchschnittliche relative Fluoreszenz pro Zelle wurde gegen die eingesetzte (d.h. gebundene) Menge an anti-E Antikörper 
logarithmisch aufgetragen. Aus der maximalen Steigung und dem Sättigungswert wurde ein Punkt ermittelt, der einer eingesetzten Menge von etwa 0,4 $\mu \mathrm{g}$ anti-E Antikörper entspricht (Abbildung 10). Unter der Annahme, dass jeder anti-E Antikörper nur ein einziges E-Epitop gebunden hat (für einen Antikörper besteht jedoch auf Grund zweier Bindungsstellen pro Molekül grundsätzlich die Möglichkeit bis zu zwei Epitope zu binden), ist die Anzahl Oberflächen-präsentierter Moleküle gleich der maximalen Anzahl gebundener Antikörper in der gesamten Probe, welche sich auf die durch Durchflusszytometrie bestimmte Anzahl Einzelzellen verteilt. Unter der Annahme eines Molekulargewichts des anti-E Antikörpers von $M(\operatorname{IgG})=150.000 \mathrm{~g} / \mathrm{mol}$ wurden von $4,5^{*} 10^{7}$ Zellen $\left(6,023^{*} 10^{23} / \mathrm{mol} / 150.000 \mathrm{~g} / \mathrm{mol}\right)$ $* 0,4 \mu \mathrm{g}=1,61 * 10^{12}$ Moleküle Antikörper gebunden. Dies entspricht ca. 36.000 Antikörpermolekülen pro Zelle. Folglich sind in etwa 36.000 Moleküle E-tag-EETI-CK ${ }^{\text {send }}$ auf jeder Zelle exponiert.

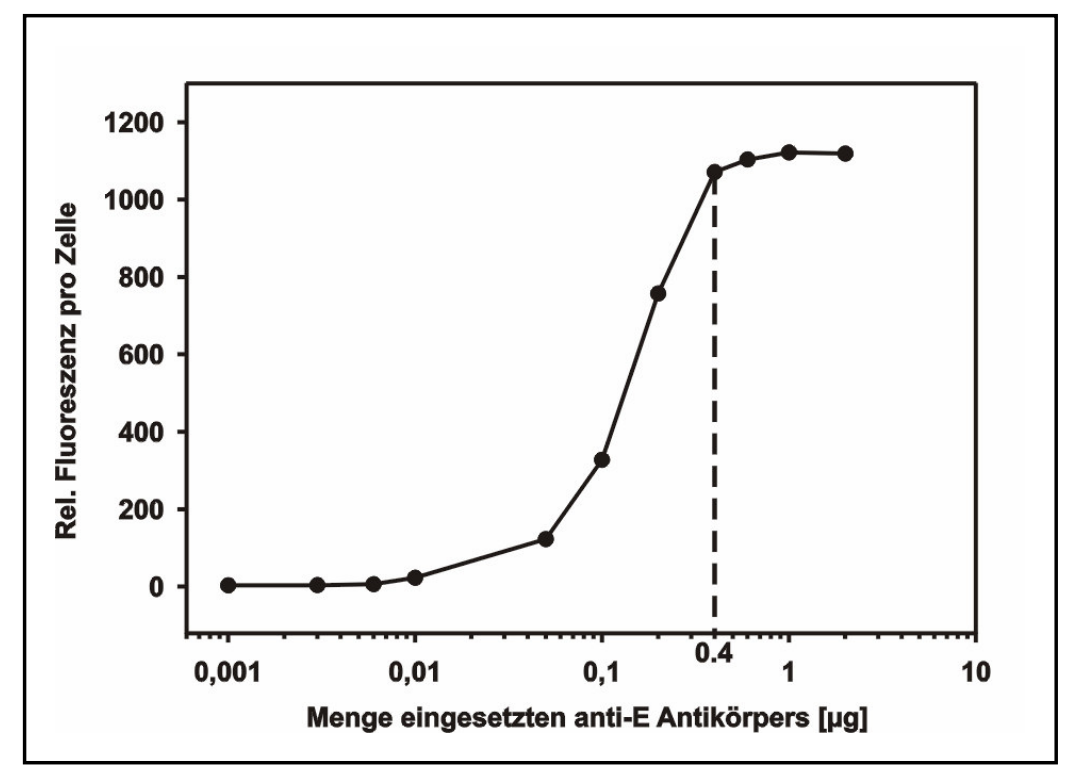

\begin{abstract}
Abbildung 10. Bestimmung der Anzahl Oberflächen-exponierter Moleküle von E-tag-EETI$C K^{\text {send }}$ durch Titration der Bindungsstellen mit anti-E Antikörper und durchflusszytometrische Bestimmung der relativen Fluoreszenz pro Zelle bei Sättigung. Stamm: DH5 $\alpha Z 1$, transformiert mit dem Plasmid pASKInt100-EETI-CK ${ }^{\text {send }}$, vollinduziert. Aufgetragen ist die durchschnittliche relative Fluoreszenz pro Zelle gegen eine definierte und steigende Menge gebundenen anti-E Antikörpers. Bei einer Menge von 0,4 $\mu$ g Antikörper ist eine Sättigung erreicht. Die daraus und aus der durchflusszytometrisch bestimmten Zellzahl errechnete Anzahl exponierter Moleküle pro Zelle beträgt in etwa 36.000 .
\end{abstract}

Neben der Bestimmung der relativen Fluoreszenz pro Zelle durch Durchflusszytometrie, wurde in einem vergleichbaren Ansatz die Gesamtfluoreszenz von mit steigender anti-E Antikörpermenge markierten Proben mit definierter Zellzahl (durchflusszytometrisch bestimmt) Fluorezenz-spektrometrisch ermittelt und diese anschließend auf eine relative Fluoreszenz pro Zelle zurückgerechnet. Nach einer ähnlichen Auftragung wie in Abbildung 10 wurde die maximal gebundene Anzahl Antikörpermoleküle pro Zelle bestimmt (nicht gezeigt). Die auf diese Weise erhaltene Anzahl Oberflächen-exponierter Moleküle E-tag-EETI-CK send war gut mit dem durch das Durchflusszytometrie basierte Verfahren bestimmten Wert vergleichbar. Die hier geschilderten Experimente lassen den Schluss zu, dass es in Fusion mit dem verwendeten EaeA' Konstrukt möglich ist, eine 
vergleichsweise große Anzahl Passagierdomänen auf der Oberfläche einer E. coli Zelle zu präsentieren.

\subsubsection{Regulation der Nettoakkumulation von Intimin'-Fusionsprotein in der äußeren Membran von $E$. coli}

Versuche, die Nettoakkumulation von Intimin'-EETI-CK ${ }^{\text {send }}$ Fusionsprotein in der äußeren Membran durch Variation der Konzentration an Induktor der Transkription zu regulieren, scheiterten. Bei niedrigen eingesetzten Konzentrationen an Induktor waren in den meisten Zellen die Expression nicht induziert, während in einem geringen Anteil eine Vollinduktion vorlag. Mit zunehmender Konzentration an Induktor nahm der Anteil vollinduzierter Zellen zu. Allerdings wurde bei keiner der eingesetzten Konzentrationen an Anhydrotetrazyklin eine Bakterienpopulation mit intermediärer Anzahl Oberflächenexponierter Intimin-Fusionsmoleküle erhalten. Dieses Ergebnis wurde auch bei Verwendung von Lpp-OmpA als Zelloberflächen-Ankerdomäne beobachtet (Daugherty et al., 1999, Christmann et al., 1999).

Auf Basis der Transkriptionskontrolle schien es somit nicht möglich zu sein, das Ziel einer regulierten Nettoakkumulation des Oberflächen-exponierten Intimin-Fusionsproteins zu verwirklichen. Eine Alternative sollte die zusätzliche Regulation auf Translationsebene sein. Durch die Variation der Menge an Suppressor tRNA, welche für die Translation über das amber Stopkodon an Position \#35 des eaeA'-Gens hinweg notwendig ist, konnte eine Regulation bewerkstelligt werden. In Abbildung 11 ist die doppelte Regulation schematisch dargestellt.

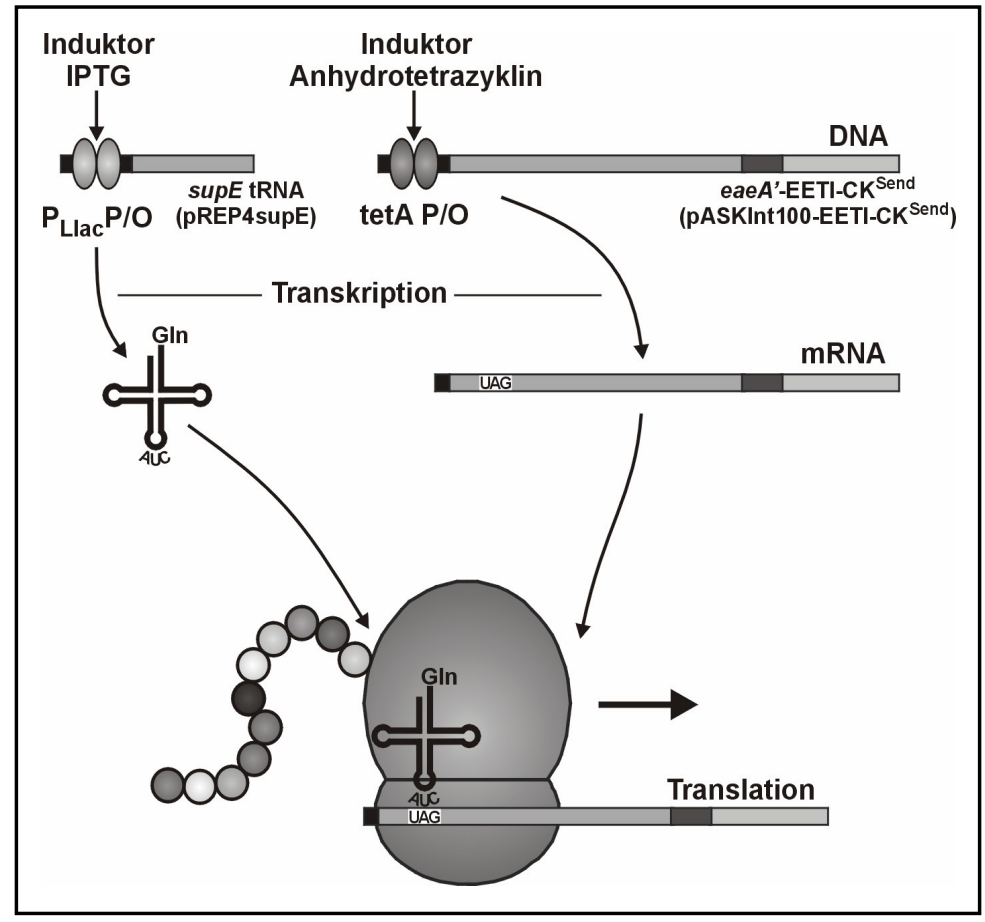

Abbildung 11. Regulation der Nettoakkumulation von Intimin'-Fusionsprotein in der äußeren Membran von E.coli. Die Induktion durch Anhydrotetrazyklin führt zur Transkription der unter tetA Promotor stehenden eaeA' mRNA von pASKInt100 aus. Die IPTG induzierte Synthese von supE Suppressor tRNA führt zur Suppression an dem UAG Kodon \#35 des eaeA'-Transkripts und zu einem Translationsprodukt der vollen Länge. 
Das Plasmid pREP4-supE kodiert für die Sequenz der Glutaminyl- amber Suppressor tRNA unter Kontrolle des $P_{\text {Llac }}$ Promotors/Operators. Dieses Plasmid enthält einen p15A Replikationsursprung und ein Kanamycin-Resistenzgen und ist folglich kompatibel mit dem Oberflächenpräsentationsvektor pASKInt100 und seinen Derivaten.

\subsubsection{Konstruktion des Plasmids pREP4-supE.}

Das Plasmid pREP4-supE wurde in Zusammenarbeit mit Dr. Harald Kolmar konstruiert (siehe Anhang 8.2.2). Hier befindet sich das supE tRNA-Gen unter der Kontrolle des $P_{\text {Llac }}$ Promotors/Operators. Um dies in den Vektor pREP4 einzubringen, wurde mittels der Oligonukleotide SupE2-Eco-up und SupE2-Mlu-lo ausgehend von chromosomaler DNA von E. coli 71-18 als Matrize ein DNA-Segment mit den kodierenden Sequenzen für die tRNA $^{\mathrm{Gln}(\mathrm{CAA})}$, die tRNA ${ }^{\mathrm{Gln}(\mathrm{CCT})}$, die tRNA ${ }^{\text {Met }}$, die supE tRNA und die tRNA ${ }^{\mathrm{Gln}(\mathrm{AAT})}$ amplifiziert und über die Restriktionsschnittstellen EcoRI und MluI in den ebenso gespaltenen Vektor pZA22-MCS1 (Lutz \& Bujard 1997, siehe auch 4.2) eingebracht. Der resultierende Vektor pZA22-supE wurde mit XhoI und XbaI gespalten, die überhängenden Enden wurden mit T4 DNA-Polymerase aufgefüllt und das die supE tRNA enthaltende Fragment wurde in die SmaI Schnittstelle des Plasmids pREP4 (Fa. Oiagen, siehe auch 4.2) kloniert, was das Plasmid pREP4-supE ergab. Die Klonierung von pREP4-supE ist in Abbildung 12 zusammenfassend dargestellt.

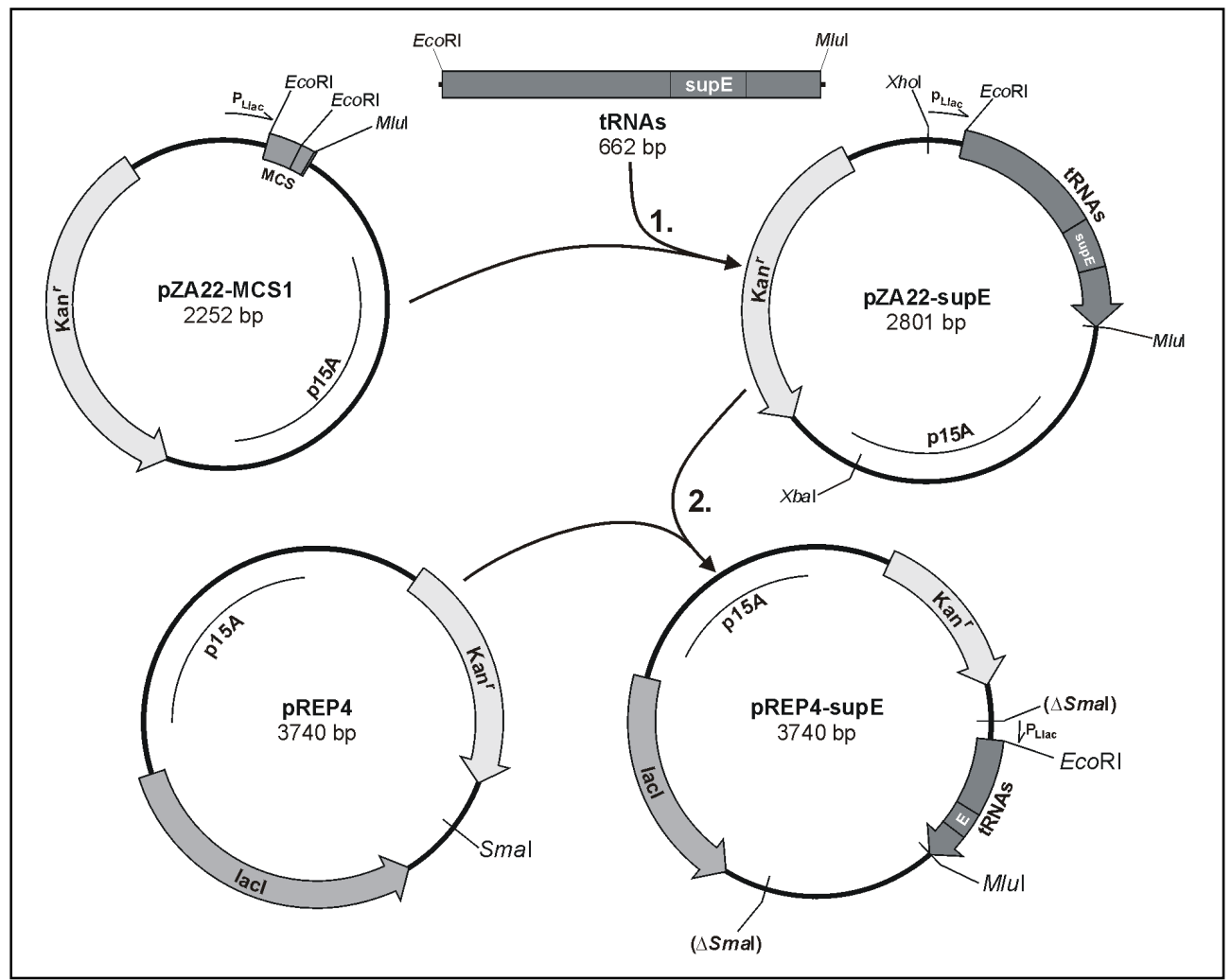

Abbildung 12. Schematische Darstellung der Erzeugung des Plasmids pREP4-supE. (1.) Klonierung der Sequenz aus fünf tRNA-Genen, darunter die supE tRNA (bezeichnet als supE oder E) über EcoRI/MluI in dem Vektor pZA22-MCS1 (Lutz \& Bujard, 1997, siehe auch 4.2). (2.) Umsetzen der tRNA-Gene mitsamt dem $P_{\text {Llac }}$-Promotor/Operatorregion aus pZA22MCS1 über die SmaI-Schnittstelle des Vektor pREP4 (Fa. Oiagen, siehe auch 4.2) durch Spaltung von pZA22-supE mit XhoI und XbaI und Auffüllen der anfallenden 5' Überhänge mittels T4 DNA-Polymerase. Weitere Informationen im Text und in Kapitel 4.2. 


\subsubsection{Graduelle Induktion der Genexpression und Oberflächenpräsentation des Intimins}

Zellen des Stammes WK6 (kein amber Suppressor-Stamm), welche die Plasmide pREP4supE und pASKInt100-EETI-CK ${ }^{\text {send }}$ enthielten, wurden über Nacht in Anwesenheit unterschiedlicher Mengen IPTG inkubiert, um die Transkription von amber Suppressor tRNA zu induzieren. Zellen dieser Kultur wurden subkultiviert in identischem Medium mit derselben IPTG Konzentration. Nach Induktion mit Anhydrotetrazyklin $(0,2 \mu \mathrm{g} / \mathrm{ml})$ bei einer O.D. ${ }_{600}$ von 0,2 für eine Stunde wurden die Zellen geerntet und nach Markierung mit der anti-E Kaskade durchflusszytometrisch untersucht. Die durchschnittliche, relative Fluoreszenz pro Zelle wurde bestimmt und gegen die Konzentration an Induktor IPTG aufgetragen. Das Ergebnis ist in Abbildung 13 dargestellt.

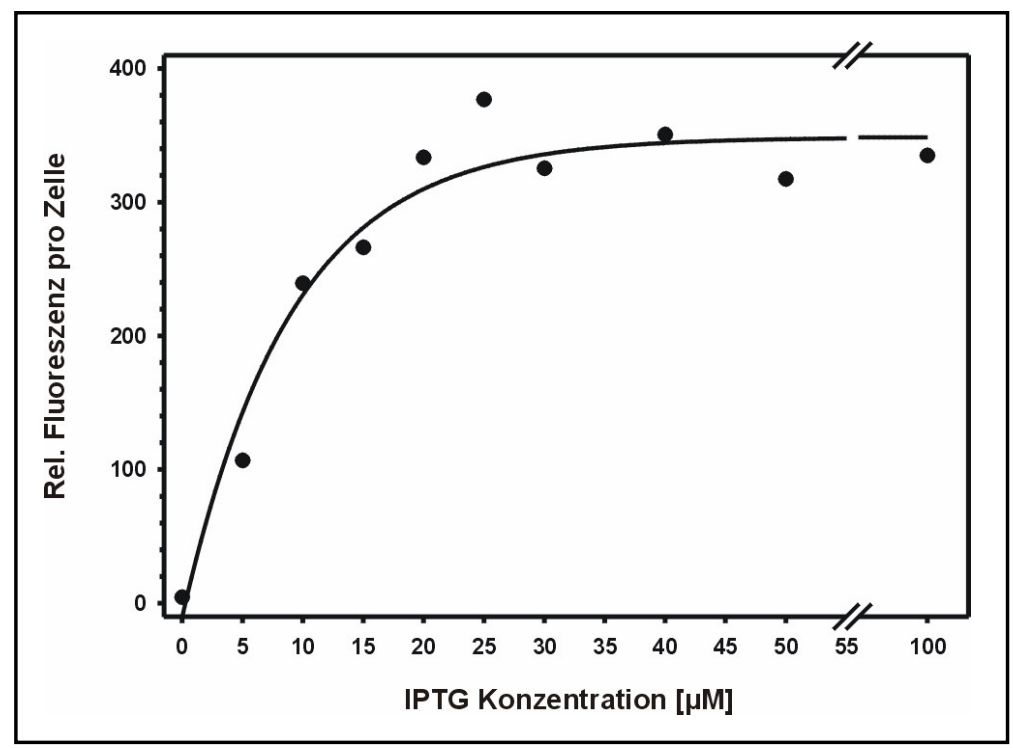

Abbildung 13. Dose/response Kurve der relativen Fluoreszenz Intimin'-E-tag-EETI-CK ${ }^{\text {send }}$ präsentierender Zellen, markiert mit anti-E Antikörper in Abhängigkeit von der eingesetzten IPTG Konzentration.

Bis zu einer Konzentration von $20 \mu \mathrm{M}$ IPTG nahm die durchschnittliche Fluoreszenz pro Zelle zu. Ähnliche Kurvenverläufe lassen sich für die IPTG Modulation der Transkriptionregulation von Gen-Expressionen unter $P_{\text {Llac }}$ Promotor/Operator Kontrolle beobachten (Lutz \& Bujard, 1997). Der Maximalwert der Anzahl der auf der Zelloberfläche exponierten Moleküle war dabei immer noch in etwa 50 \% unter einem Wert angesiedelt, welcher bei der Transkription eines chromosomal kodierten amber Suppressor tRNA-Gens, wie in DH5 $\alpha$ Z1 oder 71-18 erreicht wird. Die dort stattfindende Überproduktion der Suppressor tRNA, die unter Kontrolle des sehr starken ribosomalen RNA Promotors steht, kann durch eine Transkription ausgehend von dem in den geschilderten Experimenten eingesetzten $P_{\text {Llac }}$ Promotor nicht erreicht werden. 


\subsection{Zelloberflächenpräsentation strukturell unterschiedlicher Domänen durch EaeA'}

In den vorangegangenen Experimenten wurde das neu entworfene Zelloberflächenpräsentationsverfahren auf der Basis des EaeA' Proteins enterohämorrhagischer Escherichia coli hinsichtlich seiner biotechnologischen Anwendbarkeit evaluiert. Der zentrale Parameter war hierbei die Vitalität der Wirtszellen bei gleichzeitiger Exposition einer möglichst großen Anzahl Moleküle auf der Zelloberfläche. Mit dem Mikroprotein EETI-CK ${ }^{\text {send }}$ wurde in diesen sondierenden Experimenten eine sehr kleine Domäne für die Exposition eingesetzt, einer möglichen Ausgangsstruktur für die Erzeugung umfangreicher konformationell fixierter Peptid-Bibliotheken und die Durchmusterung dieser Cystin-Knoten Mikroproteine nach Varianten mit neuen Bindeeigenschaften (Wentzel et al., 2001). Um zu untersuchen, ob es möglich ist, auch in ihren räumlichen Ausmaßen größere Passagierdomänen auf der Zelloberfläche zu präsentieren, wurden aufeinander folgend unterschiedliche Proteine für eine Fusion mit Intimin' ausgewählt. Zum Nachweis der Oberflächenexposition von mit Intimin' fusionierten Passagierdomänen wurde sowohl amino- als auch carboxyterminal eine Epitopsequenz angefügt. Während der E-tag als genereller Nachweis der Lokalisation des EaeA'-Konstruktes in der äußeren Membran herangezogen werden kann, da er sich unmittelbar an die Intimindomäne anschließt, kann durch den Nachweis des Sendai-Epitops eine Aussage über das Ausmaß der Präsentation einer in der Sequenz davor befindlichen Passagierdomäne getroffen werden. Wenn beide, die Passagierdomäne flankierenden Epitope Oberflächen-exponiert sind, ist es plausibel zu schließen, dass auch das dazwischen liegende Passagierprotein auf der Zelloberfläche lokalisiert ist. Damit ist es möglich, die Zelloberflächenpräsentation von Proteinen zu untersuchen, für die keine Antikörper zur Immunfluoreszenzfärbung vorliegen. Die strukturellen und funktionellen Eigenschaften der verwendeten Passagierdomänen werden in den nachfolgenden Abschnitten 2.2.1 bis 2.2.5 kurz beschrieben, jeweils gefolgt von der Schilderung der Experimente zu deren Oberflächenpräsentiation via Intimin'-Fusion.

\subsubsection{Präsentation von $R E I_{v}$ auf Zellen von $E$. coli}

Das Intimin EaeA in seiner natürlichen Form exponiert insgesamt vier Domänen auf der bakteriellen Zelloberfläche. Während die C-terminale Domäne E3 eine Lektin-ähnliche Struktur hat, besitzen zumindest die beiden davor liegenden Domänen E1 und E2 eine Immunglobulin-ähnliche Faltung. Dieses Faltungsmotiv, das ausschließlich aus $\beta$ Faltblättern besteht, ist für die Domäne E0 vorhergesagt und auch die Transmembrandomäne soll demnach ausschließlich aus $\beta$-Strängen bestehen (Luo et al., 2000). Als weitere Passagierdomäne für den Nachweis der Exposition durch Fusion an EaeA' wurde neben EETI-CK ${ }^{\text {send }}$ für einen strukturell eher konservativen Austausch ein Protein ausgewählt, das wie die EaeA Domänen E1 und E2 ebenfalls eine Immunglobulin-Faltungsmotiv aus $\beta$ Faltblattstrukturen (anders als E1 und E2 zusätzlich stabilisiert durch eine Disulfidbrücke) aufweist, die Immunglobulin-Domäne $R E I_{v}$. 


\title{
2.2.1.1 Das Bence-Jones Protein $R E I_{v}$
}

Bence-Jones Proteine sind freie leichte Ketten von Immunglobulinen und kommen im Urin vieler Patienten vor, die an multiplem Myelom leiden (Maldonado et al., 1975). Ein Beispiel aus dieser Gruppe ist das REI Protein, das aus der gesamten $\kappa$ leichten Immunglobulin-Kette und der korrespondierenden variablen Domäne besteht (Kolmar et al., 1994). Die solitäre variable Domäne der $\kappa$ leichten Kette des humanen Immunglobulins wird als $R E I_{v}$ bezeichnet. Das Protein hat eine Länge von 107 Aminosäuren bei einem relativen Molekulargewicht von etwa 12.000 .

Das in $R E I_{v}$ vorliegende Immunglobulin-Faltungsmotiv besteht aus zwei einander gegenüberliegenden $\beta$-Faltblättern jeweils gebildet aus mehreren antiparallelen $\beta$-Strängen. Die sequenzielle relative Lage der einzelnen $\beta$-Stränge folgt der so genannten "greek-key" Anordnung (Abb. 14). Die beiden $\beta$-Faltblätter sind durch eine unter den ImmunglobulinDomänen konservierte Disulfidbrücke kovalent verknüpft, welche in dem hydrophoben Kern der Domäne verborgen ist (Amzel \& Poljak, 1979). Diese eine Disulfidbrücke ist für die Aufrechterhaltung einer geordneten Faltung des Wildtyp $R E I_{v}$ Proteins notwendig (Frisch et al., 1994, 1996).

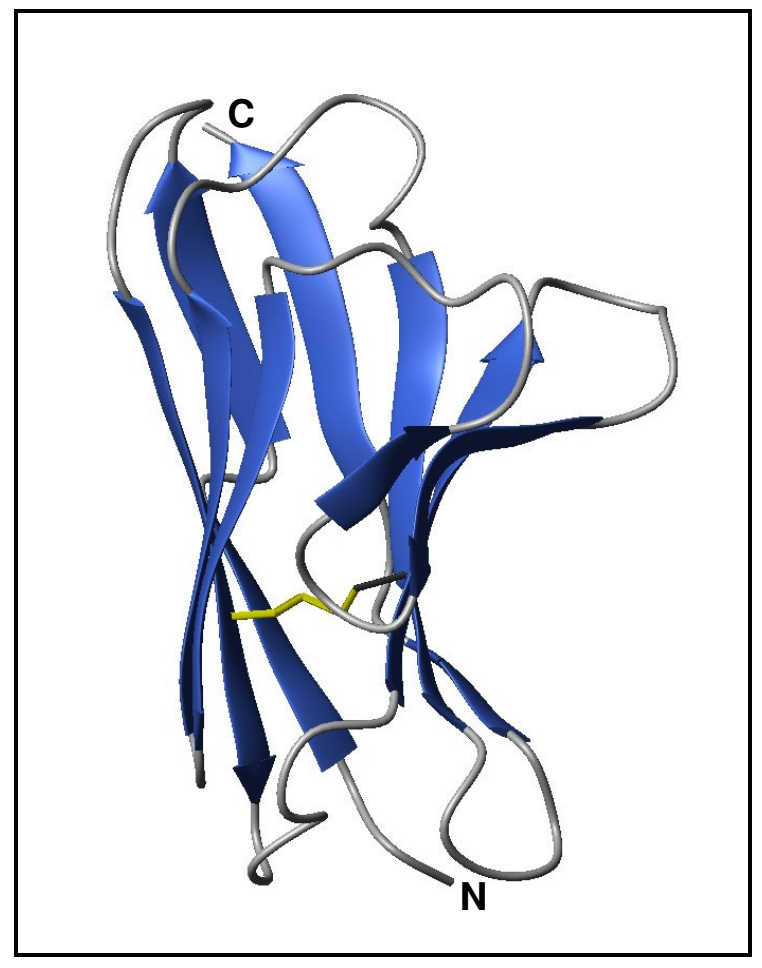

\begin{abstract}
Abbildung 14. Schematische Darstellung der variablen Immunglobulin-Domäne, $\kappa$ leichte Kette $R E I_{v}$. $\beta$-Stränge sind mit ihrer Orientierung in Pfeilrichtung in blau, verbindende Regionen in grau dargestellt. Die eine im Molekül vorkommende Disulfidbrücke der CysteinReste \#23 und \#88 innerhalb des hydrophoben Kerns des Moleküls ist in gelb eingezeichnet. (Erzeugt unter Verwendung von Molmol, Version 2K.2, Reto Konradi, PDB: 1REI, Epp et al., 1975).
\end{abstract}

\subsubsection{Klonierung des $R E I_{v}$ Gens in pASKInt100}

Um überprüfen zu können, ob, vermittelt durch Intimin', auch $R E I_{v}$ auf der E.coli Zelloberfläche exponiert werden kann, musste zunächst das dieser Domäne zugrundeliegende $R E I_{v}$-Gen in einen Sequenzkontext mit dem eaeA'-Gen gestellt werden. 
Dies geschah durch die Klonierung des Gens in den Präsentationsvektor pASKInt100. Das Gen für REI $I_{v}$ wurde durch PCR Amplifikation auf dem Plasmid pHKREI (Kolmar et al., 1992, siehe auch 4.2) als Matrize sowie mittels der Oligonukleotide EheI-up und REI-lo-BgIII erhalten. Das PCR-Produkt wurde mit EcoRV und BglII gespalten und das erhaltene Fragment mit dem SmaI und BglII gespaltenen Vektorfragment des Plasmids pASKInt100(TmDegP) ligiert. Das Rezipientenplasmid ist ein Abkömmling von pASKInt100 (Wentzel et al., 2001), in dem ein Fragment des DegP-Gens aus Thermotoga maritima in N-terminaler Fusion mit der kodierenden Sequenz des Sendai-Epitops vorliegt. Es besteht in diesem Vektor jedoch kein durchgehendes Leseraster zwischen dem Intimin'-Etag- und dem TmDegPSendai-Modul. Zwischen der kodierenden Sequenz für das E-Epitop und dem TmDegPGenfragment befindet sich die SmaI Schnittstelle von pASKInt100, zwischen dem TmDegPGenfragment und der dahinter liegenden Sendai DNA-Sequenz eine BglII Schnittstelle. Durch Klonierung von DNA Fragmenten über die Schnittstellen SmaI und BglII lässt sich folglich ein durchgehendes Leseraster Intimin'-E-tag-X-Sendai erzeugen. Auf diesem Wege wurde das Plasmid pASKInt100-REI erhalten.

\subsubsection{Präsentation von $R E I_{v}$ durch Fusion an $E a e A^{\prime}$}

Nach der Transformation von Zellen des Stammes 71-18P' mit pASKInt100-REI wurden mit einer daraus hervorgegangenen Einzelkolonie $50 \mathrm{ml}$ Chloramphenicol-haltiges dYTMedium $(25 \mu \mathrm{g} / \mathrm{ml})$ inokuliert. Die Expression des Fusionsproteins wurde nach Methode 5.5.1 induziert, und anschließend wurde jeweils ein geringer Volumenanteil der Kultur für die Fluoreszenzmarkierung mit der anti-Sendai- bzw. der anti-E Kaskade nach Methode 5.5.2 aufbereitet. Die Proben wurden sodann durchflusszytometrisch vermessen (Methode 5.5.3). Das Ergebnis ist in Abbildung 15A dargestellt. Es ist eine Verschiebung des Kurvenmaximums hin zu höherer Fluoreszenz sowohl bei der anti-E-, als auch bei antiSendai-Markierung zu erkennen. Als Vergleich dienten unmarkierte Zellen desselben Typs. Die auf der Bindung des anti-Sendai Antikörpers beruhende Markierung bleibt hinter der des anti-E Antikörpers leicht zurück, was auf eine schlechtere Bindung des anti-Sendai Antikörpers zurückgeführt werden kann. In jedem Fall ist die Bindung beider Antikörper für den qualitativen Fluoreszenznachweis ausreichend. Die Immunglobulin-Domäne $R E I_{v}$ wird von Zellen des Stammes 71-18 gut auf der Oberfläche präsentiert.

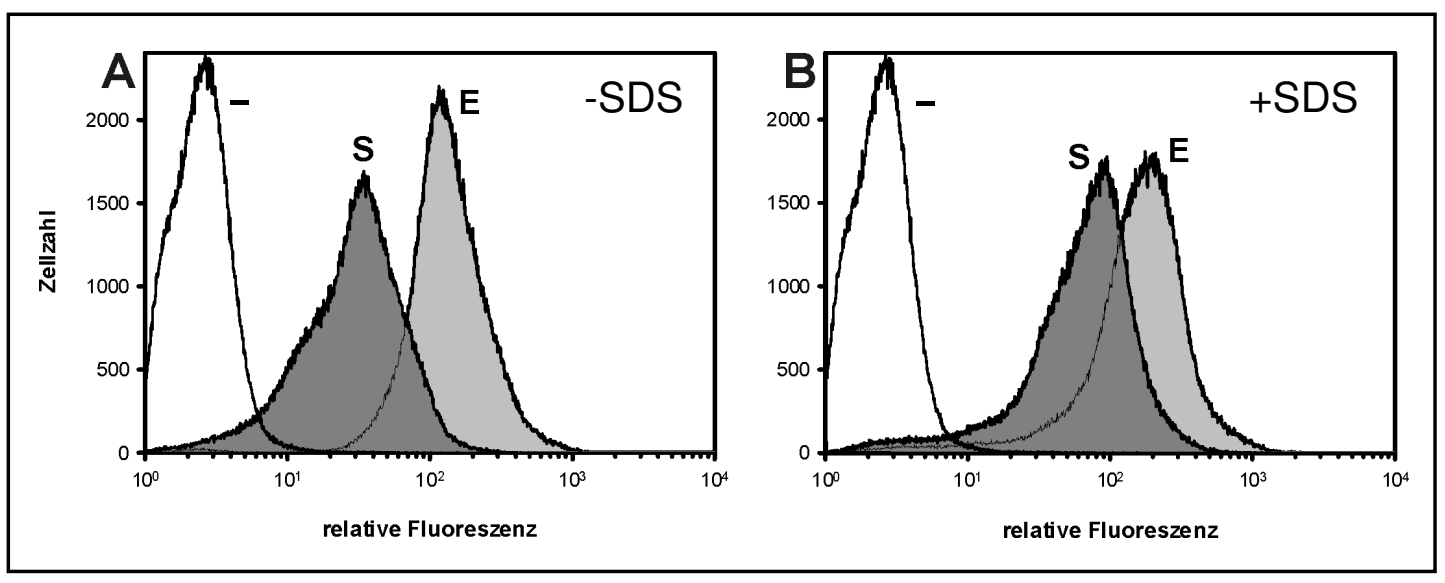

Abbildung 15. FACS Histogramme von pASKInt100-REI tragenden Zellen von 71-18P'. (A) Nach Induktion der EaeA'-Expression (siehe Methode 5.5.1) wurden die Zellen nacheinander mit anti-Sendai Antikörper (S) oder anti-E Antikörper (E), biotinyliertem anti- 
Maus Antikörper und Streptavidin, R-Phycoerythrin-Konjugat gemäß Methode 5.5.2 behandelt. Als Kontrolle dienten unmarkierte Zellen derselben Kultur. (B) wie (A) jedoch unter Verwendung modifizierter Wachstumsbedingungen in Anwesenheit von SDS gemäß b) (siehe Text).

Zusätzlich zum Stamm 71-18P' wurde eine Exposition von REI v auch auf Zellen des Stammes DH5aZ1 untersucht (Abb. 18B). Aus diesem Experiment geht hervor, dass das Protein hier in höherer Kopienzahl auf der Oberfläche der Zellen präsentiert wird, da das Maximum der Fluoreszenz zu höherer Kanalzahl hin verschoben ist. Der Befund einer verminderten Nettoakkumulation von $R E I_{v}$ im Stamm 71-18 im Vergleich zu der des EETI-II Mikroproteins weist darauf hin, dass der Prozess der Translokation durch die äußere Membran behindert ist. Möglicherweise stellt eine intakte äußere Membran eine generelle Barriere für die Translokation dar. Alternativ oder kumulativ könnte auch die Bildung eines Makrozyklus der Polypeptidkette durch kovalente Verknüpfung der Cysteinseitenketten \#23 und \#88 den Export der Passagierdomäne behindern. Um diese Möglichkeiten experimentell zu untersuchen, wurden zum einen während des Wachstums der Bakterien Chemikalien zugesetzt, von denen bekannt ist, dass sie Membran-destabilisierend wirken. Zum anderen wurde durch Zugabe von Reduktionsmitteln versucht, auf die Bildung von Disulfidbrücken Einfluss zu nehmen. Abweichend von den Wachstumsbedingungen nach 5.5.1 wurden folgende Versuchsanordnungen verfolgt.

a) Wachstum in Anwesenheit von EDTA einer Endkonzentration von $1 \mathrm{mM}$, gefolgt von der Induktion der Expression mit Anhydrotetrazyklin $(0,2 \mu \mathrm{g} / \mathrm{ml}$ Endkonzentration) bei einer O.D.600 von 0,2, sodann weiteres Wachstum für eine Stunde bei $37^{\circ} \mathrm{C}$ und anschließende Markierung wie oben nach Methode 5.5.2,

b) Wachstum in Anwesenheit von $0,1 \%(w / v)$ SDS, gefolgt von der Überführung in SDS-freies Medium durch Zentrifugation (4000 rpm, 10 min, RT) und Resuspendieren sowie Induktion der Expression mit $0,2 \mu \mathrm{g} / \mathrm{ml}$ Anhydrotetrazyklin bei einer O.D.600 von 0,2 , sodann weiteres Wachstum für eine Stunde bei $37^{\circ} \mathrm{C}$ und anschließende Markierung wie oben nach Methode 5.5.2,

c) Wachstum in Anwesenheit von $\beta$-Mercaptoethanol einer Endkonzentration von $20 \mathrm{mM}$, gefolgt von der Induktion der Expression mit 0,2 $\mu \mathrm{g} / \mathrm{ml}$ Anhydrotetrazyklin bei einer O.D. ${ }_{600}$ von 0,2, sodann weiteres Wachstum für eine Stunde bei $37^{\circ} \mathrm{C}$ und anschließende Markierung wie oben nach Methode 5.5.2,

d) Verwendung des Stammes 71-18dsbA [DsbA ist in E.coli für die Bildung von Disulfidbrücken essentiell und beschleunigt deren Ausbildung in vivo (Bardwell et al., 1991)] und Wachstum ohne weitere Zusätze, Induktion der Expression gemäß Methode 5.5.2,

e) wie a) unter Verwendung des Stammes 71-18dsbA,

f) wie b) unter Verwendung des Stammes 71-18dsbA,

g) wie c) unter Verwendung des Stammes 71-18dsbA.

Die Nettoakkumulation von $R E I_{v}$ auf der Oberfläche von 71-18P' Zellen konnte nur durch Anwendung der Wachstumsbedingungen nach c) $(0,1 \%$ (w/v) SDS im Medium) ein 
wenig erhöht werden. Das Ergebnis dieser Optimierung ist in Abbildung 15B in Form eines durchflusszytometrischen Diagramms wiedergegeben. Die hier unter a) bis g) aufgeführten Modifikationen des Standardverfahrens fanden auch bei der Optimierung der Präsentation der in den folgenden Kapiteln vorgestellten Passagierdomänen Anwendung. Durch die Behandlung mit SDS wird die äußere Membran der Zellen möglicherweise soweit destabilisiert, dass der Transmembrantransport von in diesem Falle REI auf 71-18P'-Zellen erleichtert wird. Ein Einfluss des Detergenz auf die Proteinfaltung sollte in dem gewählten Versuchsaufbau nicht bestehen, da das SDS-haltige Medium vor der Induktion der Expression des Fusionsproteins bereits wieder durch SDS-freies Medium ersetzt wurde. Die verbesserte $R E I_{v}$ Exposition durch Zusatz von SDS deutet darauf hin, dass die Beschaffenheit der äußeren Membran der Zellen einen wichtigen Einfluss auf die Translokation der Passagierdomäne $R E I_{v}$ durch das Intimin EaeA hat.

\subsubsection{Präsentation von Interleukin 4 auf Zellen von $E$. coli}

Das vorangegangene Kapitel beschreibt die Intimin' vermittelte Oberflächenpräsentation der Immunglobulin-Domäne $R E I_{v}$, einem Protein mit ausschließlich aus $\beta$-Strängen bestehenden Sekundärstrukturelementen, stabilisiert durch eine Disulfidbrücke, auf Zellen von E. coli 71-18P'. Im Rahmen dieses als eher konservativ anzusehenden Austausches der natürlichen Immunglobulin-ähnlichen Domäne E2 von EaeA durch $R E I_{v}$ konnte eine gute Präsentation nachgewiesen werden. Um zu untersuchen, ob es möglich ist, neben all- $\beta$ Proteinen auch Proteine mit $\alpha$-helikalen Sekundärstrukturelementen über Intimin' zu präsentieren, wurde das humane Interleukin 4 als Passagierdomäne ausgewählt.

\subsubsection{Homo sapiens Interleukin 4}

Interleukin 4 (Il-4) lässt sich in die Gruppe der Zytokine einordnen. Zytokine werden unter anderem durch Zellen des Immunsystems gebildet und dienen dort als Mediatorsubstanzen. Sie sind verantwortlich für die Induktion und den Verlauf der T-Zellvermittelten zytotoxischen Immunreaktion sowie die Aktivierung und Proliferation von BZellen (Janeway \& Travers, 1995). Als Interleukine werden allgemein solche Zytokine bezeichnet, welche von T-Zellen produziert werden. Interleukin 4 wurde in der Literatur zunächst als B-Zell-Wachstumsfaktor (BSF-1 bzw. BCGF-I) beschrieben (Yokota, et al., 1986, Coffman et al., 1986) und wird von aktivierten T-Helferzellen ( $T_{H}$ 2-Zellen) sezerniert (Del Prete, 1992) und ist außerdem in der Lage, das Verhältnis von $T_{H} 1$-Zellen zu $T_{H} 2$-Zellen hin zu letzteren zu verschieben (z.B. Rocken et al., 1994). Interleukin 4 wird aus diesem Grund als antiinflammatorisch wirkendes Zytokin z.B. bei der Therapie von Psoriasis (Schuppenflechte) oder bei anderen $T_{H} 1$ assoziierten Autoimmunkrankheiten in der Medizin eingesetzt (Ghoreschi et al., 2003). Es wirkt als autokriner T-Zell-stimulierender Faktor in Abwesenheit von Il-2 (z.B. Fernandez-Botran et al., 1986) und stimuliert die Produktion von IgE bei hoher Konzentration sowie die von IgG1 bei niedriger Konzentration (z.B. Snapper et al., 1988). Weiter steigert Il-4 die Expression von MHC-Antigenen (z.B. Noelle et al., 1986). In seiner Funktion als "switching factor" ist es als Differenzierungsfaktor am Wechsel der schweren Immunglobulin Ketten bei der Antikörperproduktion beteiligt (z.B. Lebman \& Coffman, 1988). Weitere Effekte im Zusammenhang mit Il-4 ist die Hemmung der T-Zell Proliferation und zusammen mit Il-3 die Proliferation von Mastzellen (Jansen et al., 1990). 
Interleukin 4 wirkt als monomeres Protein. Seine 129 Aminosäuren machen ein relatives Molekulargewicht von etwa 14.000 aus. Die Peptidkette faltet in eine globuläre Struktur mit hydrophobem Kern, die maßgeblich aus einem Vier-Helix-Bündel besteht (Abb. 16). Stabilisiert wird die Faltung von Il-4 durch die Ausbildung dreier Disulfidbrücken (Müller et al., 1995). Ausgang für die von Il-4 vermittelte Wirkung ist dessen Bindung an unterschiedliche Typen von Il-4 Rezeptor-Komplexen und die Auslösung einer Signaltransduktions-Kaskade gefolgt von Genaktivierung und Zellproliferation (Janeway \& Travers, 1995).

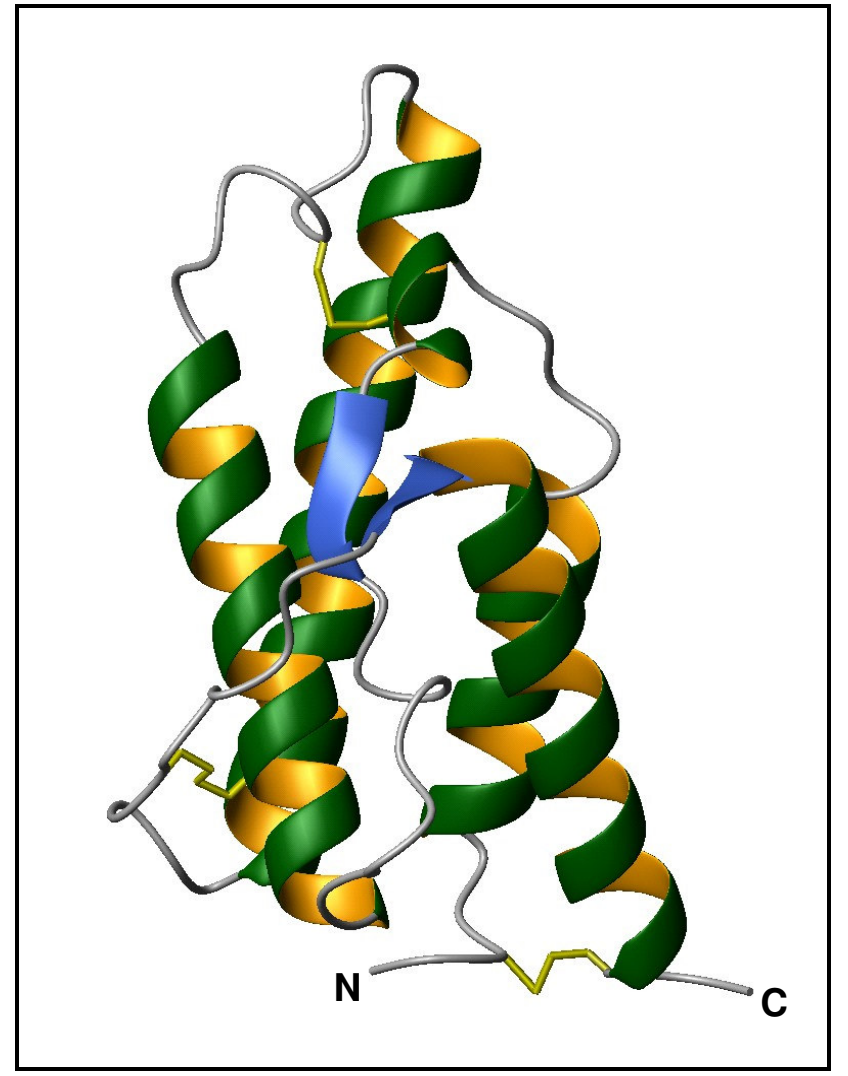

\begin{abstract}
Abbildung 16: Schematische Darstellung der Struktur des humanen Interleukin 4. $\beta$ Stränge sind mit ihrer Orientierung in Pfeilrichtung in blau, $\alpha$-Helices in grün-orange, verbindende Regionen in grau dargestellt. Die drei im Molekül vorkommenden Disulfidbrücken der Cystein-Reste \#3 und \#127, \#24 und \#65 sowie \#46 und \#99 innerhalb des Moleküls sind in gelb eingezeichnet. (Erzeugt unter Verwendung von Molmol, Version 2K.2, Reto Konradi, PDB: 1HIK, Müller et al., 1995).
\end{abstract}

\title{
2.2.2.2 Klonierung des Interleukin 4 Gens in pASKInt100
}

Das Il-4-Gen lag zu Beginn der Arbeit bereits kloniert in dem Plasmid pRPR9IL-4FD vor, welches dankenswerter Weise von Dr. Karlheinz Friedrich, Universität Jena, zur Verfügung gestellt wurde. Das Il-4 Gen wurde mit den Primern IL4-up und IL4-send-low amplifiziert. pRPR9IL-4FD diente in der PCR als Matrize. IL4-send-low führte dabei die kodierende Sequenz für das Sendai-Epitop ein. Das PCR-Produkt wurde mit SmaI und BamHI gespalten und mit dem ebenso gespaltenen Vektor pASKInt100-EETI-CK ${ }^{\text {send }}$ ligiert. Das resultierende Plasmid erhielt den Namen pASKInt100-IL4. 


\subsubsection{Präsentation von Il-4 durch Fusion an $E a e A^{\prime}$}

Nach der Transformation von Zellen des Stammes 71-18P' mit dem Plasmid pASKInt100-IL4 wurden mit einer daraus hervorgegangenen Einzelkolonie $50 \mathrm{ml}$ Chloramphenicol-haltiges $(25 \mu \mathrm{g} / \mathrm{ml})$ dYT-Medium inokuliert. Die Zellen wurden nach Methode 5.5.1 behandelt und anschließend wurde jeweils ein geringer Volumenanteil der Kultur für die Fluoreszenzmarkierung mit der anti-Sendai bzw. der anti-E Kaskade nach Methode 5.5.2 aufbereitet. Die Proben wurden anschließend durchflusszytometrisch vermessen (Methode 5.5.3). Das Ergebnis ist in Abbildung 17A dargestellt. Es ist eine deutliche Verschiebung des Kurvenmaximums hin zu höherer Fluoreszenz lediglich bei der anti-E, nur sehr geringfügig bei der anti-Sendai Markierung zu erkennen. Als Vergleich dienten hier dieselben unmarkierten Zellen wie sie unter 2.2.1.3 Verwendung fanden.

Neben dem Stamm 71-18P' wurde auch für die Oberflächenpräsentation von Il-4 zusätzlich der Stamm DH5 $\alpha Z 1$ verwendet. Vergleicht man das Ergebnis der Präsentation von Il-4 auf Zellen von 71-18P' mit der Präsentation von Il-4 auf Zellen von DH5 $\alpha Z 1$ (Abbildung 18C) so scheint dieses Protein auf 71-18P' deutlich schlechter präsentierbar zu sein. Die Anwesenheit einer starken Immunfluoreszenz nach Zellmarkierung mit dem anti-E Antikörper bei gleichzeitig nur geringfügiger Ausprägung einer anti-Sendai Markierung legt den Schluss nahe, dass die Translokation der Il-4 Domäne durch die äußere Membran von 71-18P' stark behindert ist.

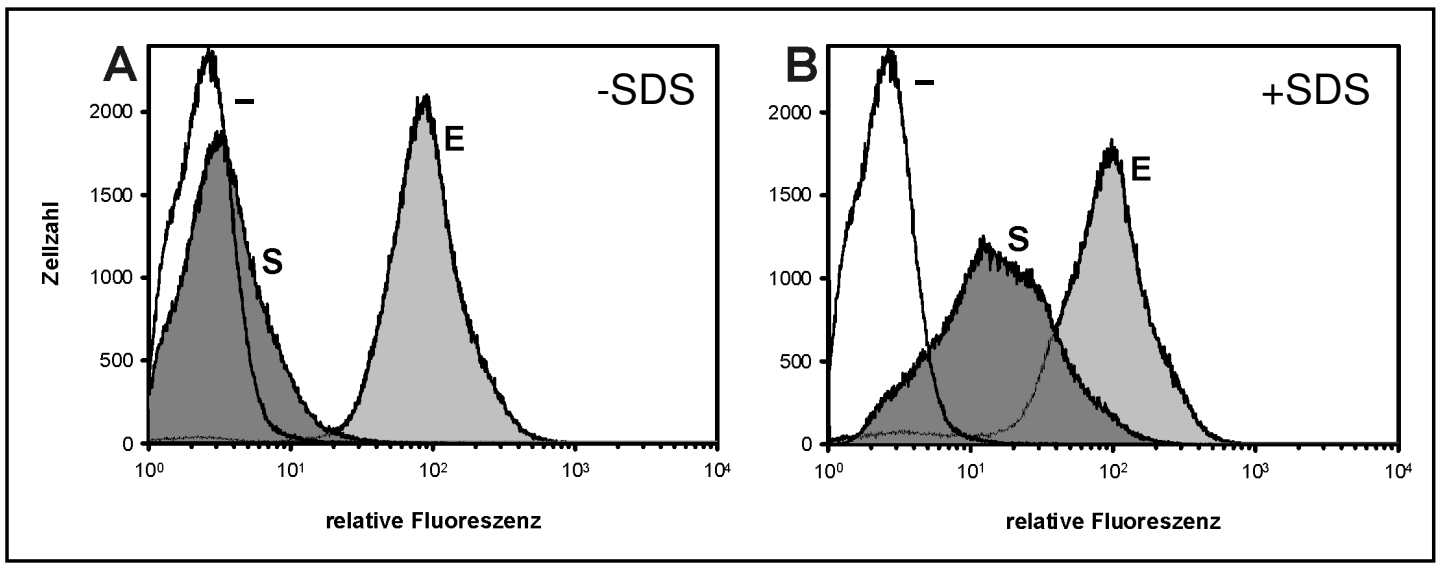

Abbildung 17. FACS Histogramme von pASKInt100-IL4 tragenden Zellen von 71-18P'. (A) Nach Induktion der EaeA'-Expression (siehe Methode 5.5.1) wurden die Zellen nacheinander mit anti-Sendai Antikörper (S) oder anti-E Antikörper (E), biotinyliertem anti-MausAntikörper und Streptavidin, R-Phycoerythrin-Konjugat gemäß Methode 5.5.2 behandelt. Als Kontrolle dienten unmarkierte Zellen derselben Kultur. (B) analog (A) jedoch unter Verwendung modifizierter Wachstumsbedingungen in Anwesenheit von SDS gemäß b) (siehe 2.2.1.3).

Das Il-4-Gen tragende Zellen desselben Typs wurden während des Kulturwachstums ebenfalls den in 2.2.1.3 angegebenen Bedingungen a) bis c) unterzogen. Hier hatte die Behandlung der Zellen nach Bedingung b) (Anwesenheit von 0,1 (w/v) SDS im Medium während des Wachstums vor der Induktion) einen deutlichen Einfluss auf den Nachweis des Sendai-Epitops und somit die Zelloberflächenexposition von Interleukin 4, während die Verwendung von EDTA und $\beta$-Mercaptoethanol im Wachstumsmedium keinen messbaren Einfluss auf die Oberflächenexposition hatte. Das Wachstum in Anwesenheit von SDS im Medium führte zu einer deutlichen Verbesserung der Präsentation bis hin zu einer 
Ausprägung wie sie bei Verwendung von DH5 $\alpha Z 1$ als Wirtsstamm zu beobachten war (siehe Abbildung 18C). Eine mögliche Erklärung für dieses Ergebnis liegt auch hier in einer möglichen Membran-destabilisierenden Wirkung von SDS (vgl. 2.2.1.3).

\subsubsection{Vergleich der Präsentation von EETI-CK ${ }^{\text {send }}, R E I_{v}$ und Il-4 über das $E a e A^{\prime}$-basierte Zelloberflächenpräsentationssystem}

Präsentationsexperimente von $R E I_{v}$ und Il-4 auf Zellen von 71-18P' erbrachten experimentelle Evidenzen, dass strukturell unterschiedliche Domänen unterschiedlich gut über Intimin' auf der Zelloberfläche präsentiert werden können. In einem vergleichenden Präsentationsexperiment unter Verwendung des Stammes DH5 $\alpha$ Z1 wurden die Domänen EETI-CK ${ }^{\text {send }}, R_{\text {EI }}$ und Il-4 via Fusion an Intimin' auf Zellen von Escherichia coli präsentiert. Zellen von DH5 $\alpha$ Z1 wurden mit den Plasmiden pASKInt100-EETI-CK ${ }^{\text {send }}$, pASKInt100-REI bzw. pASKInt100-IL4 transformiert. Nach Induktion mit Anhydrotetrazyklin (5.5.1) wurden die Zellen mit der anti-E und der anti-Sendai Markierungskaskade Immunfluoreszenz-markiert (5.5.2). Die derart behandelten Zellen wurden durchflusszytometrisch analysiert (5.5.3). Alle drei Konstrukte mit unterschiedlichen Passagierproteinen konnten mit beiden Antikörpern auf der Zelloberfläche nachgewiesen werden. Das Ergebnis ist in Abbildung 18A-C dargestellt.

Die Behandlung intakter Zellen mit Proteasen kann als Nachweis der Oberflächenpräsentation dienen (Francisco et al., 1992, Klauser et al., 1992). Nach entsprechender Behandlung sollte der extrazelluläre Anteil des Präsentationskonstruktes in der Membranfraktion nicht mehr nachweisbar sein. Um den Nachweis der Oberflächenexposition der Passagierdomäne zu führen, wurden Zellen von DH5 $\alpha Z 1$, welche mit den Plasmiden pASKInt100-EETI-CK ${ }^{\text {send, }}$ pASKInt100-REI bzw. pASKInt100-IL4 transformiert worden waren, bis zu einer O.D. ${ }_{600}$ von 0,8 herangezogen, mit ATC induziert und nach weiteren drei Stunden Wachstum geerntet. Die Zellen wurden in PBS aufgenommen und die Suspension wurde auf eine O.D.600 von 10 eingestellt. Nach Zugabe von Trypsin mit einer Endkonzentration von $50 \mu \mathrm{g} / \mathrm{ml}$ für $10 \mathrm{~min}$ wurden die Zellen mit PBS gewaschen und ebenso wie bei unbehandelten Kontrollzellen die Membranfraktion isoliert (vgl. 5.4.2). Dazu wurden die Zellen mittels French Press und Ultraschall aufgeschlossen und nicht lysierte Zellen abzentrifugiert. Der Überstand wurde nach Inkubation auf Eis in $100 \mathrm{mM}$ Tris/HCl pH 8,0, $10 \mathrm{mM}$ EDTA, $1 \%$ (v/v) Triton-X 100 für $30 \mathrm{~min}, 120 \mathrm{~min}$ mit $100.000 \mathrm{~g}$ bei $15^{\circ} \mathrm{C}$ abzentrifugiert. Die Membranfraktion wurde in Protein-Probenpuffer aufgenommen und einer SDS-Polyacrylamidgelelektrophorese (5.4.3) gefolgt von einem Western Blot (5.4.5) unterworfen. In letzterem wurde ein monoklonaler Antikörper gegen das Sendai-Epitop verwendet (Einberger et al., 1990). Das Ergebnis ist in Abbildung 18D-E wiedergegeben.

Die auftretenden Abbaubanden können auf eine aminoterminale bzw. in der Schleifenregionen der Transmembrandomäne stattgefundene Prozessierung zurückgeführt werden. Die carboxyterminale Spaltung würde dazu führen, dass das Konstrukt nach Verlust des Sendai-Epitops nicht mehr nachweisbar wäre. Ohne Behandlung mit der Protease Trypsin konnte in jedem der drei untersuchten Fälle im Vergleich zu den Kontrollpräparationen eine Bande in der erwarteten Höhe beobachtet werden, welche nach 
Trypsin-Behandlung nicht mehr vorhanden war. Dies belegt die Anwesenheit und die Exposition dieser drei untersuchten Passagierproteine auf der Oberfläche der Zellen.
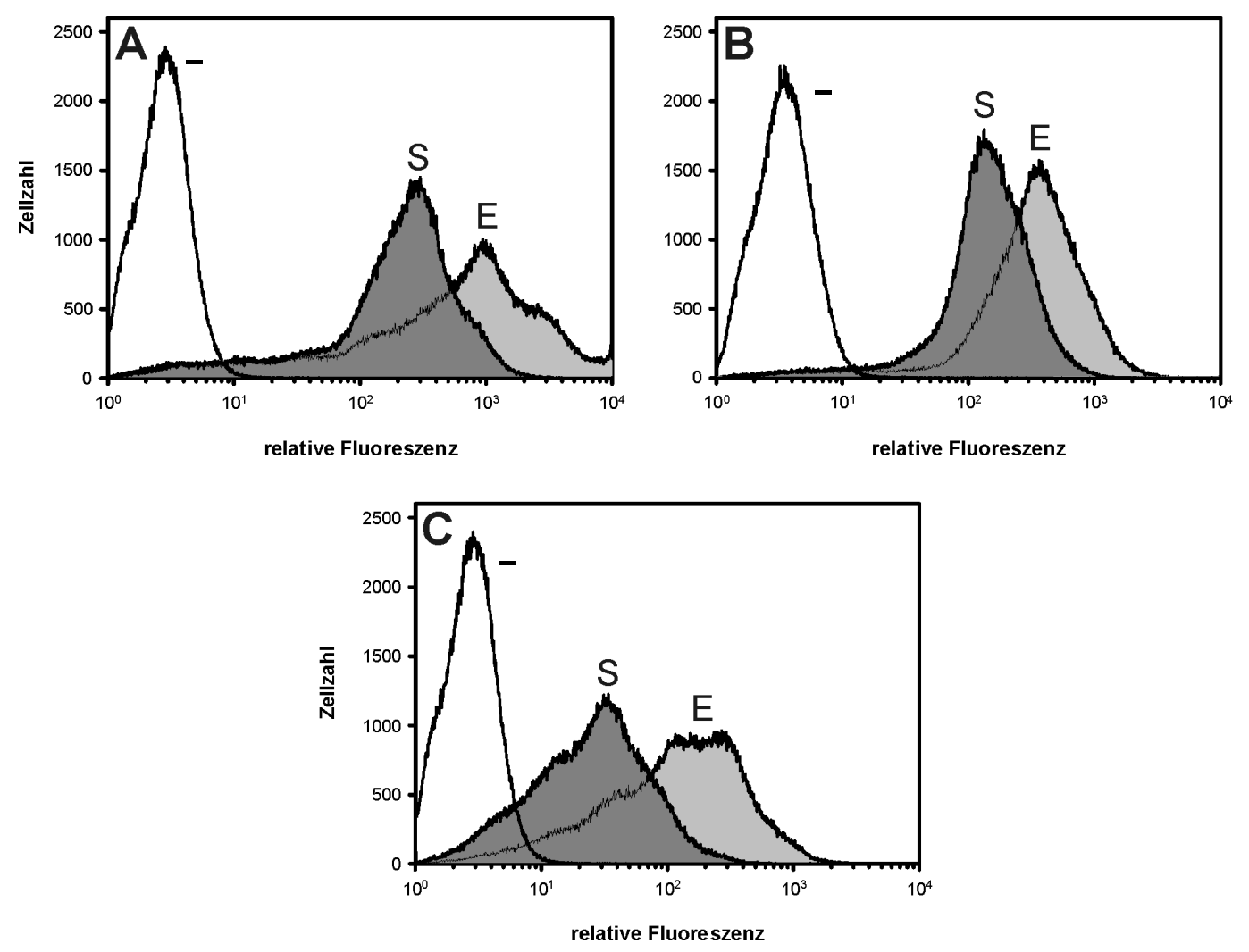

\section{D}

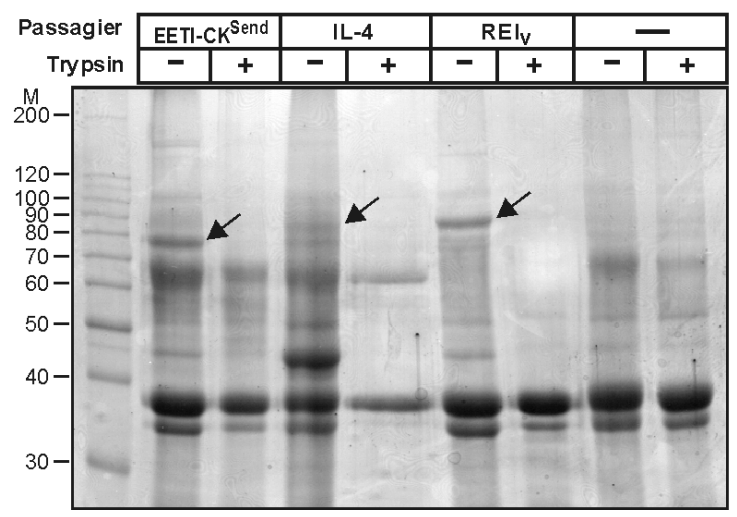

E

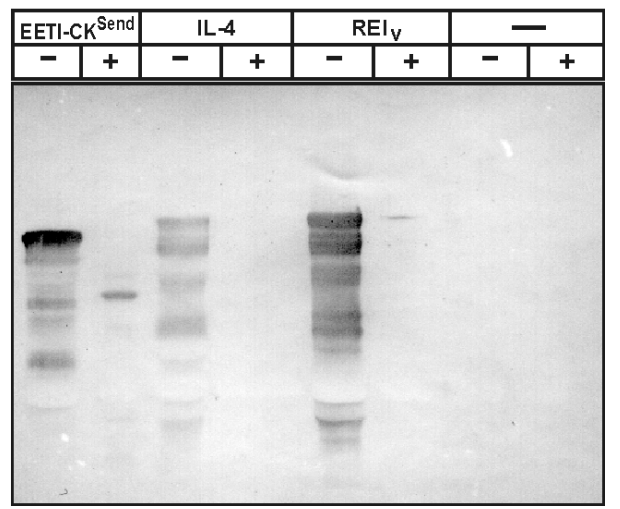

Abbildung 18. FACS Histogramme von induzierten, pASKInt100-EETI-CK ${ }^{\text {send }}(\mathrm{A})$, pASKInt100-REI (B) bzw. pASKInt100-IL4 (C) tragenden Zellen von DH5 $\alpha Z 1$. Induzierte Zellen wurden nacheinander mit anti-Sendai Antikörper (S) oder anti-E Antikörper (E), biotinyliertem anti-Maus Antikörper und Streptavidin, R-Phycoerythrin-Konjugat. Als Kontrolle (-) dienten untransformierte Zellen von DH5 $\alpha Z 1$, markiert mit anti-E Kaskade (5.5.2). SDS-PAGE (D) und Western Blot (E) zur Analyse von Oberflächenlokalisation und Protease Zugänglichkeit von Intimin'-EETI-CK ${ }^{\text {Send }}$, Intimin'-Il-4 und Intimin'-REI $I_{v}$ Fusionsproteinen. Membranpräparationen von das jeweilige Passagierprotein präsentierenden DH5 $\alpha Z 1$ Zellen wurden durch SDS-PAGE und Western Blot, entwickelt mit anti-Sendai Antikörper, analysiert. Zum Nachweis der Oberflächenlokalisation wurden von einem Anteil der mit Trypsin behandelten (+ Trypsin) oder unbehandelten Bakterien die Membranen präpariert (- Trypsin). Die jeweilige Intimin'-Fusion der erwarteten Volllänge ist durch einen Pfeil gekennzeichnet. Die Größen der Markerproteine sind angegeben (x 1000). 
Im Vergleich zu EETI-CK ${ }^{\text {send }}$ und REI fällt die Akkumulation von Il-4 geringer aus, was konsistent ist mit dem Ergebnis der durchflusszytometrischen Analysen der drei Oberflächen-präsentierten Konstrukte (Abb. 18A-C). In diesen ist das Maximum der zellulären Fluoreszenz bei Il-4 in etwa eine Größenordnung geringer als bei den beiden anderen Konstrukten.

\subsubsection{Präsentation von Calmodulin auf Zellen von $E$. coli 71-18P'}

Die Oberflächenpräsentation von $R E I_{v}$ besonders jedoch die von Interleukin 4 über das Intimin' basierte Präsentationsverfahren auf Zellen des Stammes 71-18P' konnte durch die Modifikation der Wachstumsbedingungen deutlich verbessert werden. Ohne die Zugabe von SDS während des Kulturwachstums war eine effiziente Exposition von Il-4 auf diesem Stamm nicht möglich (2.2.2.3). Offenbar gibt es für Proteine gleicher Länge, wie $R E I_{v}$ und Il-4, Determinanten, die die unterschiedliche Translokationseffizienz bestimmen. Für die Passage durch die Zytoplasmamembran war gezeigt wurden, dass eine Faltung im Zytoplasma mit einer Translokation durch die Membran nicht vereinbar ist (Randall \& Hardy, 1986, Arkowitz et al., 1993). In einem eleganten Experiment konnten Arkowitz und Mitarbeiter zeigen, dass Dihydrofolatreduktase mit angefügter Signalsequenz in das Periplasma exportiert wurde. Wenn hingegen die Zellen in Gegenwart der Liganden Methotrexat und NADPH kultiviert wurden, welcher im aktiven Zentrum des Enzyms bindet und dadurch das gefaltete Protein stabilisiert wird, war hier kein Proteinexport zu beobachten. Möglicherweise gilt dies auch für einen Export durch die äußere Membran. Es wurde daher als weiterer Kandidat für die Untersuchung des Proteinexports ein Protein ausgewählt, dessen Faltung durch den Zusatz von Agenzien moduliert werden kann, das Kalzium-bindende Protein Calmodulin.

\subsubsection{Calmodulin}

Calmodulin ist ein kleines, Hitze-stabiles Protein, das als Aktivator auf eine Vielzahl zellulärer Enzyme wirkt. Dazu gehören Proteinkinasen, und -phosphatasen, Adenylylzyklase, Kalziumpumpen der Plasmamembran, Proteine des Zytoskeletts wie z.B. Myosin I, Phosphofruktokinase, rasGAP, rasGEF und eine Vielzahl an Ionenkanälen (Cohen \& Klee, 1988, Eldik \& Watterson, 1998). Das Molekül ist in der Lage, Kalzium-Ionen mit hoher Affinität zu binden (Means \& Dedman, 1980), was in den meisten aber nicht allen Fällen Voraussetzung für die Assoziation mit einem Zielprotein ist. Die Menge des Proteins kann bis in den prozentualen Bereich des zytosolischen Gesamtproteins einer Zelle reichen, vor allem in solchen Geweben, welche mit neuronalen Prozessen assoziiert sind, die stark von der Kalzium-Regulation abhängen. Das in eukaryotischen Zellen ubiquitäre und hoch konservierte Calmodulin ist somit der wichtigste intrazelluläre Kalzium-Ionen Rezeptor (Cohen \& Klee, 1988). Sein Aktivierungsmechanismus ist am besten im Falle der Proteinkinasen verstanden. Calmodulin bindet dort an die autoinhibitorische Domäne, wodurch das katalytische Zentrum der Kinase freigelegt wird, es kommt zur Phosphorylierung, meist der Ausgangspunkt einer vielstufigen Signaltransduktionskaskade (Eldik \& Watterson, 1998).

Die molekulare Struktur von Calmodulin ist gut untersucht und wurde 1988 durch Röntgenstrukturanalyse aufgeklärt (Babu et al., 1988). Das 148 Aminosäuren lange Molekül 
mit einem relativen Molekulargewicht von ca. 16.800 besteht aus zwei globulären Domänen, welche durch einen helikalen Linker verbunden sind. Jede der beiden endständigen Bereiche besteht aus zwei Helix-Loop-Helix Motiven, welche jeweils in der Lage sind, Kalzium-Ionen zu komplexieren. Ein Molekül Calmodulin ist somit befähigt, vier Kalzium-Ionen auf kooperative Weise zu binden (Keller et al., 1982, Klevit et al., 1984, Linse et al., 1991, Pedigo \& Shea, 1995). Die Bindung bewirkt konformationelle Änderungen hin zu einer gestreckteren Form des Moleküls (Abb. 19). Die beiden endständigen Domänen besitzen ausgeprägte hydrophobe Bereiche, die in der Lage sind, ebensolche ihrer Bindungsstellen zu binden (Tanaka et al., 1982, Persechini \& Kretsinger, 1988, Babu et al., 1988). Die flexible, $\alpha$-helikale Verbindungsregion erlaubt zudem eine Varianz im Abstand der beiden Domänen zueinander, möglicherweise um eine Vielzahl unterschiedlicher Zielregionen mit Affinitäten bis in den niederen nanomolaren Bereich hinein zu adressieren (Persechini \& Kretsinger, 1988).
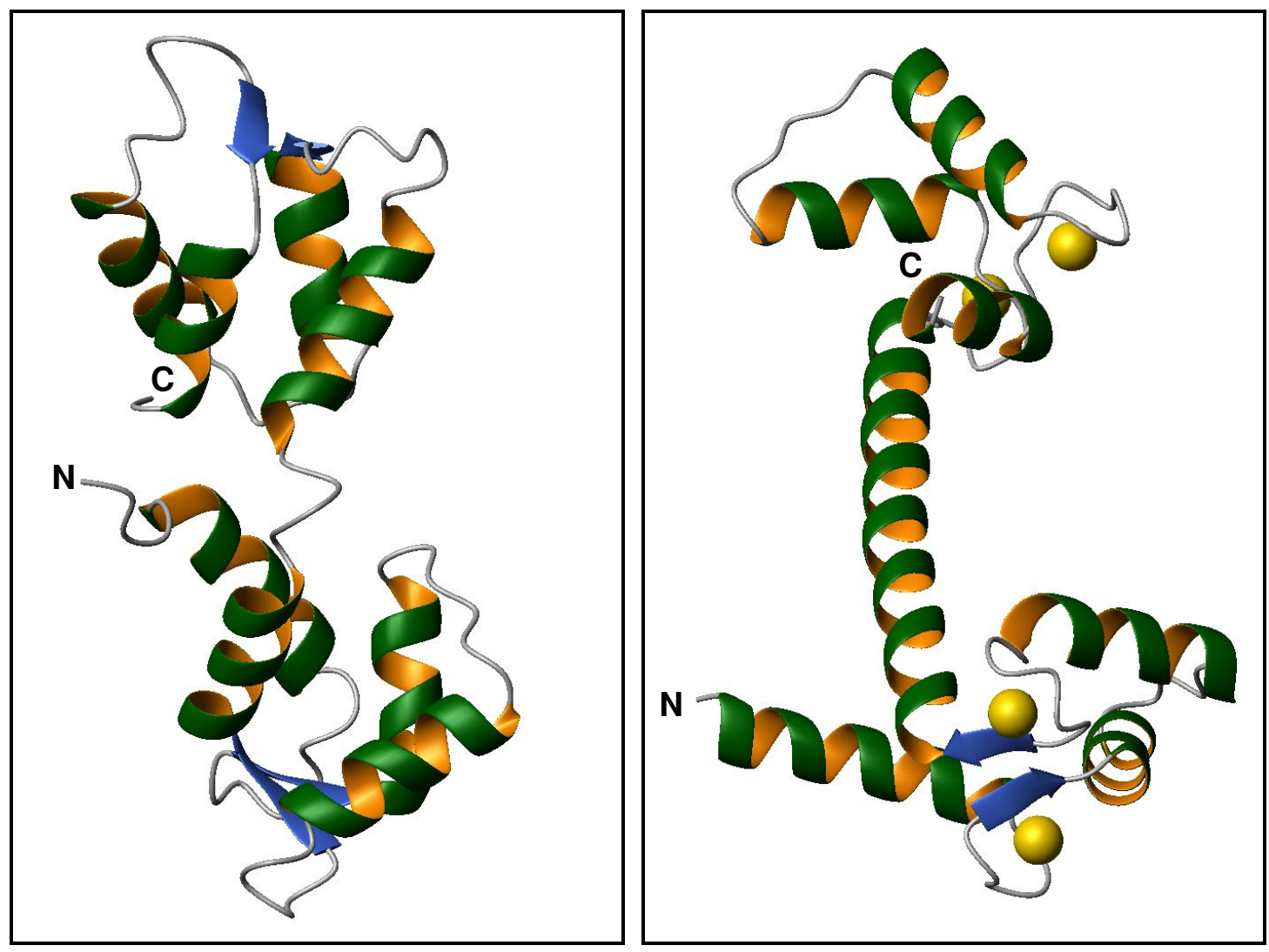

Abbildung 19. Schematische Darstellung der Struktur von Calmodulin ohne (links) und mit gebundenen Kalzium-Ionen (rechts). $\beta$-Stränge sind mit ihrer Orientierung in Pfeilrichtung in blau, $\alpha$-Helices in grün-orange, verbindende Regionen in grau dargestellt, vier gebundene Kalzium-Ionen sind als gelbe Kugeln wiedergegeben. (Erzeugt unter Verwendung von Molmol, Version 2K.2, Reto Konradi, PDB: 1CFC, Kuboniwa et al., 1995; 1CLL, Chattopadhyaya et al., 1992).

\subsubsection{Klonierung des Calmodulin-Gens in pASKInt100}

Die kodierende Sequenz des humanen Calmodulin-Gens wurde durch eine PCR unter Verwendung der Oligonukleotide Calmodulin-SmaI-up und Calmodulin-BglII-low amplifiziert. Als Matrize diente hier das Calmodulin-Gen aus einer humanen Herzmuskel-cDNA-Bank. Das erhaltene PCR-Produkt wurde mit den Restriktionsenzymen SmaI und BglII gespalten 
und in den ebenfalls mit diesen Enzymen behandelten und gereinigten Präsentationsvektor pASKInt100-(TmDegP) (siehe 2.2.1.2) kloniert. In dem so erhaltenen Plasmid pASKInt100Cal befindet sich das Calmodulin-Gen in einem durchgehenden Leseraster zwischen den kodierenden Sequenzen für EaeA'-E-tag und das Sendai-Epitop.

\subsubsection{Präsentation von Calmodulin durch Fusion mit EaeA ${ }^{\prime}$}

Nach der Transformation von 71-18P' Zellen wurden mit einer daraus erhaltenen Einzelkolonie $50 \mathrm{ml}$ Chloramphenicol-haltiges dYT-Medium $(25 \mu \mathrm{g} / \mathrm{ml})$ inokuliert. Die Zellen wurden nach Methode 5.5.1 induziert, und anschließend wurde jeweils ein Aliquot der Kultur für die Fluoreszenzmarkierung mit der anti-Sendai Kaskade bzw. der anti-E Kaskade nach Methode 5.5.2 aufbereitet. Die Proben wurden auch in diesem Fall anschließend durchflusszytometrisch vermessen (Methode 5.5.3). Das Ergebnis ist in Abbildung 20A dargestellt. Eine deutliche Verschiebung des Kurvenmaximums hin zu höherer Fluoreszenz ist lediglich bei der anti-E Markierung zu erkennen. Eine anti-Sendai Markierung konnte nicht nachgewiesen werden. Das Signal unmarkierter Zellen unterschied sich nicht von dem Ansatz mit anti-Sendai Markierung. Calmodulin ist mit dem EaeA' basierten Präsentationsverfahren unter den hier gewählten Parametern nicht auf der Oberfläche präsentierbar.
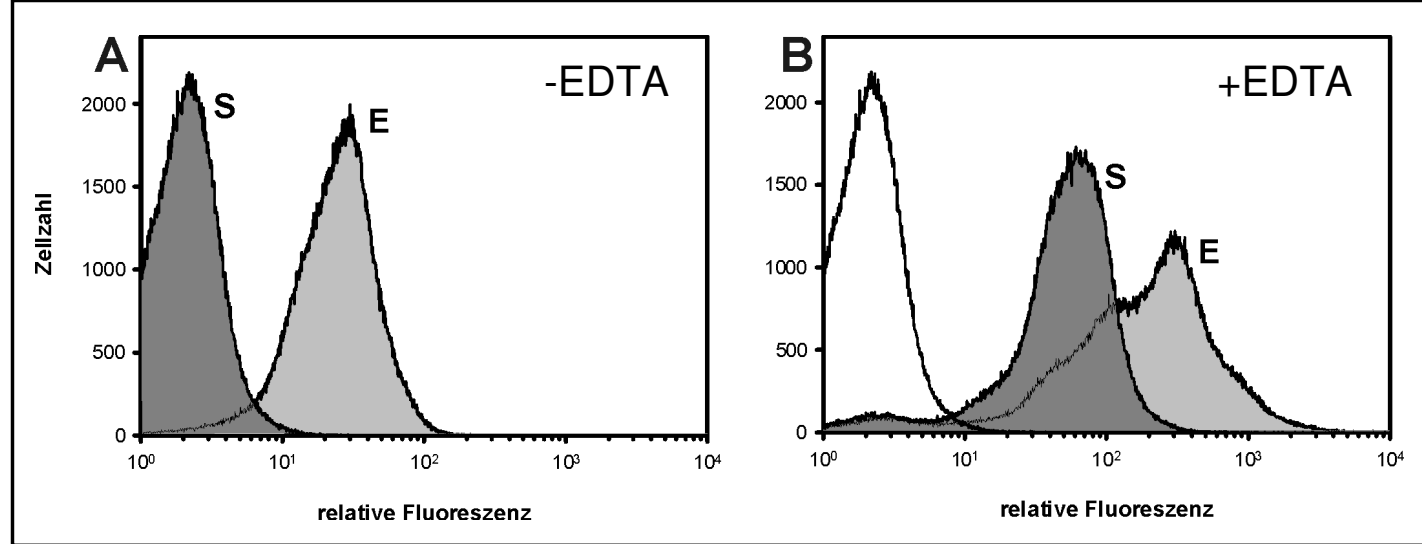

Abbildung 20. FACS Histogramme von pASKInt100-Cal tragenden Zellen von 71-18P'. (A) Nach Induktion der EaeA'-Expression (siehe Methode 5.5.1) wurden die Zellen nacheinander mit anti-Sendai Antikörper (S) oder anti-E Antikörper (E), biotinylierten anti-Maus Antikörper und Streptavidin, R-Phycoerythrin-Konjugat gemäß Methode 5.5.2 behandelt. (B) Analog (A) jedoch unter Verwendung modifizierter Wachstumsbedingungen in Anwesenheit von EDTA gemäß a) (siehe 2.2.1.3).

Auch hier wurden die Bedingungen a) bis c) wie unter 2.2.1.3 aufgeführt angewandt. Eine Anzucht der Bakterien in Gegenwart von EDTA brachte eine sehr deutliche Verbesserung der Präsentation, die übrigen Bedingungen hatten hier keinen signifikanten Einfluss. Das Ergebnis nach a) ist in Abbildung 20B wiedergegeben. Es ist eine Verschiebung des Maximums der relativen Fluoreszenz um fast zwei Größenordnungen zu verzeichnen.

Calmodulin besitzt zur Aufrechterhaltung der funktionellen Struktur pro Molekül vier Kalzium-Ionen. Die Entfernung der Kalzium-Ionen hat eine dramatische strukturelle Änderung zur Folge (Kuboniwa et al., 1995). Das Protein zeigt auch in diesem Fall eine Struktur, hauptsächlich gebildet aus zwei globulären Domänen. Sind keine Kalzium-Ionen gebunden, besteht zwischen den beiden überwiegend $\alpha$-helikalen Domänen kein stabiler 
direkter Kontakt (Abbildung 19), wie dies nach Kalziumbindung über die gestreckte $\alpha$-Helix der Fall ist. Die Präsentation von Calmodulin über EaeA' scheint nur im Kalzium-freien Zustand, dann aber sehr effizient möglich zu sein. Die während des Wachstums eingesetzte EDTA ist in der Lage, die im Medium vorhandenen Kalzium-Ionen zu komplexieren. Die mit gebundenem Kalzium offensichtlich nicht Präsentations-permissive Struktur der Domäne wird in die permissive überführt, so dass eine Oberflächenexposition sehr gut möglich und über das Sendai-Epitop nachweisbar ist. Weiter noch war es möglich, nach erneuter Zugabe von Kalzium-Ionen auf die unstrukturiertes Calmodulin exponierenden Zellen eine Konversion des Proteins in den funktionellen Faltungszustand zu induzieren. Calmodulin bindet einen definierten Bereich der Myosin light chain Kinase (MLCK, Blumenthal et al., 1985, Blumenthal \& Krebs, 1987, Gallagher et al., 1997). Dieses MyosinKinase-Peptid wurde in der Arbeitsgruppe von Dr. Harald Kolmar rekombinant in Fusion mit TEM-1 $\beta$-Laktamase und Sendai-Epitop in E. coli produziert, isoliert und gereinigt. Zellen von 71-18P', welche das Plasmid pASKInt100-Cal trugen, wurden in Anwesenheit von $1 \mathrm{mM}$ EDTA im Wachstumsmedium (Wachstumsbedingungen a) in 2.2.1.3) kultiviert, die Expression wurde induziert. Ein Aliquot der Kultur wurde abzentrifugiert, die Zellen wurden in $500 \mu \mathrm{l} 50 \mathrm{mM}$ Tris-Puffer, pH 8,0 mit $50 \mathrm{mM} \mathrm{NaCl}$ und $100 \mathrm{mM} \mathrm{CaCl}$ aufgenommen und für 5 min bei RT inkubiert. Anschließend wurde zentrifugiert und auf den Zellen gemäß Methode 5.5.2 eine Markierung mit anti- $\beta$-Laktamase, polyklonalem Kaninchen-Antiserum, biotinyliertem anti-Kaninchen Antikörper und letztlich Streptavidin, R-Phycoerythrin-Konjugat angebracht. Sodann wurde die Fluoreszenz der Zellen durchflusszytometrisch analysiert (Methode 5.5.3). Parallel zur Markierung der Zellen mit anti- $\beta$-Laktamase Antikörper wurde zum Nachweis der Oberflächenexposition zusätzlich auch eine anti-E bzw. eine anti-Sendai Markierung angebracht. Das Ergebnis ist in Abbildung 21 dargestellt.

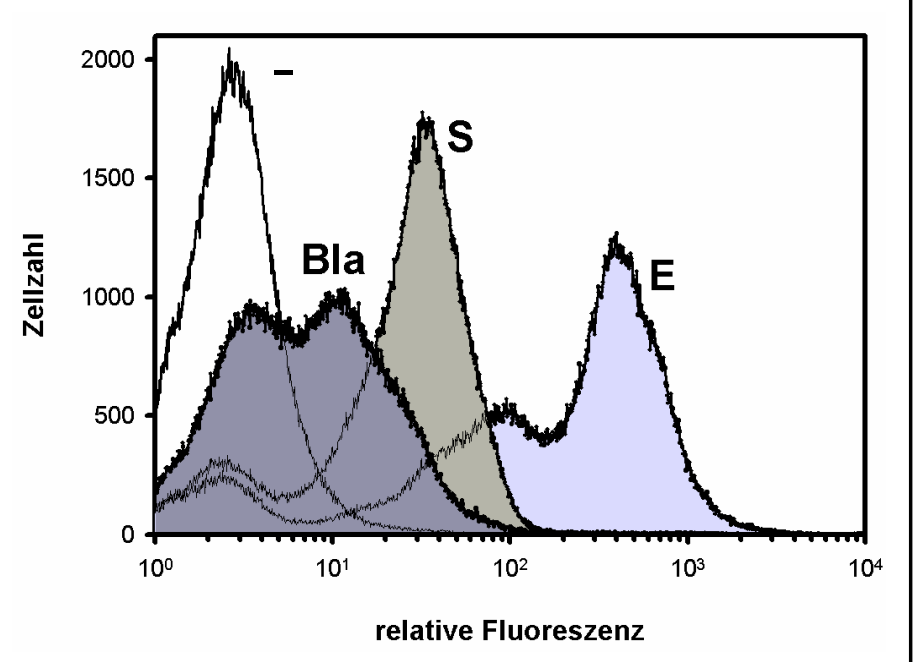

Abbildung 21. Durchflusszytometrische Analyse der Fluoreszenzmarkierung Calmodulinpräsentierender Zellen von 71-18P'. Die Zellen wurden in Anwesenheit von 1 mM EDTA gemäß a) in Kapitel 2.2.1.3 kultiviert. Nach Induktion der EaeA'-Expression wurden die Zellen nacheinander mit anti-Sendai Antikörper (S) oder anti-E Antikörper (E) bzw. MyosinKinase-Peptid/ $\beta$-Laktamase-Fusionsprotein und anti- $\beta$-Laktamase (Bla), biotinyliertem antiMaus (S und E) bzw. anti-Kaninchen (Bla) Antikörper und Streptavidin, R-PhycoerythrinKonjugat gemäß Methode 5.5.2 behandelt. 
Das Ergebnis dieses Experimentes legt den Schluss nahe, dass durch die Zugabe von Kalzium-Ionen nach der Expression von Calmodulin, dessen Translokation durch die äußere Membran ohne gebundene Kalzium-Ionen im Molekül sowie dessen Exposition auf der Zelloberfläche die Funktionalität des Proteins wieder hergestellt werden konnte. Ein natürliches Substrat von Calmodulin, die Binderegion der Myosin-Kinase, konnte in Fusion mit $\beta$-Laktamase auf der Oberfläche fixiert nachgewiesen werden. Wurden die Calmodulin exprimierenden Zellen ohne EDTA im Wachstumsmedium kultiviert, oder wird nach dem Hervorrufen der Oberflächenexposition die native Faltung nicht durch Bereitstellung von Kalzium-Ionen wieder hergestellt, konnte keine Bindung des Fusionsproteins festgestellt werden (nicht gezeigt).

Der Befund, dass Calmodulin nur dann über Intimin' durch die äußere Membran transloziert und auf der Zelloberfläche verankert nachgewiesen werden kann, wenn sich im Molekül keine die native Struktur aufrechterhaltenden Kalzium-Ionen befinden, stützt die Hypothese, dass eine Grundvoraussetzung der Präsentation von Passagierdomänen über EaeA' eine zumindest partielle Entfaltung des zu translozierenden Proteins ist.

\subsubsection{Präsentation von Streptomyces clavuligerus $\beta$-Laktamase Inhibitor Protein (BLIP) auf Zellen von E. coli 71-18P'}

Nachdem mit $R E I_{v}$ eine ausschließlich aus $\beta$-Faltblatt aufgebaute Passagierdomäne und mit Il-4 und Calmodulin zwei Proteine mit zumindest überwiegend $\alpha$-helikaler Molekülstruktur über Intimin' präsentiert worden sind, sollte nun ein Protein Oberflächenexponiert werden, das beide Sekundärstrukturelemente enthält. Außerdem sollte dem Einfluss der Ausbildung von Disulfidbrücken erhöhte Aufmerksamkeit erteilt werden. Die ausgewählte Domäne war das $\beta$-Laktamase-Inhibitor Protein BLIP aus Streptomyces clavuligerus.

\subsubsection{Das Streptomyces clavuligerus $\beta$-Laktamase Inhibitor Protein (BLIP)}

Das $\beta$-Laktamase Inhibitor Protein (Doran et al., 1990) ist ein potenter Inhibitor einer Vielzahl von $\beta$-Laktamasen, darunter auch die TEM-1 $\beta$-Laktamase aus Escherichia coli. Letztere wird mit einer Konstante $\mathrm{K}_{\mathrm{i}}$ von 0,1 nM gebunden und inhibiert (Strynadka et al., 1996b). Das Exoenzym aus Streptomyces clavuligerus besteht aus 165 Aminosäuren und besitzt ein relatives Molekulargewicht von 17.500.

Die Molekülstruktur des $\beta$-Laktamase Inhibitor-Proteins (BLIP) wurde 1996 kristallographisch gelöst (Strynadka et al., 1994, 1996b). BLIP besteht aus zwei aufeinanderfolgenden, strukturell ähnlichen Domänen, welche eine polare, konkave Oberfläche bilden (Abb. 22). Es ist damit in der Lage, die ebenfalls polare aber konvexe Oberfläche der $\beta$ Laktamase zu binden. Die $\beta$-Haarnadelschleife der einen Domäne reicht in das katalytische Zentrum des Enzyms. Ein Aspartatrest bildet dort Wasserstoffbrücken zu insgesamt vier Resten der $\beta$-Laktamase und simuliert somit die Carboxylatfunktion von Penicillin G, dem natürlichen Substrat des Enzyms (Strynadka et al., 1996a). BLIP weist in seiner Struktur sowohl $\alpha$-helikale Bereiche als auch zu einem größeren Anteil $\beta$-Faltblatt Struktur auf. Stabilisiert wird die Struktur durch die Ausbildung zweier Disulfidbrücken, eine in jeder der zwei aufeinanderfolgenden Domänen. 


\title{
2.2.5.2 Klonierung des BLIP-Gens in pASKInt100
}

Zur Klonierung des Streptomyces clavuligerus $\beta$-Laktamase Inhibitor Proteins wurde das Strukturgen mittels PCR auf einem von N. C. J. Strynadka freundlicherweise bereitgestellten Plasmid als Matrize durch Verwendung des Primerpaares BLIP-up und BLIP-low amplifiziert. Das Oligonukleotid BLIP-low kodiert dabei zusätzlich für das Sendai-Epitop. Das erhaltene PCR-Produkt wurde von T. Adams mit den Restriktionsenzymen SmaI und BamHI gespalten und in dem ebenso gespaltenen Vektor pASKInt100-EETI-CK ${ }^{\text {send }}$ kloniert. Das so erhaltene Plasmid trägt den Namen pASKInt100-BLIP und enthält das BLIP-Gen in einem durchgehenden Leseraster zwischen den kodierenden Sequenzen für EaeA'-E-tag und das Sendai-Epitop.

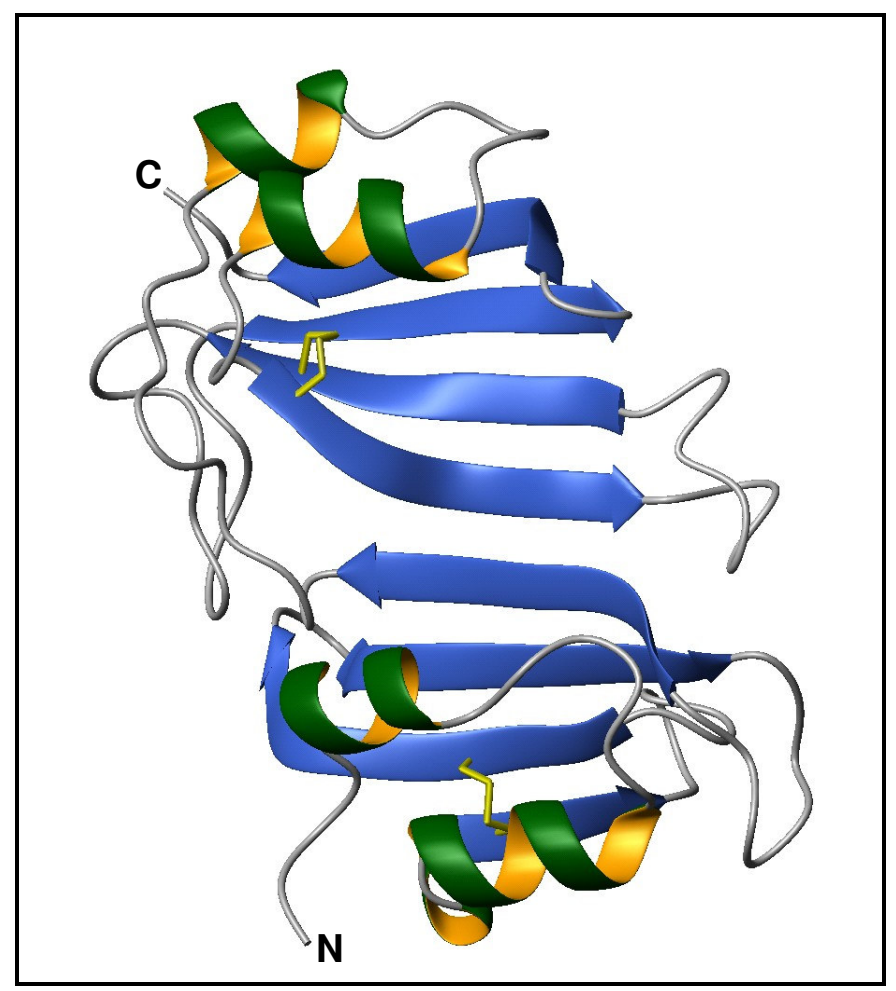

\begin{abstract}
Abbildung 22. Schematische Darstellung der Struktur des $\beta$-Laktamase Inhibitor Proteins (BLIP) aus Streptomyces clavuligerus. $\beta$-Stränge sind mit ihrer Orientierung in Pfeilrichtung in blau, $\alpha$-Helices in grün-orange, verbindende Regionen in grau dargestellt. Die zwei im Molekül vorkommenden Disulfidbrücken der Cystein-Reste \#30 und \#42 sowie \#109 und \#131 innerhalb des Moleküls sind in gelb eingezeichnet. (Erzeugt unter Verwendung von Molmol, Version 2K.2, Reto Konradi, PDB: 1JTG, Lim et al., 2001)
\end{abstract}

\subsubsection{Präsentation von BLIP durch Fusion mit EaeA $A^{\prime}$}

Nach der Transformation von Zellen von 71-18P' wurden erneut mit einer daraus erhaltenen Einzelkolonie $50 \mathrm{ml}$ Chloramphenicol-haltiges dYT-Medium $(25 \mu \mathrm{g} / \mathrm{ml})$ inokuliert. Die Zellen wurden nach Methode 5.5.1 induziert und ein Aliquot der Kultur wurde anschließend jeweils für die Fluoreszenzmarkierung mit der anti-Sendai Kaskade bzw. der anti-E Kaskade nach Methode 5.5.2 aufbereitet. Die Proben wurden anschließend durchflusszytometrisch vermessen (Methode 5.5.3). Das Ergebnis ist in Abbildung 23A dargestellt. Es ist eine deutliche Verschiebung des Kurvenmaximums hin zu höherer Fluoreszenz lediglich bei der anti-E Markierung zu erkennen. Eine anti-Sendai Markierung 
konnte wie zuvor bei der Präsentation von Calmodulin nicht detektiert werden. Das Signal unmarkierter Zellen unterschied sich auch hier nicht von dem Ansatz mit anti-SendaiMarkierung. BLIP ist wie Calmodulin mit dem EaeA' basierten Präsentationsverfahren unter den in diesem Experiment gewählten Parametern nicht auf der Oberfläche der Zellen präsentierbar.

Das BLIP-Gen tragende Zellen wurden während des Kulturwachstums zusätzlich den in 2.2.1.3 angegebenen Bedingungen a) bis g) unterzogen. Die Verwendung von SDS bzw. EDTA führte hier zu keinerlei Verbesserung der Exposition. Wurden die Zellen nach den Bedingungen c) während des Wachstums und der Expression mit $\beta$-Mercaptoethanol behandelt, konnte eine leichte Verbesserung beobachtet werden, die aber nur geringfügig über dem Signal unmarkierter Zellen lag. Eine noch ein wenig verbesserte Präsentation wurde nach Methode d) erreicht. Der hier verwendete Stamm 71-18dsbA besitzt kein funktionales $d s b A$-Gen. DsbA ist in E. coli für die Bildung von Disulfidbrücken essentiell und beschleunigt deren Ausbildung in vivo (Bardwell et al., 1991). Die im funktionalen BLIPMolekül gebildeten zwei Disulfidbrücken können in Abwesenheit von dsbA möglicherweise nur verlangsamt geschlossen werden. Die Kombination aus der Verwendung des dsbAdefizienten Stammes und einem Wachstum in Anwesenheit von Reduktionsmittel wie nach g), lieferte hier das beste Ergebnis (Abbildung 23B).
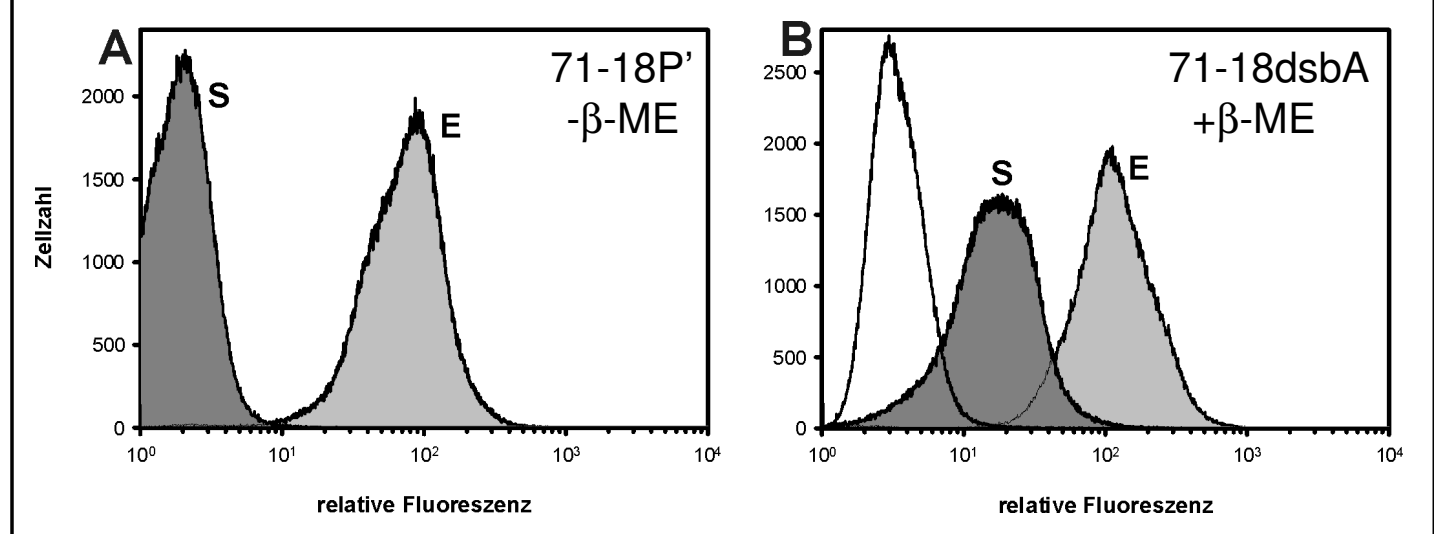

Abbildung 23. FACS Histogramme von pASKInt100-BLIP tragenden Zellen von 71-18P'. (A) Nach Induktion der EaeA'-Expression (siehe Methode 5.5.1) wurden die Zellen nacheinander mit anti-Sendai Antikörper (S) oder anti-E Antikörper (E), biotinyliertem antiMaus Antikörper und Streptavidin, R-Phycoerythrin-Konjugat gemäß Methode 5.5.2 behandelt. (B) Analog (A) jedoch unter Verwendung des Stammes 71-18dsbA und modifizierter Wachstumsbedingungen in Anwesenheit von $\beta$-Mercaptoethanol gemäß g) (siehe 2.2.1.3).

Im Falle der Präsentation von BLIP über EaeA' scheint eine frühzeitige Faltung und vor allem die Fixierung derselben in diesem Fall durch die Bildung zweier Disulfidbrücken bereits im E. coli Periplasma einer Translokation durch die äußere Membran entgegenzustehen, während im reduzierten Zustand die Polypeptidkette des $\beta$-Laktamase Inhibitor Proteins gut auf der Oberfläche exponiert werden kann. Auch in diesem Fall war wie bei der Präsentation von Calmodulin (vgl. 2.2.4.3) ein funktionaler Nachweis nach Überführen der Zellen in nicht mehr reduzierende Umgebung möglich. Die Bindung rekombinant erzeugter und gereinigter TEM-1 $\beta$-Laktamase konnte auch hier auf der Oberfläche mittels anti- $\beta$ Laktamase Markierungskaskade nachgewiesen werden (nicht gezeigt). 


\subsubsection{Präsentation von $E$. coli TEM-1 $\beta$-Laktamase auf Zellen von 71-18}

REI $I_{v}$ Il-4, Calmodulin und BLIP sind Proteine, die eine Größe zwischen 100 und 170 Aminosäuren aufweisen. Mit der TEM-1 $\beta$-Laktamase wurde in diese Serie zu präsentierender Proteindomänen ein weiteres Protein aufgenommen, welches mit 273 Aminosäuren deutlich größer ist, $\alpha$-helikale und $\beta$-Faltblatt Sekundärstrukturelemente aufweist und dessen funktionale Struktur durch eine intramolekulare Disulfidbrücke stabilisiert wird.

\subsubsection{Die TEM-1 $\beta$-Laktamase von Escherichia coli}

$\beta$-Laktam-Antibiotika üben ihre Wirkung auf membrangebundene, sogenannte DDPeptidasen aus, die für die Synthese und die Umstrukturierung von Peptidoglycan verantwortlich sind (Ghuysen, 1991, Nanninga, 1991). Die Ausbildung von Resistenzen gegen diese Art Antibiotika können zum einen mit der Veränderung dieser Enzyme oder der Membranpermeabilität (Frère et al., 1991), vor allem aber durch das Vorhandensein einer oder mehrerer $\beta$-Laktamasen begründet sein (Waley, 1988, Jacoby, 1994, Davies, 1994, Frère, 1995). $\beta$-Laktamasen sind Enzyme, die auf sehr effiziente Weise und irreversibel die Hydrolyse der Amidbindung des $\beta$-Laktamrings katalysieren und somit $\beta$-Laktame biologisch inaktivieren (Waley et al., 1992, Frère, 1995). $\beta$-Laktamasen kommen im Periplasma Gram-negativer Bakterien vor und werden von Gram-positiven Stämmen in das umgebende Medium sezerniert. Auch eine Membranassoziation ist in einigen Fällen dokumentiert (Nielsen \& Lampen, 1982, Parker \& Smith, 1993). $\beta$-Laktamasen werden aufgrund ihres katalytischen Mechanismus in Serin- (Klassen A, C und D) und ZinkEnzyme (Klasse B) unterteilt (Ambler, 1980, Jaurin \& Grundstrøm, 1981, Huovinen et al., 1988, Waley 1988, Joris et al., 1991). Die Enzyme der ersteren Gruppe besitzen einen Serinrest im aktiven Zentrum und funktionieren nach einem Drei-Schritt-Mechanismus. Nach Bindung des $\beta$-Laktams wird die Hydroxylgruppe des Serinrestes durch eine Carbonylfunktion des Antibiotikums verestert. Es entsteht das acylierte Enzym, der $\beta$ Lactamring wird geöffnet (Fisher et al., 1980, Frère et al., 1991, Waley et al., 1992). Die Rückübertragung eines Protons auf den Serinrest setzt den inaktivierten Liganden frei. Gleichzeitig wird das aktive Enzym regeneriert (Lamotte-Brasseur et al., 1991). Die Bildung des Adduktes ist vergleichbar mit der Bindung des Antibiotikums an sein physiologisches Zielprotein. Der Unterschied ist lediglich quantitativer Natur und spiegelt sich in unterschiedlichen Gleichgewichtskonstanten der einzelnen Reaktionsschritte wider, mit drastisch verschiedenem Ergebnis. $\beta$-Laktamasen inaktivieren $\beta$-Laktamantibiotika, jene inaktivieren ihrerseits wiederum DD-Proteasen (Matagne et al., 1998).

Die TEM-1 von Escherichia coli ist eine Klasse A $\beta$-Laktamase. Wie alle anderen Enzyme dieser größten und am besten untersuchten Klasse ist sie ein monomeres Enzym mit einer relativen Molmasse von ca. 29.000. Strukturell besteht es aus einer $\alpha$-helikalen und einer gemischt $\alpha$-helikalen und $\beta$-Faltblatt-Domäne. Erstere ist stabilisiert durch die einzige Disulfidbrücke im Molekül (Abb. 24). Das aktive Zentrum befindet sich in einer Einsenkung zwischen den beiden Domänen. Das aktive Serin liegt am Aminoterminus der langen, hydrophoben Helix der $\alpha$-helikalen Domäne. Der katalytische Mechanismus wird im Detail noch kontrovers diskutiert, besonders die Frage nach dem als Base fungierenden Rest, welcher die Nukleophilie des aktiven Serins erhöht, und nach dem Mechanismus der 
Regeneration des Serinrestes. Der Mechanismus, wie er von Lamotte-Brasseur und Mitarbeitern 1991 postuliert wurde, scheint jedoch durch kinetische Daten (Matagne \& Frère, 1995, Guillome et al., 1997) mehr und mehr belegt zu werden, mit Glutamat \#166 als Base, wirkend über ein Wassermolekül.

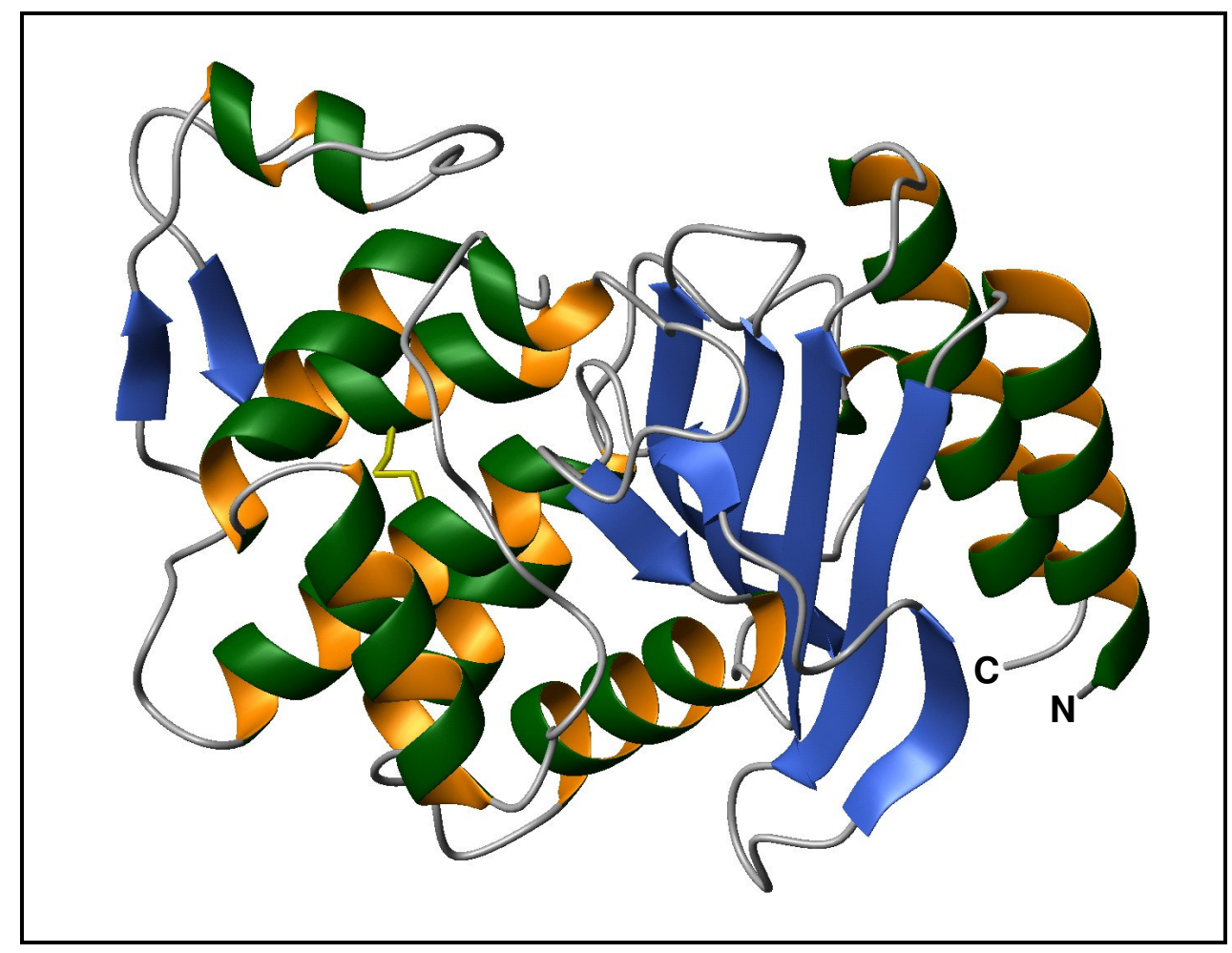

\begin{abstract}
Abbildung 24: Schematische Darstellung der Struktur der TEM-1 $\beta$-Laktamase von Escherichia coli. $\beta$-Stränge sind mit ihrer Orientierung in Pfeilrichtung in blau, $\alpha$-Helices in grün-orange, verbindende Regionen in grau dargestellt. Die eine im Molekül vorkommende Disulfidbrücke der Cystein-Reste \#77 und \#123 innerhalb des Moleküls ist in gelb eingezeichnet. (Erzeugt unter Verwendung von Molmol, Version 2K.2, Reto Konradi, PDB: 1M40, Minasov et al., 2002)
\end{abstract}

\title{
2.2.6.2 Klonierung des TEM-1 $\beta$-Laktamase-Gens in pASKInt100
}

Die kodierende Sequenz von E. coli TEM-1 $\beta$-Laktamase wurde mittels PCR amplifiziert. Als Matrize diente das Plasmid pHK5-20 (Kolmar et al., 1992), die verwendeten Oligodesoxyribonukleotide waren Bla-Sma-up und Bla-BglII-low. Das resultierende PCRProdukt wurde mit SmaI und BglII gespalten und mit dem ebenso gespaltenen Vektor pASKInt100-(TmDegP) (siehe 2.2.1.2) ligiert. Auf diesem Wege wurde das Plasmid pASKInt100-Bla erhalten. Dieses trägt das TEM-1 $\beta$-Laktamase-Gen in einem durchgehenden Leseraster zwischen den kodierenden Sequenzen für EaeA'-E-tag und das Sendai-Epitop.

\subsubsection{Präsentation von TEM-1 $\beta$-Laktamase durch Fusion mit EaeA ${ }^{\prime}$}

Nach der Transformation von Zellen von 71-18P' wurden mit einer daraus erhaltenen Einzelkolonie $50 \mathrm{ml} 25 \mu \mathrm{g} / \mathrm{ml}$ Chloramphenicol-haltiges dYT-Medium inokuliert. Die Expression des Oberflächenpräsentations-Fusionsproteins wurde nach Methode 5.5.1 induziert und ein Aliquot der Kultur wurde anschließend jeweils für die Fluoreszenzmarkierung mit der anti-Sendai Kaskade bzw. der anti-E Kaskade nach Methode 5.5.2 aufbereitet. Die Proben wurden anschließend durchflusszytometrisch vermessen (Methode 
5.5.3). Das Ergebnis ist in Abbildung 25 dargestellt. Es ist eine deutliche Verschiebung des Kurvenmaximums hin zu höherer Fluoreszenz lediglich bei der anti-E Markierung zu erkennen. Eine anti-Sendai Markierung konnte wie zuvor bei der Präsentation von Calmodulin und BLIP nicht angebracht werden. Das Signal unmarkierter Zellen unterschied sich nicht von dem Ansatz mit anti-Sendai Markierung. TEM-1 $\beta$-Laktamase ist wie Calmodulin und BLIP mit dem EaeA' basierten Präsentationsverfahren unter den in diesem Experiment gewählten Parametern nicht auf der Zelloberfläche präsentierbar.

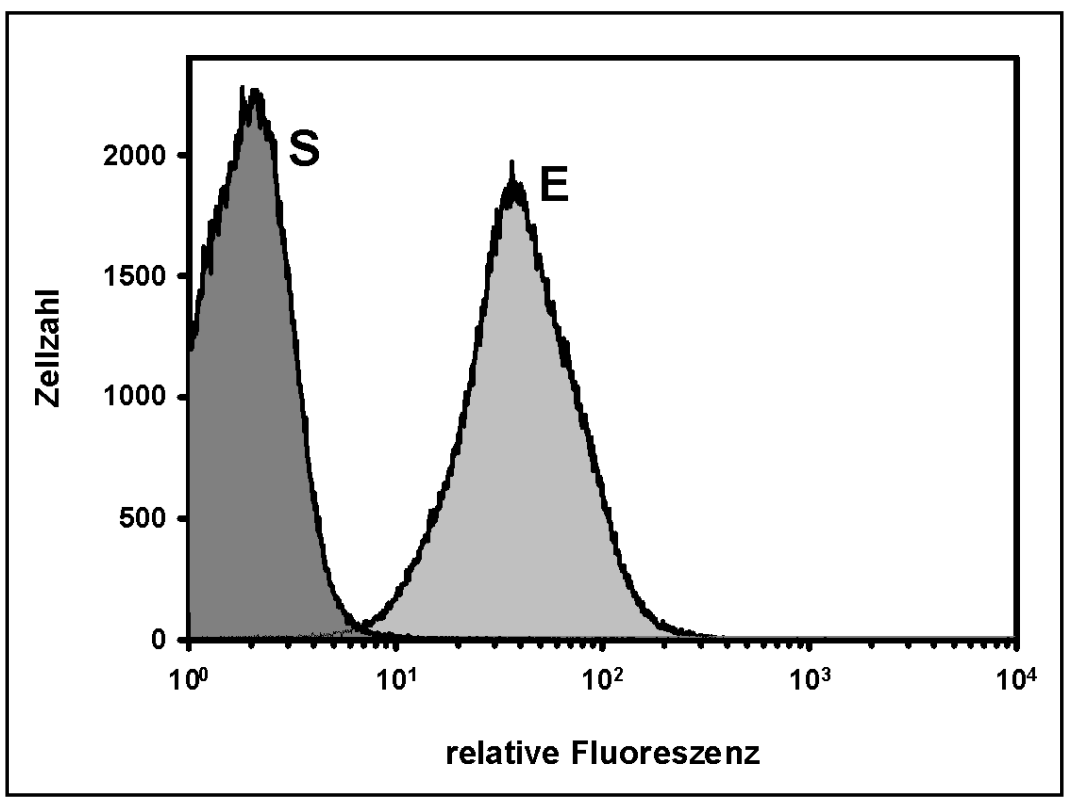

Abbildung 25. FACS Histogramm von pASKInt100-Bla tragenden Zellen von 71-18P'. Nach Induktion der EaeA'-Expression (siehe Methode 5.5.1) wurden die Zellen nacheinander mit anti-Sendai Antikörper (S) oder anti-E Antikörper (E), biotinyliertem anti-Maus Antikörper und Streptavidin, R-Phycoerythrin-Konjugat gemäß Methode 5.5.2 behandelt.

Das TEM-1 $\beta$-Laktamase Gen tragende Zellen wurden während des Kulturwachstums zusätzlich den in 2.2.1.3 angegebenen Bedingungen a) bis g) unterzogen. Weder das Wachstum in Anwesenheit des Detergenz SDS oder des Chelatkomplex-Bildners EDTA noch ein Einfluss auf das Ausbilden der einen, im nativen Molekül vorhandenen Disulfidbrücke durch Wachstum in Anwesenheit von Reduktionsmittel, führte zu einer Oberflächenexposition. Die Verwendung von 71-18dsbA als Wirtsstamm führte weiter ebenso wenig zu einer Exposition von $\beta$-Laktamase wie die Kombination desselben mit der Chemikalienbehandlung während des Wachstums. Trotz dieser Optimierungsversuche blieb TEM-1 $\beta$-Laktamase von Escherichia coli mittels des EaeA' basierten Präsentationsmoduls nicht auf der Zelloberfläche exponierbar.

\subsubsection{Zufallsmutagenese zur Erzeugung und Präsentation von $\beta$-Laktamase- Varianten}

Zusammen mit H. Kolmar wurden Experimente durchgeführt, die zum Ziel hatten, Varianten von TEM-1 $\beta$-Laktamase zu generieren und zu isolieren, die via Fusion an Intimin' auf der Zelloberfläche nachgewiesen werden können. Aus der so gewonnenen Sequenzinformation der Translokations-kompetenten Varianten sollten Ergebnisse erhalten werden, 
die Auskunft über den Grund geben, warum TEM-1 $\beta$-Laktamase mit dieser Methode nicht Oberflächen-exponierbar ist.

Zellen des E. coli Stammes 71-18mutS (enthält eine Transposon 10 Insertion im mutS Gen und vermittelt daher eine Resistenz gegen Tetrazyklin) wurden nacheinander mit den Plasmiden pASKInt100-Bla und pZA22-mutD transformiert. Das Plasmid pZA22-mutD ist ein Derivat von pZA22-MCS1 (siehe 4.2), in dem unter Kontrolle des $P_{\text {Llac }}$ Promotors das mutD Gen exprimiert werden kann. Das MutD Protein ist eine dominante Variante der dnaQ kodierten $\varepsilon$-Untereinheit der replikativen Polymerase III ohne Exonukleaseaktivität. Es ist noch in der Lage, das Polymerase III Holoenzym zu bilden, das dann jedoch keine proofreading Aktivität mehr aufweist. Die Überproduktion von MutD führt zu einer starken Erhöhung der Mutationsrate im Zuge der Replikation (Echols et al., 1983, Selifonova et al., 2001). Mit je $150 \mu$ l einer Übernacht-Kultur von Zellen dieser genetischen Ausstattung wurden parallel vier Kolben mit dYTCm ${ }^{25} \mathrm{Kan}^{75}$ beimpft und die Kulturen über Nacht bei $30{ }^{\circ} \mathrm{C}$ kultiviert. Mit je $150 \mu \mathrm{l}$ der resultierenden Kulturen wurden sodann erneut parallel vier Kolben mit dYTCm ${ }^{25} \mathrm{Kan}^{75}$ inokuliert und wie angegeben inkubiert. Der Vorgang wurde insgesamt fünfmalig wiederholt. Aus den vier Kulturen der fünften Inkubationsrunde wurden je $250 \mu \mathrm{l}$ entnommen und mit den insgesamt $1000 \mu \mathrm{l} 50 \mathrm{ml}$ dYTCm ${ }^{25} \mathrm{Kan}^{75}$, welches mit $0,5 \%$ (w/v) SDS, $1 \mathrm{mM}$ EDTA und $15 \mathrm{mM} \beta$-Mercaptoethanol versetzt worden waren, inokuliert. Die Kultur wurde bis zu einer O.D.600 von 0,2 kultiviert und sodann $10 \mathrm{ml}$ davon mit $1 \mu \mathrm{l}$ Anhydrotetrazyklin versetzt. Zur Isolierung von $\beta$-Laktamase Varianten, die Translokations-kompetent sind, wurde von dem Befund Gebrauch gemacht, dass E. coli Zellen, die in Gegenwart von $0,1 \%$ (w/v) SDS kultiviert wurden, nach Induktion der Expression des intimin'- $\beta$-Laktamase Fusionsgens sich nicht weiter vermehren und in der Bakterienkultur eine massive Zelllyse $\mathrm{zu}$ beobachten war. Nach einer Inkubation von 2 Stunden wurden mit $5 \mathrm{ml}$ der Kultur $50 \mathrm{ml}$ dYTCm ${ }^{25} \mathrm{Kan}^{75}$ inokuliert und diese dann über Nacht bei $30{ }^{\circ} \mathrm{C}$ inkubiert. Anschließend wurden erneut $50 \mathrm{ml} \mathrm{dYTCm}{ }^{25} \mathrm{Kan}^{75}$, welches mit $0,5 \%$ (w/v) SDS, $1 \mathrm{mM}$ EDTA und $15 \mathrm{mM} \beta$-Mercaptoethanol versetzt worden waren, inokuliert. Nach Induktion der Expression mit ATC bei einer O.D.600 von 0,2 und weiterem Wachstum der Kultur für eine Stunde wurden die Zellen mit der anti-Sendai Kaskade markiert (Methode 5.5.2). In drei aufeinander folgenden Sortierrunden mittels FACS wurden aus einem Sortierfenster der Kanäle 300 bis 800 letztendlich 150.000 Zellen aussortiert (Methode 5.5.3). Diese wurden sodann auf dYTCm ${ }^{25} \mathrm{Kan}^{75}$ Platten plattiert und über Nacht bei $37^{\circ} \mathrm{C}$ kultiviert. Die erhaltenen Kolonien wurden mit frischem Medium von den Platten abgespült, auf dYTAmp ${ }^{20}$ Tet $^{10}$ Platten plattiert und erneut kultiviert. Durch die Selektion auf Ampicillin-Resistenz an dieser Stelle werden alle diejenigen Zellen, die aufgrund von Mutationen keine funktionale $\beta$-Laktamase mehr produzieren, aus dem Experiment entfernt. Die aus der Selektion auf Ampicillin-Resistenz hervorgegangenen Klone wurden von der Platte abgenommen. Mit diesen wurden $50 \mathrm{ml} \mathrm{dYTCm}{ }^{25} \mathrm{Kan}^{75}$ inokuliert, welches 0,5\% (w/v) SDS, $1 \mathrm{mM}$ EDTA und $15 \mathrm{mM} \beta$-Mercaptoethanol enthielt. Nach der Induktion der Expression bei einer O.D.600 von 0,2 wurde nach einer weiteren Inkubation für $1 \mathrm{~h}$ ein Aliquot der Zellen mit der anti-Sendai Kaskade (5.5.2) Fluoreszenz-markiert. Eine zum Vergleich des Kulturwachstums an dieser Stelle parallel kultivierte Kultur von 71-18mutS, welcher die Ausgangsplasmide pASKInt100-Bla und pZA22-mutD trug, zeigte Lysis zum Zeitpunkt der Induktion der Expression mit Anhydrotetrazyklin. Es wurden 10.000 Zellen 
aussortiert, die nach Markierung mit der anti-Sendai Kaskade eine erhöhte Fluoreszenz zeigten. Diese wurden auf dYTCm ${ }^{25} \mathrm{Kan}^{75}$ Platten plattiert und über Nacht bei $37^{\circ} \mathrm{C}$ kultiviert. Von auf diesem Wege erhaltenen Einzelklonen wurde die individuelle Oberflächenpräsentation des Sendai-Epitops (und somit auch indirekt die der $\beta$-Laktamase) bestimmt. Bei allen untersuchten Klonen war die Exposition des Sendai-Epitops durch die Zelloberflächenmarkierung nachweisbar. Von diesen Klonen wurden die Plasmide isoliert und die Sequenz des $\beta$-Laktamase-Gens bestimmt. Das Ergebnis ist in Tabelle 1 dargestellt.

\begin{tabular}{|l|c|c|}
\hline Klon Nr. & Austausch (Protein) & Austausch (DNA) \\
\hline K2 & C123R & TGC->CGC \\
\hline K3 & C123R & TGC->CGC \\
& T109T & ACA->ACG \\
\hline K6 & C123R & TGC->CGC \\
\hline K7 & C77R & TGT->CGT \\
\hline K8 & C123Y & TGC->TAC \\
\hline K10 & C123R & TGC->CGC \\
\hline K11 & C123R & TGC->CGC \\
\hline K14 & C123R & TGC->CGC \\
\hline
\end{tabular}

Tabelle 1. Mutationen von acht Klonen aus der ungerichteten in vivo Mutagenese von pASKInt100-Bla tragenden E. coli 71-18mutS Zellen. Zur Durchführung des Mutageneseexperimentes siehe Text.

Es wurden ausschließlich Klone erhalten, die Austausche eines der beiden die eine stabilisierende Disulfidbrücke bildenden Cysteine \#77 (K7) oder \#123 gegen die Aminosäure Arginin (K2, K3, K6, K10, K11, K14) oder Tyrosin (K8) aufwiesen. Offenbar ist die Bildung der Disulfidbrücke der $\beta$-Laktamase im Periplasma der Zellen mit einer Translokation durch die äußere Membran nicht vereinbar.

\subsubsection{Zur biotechnologischen Anwendung: Anreicherung das Sendai-Epitop präsentierender Zellen aus einem Klongemisch}

Verfahren zur bakteriellen Zelloberflächenpräsentation können wie andere Verfahren der Genotyp-Phänotyp-Kopplung zur Durchmusterung umfangreicher molekularer Bibliotheken nach Bindemolekülen mit neuen oder verbesserten Eigenschaften herangezogen werden. Um für das EaeA' basierte Präsentationsverfahren dieses Potential zu evaluieren, wurde ein Modellexperiment entworfen. Dieses beruht auf der Anreicherung von Proteinvarianten aus einem großen Überschuss negativer Ereignissen und somit der Simulation einer Anreicherung eines seltenen Ereignisses aus einer molekularen Bibliothek Zelloberflächen-exponierter Proteine.

Dabei sollten Zellen isoliert werden, die auf ihrer Oberfläche das Sendai-Epitop tragen. Hierzu wurden Zellen ausgewählt, die das Plasmid pASKInt100-REI trugen und somit in der Lage waren, nach Induktion der Expression das $R E I_{v}$ Protein mitsamt der C-terminalen Extension des Sendai-Epitops zu exponieren. Als Hintergrund sollten Zellen dienen, die eine Sendai-Epitop freie $R E I_{v}$ Variante exponierten. Um eine solche Variante zu erzeugen, wurde das Plasmid pASKInt100-REI mit BglII und BamHI (unmittelbar vor und hinter der 
kodierenden Sendai-Sequenz gelegen) gespalten und religiert, die überhängenden Enden des BglII-BamHI Spaltproduktes sind kompatibel, so dass auf diesem Wege die kodierende Sequenz für das Sendai-Epitop entfernt und das Plasmid pASKInt100-REI $\Delta$ send erhalten wurde.

Zellen von 71-18, welche das Plasmid pASKInt100-REI trugen, wurden 1:200.000 mit solchen Zellen gemischt, welche das Plasmid pASKInt100-REI $\Delta$ send trugen. Zellen des Gemisches wurden in $50 \mathrm{ml}$ dYT-Medium, welches mit Chloramphenicol $(25 \mu \mathrm{g} / \mathrm{ml})$ komplettiert worden war, bei $37^{\circ} \mathrm{C}$ inkubiert. Nach der Induktion der Expression des Fusionsgens gemäß Methode 5.5.1 wurde ein Aliquot der Kultur zentrifugiert, und die Zellen wurden in Folge mit anti-Sendai Antikörper, biotinyliertem anti-Maus Antikörper und Streptavidin, R-Phycoerythrin-Konjugat gemäß Methode 5.5.2 markiert. Die so markierte Zellpopulation wurden mittels des MoFlo Cell-Sorters mit einer Ereignis-Rate von 30.000/s auf Basis der Fluoreszenzintensität sortiert (Methode 5.5.3). Das Sortierfenster wurde derart gewählt, dass weniger als $0,5 \%$ der Ereignisse als positiv eingestuft wurden (Abb. 26A).

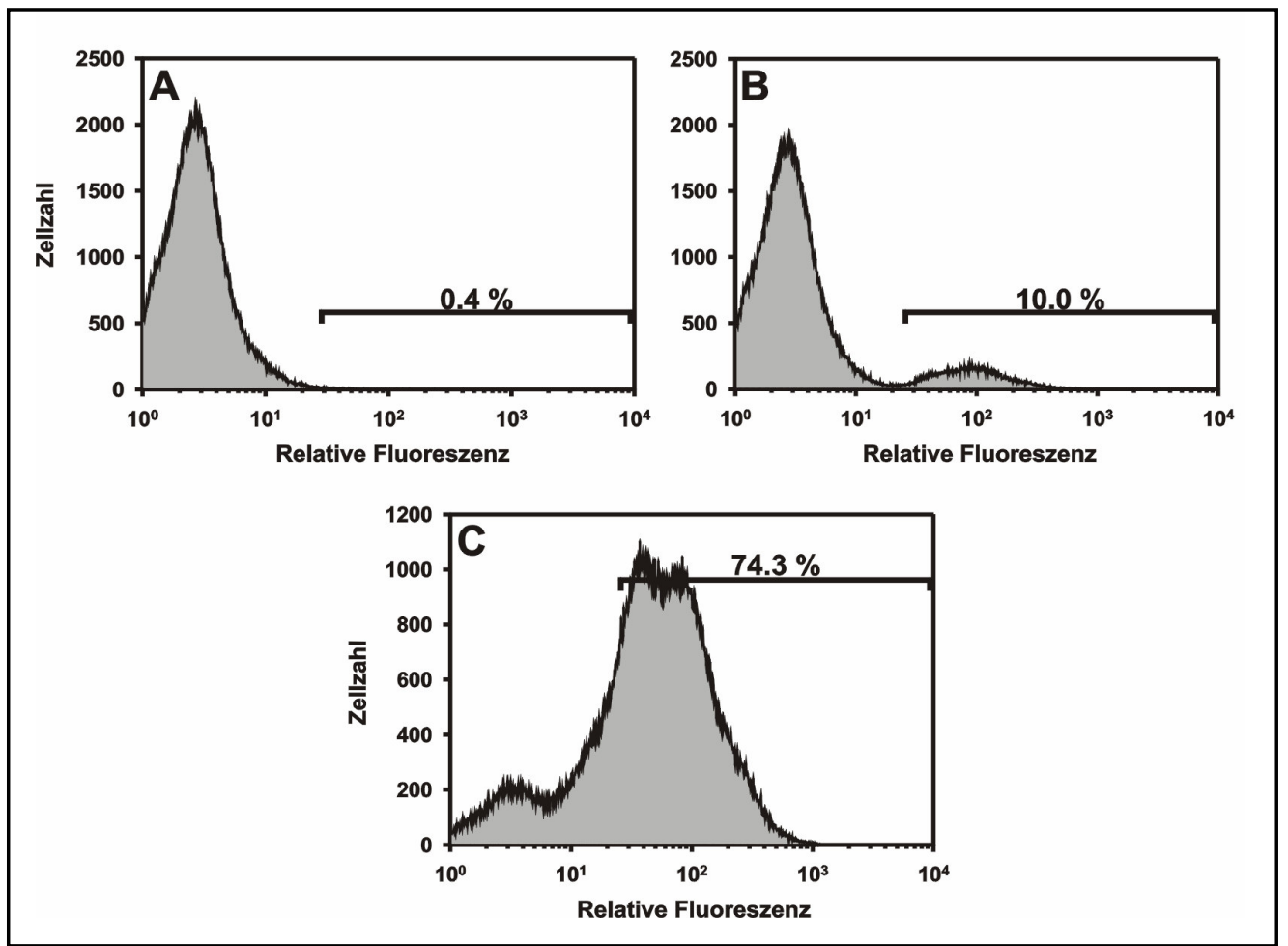

Abbildung 26: Anreicherung von pASKInt100-REI tragenden Zellen von E. coli 71-18. Die Klammer zeigt das Sortierfenster der entsprechenden Sortierrunde an und somit die Definition des entsprechenden in diesen Bereich einzuordnenden Ereignisses als ein Positives. (A) 1:200.000 Mischung von 71-18(pASKInt100-REI) und 71-18(pASKInt100REI $\Delta$ send) vor der ersten Sortierrunde; (B) Mischung nach zwei direkt aufeinander folgenden Runden FACS und Wachstum über Nacht; (C) Mischung aus Runde (B) nach erneuter Sortierung und Wachstum über Nacht.

Nach sofortiger Re-Sortierung wurden die aussortierten Zellen auf festem Medium plattiert und über Nacht bei $37^{\circ} \mathrm{C}$ inkubiert. Nachdem mit einem repräsentativen Anteil der Zellen erneut $50 \mathrm{ml}$ dYTCm ${ }^{25}$-Medium inokuliert worden waren, wurde erneut induziert, mit der anti-Sendai Kaskade markiert und sortiert. Nach zwei aufeinander folgenden 
Runden der Sortierung konnten auf diese Weise bereits $10 \%$ der Ereignisse als positiv identifiziert werden, nach einer erneuten Sortierrunde waren es $74 \%$ der Zellpopulation, welche mittels anti-Sendai Antikörper eine Fluoreszenzmarkierung trugen. Der Verlauf der Anreicherung ist in Abbildung 26 dargestellt.

Das Ergebnis dieses Anreicherungsexperimentes zeigt, dass es mit Hilfe des EaeA' basierten Oberflächenpräsentationsverfahrens prinzipiell möglich ist, seltene Ereignisse durch Fluoreszenz-aktivierte Zellsortierung anzureichern. Eine Übertragung dieses Modellexperiments auf Anreicherungsexperimente aus großen molekularen Bibliotheken wurde bereits von A. Christmann erfolgreich durchgeführt (Christmann et al., 2001). Aus zufallsmäßig erzeugten Peptidbibliotheken eines Proteins des Schweinepest-Virus konnten Aminosäuresequenzen identifiziert werden, die spezifisch von gegen das Protein gerichteten Antikörpern gebunden wurden. 


\section{Diskussion}

Verfahren zur bakteriellen Oberflächenpräsentation von Peptiden und Proteinen auf Zellen von Escherichia coli ergänzen neben dem weit verbreiteten Phage Display (Übersicht z.B. bei Willats, 2002), der Präsentation auf Hefezellen (z.B. Boder \& Wittrup, 2000) und einigen in vitro Verfahren (z.B. Amstutz et al., 2001) das Spektrum der in der molekularen Biotechnologie weit verbreiteten Methoden zur Genotyp-Phänotyp-Kopplung. Die dokumentierten Verfahren des bacterial surface display verwenden dabei ganz unterschiedliche funktionelle Plattformen, meist jedoch solche auf der Basis natürlich vorkommender Proteine der äußeren Membranen Gram-negativer Bakterien [LPp-OmpA (Francisco et al., 1992), LamB (Charbit et al., 1986), Iga $\beta$ (Klauser et al., 1992), AIDA-I (Maurer et al., 1997), INP (Jung et al., 1998), Flagellenproteine (Westerlund-Wikström et al., 1997)]. Man kann die dokumentierten Verfahren einteilen in solche, bei denen modifizierte, wirtseigene Moleküle als membranständige Ankerdomäne zum Einsatz kommen (LppOmpA, LamB, AIDA-I, Flagellenproteine bei Verwendung von Escherichia coli als Expressionswirt), und solche, die auf heterologer Expression beruhen (Iga $\beta$ aus Neisseriagonorrhoeae, INP aus Pseudomonas syringae). Grundvoraussetzung für die biotechnologische Anwendung eines jeden dieser Verfahren ist, dass die Vitalität der verwendeten Zellen nicht oder nur in begrenztem Ausmaß durch die genetische und damit verbundene physiologische Modifikation beeinträchtigt wird. Dabei kann sich sowohl die zusätzliche Expression von Konstrukten, deren Komponenten bereits durch die Wirtszelle selbst bereitgestellt werden, die Gefahr einer Unverträglichkeit bergen, wie auch diejenige eines heterologen Moleküls, welches einer anderen Bakterienart entnommen ist. Das im Rahmen dieser Arbeit entwickelte Verfahren wurde deshalb auf der Basis eines Moleküls aufgebaut, welches von E.coli stammt und dort in der äußeren Membran in hoher Kopienzahl vorkommt. Das EaeA Protein, welches die funktionelle Basis des neuen Präsentationsverfahrens auf Zellen von E.coli K12 darstellt, entstammt dem Serotypen O157:H7 enterohaemorrhagischer E. coli (EHEC), welche mit den Laborstämmen von E. coli sehr nah verwandt sind und deren Pathogenität maßgeblich auf der Anwesenheit bestimmter zusätzlicher Pathogenitätsfaktoren, kodiert in einer sogenannten Pathogenitätsinsel, beruht (Groisman \& Ochman, 1993, Kaper, 1998). EaeA ist einer dieser zusätzlichen Faktoren und ist an der Anheftung der EHEC Zellen an das Darmepithel maßgeblich beteiligt, dem Ausgangspunkt der weiteren Infektion. Die Übertragung von Teilen des EaeA Proteins auf Laborstämme von E. coli sollte folglich, so die initiale Annahme, für die strukturelle Integrität der Zellen einen geringeren Einfluss haben als andere beschriebene, funktionelle Einheiten der bakteriellen Zelloberflächenpräsentation.

Zunächst wurde der Präsentationsvektor pASKInt100 konstruiert. Dieser Vektor trägt als funktionelle Einheit den tetA Promotor/Operator des Plasmids pASK75 (Skerra, 1994) in Kombination mit der kodierenden Sequenz des diesen zu regulieren vermögenden Repressorproteins. Anders als in dem Ursprungsvektor wird von pASKInt100 eine Chloramphenicolresistenz kodiert, das ursprüngliche Gen für $\beta$-Laktamase wurde deletiert, da die Präsentation dieses Proteins auf der Zelloberfläche ein definiertes Ziel bei der Evaluation des Systems darstellen sollte. Zellen, welche das Plasmid pASKInt100-EETI$\mathrm{CK}^{\text {send }}$ trugen, präsentierten die EETI-CK ${ }^{\text {send }}$ Variante des Ecballium elaterium Trypsin 
Inhibitors II (EETI-II), nachweisbar mit einem monoklonalen Antikörper gegen das SendaiEpitop (Einberger et al., 1990). Bereits mittels des Lpp-OmpA Systems konnte die funktionelle Präsentation dieses in die Klasse der Cystin-Knoten Mikroproteine fallenden Proteins gezeigt werden (Christmann et al., 1999). Die Fluoreszenzaufnahmen in Abschnitt 2.1.2 zeigen, dass die Zellen mittels einer Antikörperkaskade markierbar sind. Es ist darüber hinaus sogar mikroskopisch zu erkennen, dass sich die Markierung offenbar auf der Oberfläche der Zellen befindet. Durch ein indirektes Verfahren wurde die Anzahl der Oberflächen-exponierten Moleküle mit durchschnittlich 36.000 pro Zelle bestimmt, einer sehr großen Anzahl, die nahe der dokumentierten Anzahl des am häufigsten in der äußeren Membran von E. coli vorkommenden Proteins OmpF liegt (vgl. 2.1.4, Bourdineaud et al., 1990). Im Rahmen der Rechnung wurde die Annahme gemacht, dass eine Stöchiometrie von 1:1 zwischen exponiertem Molekül und gebundenem Antikörper vorliegt. Immunglobuline vom Typ G (IgG) besitzen jedoch zwei bindefähige Regionen, die jeweils ein Oberflächenpräsentiertes Epitop binden können. Aus diesem Grund könnte die wirkliche Anzahl exponierter Moleküle maximal noch um den Faktor zwei höher als errechnet liegen. Es ist somit zumindest festzustellen, dass eine gegenüber anderen Präsentationsverfahren vergleichbar sehr große Anzahl an Passagierdomänen auf der Oberfläche über EaeA' exponierbar ist und dort einer Funktionsabfrage zur Verfügung steht.

Die große Anzahl präsentierter Moleküle wurde erhalten, obgleich die Transkription des EaeA' Konstruktes in voller Länge ausgehend vom tetA Promotor bereits durch das Einfügen eines amber Stop-Kodons anstelle des ersten für Glutamin kodierenden Kodons und die Verwendung eines amber Supressor-Stammes wie DH5aZ1 oder 71-18 als Expressionswirt gedrosselt worden war. Ein möglicher Grund für die trotz der Reduktion der Anzahl an EaeA' Molekülen auf translationeller Ebene immer noch sehr hohe Nettoakkumulation könnte in einer im Vergleich zur Produktion geringen Abbaurate des Membran-inserierten Intimin' Proteins in den verwendeten Stämmen liegen. Ohne die Maßnahme zur Verringerung der Nettoakkumulation von EaeA' Protein in der äußeren Membran war dessen ungehinderte Expression vom tetA Promotor mit dem Überleben der Zellen nicht vereinbar (Beobachtung Dr. H. Kolmar). Es kommt in diesem Fall möglicherweise zu einer Akkumulation von EaeA' Molekülen in der äußeren Membran, die deren Kapazität übersteigt, so dass die Membran destabilisiert wird und die Zelle zugrunde geht. Das hier zur Drosselung der Expression angewandte Verfahren der Suppression wurde bereits vormals erfolgreich bei einem Lpp-OmpA Konstrukt zur Reduktion des Expressionslevels verwendet (Christmann et al., 1999). Nachdem es sich bereits zur Anpassung der Expression zweier verschiedener Proteine gut bewährt hat, dürfte es sich generell auf die kontrollierte Expression von Proteinen der äußeren Membran anwenden lassen, die unter der Kontrolle des lac bzw. des tetA Promotors stehen.

Durch die kontrollierte Expression der für die Suppression verantwortlichen Suppressor tRNA in einem nicht amber Supressor Stamm war es möglich, die Anzahl Oberflächenexponierter Moleküle in einem bestimmten Rahmen zu variieren (2.1.5). Auf diese Weise kann eine definierte Anzahl auf der Zelloberfläche exponierter Moleküle eingestellt werden, und das Verfahren kann auch auf nicht amber Suppressor Stämme übertragen werden. Warum die Regulation der Genexpression allein über eine Transkriptionskontrolle bei 
Verwendung des tetA Promotors nicht erfolgreich ist, ist gegenwärtig unklar. Offenbar bewirkt die Variation der Induktorkonzentration lediglich die Etablierung zweier Extremzustände, nämlich der vollständigen Repression oder Derepression der Genexpression, wobei durch Erhöhung der Induktorkonzentration nur der Anteil an Zellen zunimmt, in denen eine Vollinduktion der Expression vorliegt. Die auf dem Wege der doppelten Regulation bewerkstelligte Expression ist deutlich geringer als die unter Verwendung eines Supressor-Stammes. In letzterem steht die Expression der Suppressor tRNA unter der Kontrolle des sehr starken ribosomalen RNA Promotors, einem der stärksten Promotoren überhaupt. Über den Austausch des $P_{\text {Llac }}$ Promotors zur Expression der supE tRNA durch einen stärkeren Promotor könnte es möglich sein, die Präsentation über einen noch größeren Bereich zu regulieren, Experimente, die bis zum jetzigen Zeitpunkt noch nicht angegangen wurden.

Der größte Vorteil der bakteriellen Zelloberflächenpräsentation gegenüber anderen Verfahren liegt in der Möglichkeit, positiv angereicherte Zellen direkt zu vermehren. Grundvoraussetzung dafür ist, dass die Zellen nach Expression und Selektion noch in der Lage sind, sich zu teilen und direkt wieder zu Klonen heranzuwachsen. Die Vitalität der Zellen bei Verwendung des EaeA' basierten Präsentationsverfahrens ist daher ein entscheidendes Kriterium für dessen Einsatz zur Durchmusterung großer molekularer Repertoires. Es wurde in Kapitel 2.1.3 gezeigt, dass durch die mittels Suppression kontrollierte Oberflächenpräsentation von Intimin' Fusionsprotein nur eine sehr geringfügige Einschränkung der Zellvitalität auftritt, obgleich ein gewisser Wachstumsnachteil gegenüber nicht-präsentierenden Zellen beobachtet werden konnte. Dies kann jedoch zumindest teilweise auf die physiologische Last einer zusätzlichen Expression zurückgeführt werden, die allerdings im Rahmen eines Anreicherungsexperimentes aufgrund ansonsten identischer Ausstattung der Zellen kaum einen unerwünschten Selektionsdruck ausüben dürfte. Die Synthese des Membranproteins über lediglich mehrere Stunden führte nur zu einer geringen Beeinträchtigung des Überlebens (2.1.3). Im Rahmen von Selektionsexperimenten sollte deshalb eine Induktionszeit von mehr als einer bis eineinhalb Stunden nicht überschritten werden.

Um das Verfahren in Bezug auf seine Anwendbarkeit zur Selektion seltener Ereignisse aus einem komplexen Hintergrund heraus zu testen, wurden in einem Modellexperiment das Sendai-Epitop präsentierende Zellen in drei Runden aus einem großen Überschuss ausschließlich die Immunglobulindomäne $R E I_{v}$ als Passagier präsentierender Zellen angereichert (2.2.7). Das Ergebnis zeigt, dass das Verfahren zum Zwecke der Isolierung bindefähiger Moleküle im Rahmen gerichteter Evolutionsexperimente gut nutzbar ist. Um zu verhindern, dass nach jeder Sortierrunde einzelne Klone, die sich stärker vermehren als andere, diese wegen deren schlechterer Etablierung in Kultur verdrängen, sollten die Zellen nach jeder Sortierrunde zunächst auf festem Medium wieder zu Kolonien kultiviert werden, bevor ein repräsentativer Anteil der nächsten Anreicherungsrunde zugeführt wird.

In den vorangegangen Abschnitten wurde gezeigt, dass es prinzipiell möglich ist, die Lektinbindedomäne E3 gemeinsam mit der Immunglobulindomäne E2 des Intimins EaeA enterohämorrhagischer Escherichia coli (EHEC) durch eine andere Proteindomäne, nämlich das Cystin-Knoten Inhibitor-Protein EETI-II zu ersetzen und eine Oberflächenexposition zu 
erreichen. Der Mechanismus der Translokation von Proteindomänen durch die äußere Membran der E. coli Zelle ist wenig verstanden. Arbeiten von Meyer und Mitarbeitern mit der Autotransporter-Domäne der IgA-Protease Iga $\beta$ aus Neisseria gonorrhoeae legen nahe, dass die translozierte Passagierdomäne nur in ungefaltetem Zustand auf die Zelloberfläche transportiert wird. Proteine, die intramolekulare Disulfidbrücken enthalten und bei denen wahrscheinlich bereits im Periplasma präformierte Sekundärstrukturelemente kovalent fixiert werden, werden nicht transloziert (Klauser et al., 1992). Es stellte sich daher die Frage, ob diese einschränkende Bedingung für Intimin-vermittelte Zelloberflächenexposition ebenso gilt. Es wurde daher eine Reihe von Passagierdomänen in E. coli als Fusionsprotein mit EaeA' produziert und analysiert, ob diese auf die Zelloberfläche gelangen können. Dabei wurden sowohl disulfidhaltige, als auch disulfidfreie Proteine unterschiedlicher Größe und Sekundärstruktur eingesetzt. Um untersuchen zu können, ob eine Exposition der Passagierdomäne auf der Zelloberfläche stattfindet, wurde der Präsentationsvektor so konstruiert, dass die Passagierdomäne von zwei unterschiedlichen Epitopsequenzen flankiert wird (Abb. 5). Wenn E. coli Zellen die jeweilige Passagierdomäne auf ihrer Oberfläche tragen und somit mit beiden Antikörpern eine Immunfluoreszenz zeigen, weist dies auf einen Transport durch die äußere Membran und eine Exposition des Passagierproteins auf der Zelloberfläche hin.

Neben dem Mikroprotein EETI-CK ${ }^{\text {send }}$ und der Immunglobulindomäne REI wurde versucht, folgende weitere Proteine auf der Oberfläche von E. coli Zellen zu präsentieren. Dies waren die wie REIv ebenfalls humanen Proteine Interleukin 4 (Il-4) und Calmodulin sowie das $\beta$-Laktamase Inhibitor Protein (BLIP) aus Streptomyces clavuligerus und dessen natürliches Substrat die TEM-1 $\beta$-Laktamase von Escherichia coli. Ohne weitere Optimierung der Oberflächenexposition konnte lediglich die Translokation von EETI-CK ${ }^{\text {send }}, R_{\text {R }}$ und Interleukin 4 nachgewiesen werden. Im Falle von Interleukin 4 konnte ferner ein Unterschied der Exposition in zwei unterschiedlichen Stämmen von E. coli, DH5 $\alpha Z 1$ und 71-18P' beobachtet werden. Wie aus den sondierenden Experimenten mit DH5 $\alpha \mathrm{Z1}$ und den systematischen Experimenten mit dem E. coli Stamm 71-18P', welcher außerhalb dieser Arbeit bereits routinemäßig zur Präsentation von molekularen EETI-II Bibliotheken eingesetzt wird, hervorgeht, besteht offenbar ein gewisser Einfluss des Stammhintergrundes auf die Präsentation der Passagierdomänen. Durch gelelektrophoretische Auftrennung von Membranfraktionen und anschließende Analyse mittels Western Blot unter Verwendung des Anti-Sendai Antikörpers konnte abgeleitet werden, dass die Insertion von EaeA'Interleukin 4 Fusionsprotein in die äußere Membran von E. coli DH5 $\alpha$ Z1 in geringerem Ausmaß stattfindet als die von EETI-CK ${ }^{\text {send }}$ und $R E I_{v}$. Mögliche Gründe sind ein geringeres Expressionslevel des Interleukins aufgrund anderer Kodon-Nutzung in humanen Zellen als in Escherichia coli oder ein carboxyterminaler Abbau der Vier-Helix-Domäne des Interleukin 4 durch periplasmatische Proteasen. Bei allen drei Passagier-Fusionsproteinen, mit EETI-CK ${ }^{\text {send }}$, $R E I_{v}$ und Interleukin 4, akkumulieren Abbauprodukte, was ein Hinweis auf aminoterminale Prozessierung durch eine periplasmatische Proteaseaktivität ist, welche vor allem die in Richtung des Periplasmas zeigenden Schleifen von EaeA' spaltet. Der Nachweis einer carboxyterminalen Prozessierung war im gewählten experimentellen Ansatz nicht möglich, weil ein derartiger Abbau nicht mehr über das dort befindliche Epitop nachweisbar ist. Cterminale Prozessierung spiegelt sich deshalb in einer Verringerung nachweisbarer 
Proteinmenge mittels anti-Sendai Antikörper wider. Die beobachtete geringere Nettoakkumulation von Interleukin 4 Fusionsprotein korreliert dabei mit der geringeren Fluoreszenz markierter, Il-4 präsentierender Zellen.

Benutzt man anstelle von DH5 $\mathrm{ZZ1}$ als Expressionsstamm 71-18P', so werden EETI$C K^{\text {send }}$ und $R E I_{v}$ in beiden Stämmen nahezu gleich gut präsentiert, die Exposition von Interleukin 4 hingegen reduziert sich auf ein fast nicht mehr nachweisbares Minimum. Ein möglicher Grund für diesen Unterschied könnte in der unterschiedlichen Wachstumsgeschwindigkeit der beiden Stämme liegen. DH5 $\alpha Z 1$ wächst als recA defizienter Stamm deutlich langsamer als 71-18P'. Offensichtlich ist in ersterem der Stoffwechsel generell verlangsamt, also möglicherweise auch die Proteinproduktion von EaeA'Fusionsprotein. In 71-18P' hingegen kommt es schnell zu einer Akkumulation dieses Proteins. Folgt die Faltung von Interleukin 4 einem langsamen Weg und können die drei Disulfidbrücken nicht zügig geschlossen werden, kann es bei einer zu hohen Akkumulation von Fusionsprotein möglicherweise zur Bildung von Aggregaten kommen, welche von intrazellulären Proteasen abgebaut werden. Bei geringerer Expression von Fusionsprotein pro Zeiteinheit hingegen, wie möglicherweise in DH5 $\alpha$ Z1, findet eine solche Aggregation unter Umständen nur in geringerem Ausmaß statt.

Die drei weiteren, hinsichtlich ihrer Zelloberflächenexposition untersuchten Domänen Calmodulin, BLIP und TEM-1 $\beta$-Laktamase waren auf der Oberfläche der produzierenden Zellen des Stammes 71-18P' nicht präsentierbar. Als Arbeitshypothese wurde angenommen, dass eine Destabilisierung der äußeren Membran möglicherweise die Translokation des Intimin-Fusionsproteins verbessert. Die Zellen wurden deshalb in Anwesenheit unterschiedlicher chemischer Zusätze (2.2.1.3) im Wachstumsmedium inkubiert. Dabei konnte die Il-4 Präsentation in Anwesenheit von 0,1\% (w/v) SDS deutlich verbessert werden. Die aus Lipiden aufgebaute äußere Membran von $E$. coli wird möglicherweise durch die Anwesenheit des Detergenz Dodecylsulfat derart destabilisiert, dass die Blockade der Translokation von Il-4 teilweise aufgehoben wird. Die Präsentation von Calmodulin konnte durch Kultivierung der produzierenden Zellen in Anwesenheit von EDTA einer Endkonzentration von $1 \mathrm{mM}$ sehr stark verbessert werden. Der Chelatkomplex-Bildner EDTA ist befähigt, eventuelle, von Calmodulin gebundene Kalzium-Ionen aus dem Molekül $\mathrm{zu}$ binden und zu entfernen. Es ist daher plausibel anzunehmen, dass durch Entfernen der Kalzium-Ionen das Molekül in eine translozierbare, weniger rigide gefaltete Form überführt wird und diese eine Translokation und Oberflächenpräsentation gestattet. Durch nachträgliche Zugabe von Kalzium-Ionen zu den in Anwesenheit von EDTA gewachsenen, präsentierenden Zellen konnte die funktionelle Faltung von Calmodulin auf der Zelloberfläche wiederhergestellt werden. Das Molekül ist danach wieder in der Lage, ein Fusionsprotein aus $\beta$-Laktamase und dem natürlichen Bindepeptid der Myosin-Kinase (Blumenthal et al., 1985), einem natürlichen Substrat von Calmodulin, zu binden. Dies zeigt, dass die funktionale Oberflächenpräsentation auch größerer Proteindomänen als EETI-CK ${ }^{\text {send }}$ mittels EaeA' prinzipiell möglich ist, dass die Exposition auf der Zelloberfläche jedoch von speziellen Merkmalen der Kinetik und/oder der Thermodynamik der Faltung der Passagierdomänen abhängig ist. 
Neben Interleukin 4 und Calmodulin konnte durch Behandlung mit Chemikalien während des Kulturwachstums auch das $\beta$-Laktamase Inhibitor Protein (BLIP) aus Streptomyces clavuligerus präsentiert werden. Hier war ein positiver Einfluss von Reduktionsmitteln zu beobachten. Durch Anwesenheit von $20 \mathrm{mM} \beta$-Mercaptoethanol im Medium konnte eine Verbesserung der Präsentation erreicht werden. Auch die Verwendung von 71-18dsbA als Wirtsstamm bewirkte eine erhöhte Nettoakkumulation auf der Zelloberfläche. Dieser Stamm besitzt kein funktionales DsbA Protein, welches die Ausbildung von Disulfidbrücken beschleunigt (Bardwell et al., 1991). Gefaltetes BLIP besitzt im Molekül zwei geschlossene Disulfidbrücken. Offensichtlich ist eine Ausbildung derselben bereits im Periplasma mit einer Translokation durch die äußere Membran von E. coli nicht vereinbar. In hoher Kopienzahl wurde BLIP nur dann auf der Zelloberfläche exponiert, wenn die produzierenden Zellen nicht in der Lage waren, die Bildung von Disulfidbrücken katalytisch zu beschleunigen und die spontane Disulfidbildung durch Zusatz von Reduktionsmitteln unterdrückt wurde. Es ist plausibel anzunehmen, dass unter diesen Bedingungen die Oxidation der Passagierdomäne BLIP stark verlangsamt ist und dies eine Translokation durch die äußere Membran begünstigt.

Die größte strukturelle Domäne, mit der eine Oberflächenpräsentation über EaeA' untersucht wurde, war die TEM-1 $\beta$-Laktamase von E. coli (278 Aminosäuren) und somit auch das einzige Enzym, das zu diesem Zwecke herangezogen wurde. Es wurden unterschiedliche Bedingungen experimentell evaluiert, um auch in diesem Fall eine Exposition auf der Bakterienoberfläche zu erreichen. Im Rahmen dieser Arbeit war es jedoch nicht möglich, mit dem EaeA' System die Exposition des Wildtyp Enzyms auf der Zelloberfläche zu bewerkstelligen. Durch ungerichtete Mutagenese wurden Varianten der TEM-1 $\beta$-Laktamase gewonnen, die über EaeA' auf der Oberfläche der Zellen präsentierbar waren und auch noch $\beta$-Laktamaseaktivität aufwiesen. Alle identifizierten Mutationen führten zum Austausch eines der beiden Cysteinreste im Molekül, die für die Ausbildung der Disulfidbrücke nötig sind, gegen eine raumfüllende Aminosäure (Arginin bzw. Tyrosin). Dadurch kann zum einen die Disulfidbrücke nicht mehr ausgebildet werden, und zum anderen wird die Struktur neben dieser fehlenden Stabilisierung möglicherweise durch die Ausdehnung der neuen Aminosäureseitenkette weiter destabilisiert.

Aus den Untersuchungen zur Translokation der diversen Passagierdomänen lassen sich einige mechanistische Folgerungen den Prozess der Translokation durch die äußere Membran betreffend ableiten. Es konnten drei kritische Parameter identifiziert werden: (a) die Größe der Passagierdomäne, (b) die Bildung von Disulfidbrücken im Periplasma der Zellen und (c) die Faltung der Passagierdomäne im periplasmatischen Raum. Für EETI-CK ${ }^{\text {send }}$ ist eine sehr schnelle Faltung mehrfach beschrieben (Le-Nguyen et al., 1993, Heitz et al., 1995, Wentzel et al., 1999), so dass davon auszugehen ist, dass dieses bereits im Periplasma der Zellen gefaltet vorliegt. Trotzdem wird es transloziert und präsentiert. Immunglobulindomänen kommt offensichtlich bei diesem Präsentationssystem eine Sonderstellung zu, da drei der natürlichen Intimindomänen eine Immunglubulin-ähnliche Faltung aufweisen. Allerdings werden die Domänen E0, E1 und E2 des Intimins im Gegensatz zu $R E I_{v}$ nicht durch eine intramolekulare Disulfidbrücke stabilisiert. Die Bildung dieser Disulfidbrücke in $R E I_{v}$ ist ein vergleichsweise langsamer Prozess und hat einen großen 
Anteil an der Faltung des Proteins (Schmidt, 1995, Frisch et al., 1996). Möglicherweise wird dadurch ein Zeitfenster eröffnet, in dem eine Translokation der noch nicht vollständig gefalteten Immunglobulindomäne durch die äußere Zellmembran stattfinden kann (Abb. 27A). Stabilisieren Disulfidbrücken die Faltung bereits im Periplasma, steht dies einer vollständigen Translokation durch die Bakterienhülle, wie im Falle von BLIP gezeigt, in vielen Fällen entgegen. Gleiches dürfte für die Stabilisierung der Passagierdomäne durch Heteroatome wie im Falle von Calmodulin durch Kalzium-Ionen gelten. Das Unterbinden einer frühzeitigen Stabilisierung der Faltung durch Reduktionsmittel oder Chelatoren lässt die Translokation in zumindest partiell ungefaltetem Zustand zu. Wie im Falle der $\beta$ Laktamase gibt es demgegenüber jedoch auch Proteindomänen, die selbst durch die Zugabe von Agenzien, die in anderen Fällen eine Exposition begünstigen, eine Oberflächenpräsentation über das EaeA' Protein unmöglich machen. Erst die Einführung destabilisierender Mutationen kann zur Überführung in eine Translokations-permissive Form führen.

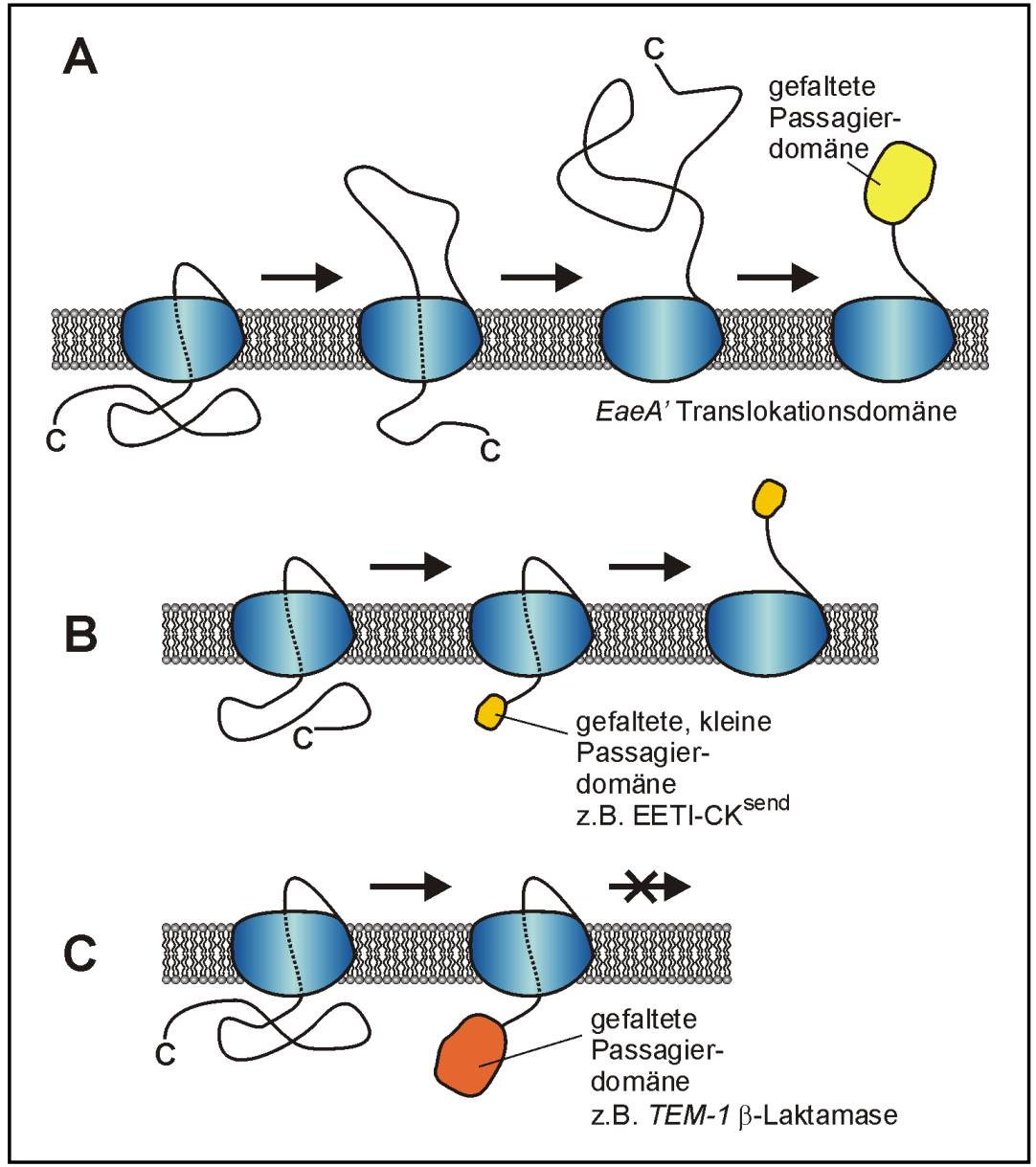

Abbildung 27. Schematische Darstellung der Intimin' vermittelten Translokation durch die äußere Membran von E. coli. (A) Autotransport-Mechanismus analog zu dem von T. F. Meyer und Mitarbeitern für AIDA-I vorgeschlagen (verändert nach Lattemann et al., 2000).

(B) Präsentation des bereits im Periplasma gefaltetem Mikroprotein EETI-CK ${ }^{\text {send }}$ über EaeA'. Das gefaltete Protein kann transloziert werden. (C) Die Faltung einer größeren Domäne, die bereits im Periplasma gefaltet vorliegt, kann nicht auf der Oberfläche präsentiert werden. Durch partielle Entfaltung kann eine Translokation wieder gewährleistet werden.

Zusammenfassend lässt sich sagen, dass mit dem Intimin' basierten Präsentationsverfahren auf E.coli ein robustes Werkzeug für die Durchmusterung umfangreicher 
molekularer Bibliotheken zur Anreicherung von Varianten mit verbesserten oder neuen Funktionalitäten zur Verfügung steht. Offenbar gelten jedoch hierbei für die Intiminvermittelte Translokation von Passagierproteinen durch die äußere Membran von E. coli die gleichen einschränkenden Bedingungen wie für die Familie der bakteriellen Autotransportproteine beschrieben (Lattemann et al., 2000). Eine vorzeitige Faltung zu translozierender Domänen und deren strukturelle Fixierung durch Disulfidbrücken bereits vor der Translokation stehen dort, wie auch im Falle von EaeA' einer Passage durch die Membran entgegen (Abb. 27C). Passagierdomänen werden nur in zumindest partiell entfaltetem Zustand transloziert. Eine Ausnahme bildet hier offenbar das Mikroprotein EETI-CK ${ }^{\text {send }}$, das drei Disulfidbrücken und einen schnellen Faltungsweg besitzt und sehr wahrscheinlich bereits gefaltet transportiert wird (Abb. 27B).

Autotransporter wie die IgA-Protease aus Neisseria gonorrhoeae ermöglichen wie Intimine die Zelloberflächenexposition einer fusionierten Passagierdomäne, sind jedoch gänzlich anders aufgebaut als diese (Pohlner et al., 1987a,b, Klauser et al., 1992, Maurer et al., 1997, Lattemann et al., 2000). Während bei ersteren die Translokatordomäne carboxyterminal angeordnet ist, ist diese bei Intiminen aminoterminal positioniert. Intimine und Autotransporter weisen zudem bezüglich ihrer Translokatorregionen keinerlei Sequenzhomologien auf. Für IgA-Protease wurde ein Mechanismus für die Translokation der Passagierdomäne vorgeschlagen, der auf eine Oligomerisierung der membranständigen Domäne beruht. Ein Export der Passagierdomäne soll demnach durch die dadurch gebildete zentrale Pore erfolgen (Veiga et al., 2002). Es wäre daher interessant zu ergründen, ob im Falle des Intimins, wie von Veiga und Mitarbeitern vorgeschlagen, die Translokation durch eine gemeinsame Membranpore, durch den Innenraum des $\beta$-Fasses eines individuellen Transmembranmoleküls, durch die Membran oder an der Protein/Lipid Grenzfläche stattfindet. Auch ohne Wissen über die mechanistischen Details des Intimin-vermittelten Proteinexports konnten empirische Rahmenbedingungen geschaffen werden, die eine Exposition diverser Passagierdomänen auf der Zelloberfläche zuließen. Damit steht nun mit Intimin' ein robustes Werkzeug zur Verfügung, unterschiedliche Passagierdomänen als Grundgerüst für die Erzeugung und Durchmusterung molekularer Repertoires einer extrazellulären Funktionsabfrage zugänglich zu machen. 


\section{Material}

\subsection{Stämme von Escherichia coli}

DH5 $\boldsymbol{\alpha}$ (Hanahan, 1983)

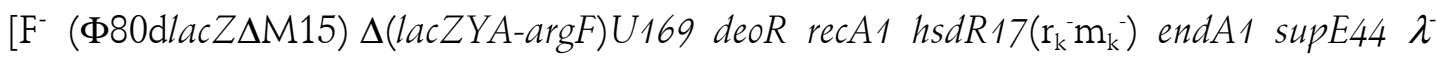
thi-1 gyrA(nal') relA1]

DH5 $\alpha Z 1$ (Lutz \& Bujard, 1997)

$\left[\mathrm{F}^{-}(\Phi 80 \mathrm{~d} l a c Z \Delta \mathrm{M} 15) \Delta(\mathrm{lacZYA}-\arg F) U 169\right.$ deoR recA1 hsdR17( $\left.\mathrm{r}_{\mathrm{k}}^{-} \mathrm{m}_{\mathrm{k}}{ }^{-}\right)$endA1 supE44 $\lambda^{-}$ thi-1 gyrA(nal $\left.{ }^{r}\right)$ relA1 tet $R^{+}$lac $\left.R^{+} s p^{r}\right]$

71-18 (Quelle: B. Müller-Hill)

[F' lacI ${ }^{\mathrm{I}}($ lac Z $\Delta \mathrm{M} 15)$ pro $\mathrm{A}^{+} \mathrm{B}^{+} \Delta$ (lac-proAB) supE thi-1]

71-18P' (Quelle: H. Kolmar)

71-18P' wurde selektiert als resistente Stamm-Variante von 71-18 nach Infektion mit einem lytischen E. coli Phagen nicht näher charakterisierter Art. Zellen dieses Stammes tragen wahrscheinlich eine nicht näher bestimmte Mutation in einem exponierten Rezeptorprotein der Bakterienoberfläche und sind mit einigen lytischen Phagen wie z.B. T5 nicht infizierbar.

71-18dsbA (Quelle: H. Kolmar)

[F' lac I (lacZ $\Delta \mathrm{M} 15)$ pro $\mathrm{A}^{+} \mathrm{B}^{+} \Delta($ lac-proAB) sup E thi-1 dsbA::kan1]

Der Stamm 71-18dsbA wurde durch P1-Transduktion von dsbA::kan1 aus JCB609 (Bardwell et al., 1991) in 71-18 hergestellt.

71-18mutS (Kramer, et al., 1984)

[F' lac I' (lacZ $\Delta \mathrm{M} 15)$ pro $\mathrm{A}^{+} \mathrm{B}^{+} \Delta($ lac-proAB) sup E thi-1 mutS::Tn10]

WK6 (Quelle: W. Kramer)

[F' lac ${ }^{q}($ lacZ $\Delta \mathrm{M} 15)$ proA $^{+} \mathrm{B}^{+} \Delta\left(\right.$ lac-proAB) galE strA nal $\left.{ }^{\mathrm{r}}\right]$ 


\title{
4.2 Plasmide
}

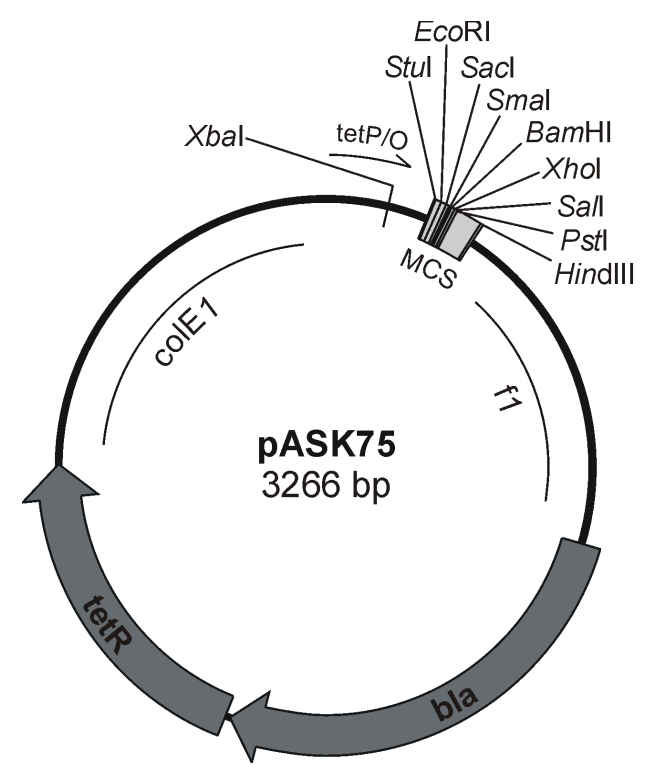

\author{
Name: pASK75 \\ Größe: $\quad 3266$ bp \\ Elemente: $\quad \beta$-Laktamase Gen (bla) \\ TetA-Repressor (tetR) \\ colE1-Replikationsurprung (colE1) \\ f1-Replikationsursprung (f1) \\ TetA Pomotor/Operator-Region \\ $($ tetP/O) \\ multiple cloning site (MCS) \\ wichtige Restriktionsschnitt- \\ stellen der MCS sind angegeben
}

Zitat: Skerra, 1994

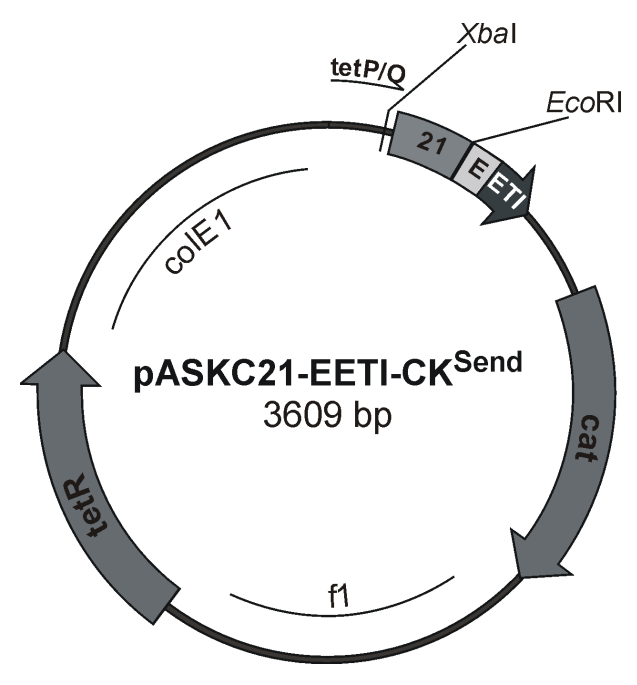

Name: pASKC21-EETI-CK ${ }^{\text {send }}$

Größe: $\quad 3609$ bp

Elemente: Chloramphenicol-Acetyltransferase-Gen (cat)

TetA-Repressor (tetR)

colE1-Replikationsurprung (colE1)

f1-Replikationsursprung (f1)

TetA Pomotor/Operator-Region $($ tetP/O)

OmpA21-E-tag-EETI-II Ober-

flächenpräsentationsmodul (21-E-ETI)

Zitat: nicht veröffentlicht, verändert nach Christmann et al., 1999 (pASK21-EETI)

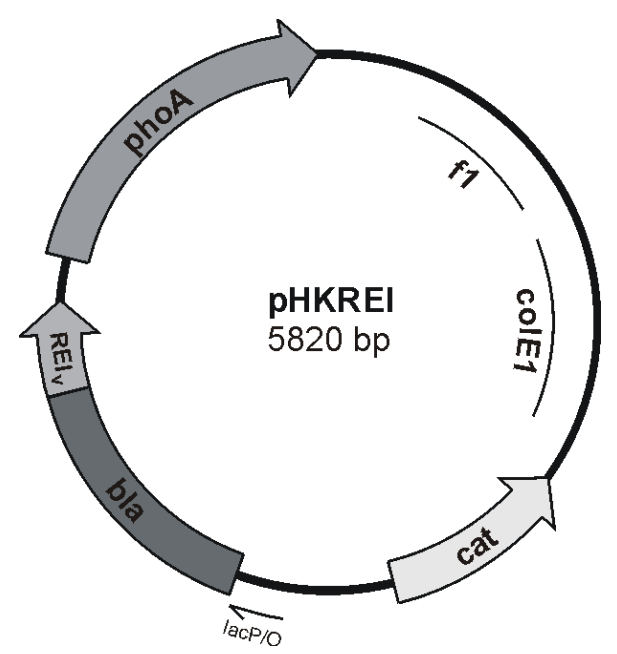

Name: $\quad$ pHKREI

Größe: $\quad 5820$ bp

Elemente: Chloramphenicol-Acetyltransferase-Gen (cat) colE1-Replikationsurprung (colE1) f1-Replikationsursprung ( $f 1)$ lac Pomotor/Operator-Region (lacP/O)

$\beta$-Laktamase Gen (bla)

$R E I_{v}$ kodierende Sequenz

kodierende Sequenz für alkalische Phosphatase (phoA)

Zitat: $\quad$ Kolmar et al., 1992 

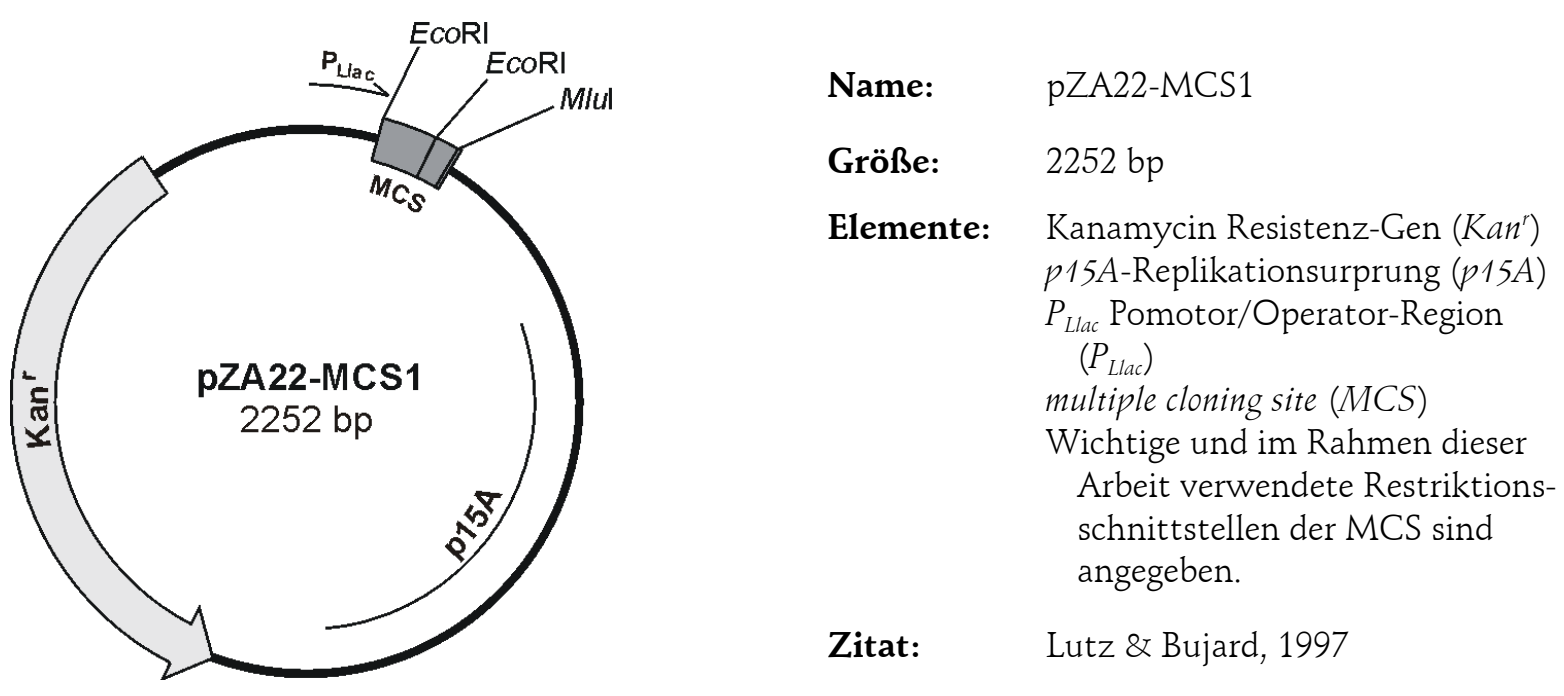

Zitat: $\quad$ Lutz \& Bujard, 1997

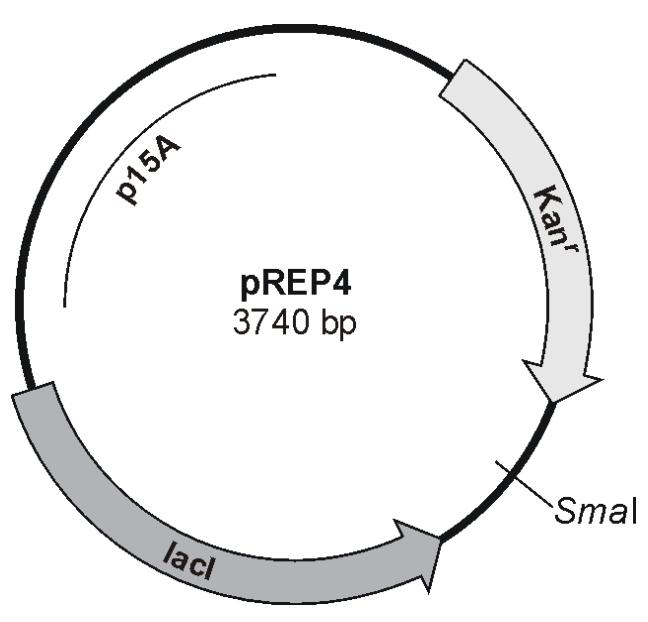

\author{
Name: $\quad$ pREP4 \\ Größe: $\quad 3740 \mathrm{bp}$ \\ Elemente: Kanamycin Resistenz-Gen $\left(\mathrm{Kan}^{r}\right)$ \\ p15A-Replikationsurprung (p15A) \\ multiple cloning site (MCS) \\ codierende Sequenz für den Lac- \\ Repressor (lacl) \\ Die im Rahmen dieser Arbeit \\ verwendete Restriktions- \\ schnittstelle für SmaI ist \\ angegeben.
}

Quelle: Qiagen

\title{
4.3 Oligodesoxyribonukleotide
}

Synthetische Oligodesoxyribonukleotide wurden bezogen von den Unternehmen Metabion GmbH (Martinsried), SigmaARK GmbH (Darmstadt) und MWG Biotech AG (Ebersberg).

\subsubsection{Oligodesoxyribonukleotide für die Sequenzierung}

ASK-up-IR

Etag-Seq-up

Int100-low

pASKD-IR

pASKU-IR

RSPU-IR
5'-(IRD800)-TACCACTCCCTATCAGTG-3'

5'-(IRD800)-AATTCCTCCAACGCCCCTG-3'

5'-(IRD800)-TATCAACAGGGACACCAGG-3'

5'-(IRD800)-GTGATAGAGAAAAGTGAA-3'

5'-(IRD800)-TTAATGCGCCGCTACAGG-3'

5'-(IRD800)-GTGAATTTCGACCTCTAG-3' 
4.3.2 Oligodesoxyribonukleotide für die Amplifikation mittels PCR ASKprom-BglII-up 5'-GCGCAGATCTCCATCGAATGGCCAGATG-3“ ASKprom-Nhe 5`-GCGCGCTAGCCCATCGAATGGCCAGATG-3`

AWcatlow 5'-CGCGTCGACAAGCTTGAAAACGTTTCAGTTTGC-3'

AW-cat-Sal-low 5'-GCGCGTCGACAAAAATTACGCCCCGCCCT-3` Bla-BgllI-low 5'-GCCCAGATCTCCAATGCTTAATCAGTGAG-3`

Bla-Sma-up 5‘-GCGCCCCGGGCACCCAGAAACGCTGGTG-3‘

BLIP-low 5'-GCGCGGATCCTTATGATGAATCGTATGGTTCGATATCACCTAATGATCCATCTACAAGGTCCCACTGCCG

BLIP-up 5'-GCGCGCCCGGGGCGGGGGTGATGACCGGGG-3'

Calmodulin-BglII-low 5'-GCGCAGATCTCTTTGCAGTCATCATCTGTACAAAC-3'

Calmodulin-Sma-up

Cat-Hind-low

5'-GCGCCCCGGGATGGCTGATCAGCTGACCGAAGAAC-3'

Cat-Hind-Mitte-low 5'-GCGCAAGCTTACTTTGCAGTCATCATCTG-3'

EheI-up

5'-CCACAAGCTTGAAAACGTTTCAG-3‘

Etag-PvuII-up 5'-CAGCTGTTGCCCGTCTCG-3'

IL4-Send-low 5'-GCGCCAGCTGGGTGCGCCGGTACCGTATCC-3' 5'-GCGCGGATCCTTATGATGAATCGTATGGTTCGATATCACCTAATGATCCATCGCTCGAACACTTTGAATATT-3'

IL4-up 5'-GCGCCCCGGGCACAAGTGCGATATCACC-3'

Intilo1 5'-GCGCCAATTGCGCTGGCCTTGGTTTGATC-3'

Intimin-amber-low

5'-GCGCGAATTCTAATTAACATAAAAAAACAATCC-3'

Intimin-up 5'-GCGCTCTAGATAACGAGGGCAAAAAATGATTACTCATGGTTGTTATAC-3'

pASK-cat-5'-seqlo

5'-TATCAACAGGGACACCAGG-3'

REI-lo-BgIII 5'-GCGCAGATCTCCTAGTGATTTGAAGCTTAG-3'

RSPX

5'-GTGAATTTCGACCTCTAG-3'

SupE2-Eco-up

5'-GCGCGAATTCACCAGAAAGCGTTGTACGG-3'

SupE2-Mlu-lo 5'-GCGCACGCGTAAGACGCGGCAGCGTCGC-3'

\subsection{DNA-Längenstandards und Protein-Molekulargewichtsmarker}

\subsubsection{DNA-Längenstandards}

Lösungen von DNA-Längenstandards (MBI Fermentas) wurden mit TE-Puffer und Sucrosefarbmarker auf eine DNA-Konzentration von $0,1 \mu \mathrm{g} / \mu \mathrm{l}$ eingestellt und bei $4{ }^{\circ} \mathrm{C}$ gelagert. 


\section{1kb-DNA-Leiter}

Fragmentlängen in bp:

$10000,8000,6000,5000,4000,3500,3000,2500,2000,1500,1000,500$

\section{0 bp-DNA-Leiter}

Fragmentlängen in bp:

$1000,900,800,700,600,500,400,300,200,100,80$

\section{$\lambda$-DNA, Eco47I geschnitten}

Fragmentlängen in bp:

8126, 6555, 6442, 3676, 2605, 2555, 2134, 2005, 1951, 1612, 1420, 1284, 985, 974, 894, $597,590,513,511,433,398,345,310,308,272,242,215,151,88,72,67,45,42,32,28$, 23

\section{$\lambda$-DNA, Eco91I geschnitten}

Fragmentlängen in bp:

8453, 7242, 6369, 5687, 4822, 4324, 3675, 2323, 1929, 1371, 1264, 702, 224, 117

\section{$\lambda$-DNA, HindIII geschnitten}

Fragmentlängen in bp:

23130, 9416, 6557, 4361, 2322, 2027, 564, 125

\subsubsection{Molekulargewichtsmarker für Proteine}

\section{"low-range"-Standard (BioRad)}

relatives Molekulargewicht: 97400 (Phosphorylase b, Kaninchenmuskel), 66200 (Rinderserum-Albumin, Rinderserum), 42700 (Ovalbumin, Hühnereiweiß), 31000 (Kohlensäure-Anhydrase, Rind), 21500 (Trypsin-Inhibitor, Soyabohne), 14400 (Lysozym, Hühnereiweiß)

\section{Molekulargewichtsstandard „protein ladder" (MBI Fermentas)}

Bestehend aus 14 rekombinant erzeugten Proteinen der relativen Molekulargewichte 10 000, 15 000, 20 000, 25 000, 30 000, 40 000, 50 000, 60 000, 70 000, 85 000, 100 000, 120 000, 150000 und 200 000; die Bande bei 50000 erscheint stärker ausgeprägt.

\subsection{Chemikalien}

\section{Acros Organics, Geel, Belgien}

Anhydrotetrazyklin

\section{Applichem, Darmstadt}

Isopropyl- $\beta$-D-thiogalactopyranosid (IPTG)

\section{Baker, Deventer, Niederlande}

Dimethylformamid

\section{Biozym, Hessisch Oldendorf}

Chill Out 14 Flüssigwachs 


\section{Boehringer Mannheim, Mannheim}

ATP, Ampicillin (Natriumsalz), 2'-Desoxyribonukleosid-5'-triphosphate (dATP, dCTP, dGTP, dTTP)

\section{Calbiochem-Novabiochem Corporation, La Jolla, CA.,USA}

PADAC (Substrat für $\beta$-Laktamase)

\section{Carl Roth, Karlsruhe}

Paraffin, Einmalküvetten für Photometer, Rotiphorese 30, Rotiphorese 40, APS, NBT, BCIP

\section{Difco, Dreieich}

Bacto-Agar

Fluka, Neu-Ulm

DMSO, Bromphenolblau, Glyzerin, $\beta$-Mercaptoethanol, Saccharose, Trypsin, Coomassie Brillant Blue R, Natriumchlorid, D(+)-Glukose Monohydrat

\section{Gerbu, Gaiberg}

IPTG

\section{Gibco BRL, Eggenstein}

Yeast Extract

ICN Biochemicals, Aurora, OH., USA

Borsäure, EDTA, Tris

Life Technologies, Gaithersburg, MD., USA

UltraPure Agarose (Electrophoresis Grade)

\section{Merck, Darmstadt}

Alle nicht explizit aufgeführten Chemikalien, die zur Anwendung kamen.

\section{Metabion, Martinsried}

Oligodesoxyribonukleotide

MJ Research, Waltham, MA., USA

Chill Out 14 (Flüssigwachs)

MWG Biotech, Ebersberg

Oligodesoxyribonukleotide

National Diagnostics, Atlanta, GA., USA

Protogel, Sequagel XR, Sequagel Complete

\section{Oxoid, Wesel}

Agar Bacteriological, Trypton, Yeast Extract

Riedel-De Haen, Seelze

Ammoniumacetat, Chloroform, Ethanol, Formamid, Methanol, Natriumchlorid, Salzsäure, Ammoniumsulfat

\section{Serva, Heidelberg}

DTT, EDTA, D(+)-Glukose Monohydrat, SDS, TEMED, APS 
Sigma-Aldrich, München

Borsäure, Ethidiumbromid, Bromphenolblau, Tris, Triton X-100, Chloramphenicol, Kanamycin, Tween 20 (Polyethylen-Sorbitan-Monolaureat), Tetrazyklin

Sigma-ARK, Steinheim

Oligodesoxyribonukleotide

\subsection{Enzyme und Proteine}

\section{Amersham Pharmacia}

Anti-E Antikörper, monoklonal

5prime-to-3prime Inc., Boulder, CO., USA

Anti- $\beta$-Laktamase Antikörper (polyklonaler Anti- $\beta$-Laktamase-Kaninchen-Antikörper)

\section{BioRad, München}

Molekulargewichtsstandard für SDS-Polyacrylamid-Gelelektrophorese (SDS-PAGE molecular weight standard, 'low-range')

\section{MBI Fermentas, Vilnius, Litauen}

DNA-Längenstandards, Restriktionsendonukleasen, Rinderserumalbumin (BSA), T4 DNA-Ligase, T4 DNA-Polymerase, T4 Polynukleotidkinase, calf intestine Alkalische Phosphatase (CIAP), Molekulargewichtsstandard für SDS-PolyacrylamidGelelektrophorese, Puffer für benannte Enzyme

Molecular Probes, Eugene, OR., USA

Streptavidin, R-Phycoerythrin-Konjugat $(1 \mathrm{mg} / \mathrm{ml})$

\section{New England Biolabs, Bad Schwalbach}

Restriktionsendonukleasen, Puffer für Restriktionsendonukleasen, Rinderserumalbumin (BSA)

Promega, Madison, WI., USA

Tfl-Polymerase $(5 \mathrm{u} / \mu \mathrm{l})$

\section{Sigma, Deisenhofen}

$\alpha$-Rabbit IgG (whole molecule), Biotin-Konjugat (polyklonaler Anti-KaninchenAntikörper), $\alpha$-Mouse IgG (whole molecule), Biotin-Konjugat (polyklonaler AntiMaus-Antikörper), $\alpha$-Mouse IgG (whole molecule), Alkalische Phosphatase-Konjugat (polyklonaler Anti-Maus-Antikörper), Ponceau S

\subsection{Sonstige Materialien und Geräte}

\section{American National Can., Greenwich, CN., USA}

Parafilm "M" Laboratory Film

\section{Amersham Pharmacia / LKB, Freiburg}

Elektrophorese Stromversorger ECPS 3000/150, Novoblot Elektrophoretische Transferapparatur, AutoRead 1000 Sequencing Kit, Ultrospec II Spektralphotometer (LKB Biochrom)

\section{Ansell, München}

Puderfreie Einmal-Handschuhe 
Bender \& Hobein, Zürich, Schweiz

Vortex Genie 2

BioRad, München

Gene Pulser und Pulse Controller, Elektroporationsküvetten

Biozym, Hessisch Oldendorf

PCR-Tube ultradünn, 0,2 $\mathrm{ml}$

Branson Ultrasonics, Danbury, CT., USA

Sonifier Ultraschallstab und Steuereinheit

Coulter Corporation (Epics Division), Hialeah, FL., USA

EPICS Alignment Fluorespheres for optical alignment of flow cytometers, fluoreszierende MicroBeads

Cytomation Inc., Fort Collins, CO., USA

MoFlo Cytometer mit Cyclone Sortiereinheit, Fluorescence Activated Cell Sorter (FACS) mit Coherent Laser Enterprise II, CyClops Software-Paket

\section{Eppendorf-Netheler-Hinz, Hamburg}

Reaktionsgefäße $1,5 \mathrm{ml}$ (blau, grün, gelb, rot), Multipipette, Combitips für die Multipipette 0,5 ml, 1,25 ml, 2,5 $\mathrm{ml}, 12,5 \mathrm{ml}$

\section{Genomed, Bad Oeyenhausen}

JetStar Plasmid Midiprep Kit 2.0

Gilson, Middleton, WI., USA

Mikroliter-Pipetten, $1000 \mu \mathrm{l}, 200 \mu \mathrm{l}, 20 \mu \mathrm{l}$ und $10 \mu \mathrm{l}$

Hardware \& Service, Groß Schneen

Agarosegelkammern, Heizblock-Thermostate

Heinzinger, Rosenheim

Stromversorger LNGs 350-06

Helma, Müllheim/Baden

Quarzküvetten (0,5 $\mathrm{ml}$ und $2 \mathrm{ml}, 1 \mathrm{~cm}$ Schichtdicke)

\section{Heraeus, Hanau}

Mikrobiologische Brutschränke

Herolab, Wiesloch

UVT2035 302 nm UV-Leuchttisch

\section{Hettich Zentrifugen, Tuttlingen}

Kühlzentrifuge Mikro Rapid/K, Kühlzentrifuge Rotanta/RPC, Kühlzentrifuge Roto Silenta/RP, Kühlzentrifuge Rotixa/RP, Mikroliter-Tischzentrifuge

Hoefer Scientific, San Francisco, CA., USA

Platten für SDS-Gele, Midget-Apparatur

Infors HT, Bottmingen-Basel, Schweiz

Schüttelwasserbad, Inkubationsschüttler 
Ingold, Steinbach/Ts

pH-Elektrode U402-M5

Invitek, Berlin

Invisorp Spin Plasmid Mini Kit, Invisorp Spin DNA Extraction Kit, dNTP

IKA-Labortechnik, Staufen

beheizbarer Magnetrührer IKAMAG RCT

Knick, Berlin

pH-Meter 761 Calimatic

\section{Kontron, Eching}

Zweistrahl-Spektralphotometer Uvicon 930, Centrikon T-1055 Ultrazentrifuge + TST41-14 Schwenkbecherrotor, Ultrazentrifugenröhrchen

\section{Köttermann Labortechnik, Uetze/Hänigsen}

Wasserbad

\section{Li-Cor Biosciences, Lincoln, NE., USA}

DNA Sequencer Model 4000L und 4100L, incl. Softwarepaket BaseImagIR V2.21

\section{Machery \& Nagel, Düren}

Nucleotrap und NucleotrapCR Kit

\section{Menzel-Gläser, Braunschweig}

Objektträger (76 x 26 mM), Deckgläser (18 x 18 mM)

\section{Merck, Darmstadt}

pH-Indikator-Teststäbchen

\section{Millipore, Eschborn}

Filtereinheiten Millex FG13, Ultrafree-20 Nanopore-Wasser-Anlage

MJ Research, Waltham, MA., USA

DNA Thermal Mini-Cycler PTC-150

MWG Biotech, Ebersberg

Primus 96 Thermo-Cycler

Nalgene, Hereford, England

Cryoware Cryovial (2 ml-Röhrchen für Gefrierkulturen)

\section{Qiagen, Hilden}

OIAquick Gel Extraction Kit, OIAprep Spin Miniprep Kit

\section{Sarstedt, Nümbrecht}

Reaktionsgefäße $1,5 \mathrm{ml}$ und $2 \mathrm{ml}$, Petrischalen, Röhrchen $5 \mathrm{ml}$, Röhrchen $12 \mathrm{ml}$, Röhrchen $50 \mathrm{ml}$

\section{Sartorius, Göttingen}

Minisart NML Sterilfilter 0,2 $\mu \mathrm{m}$ und $0,45 \mu \mathrm{m}$, Sartorius Universal U 4800P Feinwaage

\section{Savant Instruments, Vaterstetten}




\section{Schleicher \& Schuell, Dassel}

Nitrozellulose-Membranen (0,45 $\mu \mathrm{m}), 3$ MM-Filterpapier (Whatman)

Schott, Mainz

Glaswaren

SLM Aminco, Rochester, NY., USA

French Pressure Cell Press, French Pressure Cell

\section{Sorvall, Bad Nauheim}

Zentrifuge RC-5C, Rotortypen SS34, HB-4 und GSA

\section{Terumo, Leuven, Belgien}

Syringe Spritzen, $5 \mathrm{ml}, 10 \mathrm{ml}, 30 \mathrm{ml}$

\section{Wissenschaftlich-Technische Werkstätten, Weilheim}

pH-Meter-522

\section{Zeiss, Oberkochen}

Mikroskop Axioskop mit Durchlicht- und Auflichtfluoreszenz (Filtersätze: 487902 und 487909) und Kameraaufsatz, Okulare: Vergrößerung 10 x, Sehfeldzahl 20, Objektive: Plan Neofluar 63 x/1,25 Oil, 440480, Plan Neofluar 100 x/1,25 Oil, 440460, Acroplan $20 \mathrm{x}, 440845$, Immersionsöl

\subsection{Zusammensetzung der Nährmedien}

\section{dYT-Medium}

$1 \%(w / v)$ Hefe-Extrakt, 1,6\% (w/v) Trypton, 0,5\% (w/v) $\mathrm{NaCl}$

\section{M9-Minimalmedium}

$7 \mathrm{~g} \mathrm{Na}_{2} \mathrm{HPO}_{4} \times 2 \mathrm{H}_{2} \mathrm{O}, 3 \mathrm{~g} \mathrm{K \textrm {K } _ { 2 }} \mathrm{PO}_{4}, 1 \mathrm{~g} \mathrm{NH} \mathrm{Nl}_{4} \mathrm{Cl} 2 \mathrm{O}$ ad $1000 \mathrm{ml}$. Komplettiert mit $25 \mathrm{ml} 20 \%$ (w/v) Glukose, $1 \mathrm{ml} 100 \mathrm{mM} \mathrm{CaCl}_{2}, 1 \mathrm{ml} 1 \mathrm{M} \mathrm{MgSO}_{4}, 5 \mathrm{ml} \mathrm{0,1} \mathrm{mM} \mathrm{FeCl}_{3}$, $1 \mathrm{ml} \mathrm{0,1 \% (w/v)} \mathrm{Thiamin,} \mathrm{jeweils} \mathrm{aus} \mathrm{sterilen} \mathrm{Lösungen} \mathrm{zugesetzt.}$

\section{LB-Medium}

$1 \%(w / v)$ Hefe-Extrakt, 0,5\% (w/v) Trypton, $1 \%(w / v) ~ N a C l$

Die Nährmedien wurden zur Sterilisation 20 min bei $120^{\circ} \mathrm{C}$ autoklaviert.

Für feste Medien wurden vor dem Autoklavieren 1,5\% (w/v) Agar Bacteriological (Oxoid) zugegeben.

Antibiotika wurden aus den entsprechenden 1000fach konzentrierten Stammlösungen bis zu einer Endkonzentration von $25 \mathrm{mg} / \mathrm{l}$ Chloramphenicol, $12,5 \mathrm{mg} / \mathrm{l}$ Tetrazyklin bzw. $75 \mathrm{mg} / \mathrm{l}$ Kanamycin zugegeben.

\subsection{Lösungen und Puffer}

\section{Alkalische Phosphatase-Puffer}

0,1 M Tris-HCl, pH 9,5, 0,1 M NaCl, 0,05 $\mathrm{M} \mathrm{MgCl}_{2}$

\section{APS-Stammlösung}

$10 \%$ APS in Wasser 
ATC-Stammlösung

$2 \mathrm{mg} / \mathrm{ml}$ Anhydrotetrazyklin in Dimethylformamid

BCIP-Stammlösung

$50 \mathrm{mg} / \mathrm{ml} \mathrm{BCIP}$ in Dimethylformamid

Blocking-Puffer

$5 \%$ BSA in PBS-Puffer

Calf Intestine Alkalische Phosphatase Puffer (10x)

0,1 M Tris- $\mathrm{HCl}, \mathrm{pH} 7,5,0,1 \mathrm{M} \mathrm{MgCl}_{2}$

Chloramphenicol-Stammlösung

$25 \mathrm{mg} / \mathrm{ml}$ Chloramphenicol in $96 \%$ Ethanol

dNTP-Stammlösung

je $100 \mathrm{mM}$ dNTP ( $\mathrm{N}=\mathrm{A}, \mathrm{C}, \mathrm{G}, \mathrm{T})$, mit $1 \mathrm{M}$ Tris-Base auf $\mathrm{pH}$ 7,0 eingestellt

dNTP-Stammlösung für die PCR

je $10 \mathrm{mM}$ dNTP (N = A, C, G, T), aus dNTP-Stammlösungen mit Wasser verdünnt

E1 (Jetstar 2.0 Plasmid Kit (Genomed))

50 mM Tris-HCl, pH 8,0, 10 mM EDTA, $100 \mu \mathrm{g} / \mathrm{ml}$ RNaseA

E2 (Jetstar 2.0 Plasmid Kit (Genomed))

$200 \mathrm{mM} \mathrm{NaOH}, 1 \%$ (w/v) SDS

E3 (Jetstar 2.0 Plasmid Kit (Genomed))

3,2 M Kaliumacetat-Essigsäure, pH 5,5

E4 (Jetstar 2.0 Plasmid Kit (Genomed))

$600 \mathrm{mM} \mathrm{NaCl}, 100$ mM Natriumacetat-Essigsäure, pH 5,0

E5 (Jetstar 2.0 Plasmid Kit (Genomed))

800 mM NaCl, 100 mM Natriumacetat-Essigsäure, pH 5,0

E6 (Jetstar 2.0 Plasmid Kit (Genomed))

$1,25 \mathrm{M} \mathrm{NaCl}, 100$ mM Tris-HCl, $\mathrm{pH}$ 8,5

Ethidiumbromid-Stammlösung (10x)

$10 \mathrm{mg} / \mathrm{ml}$ Ethidiumbromid

Formamid-Farbmarker

91,2 \% Formamid, 20 mM EDTA, pH 8,3, 0,15 mM Bromphenolblau

Hoechst-Puffer (nicht reduzierend)

8 M Harnstoff, 200 mM Tris-Base, $2 \%$ (w/v) SDS, 0,15 mM Bromphenolblau

Hoechst-Puffer (reduzierend)

8 M Harnstoff, 200 mM Tris-Base, $2 \%$ (w/v) SDS, 200 mM Dithiothreitol (DTT),

$0,15 \mathrm{mM}$ Bromphenolblau

IPTG-Stammlösung

1 M IPTG in Wasser, sterilfiltriert 


\section{Kanamycin-Stammlösung}

$75 \mathrm{mg} / \mathrm{ml}$ Kanamycin in Wasser

KGB-Puffer (10x)

1 M Kaliumglutamat, 250 mM Tris-Acetat, pH 7,5, 100 mM Magnesiumacetat, 5 mM $\beta$-Mercaptoethanol

\section{Laemmli-Puffer (Laufpuffer für die SDS-PAGE)}

25 mM Tris-HCl, 200 mM Glycin, 0,1 \% (w/v) SDS

\section{NBT-Stammlösung}

$75 \mathrm{mg} / \mathrm{ml} \mathrm{NBT}$ in Dimethylformamid

\section{Nucleotrap- und NucleotrapCR-Puffer (Macherey \& Nagel)}

Zusammensetzung der Puffer NT1, NT2, NT3, sowie der Nucleotrap- und NucleotrapCR-Suspension sind vom Hersteller nicht angegeben.

\section{PAG-Färbelösung}

50 \% (v/v) Methanol, 10 \% Essigsäure, 0,75 \% Coomassie Brillant Blue R

\section{PBS-Puffer}

$140 \mathrm{mM} \mathrm{NaCl}, 10 \mathrm{mM} \mathrm{KCl}, 6,4 \mathrm{mM} \mathrm{Na}_{2} \mathrm{HPO}_{4}, 2 \mathrm{mM} \mathrm{KH}_{2} \mathrm{PO}_{4}$

\section{PBST-Puffer}

$140 \mathrm{mM} \mathrm{NaCl}, 10 \mathrm{mM} \mathrm{KCl}, 6,4 \mathrm{mM} \mathrm{Na}_{2} \mathrm{HPO}_{4}, 2 \mathrm{mM} \mathrm{KH}_{2} \mathrm{PO}_{4}, 0,05$ \% (v/v) Tween 20

\section{Phenollösung (Grinsted \& Bennet, 1990)}

$500 \mathrm{~g}$ festes Phenol wurden in $130 \mathrm{ml}$ Wasser, 7,5 $\mathrm{ml} 2 \mathrm{~N} \mathrm{NaOH}$ und $6 \mathrm{ml} 1 \mathrm{M}$ Tris$\mathrm{HCl}$, pH 7,5 gelöst. Zum Schutz vor Oxidation wurde 8-Hydroxychinolin $(0,1 \%$ $(w / v))$ hinzugefügt und die Lösung lichtgeschützt in einer dunklen Flasche bei $4{ }^{\circ} \mathrm{C}$ gelagert. Die so präparierte Phenollösung wird im folgenden als Phenol, die Mischung aus je $50 \%$ (v/v) Phenollösung und Chloroform wird im Rahmen dieser Arbeit als Phenol/Chloroform bezeichnet.

\section{Phenol/TE}

Phenol p.A. mit TE-Puffer gesättigt, 0,1 \% (w/v) 8-Hydroxychinolin

\section{Phenol/Chloroform}

1 Vol Phenol/TE, 1 Vol Chloroform

\section{Ponceau S-Färbelösung}

$0,3 \%$ (w/v) Ponceau S (3-Hydroxy-4-(2-sulfo-4-(4-sulfophenylazo)-phenylazo)-2,7naphthalendisulfonsäure), $3 \%(\mathrm{w} / \mathrm{v})$ Trichloressigsäure, $3 \%(\mathrm{w} / \mathrm{v})$ Sulfosalicylsäure

\section{Protein-Probenpuffer}

62,5 mM Tris-HCl, pH 6,8, 10 \% (v/v) Glyzerin, 70 mM ß-Mercaptoethanol, 0,0025 \% (w/v) Bromphenolblau

\section{Reaktionspuffer für Restriktionsendonukleasen (MBI Fermentas)}

Blau: $\quad 10 \mathrm{mM}$ Tris- $\mathrm{HCl}, \mathrm{pH} 7,5,10 \mathrm{mM} \mathrm{MgCl}_{2}$

Grün: $10 \mathrm{mM}$ Tris-HCl, pH 7,5, $10 \mathrm{mM} \mathrm{MgCl}_{2}, 50 \mathrm{mM} \mathrm{NaCl}$

Orange: $50 \mathrm{mM}$ Tris- $\mathrm{HCl}, \mathrm{pH}$ 7,5, $10 \mathrm{mM} \mathrm{MgCl}_{2}, 100 \mathrm{mM} \mathrm{NaCl}$ 
Rot: $\quad 10 \mathrm{mM}$ Tris-HCl, pH 8,5, $10 \mathrm{mM} \mathrm{MgCl}_{2}, 100 \mathrm{mM} \mathrm{KCl}$

Gelb: $\quad 33$ mM Tris-Essigsäure, pH 7,9, 10 mM Magnesiumacetat, 66 mM Kaliumacetat

\section{Reaktionspuffer für Restriktionsendonukleasen (NEB)}

NEB1: $\quad 10 \mathrm{mM}$ Bis-Tris Propan-HCl, pH 7,0, 10 mM MgCl $2,1 \mathrm{mM} \mathrm{DTT}$

NEB2: $\quad 10 \mathrm{mM}$ Tris-HCl, $\mathrm{pH}$ 7,9, $10 \mathrm{mM} \mathrm{MgCl}_{2}, 50 \mathrm{mM} \mathrm{NaCl}, 1 \mathrm{mM}$ DTT

NEB3: $\quad 50$ mM Tris- $\mathrm{HCl}, \mathrm{pH}$ 7,9, $10 \mathrm{mM} \mathrm{MgCl} 2,100 \mathrm{mM} \mathrm{NaCl}, 1 \mathrm{mM}$ DTT

NEB4: 20 mM Tris-Essigsäure, pH 7,9, 10 mM Magnesiumacetat, 50 mM Kaliumacetat, $1 \mathrm{mM} \mathrm{DTT}$

\section{RNaseA-Stammlösung}

$10 \mathrm{mg} / \mathrm{ml}$ RNaseA, $10 \mathrm{mM}$ Tris- $\mathrm{HCl}, \mathrm{pH}$ 7,5, $15 \mathrm{mM} \mathrm{NaCl}, 20 \mathrm{~min}$ auf $100{ }^{\circ} \mathrm{C}$ erhitzt, langsam auf RT abgekühlt und bei $4^{\circ} \mathrm{C}$ gelagert

\section{Sammelgelpuffer für SDS-Polyacrylamidgele}

1,25 M Tris-HCl, $\mathrm{pH}$ 6,8

SSC (1x)

$150 \mathrm{mM} \mathrm{NaCl}, 15 \mathrm{mM}$ Tri-Na-Citrat, $\mathrm{pH}$ 7,0

\section{Sucrosefarbmarker}

$60 \%(\mathrm{w} / \mathrm{v})$ Sucrose, 0,1\% (w/v) Bromphenolblau, 0,1\% (w/v) Xylencyanol FF in 1x TAE

T4 DNA-Ligase-Puffer

$400 \mathrm{mM}$ Tris- $\mathrm{HCl}, \mathrm{pH} 7,8$ bei $25^{\circ} \mathrm{C}, 100 \mathrm{mM} \mathrm{MgCl}$, $100 \mathrm{mM}$ DTT, 5 mM ATP

T4 DNA-Polymerase-Puffer (5x)

335 mM Tris- $\mathrm{HCl}$, pH 8,8, $33 \mathrm{mM} \mathrm{MgCl}_{2}, 5 \mathrm{mM}$ DTT, $84 \mathrm{mM}\left(\mathrm{NH}_{4}\right)_{2} \mathrm{SO}_{4}$

\section{Taq DNA-Polymerase-Puffer / Taq-Puffer}

$50 \mathrm{mM} \mathrm{KCl}, 100$ mM Tris-HCl, pH 9,0, 15 mM MgCl 2,1 \% (w/v) Triton X 100

\section{TBE-Puffer}

89 mM Tris-Base, 89 mM Borsäure, 2,5 mM EDTA

\section{TE-Puffer}

10 mM Tris-HCl, 0,5 mM EDTA, pH 8,0, aus Stammlösungen zusammengestellt

Tfl DNA-Polymerase-Puffer (20x)

$1 \mathrm{M}$ Tris-HCl, pH 9,0, 400 mM Ammoniumsulfat, 30 mM MgCl 2

\section{Trenngelpuffer für SDS-Polyacrylamidgele}

1,875 M Tris- $\mathrm{HCl}, \mathrm{pH} 8,8$

\section{Tris-Puffer}

Tris(hydroxymethyl)-aminomethan in Wasser auflösen und den pH-Wert mit Säure einstellen. Für Tris-HCl wird Salzsäure, für Tris-Acetat wird Essigsäure verwendet. Der pH-Wert von Tris-Puffer kann mit normalen $\mathrm{pH}$-Elektroden nicht genau bestimmt werden, weswegen $\mathrm{pH}$-Indikatorpapier verwendet werden muss. 


\section{Western Blot-Transferpuffer}

25 mM Tris-HCl, 192 mM Glycin, 20 \% (v/v) Methanol

Alle Puffer und Lösungen wurden, soweit nicht anders angegeben, mit demineralisiertem Wasser (Millipore, Nanopore-Wasser-Anlage) angesetzt.

\subsection{Verwendete Computer-Software}

Windows NT, 2000, XP (Microsoft Corporation)

Office 97, 2000, Word 2002 (Microsoft Corporation)

Internet Explorer Version 5.0, 6.0 (Microsoft Corporation)

Netscape Communicator Version 4.51 (Netscape)

Acrobat Reader Version 5.0 (Adobe)

Vector NTI 5 (Demonstration Version) (Informax Inc.)

SigmaPlot 2000, Version 8.0 (Demonstration Version) (Jandel Software, SPSS Inc.)

Molmol Version 2K.2 (Reto Koradi)

Chromas 1.45 (Conor Mc Carthy, School of Health Science, Griffith University, Gold Coast Campus, Southport, Queensland, Australia)

Corel Draw 9.397 (Corel Corporation)

EndNote 6.0 (Trial Version) (Thomson ISI ResearchSoft) 


\section{Methoden}

\subsection{Handhabung von Bakterien}

\subsubsection{Lagerung von Escherichia coli}

Zur dauerhaften Lagerung der im Rahmen dieser Arbeit verwendeten Bakterienstämme wurden Glyzerinkulturen angelegt. Dazu wurde $1 \mathrm{ml}$ einer stationären Übernachtkultur des betreffenden Bakterienstammes mit $3 \mathrm{ml}$ durch Autoklavieren sterilisiertem Glyzerin versetzt und bei $-20^{\circ} \mathrm{C}$ in einem Schraubdeckelgefäß eingelagert. Bakterienstämme, die häufiger Verwendung fanden, wurden auf M9-Minimalmediumsplatten ausgestrichen und bei $37^{\circ} \mathrm{C}$ über Nacht kultiviert. In dieser Form konnten sie anschließend bei $4{ }^{\circ} \mathrm{C}$ für bis zu acht Wochen aufbewahrt werden.

\subsubsection{Vermehrung von Escherichia coli}

Alle verwendeten Escherichia coli-Stämme wurden, wenn nicht explizit anders spezifiziert, bei $37^{\circ} \mathrm{C}$ in dYT-Medium vermehrt. Im Falle von Plasmid-kodierter Resistenz wurden die Medien mit den entsprechenden Antibiotika aus sterilen Stammlösungen komplettiert. Bis zu einem Volumen von $5 \mathrm{ml}$ wurden die Kulturen zur Sicherstellung ausreichender Luftzufuhr unter Rollen in Kulturröhrchen inkubiert. Kulturen mit einem Volumen von bis zu $50 \mathrm{ml}$ wurden zu diesem Zweck in $100 \mathrm{ml}$ Erlenmeyerkolben bei 150 Upm unter einer Wärmehaube geschüttelt. Kulturen mit einem Volumen von $1.000 \mathrm{ml}$ wurden in der Regel mit $25 \mathrm{ml}$ einer Vorkultur in logarithmischer Wachstumsphase beimpft und bei ebenfalls $150 \mathrm{Upm}$ im temperierbaren Schüttel-Wasserbad inkubiert.

Die Zelldichte von Flüssigkulturen wurde durch Messung der Optischen Dichte bei $600 \mathrm{~nm}$ (O.D.600) photometrisch bestimmt. Gegebenfalls wurden die Kulturen mit sterilem dYTMedium bis zu einer O.D.600 von maximal 1 verdünnt.

\subsubsection{Transformation von Escherichia coli}

Zur Transformation von Escherichiacoli Zellen wurde standardmäßig nach der Elektroporationsmethode (Dower et al., 1988) verfahren. Zur Plasmid-Vermehrung und zur Vermehrung von durch Ligation von DNA-Fragmenten erzeugten Plasmiden wurden $50 \mathrm{ml}$ dYT-Medium mit Zellen des entsprechenden Bakterienstammes von einer M9-Minimalmediumsplatte inokuliert und diese bis zu einer O.D.600 von 0,4 bis maximal 0,6 vermehrt. Die Zellen wurden durch Zentrifugation in einem $50 \mathrm{ml}$ Schraubdeckelgefäß pelletiert (Hettich-Kühlzentrifuge Rotanta/RPC, $4000 \mathrm{Upm}, 10 \mathrm{~min}, 4^{\circ} \mathrm{C}$ ) und in $50 \mathrm{ml}$ eiskaltem, autoklaviertem demineralisierten Wasser durch wiederholtes Auf- und Abpipettieren aufgenommen und erneut unter denselben Bedingungen wie zuvor abzentrifugiert. Dieses Waschen der Zellen wurde zweimalig wiederholt, wobei bei der ersten Wiederholung in $40 \mathrm{ml}$, bei der zweiten in $30 \mathrm{ml}$ eiskaltem, sterilem demineralisierten Wasser resuspendiert wurde. Nach dem letzten Zentrifugationsschritt wurde der Überstand verworfen und die Zellen des Pellets in $200 \mu \mathrm{l}-400 \mu \mathrm{l}$ eiskaltem Wasser resuspendiert. Während der gesamten Prozedur wurden die Zellen auf Eis gelagert.

Zur Transformation wurden auf Eis 100-150 $\mu$ l der vorbereiteten Zellsuspension mit 0,5-4 $\mu \mathrm{l}$ DNA-Lösung versetzt und in eine vorgekühlte Elektroporationsküvette $(0,2 \mathrm{~cm}, \mathrm{Fa}$. BioRad) 
überführt. Der Vorgang der Elektroporation wurde mit Hilfe eines Gene Pulsers der Firma BioRad unter folgenden Bedingungen durchgeführt: Stromstärke $200 \mathrm{~mA}$, Spannung 2,5 V, Feldstärke $6250 \mathrm{~V} / \mathrm{cm}$, Impuls $5 \mathrm{~s}$, Zeitkonstante 4,0-4,5 ms, Raumtemperatur. Unmittelbar nach der Auslösung des Potentialpulses wurde $1 \mathrm{ml}$ steriles, Antibiotika-freies dYT-Medium in die Elektroporationsküvette hinzugegeben, der gesamte Inhalt in ein steriles 1,5 ml Reaktionsgefäß überführt und die Zellsuspension für eine Stunde bei $37^{\circ} \mathrm{C}$ inkubiert. Anschließend wurde der Ansatz unter anderem zur Bestimmung der Transformationsausbeute in Verdünnung auf selektive Vollmediums-Agarplatten ausgestrichen, bzw. es wurden mit diesem $50 \mathrm{ml}$ selektives dYT-Medium inokuliert.

\subsection{Molekularbiologische Arbeitsmethoden}

Molekularbiologische Arbeitstechniken, die im Folgenden nicht explizit aufgeführt und beschrieben sind, wurden nach Sambrook et al. (1989) durchgeführt.

\subsubsection{Vorbereitung von Geräten und Lösungen}

Hitzestabile Geräte wurden durch Erhitzen für 20 min auf $181^{\circ} \mathrm{C}$ sterilisiert. Hitzestabile Lösungen wurden für 20 min bei $121^{\circ} \mathrm{C}$ autoklaviert. In der Hitze nicht beständige Geräte wurden mit 70 \% (v/v) Ethanol gereinigt und getrocknet. Hitzelabile Bestandteile von Lösungen wurden als konzentrierte Stammlösungen hergestellt und vor der Zugabe zu bereits sterilen Lösungen mittels eines Membranfilters mit einer Porengröße von $0,2 \mu \mathrm{m}$ sterilfiltriert.

\subsubsection{Reinigung und Präzipitation von Nukleinsäuren}

\subsubsection{Alkoholische Präzipitation von DNA}

Zur Präzipitation von DNA in wässrigem Milieu wurde die DNA-haltige Lösung mit 1/10 Vol. 7 M Ammoniumacetatlösung sowie 3 Vol. 96 \% Ethanol versetzt und in der Regel $45 \mathrm{~min}$ bei $-20^{\circ} \mathrm{C}$ inkubiert. Es folgte eine Zentrifugation in der Kälte (13 $000 \mathrm{Upm}, 15 \mathrm{~min}$, $4{ }^{\circ} \mathrm{C}$ ). Das DNA-haltige Pellet wurde sodann mit 3 Vol. 70 \% (v/v) Ethanol gewaschen und die DNA erneut bei identischen Bedingungen pelletiert. Der Überstand wurde verworfen, eventuelle Reste von Ethanol und Ammoniumacetat wurden anschließend bei $37^{\circ} \mathrm{C}$ durch Abdampfen entfernt und auf diesem Wege das DNA-Pellet getrocknet. Die trockene DNA wurde danach bis zur gewünschten Konzentration in sterilem demineralisierten Wasser gelöst.

Gelegentlich wurde DNA anstelle mit Ethanol mit 2-Propanol präzipitiert, dies besonders um mit Blick auf nachfolgende sensible enzymatische Reaktionen die KoPräzipitation von Salzen zu minimieren. Bei einer Isopropanolfällung wurde die DNAhaltige Lösung mit 0,7 Vol. 2-Propanol versetzt. Wie auch nach einer Ethanolfällung wurde anschließend mit $70 \%$ (v/v) Ethanol gewaschen.

\subsubsection{Extraktion von DNA in wässrigen Lösungen mit Phenol, Phenol/Chloro- form oder Chloroform}

Zur Entfernung von Proteinen und hydrophoben Kontamination wie beispielsweise Ethidiumbromid diente die Extraktion von wässrigen DNA-Lösungen mit Phenol, 
Phenol/Chloroform und Chloroform. Die DNA-Lösung wurde aufeinander folgend mit 1 Vol. Phenol, 1 Vol. Phenol/Chloroform (1:1) und 1 Vol. Chloroform versetzt und gründlich gemischt. Um die zwei Phasen vollständig zu trennen, wurde der Ansatz zentrifugiert (13.000 Upm, $3 \mathrm{~min}, \mathrm{RT}$ ) und anschließend die Oberphase in ein neues Reaktionsgefäß überführt. Es folgten weitere Extraktionsschritte, zuletzt mit 1 Vol. Chlorofom, um Reste von Phenol zu entfernen, gefolgt von einer alkoholischen Präzipitation der DNA aus der wässrigen Phase.

\subsubsection{Agarosegelelektrophorese von Nukleinsäuren}

Die Auftrennung von DNA-Fragmenten wurde in Agarosegelen unterschiedlicher Größe und Konzentration ( $1 \%-2 \%(w / v)$ Agarose in $1 \times$ TBE-Puffer) durchgeführt. Kurze Fragmente wurden in höherprozentigen, lange Fragmente in niedrigprozentigen Gelen aufgetrennt. Gele für analytische Zwecke besaßen in der Regel eine Agarosekonzentration von $1 \%(w / v)$. Die Agarose wurde in 1 x TBE-Puffer bis zur vollständigen Lösung in einem Mikrowellenofen aufgekocht. Nach Abkühlen der Lösung auf ca. $65^{\circ} \mathrm{C}$ wurde zum späteren Fluoreszenznachweis von DNA in der Regel $0,5 \mu \mathrm{g} / \mathrm{ml}$ Ethidiumbromid zugesetzt. Gele wurden entweder in einer Gelschale $(125 \times 80 \times 7,5 \mathrm{~mm})$ oder im Falle von MiniGelkammern ( $100 \times 7 \times 0,5 \mathrm{~mm}$, Hardware \& Service) direkt in einen abgegrenzten Bereich der Elektrophoresekammer gegossen. Als Laufpuffer wurde ausschließlich das gesamte Gel bedeckender 1 xTBE-Puffer verwendet. Die aufzutrennenden Proben wurden mit mindestens 1/5 Vol. Sucrosefarbmarker versetzt und in die Geltaschen gegeben. Elektrophoresen wurden bei einer konstanten Spannung zwischen $40 \mathrm{~V}$ und maximal $130 \mathrm{~V}$ für 2060 min durchgeführt (5 bis $10 \mathrm{~V} / \mathrm{cm}$ Feldstärke). Die aufgetrennten DNA-Fragmente wurden im UV-Durchlicht (302 nm Wellenlänge) durch die Fluoreszenz des eingelagerten Ethidiumbromids sichtbar gemacht und dokumentiert. Zur Längen- und Konzentrationsbestimmung der DNA-Banden wurden DNA-Fragmentlängenstandards (DNA-Konzentration: $100 \mathrm{ng} / \mu \mathrm{l}$ ) parallel zu den Proben aufgetrennt.

\subsubsection{Reinigung von DNA aus Agarosegelen}

Zur Isolierung von DNA-Fragmenten aus Agarosegelen kamen kommerziell erhältliche Fertigprodukte unterschiedlicher Hersteller zum Einsatz. Explizit waren dies: das NucleotrapKit der Firma Macherey \& Nagel, das DNA Extraktions Kit der Firma Invitek sowie das QiaSpin Gel Extraktions Kit der Firma Qiagen. Die aus dem Gel aufzureinigenden DNAFragmente wurden möglichst ohne UV-Exposition auf dem UV-Durchlicht-Tisch mit Hilfe eines sauberen Skalpells ausgeschnitten, in ein 1,5 ml Reaktionsgefäß überführt und gewogen. Es folgte die von dem jeweiligen Hersteller angegebene Prozedur zur Reinigung der DNA aus dem Agarosegelstück. Letztendlich wurde die DNA in $50 \mu$ l autoklaviertem demineralisierten Wasser aufgenommen und für weitere Manipulationen eingesetzt.

\subsubsection{Abtrennung von Oligonukleotiden und kurzen DNA-Fragmenten mit Hilfe des NucleotraPCR-Kits (Macherey \& Nagel)}

Um aus einer komplexen DNA-Lösung Salze, Mononukleotide sowie kurze DNAFragmente (z.B. Oligonukleotide aus einer PCR) zu entfernen, wurde das NucleotrapCR-Kit der Firma Macherey \& Nagel eingesetzt. Die NucleotrapCR-Suspension schließt dabei DNA- 
Fragmente mit einer Größe von bis zu 150 bp von der Sorption aus. Das Volumen der DNAhaltigen Lösung wurde mit Wasser auf ein Volumen von $100 \mu \mathrm{l}$ aufgefüllt und die Lösung einer Extraktion mit Chloroform unterzogen. Anschließend wurde nach dem "direct purification"-Protokoll des Herstellers verfahren und im letzten Schritt des Protokolls die gereinigte DNA mit $50 \mu \mathrm{l}$ Wasser eluiert.

\subsubsection{Isolierung von Plasmid-DNA}

Zur Isolierung von Plasmid-DNA im präparativen Maßstab kam das JetStar Plasmidpräparations Kit der Firma Genomed zum Einsatz, welches auf der alkalischen Lyse von Bakterienzellen beruht. Zellen einer stationären $50 \mathrm{ml}$ Übernachtkultur in dYT-Medium wurden in einem $50 \mathrm{ml}$ Röhrchen pelletiert (Hettich-Kühlzentrifuge Rotanta/RPC, $4.000 \mathrm{Upm}, 10 \mathrm{~min}, \mathrm{RT})$. Der Überstand wurde verworfen und das Zellpellet entlang der Vorschrift des Herstellers aufgearbeitet. Die präparierte Plasmid-DNA wurde in der Regel in $200 \mu \mathrm{l}$ sterilem demineralisierten Wasser aufgenommen. Es folgte die photometrische Bestimmung des DNA-Gehaltes der Lösung durch Messung der Absorption bei $260 \mathrm{~nm}$.

Die Präparation von Plasmid-DNA im analytischen Maßstab wurde mit Hilfe des Plasmid Miniprep Kits der Firma Invitek durchgeführt. Hier wurde in der Regel von $2 \mathrm{ml}$ einer stationären Übernachtkultur ausgegangen. Es wurde streng nach der Vorschrift des Herstellers verfahren und am Ende des Protokolls in einem Volumen von $50 \mu$ l sterilem demineralisierten Wasser Plasmid-DNA erhalten.

\subsubsection{Bestimmung der Konzentration von DNA in wässrigen Lösungen}

Die Konzentration einer wässrigen Lösung von Nukleinsäuren wurde aus der Messung der Absorption einer entsprechenden Verdünnung bei $260 \mathrm{~nm}$ nach dem Lambert-Beerschen Gesetz bestimmt. Die Messung wurde gegen Wasser in einer Quarzküvette mit einer Schichtdicke von $1 \mathrm{~cm}$ durchgeführt. Eine $\mathrm{O}_{\text {.D.260 }}$ von 1 entspricht dabei einer Konzentration von $50 \mu \mathrm{g}$ dsDNA / ml. Es wurde in der Regel eine 200 fache Verdünnung der Lösung in einem Endvolumen von $1 \mathrm{ml}$ hergestellt und photometrisch vermessen (Zweistrahl-Spektralphotometer Uvicon 930, Fa. Kontron). Durch zusätzliche Messung der Absorption bei $280 \mathrm{~nm}$ Wellenlänge konnte über den Vergleich der beiden Messwerte eine Aussage über die Reinheit der Nukleinsäurelösung gemacht werden. In proteinfreien Proben liegt der Quotient von O.D.260 / O.D.280 bei 2.

\subsection{Enzymatische Manipulation von DNA}

\subsubsection{Klonierung von DNA-Fragmenten in Escherichia coli}

Unter einer Klonierung versteht man die Neukombination eines zu klonierenden DNAFragments mit einem in einem Wirtsorganismus replizierbaren Vektor zum Zwecke der Amplifikation des daraus hervorgehenden Plasmidkonstruktes. Im Rahmen dieser Arbeit kamen als Wirtsorganismus ausschließlich Stämme von Escherichia coli zur Anwendung. Das klonierte DNA-Fragment kann so beispielsweise in einen DNA-Kontext gesetzt werden, welcher eine solitäre Expression oder eine Expression in Fusion mit im Vektorfragment vorliegenden DNA-Bereichen in einer Wirtszelle bewirkt. Wichtige Elemente des Vektoranteils sind - neben mindestens einem Replikationsursprung für die Amplifikation in 
mindestens einer Spezies Wirtsorganismus - zur Selektion auf das Vorhandensein des Plasmids in der Wirtszelle ein dieser eine Resistenz gegen ein Antibiotikum vermittelndes exprimierbares Gen sowie fallweise für die Expression des zu klonierenden DNA-Fragments eine Promotor/Operator Region zur Bindung der Transkriptions-ausführenden und regulierenden zellulären Komponenten. Die Klonierung erfolgt in den meisten Fällen über sowohl das zu klonierende DNA-Fragment flankierende als auch an geeigneter Stelle im Vektorfragment vorkommende Erkennungs- und Spaltstellen von Restriktionsendonukleasen und hat in der Regel folgende Arbeitsschritte zum Inhalt:

1. Amplifikation von Vektor-Plasmiden in diesem Falle in Zellen von Escherichia coli und Isolierung derselben durch Aufschluss und Affinitätsreinigung (Methode 5.2.6),

2. Bereitstellung der zu klonierenden DNA-Fragmente z.B. durch PCR-Amplifikation mit spezifischen Oligodesoxyribonukleotiden (Methode 5.3.5) oder, sofern der betreffende Abschnitt bereits kloniert in einem Plasmid vorliegt, ebenfalls durch Amplifikation des betreffenden Plasmids in Escherichia coli und Isolierung desselben durch Aufschluss und Affinitätsreinigung (siehe oben 1.),

3. Spaltung des Vektorfragments mit geeigneten Restriktionsendonukleasen; Spaltung des amplifizierten Insert-Bereichs mit entsprechenden Restriktionsendonukleasen (Methode 5.3.2),

4. Fallweise Auftrennung der gewünschten Fragmente in und Isolierung derselben aus Agarosegelen (Methode 5.2.3) sowie deren Reinigung z.B. durch Affinitätschromatographie (Methode 5.2.4),

5. Kovalente Verknüpfung von Vektor- und Insert-Fragment über die kompatiblen Doppelstrangenden mit Hilfe von T4 DNA-Ligase (Methode 5.3.4),

6. Transformation von Zellen des gewünschten Wirtsstammes mit den Ligationsprodukten durch Elektroporation (Methode 5.1.3),

7. Selektion von Transformanten durch Koloniewachstum auf selektivem, Antibiotikum enthaltenden Medium,

8. Identifizierung von Klonen mit gewünschter Vektor-Insert Verknüpfung durch Kolonie-PCR-Screening (Methode 5.3.5), Testspaltung nach Plasmidisolierung (Methoden 5.3.2 und 5.2.6) und anschließende Sequenzierung des relevanten Plasmidbereichs (Methode 5.3.6).

\subsubsection{Spaltung von DNA mit Restriktionsendonukleasen}

DNA aus PCR-Ansätzen (5.3.5) sowie Plasmid-DNA wurde mit Restriktionsendonukleasen unter den vom jeweiligen Hersteller des Enzyms empfohlenen Temperatur- und Pufferbedingungen gespalten. Gleichzeitige Spaltungen mit mehreren Enzymen wurden unter den Pufferbedingungen durchgeführt, die laut Hersteller zu einer mindestens 50 \%igen bis $100 \%$-igen Spaltaktivität der Endonukleasen Anlass gaben. War eine Doppelspaltung wegen Inkompatibilität der Enzyme in den mitgelieferten Puffern nicht möglich, wurden die Spaltungen nacheinander unter den vom Hersteller der Enzyme empfohlenen Bedingungen durchgeführt, alternativ wurde KGB-Puffer verwendet. In diesem Puffer zeigen 
fast alle Restriktionsendonukleasen bei den empfohlenen Konzentrationen eine gute Aktivität (Sambrook et al., 1989). Die DNA wurde in der Regel in einer Endkonzentration des Spaltungsansatzes von $100 \mathrm{ng} / \mu 1$ mit 1 - 2 Einheiten Enzym pro Mikrogramm DNA für $1 \mathrm{~h}$ inkubiert. Längeren Inkubationszeiten wurde mit einer Verringerung der Enzymmenge begegnet.

\subsubsection{Auffüllen überhängender DNA-Enden}

Zum Auffüllen von beispielsweise nach Spaltung mit Restriktionsendonukleasen entstehenden überhängenden DNA-Enden wurde T4 DNA-Polymerase verwendet. Die Reaktion wurde bei Raumtemperatur und in Anwesenheit von $250 \mu \mathrm{M}$ dNTPs durchgeführt. Nach 30 min wurde die Auffüllreaktion durch Extraktion der T4 DNAPolymerase mit Phenol/Chloroform beendet.

\subsubsection{Ligation von DNA-Fragmenten}

Die Ligation von DNA-Fragmenten zu einem zirkulären Ligationsprodukt wurde mit einem bis zu fünffachen molaren Überschuss an DNA-Insert-Fragment gegenüber dem DNA-Vektor-Fragment durchgeführt. Verwendet wurde T4 DNA-Ligase-Puffer aus einer fünffach konzentrierten Stammlösung und ca. 2 u T4 DNA-Ligase in einem ProbenEndvolumen von 30 - $50 \mu$ l. Die Reaktion erfolgte in der Regel durch Inkubation über Nacht bei $15^{\circ} \mathrm{C}$. Die ligierte DNA wurde vor einem Einsatz zur Transformation von E. coli-Zellen einmalig mit Chloroform extrahiert (5.2.2.2) und mittels Ethanol präzipitiert (5.2.2.1).

\subsubsection{Polymerase-Kettenreaktion (PCR) (Mullis \& Faloona, 1987; Saiki et al., 1988)}

Mit Hilfe der Polymerase-Kettenreaktion ist es möglich, DNA-Fragmente enzymatisch zu amplifizieren und so auch aus einem komplexen DNA-Gemisch heraus selektiv eine definierte DNA-Matrize spezifisch $z u$ vervielfachen. Im ersten Schritt wird die doppelsträngige DNA-Vorlage durch Erhitzen in einzelsträngige DNA überführt (Denaturierung). Beim Absenken der Temperatur lagern sich zwei im Überschuss angebotene Oligodesoxyribonukleotid-Primer an die Matritzen-DNA an (PrimerHybridisierung) und flankieren die zu amplifizierende komplementäre Zielregion. Die Primer werden mit Hilfe einer thermostabilen DNA-Polymerase komplementär zur ursprünglichen Duplex-DNA verlängert (Primer-Extension). Es wird eine bestimmte Anzahl an Amplifikationszyklen durchgeführt, wodurch sich die durch die beiden Primer flankierte DNA-Region in dem Ansatz akkumuliert.

Die PCR-Bedingungen wurden je nach Länge der zu amplifizierenden Sequenz sowie der Länge und des G/C-Gehaltes der verwendeten spezifischen Primer angepasst. Die Reaktionen wurden in einem Gesamtvolumen von $50 \mu$ l durchgeführt. Als Matrize wurden in der Regel zwischen fünf und $25 \mathrm{ng}$ DNA eingesetzt. Des weiteren enthielten die Ansätze $10 \mathrm{pmol}$ eines jeden Primers, $200 \mu \mathrm{M}$ jedes dNTPs, 2,5 $\mu \mathrm{l}$ Tfl DNA-Polymerase-Puffer (20x), $2 \mathrm{mM}$ $\mathrm{MgCl}_{2}$ und $1 \mathrm{u}$ Tfl DNA-Polymerase. Zum Schutz vor Verringerung des Reaktionsvolumens durch Verdampfen von Wasser aus den Ansätzen wurden diese mit $25 \mu$ l Chill Out 14 Flüssigwachs (Fa. Biozym) oder Paraffin überschichtet. Die Länge und die Temperatur der einzelnen Reaktionsschritte der PCR-Zyklen, sowie deren Anzahl wurde durch die Wahl der 
Matrize, die Basenzusammensetzung und Länge der Primer, sowie durch die Länge der zu amplifizierenden Sequenz bestimmt. Die Denaturierungsphase erfolgte für 2 min bei $98^{\circ} \mathrm{C}$. Bei sich anschließenden $85^{\circ} \mathrm{C}$ wurde die Tfl DNA-Polymerase hinzugegeben und der erste Zyklus der PCR gestartet (hot start). Die zyklische Denaturierung erfolgte in der Regel für $30 \mathrm{~s}$ bei $94^{\circ} \mathrm{C}$, gefolgt von der Primer-Hybridisierung mit einer Dauer von in der Regel ebenfalls $30 \mathrm{~s}$ bei der für das jeweilige Primer-Paar charakteristischen Temperatur. Die Elongationsreaktion (Primer-Verlängerung) wurde bei $72{ }^{\circ} \mathrm{C}$ für $30 \mathrm{~s}$ pro $1.000 \mathrm{bp}$ durchgeführt. Die Anzahl der Zyklen betrug zwischen 25 und 30. Die Schmelztemperatur $T_{M}$ eines Oligodesoxyribonukleotids wurde nach folgender empirischer Formel (1) berechnet, welche sowohl den relativen G/C-Gehalt (\% G/C) als auch die Länge der Primer ( $n$ ) mit einbezieht:

$$
T_{M}\left[{ }^{\circ} \mathrm{C}\right]=69,3+0,41 \cdot(\% \mathrm{G} / \mathrm{C})-\frac{650}{n}
$$

Die errechnete Temperatur lag in der Regel zwischen $45^{\circ} \mathrm{C}$ und $60^{\circ} \mathrm{C}$. Die optimale Hybridisierungs-Temperatur $T_{A}$ für die Durchführung einer PCR wurde nach (2) bestimmt, sofern die nach (1) errechneten Temperaturen nicht mehr als $10^{\circ} \mathrm{C}$ voneinander abwichen. $T_{M_{1}}$ und $T_{M_{2}}$ stehen dabei für die Schmelztemperaturen der beiden verwendeten Primer.

$$
T_{A}=\frac{\left(T_{M 1}+T_{M 2}\right)}{2}-3^{\circ} \mathrm{C}
$$

Differierten die nach (1) errechneten Temperaturen um mehr als $10^{\circ} \mathrm{C}$ wurde ausschließlich der geringere Wert als Variable $T_{M^{\prime}}$ bzw. $T_{M_{2}}$ in (2) eingesetzt.

Zur direkten Amplifikation von DNA-Bereichen aus Bakterienzellen kam eine modifizierte PCR zur Anwendung ("Kolonie-PCR"). Mit dieser Methode kann schnell und eindeutig das Vorhandensein eines definierten Plasmid-Abschnitts in Bakterienklonen direkt nachgewiesen werden. In PCR-Gefäßen $(0,2 \mathrm{ml})$ wurden $25 \mu \mathrm{l}$ Taq DNA-Polymerase-Puffer vorgelegt. Mit einem sterilen Zahnstocher wurden Zellen aus einer Bakterienkolonie aufgenommen, einfach auf einer Mediumsplatte ausgestrichen und die restlichen Zellen in dem PCR-Gefäß resuspendiert. Die Bakteriensuspension wurde in die PCR-Maschine gestellt, die übrigen Agenzien wurden in Form eines Master-Mixes zusammengegeben und der Ansatz wurde mit $25 \mu$ l Chill out 14 Flüssigwachs oder Paraffin überschichtet. Für zehn PCR-Reaktionen wurden $2 \mu \mathrm{l}$ Taq DNA-Polymerase (wurde aus einer Präparation innerhalb der Abteilung bereitgestellt, eine Konzentrationsangabe ist deshalb nicht möglich), $30 \mu \mathrm{l}$ 10 x Taq DNA-Polymerase-Puffer , $10 \mu \mathrm{l}$ dNTPs (je $10 \mathrm{mM}$ ), jeweils 50 pmol der zu verwendenden Primer und Wasser bis auf $300 \mu \mathrm{l}$ zusammengegeben. Folgendes PCRProgramm kam zur Anwendung: 2 min $98^{\circ} \mathrm{C}$, Zugabe von $25 \mu \mathrm{l}$ Master-Mix bei $85^{\circ} \mathrm{C}, 30$ Zyklen mit $30 \mathrm{~s} 94^{\circ} \mathrm{C}, 30 \mathrm{~s}$ spezifische Hybridisierungstemperatur, $1 \mathrm{~min} / \mathrm{kb} 72{ }^{\circ} \mathrm{C}$, danach Abkühlung auf $4^{\circ} \mathrm{C}$. Die Hybridisierungstemperatur wurde wie oben beschrieben ermittelt. Der Erfolg der "Kolonie-PCR" wurde auf einem Agarosegel bestimmt (5.2.3).

\subsubsection{DNA-Sequenzbestimmung}

Für die durchgeführten Sequenzierungen wurden ausschließlich $45 \mathrm{~cm}$ lange Sequenziergele hergestellt. Die Gießkammer für Gele dieser Art wurde aus zwei Glasplatten, zwei Spacern und zwei Halterungen zusammengebaut. Dabei wurden die Glasplatten zuerst 
mit demineralisiertem Wasser gewaschen und danach mit 2-Propanol behandelt, um eine staub- und fettfreie, glatte Oberfläche zu gewährleisten. In einem Becherglas wurden $30 \mathrm{ml}$ SequagelXR, 7,5 ml Sequagel Complete, $3 \mathrm{ml}$ Protogel und $400 \mu \mathrm{l}$ DMSO vermischt. Zum Start der Polymerisation wurden $300 \mu \mathrm{l}$ APS-Stammlösung untergemischt, und der Inhalt des Becherglases wurde mittels einer Spritze zwischen die beiden Glasscheiben gegeben. Das Gel wurde mit einem Taschenkamm versehen und die Andruckplatte eingespannt. Das Gel wurde in der Horizontalen bis zur vollständigen Polymerisation gelagert. Zur Sequenzbestimmung wurde das Gel in einen $\mathrm{Li}$-Cor DNA-Sequenzierautomaten (Fa. MWG Biotech) eingesetzt. Die beiden Pufferkammern wurden mit $1 \mathrm{x}$ TBE-Puffer bis zu den Markierungen gefüllt, die Elektroden aufgesetzt, und es wurde ein Vorlauf des Gels von 60 min Dauer gestartet, um das Elektrophoresesystem zu äquilibrieren und das Gel auf die vorgesehenen $50^{\circ} \mathrm{C}$ zu erhitzen. Die Laufbedingungen für sowohl Vor- als auch Hauptlauf waren: $1500 \mathrm{~V}, 37 \mathrm{~mA}, 50 \mathrm{~W}, 50^{\circ} \mathrm{C}$. Während des Vorlaufes wurden Laser und Optik des Sequenzier-Automaten auf das Gel abgestimmt und nach Beendigung des Vorlaufes die Proben aufgetragen. Der Hauptlauf wurde nach einigen Stunden automatisch beendet. Die Sequenzauswertung erfolgte entweder manuell oder mit Hilfe des Softwarepakets BaseImagIR V.2.21.

Zusätzlich zur Sequenzierung mit dem Li-Cor DNA-Sequenzierautomaten wurde gegen Ende der praktischen Arbeit verschiedentlich der Sequenzier-Service des Göttingen Genomics Laboratory $\left(\mathrm{G}_{2} \mathrm{~L}\right)$ in Anspruch genommen. Die Auswertung der erhaltenen Sequenzinformation erfolgte in diesem Fall mittels des Chromas Sequenzanalyseprogramms.

\subsection{Proteinchemische Arbeitsmethoden}

\subsubsection{Bestimmung der Konzentration von Proteinen in einer wässrigen Lösung}

Die Proteinkonzentration einer wässrigen Proteinlösung wurde spektroskopisch bestimmt. Die Absorption von Licht einer Wellenlänge von 280 nm (O.D.280) dient dabei als eine charakteristische Größe. Eine O.D.280 von 1 entspricht in etwa einer Proteinkonzentration von $1 \mathrm{mg} / \mathrm{ml}$. Als Referenzwert wurde das Lösungsmittel vermessen. Die Proteinlösungen wurden jeweils soweit verdünnt, dass die gemessene Optische Dichte einen Wert von 1 in keinem Fall überschritt. An der Optischen Dichte von Proteinen sind die aromatischen Reste der Aminosäuren maßgeblich beteiligt. Tryptophanreste alleine führen zu einer molaren Extinktion bei $280 \mathrm{~nm}$ von $5.500 \mathrm{M}^{-1} \mathrm{~cm}^{-1}$, gefolgt von Tyrosin-Resten mit einem molaren Extinktionskoeffizienten von $1.490 \mathrm{M}^{-1} \mathrm{~cm}^{-1}$. Einen nur geringen Anteil besitzen Disulfidbrücken mit einer Extinktion bei $280 \mathrm{~nm}$ von $125 \mathrm{M}^{-1} \mathrm{~cm}^{-1}$. Aus diesen Vorgaben ergibt sich ein molarer Extinktionskoeffizient für ein Protein aus der Anzahl seiner Tryptophan- und Tyrosinreste, sowie der Anzahl an Disulfidbrücken. Zusammengefasst lässt sich der molare Extinktionskoeffizient durch folgende Gleichung (3) berechnen (Pace et al., 1995):

$$
\mathcal{E}(\text { Protein })=5500 *\left[\sum \operatorname{Trp}\right]+1490 *\left[\sum \text { Tyr }\right]+125 *\left[\sum \text { Disulfid }\right]
$$

Bovines Trypsin mit 4 Tryptophanresten, 10 Tyrosinresten und 6 Disulfidbrücken besitzt somit beispielsweise einen molaren Extinktionskoeffizienten von $37.650 \mathrm{M}^{-1} \mathrm{~cm}^{-1}$. 


\subsubsection{Präparation von Proteinen der äußeren Membran von Escherichia coli-Zellen (verändert nach Klauser et al., 1992)}

Zur Gewinnung der Proteinenfraktion der äußeren Membran von Escherichia coli wurden die in der logarithmischen Wachstumsphase befindlichen Bakterienzellen einer $50 \mathrm{ml}$ Kultur bei einer O.D. 600 von 0,8 mit Induktor (z.B. Anhydrotetrazyklin) versetzt, weitere drei Stunden bei $37^{\circ} \mathrm{C}$ kultiviert und schließlich durch Zentrifugation geerntet (HettichKühlzentrifuge Rotanta/RPC, $4000 \mathrm{Upm}, 10 \mathrm{~min}, \mathrm{RT}$ ). Das Zellpellet wurde in $7 \mathrm{ml}$ PBS resuspendiert, und die Zellen wurden mittels einer French Press (SLM Aminco, 1000 psi, große Zelle, 1-2 Passagen) aufgeschlossen. Das so erhaltene Lysat wurde in einem $50 \mathrm{ml}$ Röhrchen für $10 \mathrm{~min}$ bei $4000 \mathrm{Upm}$ und $4{ }^{\circ} \mathrm{C}$ zentrifugiert, um noch intakte Zellen zu entfernen. Der Überstand wurde mit $100 \mathrm{mM}$ Tris/Cl pH 8,0, $10 \mathrm{mM}$ EDTA, 1 \% (v/v) Triton-X 100 (Endkonzentrationen) versetzt und der Ansatz für 30 min auf Eis inkubiert. Anschließend wurde die Lösung in ein $13 \mathrm{ml}$ Ultrazentrifugenröhrchen überführt, das Röhrchen gegebenenfalls mit PBS aufgefüllt und der Ansatz mit Paraffin überschichtet. Das Röhrchen wurde tariert in den TST41-14-Schwenkbecherrotor geladen und in der Kontron Centrikon T-1055 Ultrazentrifuge im Vakuum zentrifugiert $\left(100.000 \mathrm{~g}, 2 \mathrm{~h}, 15^{\circ} \mathrm{C}\right)$. Die im Pellet vorliegenden Proteine der äußeren Membran wurden mit $200 \mu$ l Protein-Probenpuffer oder Hoechst-Puffer versetzt und zwecks Lösung mit Ultraschall (Branson Sonifier W-250, 10 $15 \mathrm{mal}, 40 \%$, Stufe 2) behandelt und anschließend für $10 \mathrm{~min}$ auf $100^{\circ} \mathrm{C}$ erhitzt. Danach wurde zentrifugiert $\left(13.000 \mathrm{Upm}, 5 \mathrm{~min}, 4^{\circ} \mathrm{C}\right)$, der Überstand wurde in ein neues Reagenzgefäß überführt und an dieser Stelle gegebenenfalls bei $-20^{\circ} \mathrm{C}$ aufbewahrt. Unmittelbar vor der gelelektrophoretischen Analyse wurde ein Aliquot der Probe erneut für 10 min auf $100{ }^{\circ} \mathrm{C}$ erhitzt und maximal $20 \mu \mathrm{l}$ des Ansatzes auf ein Polyacrylamidgel aufgetragen.

\subsubsection{Denaturierende Polyacrylamidgelelektrophorese (SDS-PAGE)}

Proteine lassen sich unter denaturierenden Bedingungen über SDS-haltige Polyacrylamidgele der Größe nach auftrennen (Laemmli, 1970). Die hergestellten Gele hatten eine Größe von 100 × 60 × 0,75 mm. Es wurden ausschließlich 12,5\% ige (w/v) SDS-Polyacrylamidgele verwendet.

\subsubsection{Herstellung 12,5\% iger (v/v) Polyacrylamidgele}

In dem verwendeten Gelgießstand wurden in der Regel 10 Polyacrylamidgele gleichzeitig hergestellt. Die Gele wurden zwischen eine Aluminiumoxid- und eine Glasplatte gegossen. Für das Trenngel wurden 17,3 ml $30 \%$ (w/v) Acrylamid, 0,8 \% (w/v) Bisacrylamid (Protogel), 13,5 ml Trenngelpuffer, $675 \mu \mathrm{l} 20 \%$ (w/v) SDS, 24,9 ml Wasser, $34 \mu \mathrm{l}$ TEMED und zuletzt $225 \mu$ l APS-Stammlösung vereinigt und bis zu einer Höhe von ca. $5 \mathrm{~cm}$ in den Gelgießstand gegossen. Jedes Gel wurde mit $500 \mu 196 \%$ Ethanol überschichtet. Nach vollständiger Polymerisation des Acrylamids wurde das Ethanol mit demineralisiertem Wasser vollständig von den Gelen entfernt. Für das verwendete Sammelgel wurden $4 \mathrm{ml}$ $30 \%(\mathrm{w} / \mathrm{v})$ Acrylamid, 0,8\%(w/v) Bisacrylamid (Protogel), 2,625 ml Sammelgelpuffer, $263 \mu \mathrm{l} 20 \%$ (w/v) SDS, 18,9 ml Wasser, $26 \mu \mathrm{l}$ TEMED und zuletzt $90 \mu \mathrm{l}$ APS-Stammlösung zusammengegeben. Jedes Gel wurde bis zur Oberkante des Gelgießstands befüllt, zuletzt wurden die Taschenkämme eingebracht. Nach vollständiger Polymerisation wurden die Gele 
aus dem Gelgießstand entfernt, einzeln in mit demineralisiertem Wasser befeuchtete Papiertücher eingeschlagen und gemeinsam in Plastiktüten verpackt. In dieser Form wurden die Gele für maximal einige Wochen bei $4{ }^{\circ} \mathrm{C}$ gelagert.

\subsubsection{Durchführung der SDS-Polyacrylamidgelelektrophorese}

Das Polyacrylamidgel wurde in der Laufkammer befestigt und der Taschenkamm entfernt. Die obere und die untere Kammer wurden mit Laemmli-Puffer befüllt und die Proben wurden, mit 1/2 bis 1 Vol Protein-Probenpuffer versetzt, in die Geltaschen gefüllt. Als Protein-Molekulargewichtsstandard dienten der 'low-range' Protein-Standard der Firma BioRad bzw. die Protein Ladder der Firma MBI Fermentas. Die Elektroden wurden mit der Stromversorgung verbunden. Die Elektrophorese wurde bis zum Durchlauf der Farbmarkerbande konstant bei 6 W Leistung durchgeführt.

\subsubsection{Entwicklung eines SDS-Polyacrylamidgels}

Zum Sichtbarmachen von Proteinbanden in einem Polyacrylamidgel wurde dieses in einer Schale mit einer Lösung aus $10 \mathrm{ml}$ PAG-Färbelösung und $10 \mathrm{ml} 30$ \% (v/v) Essigsäure 15 min bei Raumtemperatur unter leichtem Schütteln eingefärbt. Zum Entfärben wurde das Gel zweimalig für 4 min in einem Mikrowellengerät mit Wasser bedeckt gekocht.

\subsubsection{Biochemischer Nachweis von $\beta$-Laktamase}

Zum Nachweis von $\beta$-Laktamase in einem Proteinpräparationsansatz wurde das $\beta$-Laktamase-Substrat PADAC (Fa. Calbiochem) verwendet. Dieses Substrat besitzt eine intensiv-rote Farbe, welche nach Umsatz durch $\beta$-Laktamase in eine gelbe Färbung übergeht. Zum Nachweis von $\beta$-Laktamase in einem Präparationsansatz wurden $50 \mu$ l Proteinlösung mit $1 \mu \mathrm{l}$ einer PADAC Stammlösung $(10 \mathrm{mg} / \mathrm{ml})$ versetzt. Nach wenigen Sekunden konnte bei Anwesenheit von $\beta$-Laktamase in dem untersuchten Ansatz ein Umschlag von rot nach gelb beobachtet werden.

\subsubsection{Nachweis von Proteinen auf Nitrozellulose-Membranen (Western Blot)}

Zum Nachweis von auf SDS-Polyacrylamidgelen aufgetrennten Proteinen wurden diese mittels Elektrotransfer auf eine Nitrozellulosemembran übertragen (Westermeier, 1990). Hierzu wurde ein Filterpapier (Fa. Schleicher \& Schuell) in der Größe des Polyacrylamidgels mit Western Blot-Transferpuffer getränkt und auf die Graphitanode einer Transfer-Apparatur (Novoblot, Fa. Amersham Biosciences) gelegt. Auf das Filterpapier wurde eine auf Gelgröße zugeschnittene Nitrozellulosemembran (Fa. Schleicher \& Schuell) aufgebracht, welche zuvor ebenfalls mit Western Blot-Transferpuffer getränkt worden war. Das Proteine enthaltende Polyacrylamidgel wurde in Western Blot-Transferpuffer geschwenkt und im feuchten Zustand auf die Nitrozellulose gebettet. Ein weiteres Filterpapier wurde, ebenfalls getränkt, darauf gelegt. Es folgten das Aufsetzen der Kathode und der Elektrotransfer der Proteine auf die Membran. Die Proteine wurden für $1 \mathrm{~h}$ bei einer konstanten Spannung von $10 \mathrm{~V}$ aus dem Gel auf die Nitrozellulose transferiert. Nach dem Transfer wurde die Membran für 3 min mit Ponceau S-Färbelösung inkubiert und danach kurz in demineralisiertem Wasser geschwenkt. Mit einem Bleistift wurden die nun sichtbaren Laufspuren und die Banden des 
Molekulargewichtsstandards markiert, bevor die Membran zweimal für je 10 min mit $20 \mathrm{ml}$ PBS-Puffer gewaschen wurde. Anschließend wurde für $1 \mathrm{~h}$ in $20 \mathrm{ml}$ Blocking-Puffer unter leichtem Schwenken inkubiert, bevor dreimal 10 min mit je $20 \mathrm{ml}$ PBST-Puffer gewaschen wurde. Es folgte eine mehrstündige Inkubation der Membran mit $1 \mu l$ des ersten Antikörpers $(1 \mathrm{mg} / \mathrm{ml})$ in $20 \mathrm{ml}$ PBS-Puffer. Nach erneut dreimaligem Waschen mit PBST-Puffer wurde $1 \mu \mathrm{l}$ des alkalische Phosphatase-gekoppelten zweiten Antikörpers $(1 \mathrm{mg} / \mathrm{ml})$ in $20 \mathrm{ml}$ PBSTPuffer zugegeben. Nach einer Inkubation für $1 \mathrm{~h}$ wurde noch dreimal mit PBST-Puffer und einmal mit demineralisiertem Wasser gewaschen, bevor der "Western Blot" entwickelt wurde. Dazu wurde eine Lösung aus 2,5 $\mu \mathrm{l} \mathrm{NBT-} \mathrm{und} 30 \mu 1$ BCIP-Stammlösung in $10 \mathrm{ml}$ alkalische Phosphatase-Puffer frisch hergestellt und auf die Membran gegeben. Nach kurzer Inkubation bei RT wurden Banden sichtbar. Durch einmaliges Waschen mit demineralisiertem Wasser wurde die Reaktion beendet und das Ergebnis durch Scannen dokumentiert.

\subsection{Zellbiologische Arbeitsmethoden}

\subsubsection{Induktion der Expression in Bakterienkulturen}

Im Rahmen dieser Arbeit kamen Plasmide zum Einsatz, welche die regulierte Expression kodierter Gene erlauben. Verwendet wurde die lac Promotor/Operatorregion und die tetAPromotor/Operatorregion. Die Induktion der Transkription vom lac Promotor aus wurde durch Zugabe von IPTG bis zu einer Endkonzentration von $1 \mathrm{mM}$ in einer in der logarithmischen Wachstumsphase befindlichen Kultur von E. coli erreicht. Es folgte in der Regel das weitere Wachstum bis in die stationäre Wachstumsphase. Die Expression ausgehend vom tetA Promotor/Operator wurde in der Regel durch Anhydrotetrazyklin, welches auf E. coli im Gegensatz zu Tetrazyklin nicht antibiotisch wirkt, induziert. Für die Expression von Intimin-Fusionsprotein von pASK75-Derivaten (Skerra, 1994) aus wurde dYT-Medium mit dem ein entsprechendes Expressionsplasmid enthaltenden Stamm inokuliert und bei $37^{\circ} \mathrm{C}$ bis zu einer O.D. 600 von 0,2 bis 0,3 inkubiert und bei Erreichen einer O.D. 600 von 0,2 bis $0,3 \mathrm{mit} 0,2 \mu \mathrm{g} / \mathrm{ml}$ Anhydrotetrazyklin für $60 \mathrm{~min}$ induziert. Die Expression in 71-18mutS wurde in der Regel durch Zugabe von Tetrazyklin mit einer Endkonzentration von $12,5 \mu \mathrm{g} / \mathrm{ml}$ induziert. Das in diesem Stamm integrierte Transposon 10 vermittelt den Zellen eine Resistenz gegen dieses Antibiotikum. Besonders bei gewünschter längerer Induktionsdauer kam dieser Stamm zur Anwendung. Die höhere Stabilität von Tetrazyklin gegenüber Anhydrotetrazyklin bei $37^{\circ} \mathrm{C}$ erlaubt längere Induktionszeiten.

\subsubsection{Fluoreszenzmarkierung von Escherichia coli Zellen}

Für die Fluoreszenzmarkierung Epitope präsentierender E. coli Zellen wurden in der Regel 200-500 $\mu$ l einer Expressions-induzierten Kultur (5.5.1) herangezogen. Die Zellen wurden in einem Reaktionsgefäß pelletiert (13.000 Upm, 2 min, $4{ }^{\circ} \mathrm{C}$ ). Die Zellen wurden in $10 \mu 1$ 1:10 in PBS-Puffer verdünntem ersten Antikörper (Anti-Sendai-Antikörper (Einberger, et al., 1990), Anti-E-Antikörper (Amersham Biosciences), Anti- $\beta$-Laktamase-Antikörper (5prime-to-3prime Inc.)) resuspendiert und für 5 min bei RT inkubiert. Nach Zugabe von $500 \mu \mathrm{l} 1 \mathrm{x}$ PBS-Puffer folgte eine erneute Zentrifugation (13.000 Upm, $2 \mathrm{~min}, 4^{\circ} \mathrm{C}$ ). Das Pellet wurde in $10 \mu \mathrm{l}$ 1:10 in PBS-Puffer verdünntem, biotinylierten zweiten Antikörpern ( $\alpha$ - 
Maus IgG, $\alpha$-Kaninchen IgG, Biotin-Konjugate (Fa. Sigma-Aldrich)) resuspendiert und der Ansatz erneut für 5 min bei RT inkubiert. Nach erneuter Zugabe von $500 \mu 11$ x PBS-Puffer und Zentrifugation wie oben beschrieben erfolgte die Inkubation der Zellen in 10 $\mu 1$ 1:10 in PBS-Puffer verdünntem Streptavidin, R-Phycoerythrin-Konjugat (Fa. Molecular Probes) für weitere 5 Minuten. Nach Zugabe von $500 \mu$ l PBS-Puffer wurden die Zellen ein letztes Mal pelletiert und in $50 \mu \mathrm{l} 1 \mathrm{x}$ PBS-Puffer aufgenommen. So aufbereitet konnten sie für die Untersuchung mit Hilfe des Fluoreszenz-Mikroskops oder die Durchflusszytometrie herangezogen werden.

\subsubsection{Durchflusszytometrie und Fluoreszenz-aktivierte Zellsortierung von Escherichia coli Zellen}

Für durchflusszytometrische Untersuchungen und Fluoreszenz-aktivierte Zellsortierungen wurde ein Gerät der Firma Cytomation (Fort Collins, USA) verwendet. Es wurden nach 5.5.2 präparierte Zellen herangezogen (Markierung mit R-Phycoerythrin als fluoreszierendem Farbstoff). Der Strahlengang des FACS wurde unter Verwendung fluoreszierender MicroBeads (Fa. Coulter) justiert und fokussiert, und die Photomultiplier wurden auf die Werte 730 (side scatter), 600 (FITC-Fluoreszenz), 600 (PhycoerythrinFluoreszenz) eingestellt. Die Anzahl der Ereignisse wurde bei einer Tropfenzahl zwischen 95.000 und 100.000 pro Sekunde auf maximal 30.000 pro Sekunde begrenzt. Der Hintergrundwert betrug in keinem Fall mehr als 100 Ereignisse pro Sekunde (0,3\%). Es wurden in der Regel 300.000 Ereignisse vermessen. Die Datenverwaltung erfolgte mittels des Softwarepakets CyClops. Die weitere Aufbereitung der gewonnen Daten wurde mit dem Programm SigmaPlot for Windows (Fa. Jandel Software) durchgeführt. Sollte eine Sortierung durchgeführt werden, wurde zusätzlich zur Justierung des Strahlengangs und des Flüssigkeitsstrahls auch noch der Tropfenabrisspunkt eingestellt und die Tropfenverzögerung bestimmt und kalibriert. Je nach Anreicherungsgrad wurde im single-sort- oder enrich-Modus sortiert, um nach Bedarf negative von positiven Ereignissen scharf oder weniger scharf voneinander abzutrennen. Die positiven Zellen konnten entweder in $5 \mathrm{ml}$ Röhrchen sortiert werden oder mit Hilfe des CyClone-Einzelablagearms einzeln in mit flüssigem Medium gefüllte Mikrotiterplatten oder auf Festmediums-Platten abgelegt werden. Die Frequenz der Ereignisse betrug zwischen 5.000 und 25.000 pro Sekunde bei einem Druck im Probenröhrchen zwischen 59 und 61 psi. 


\section{Zusammenfassung}

Die Entwicklung neuer Wirkstoffe zur Bekämpfung unterschiedlichster Erkrankungen des Menschen ist das gemeinsame Ziel zahlloser Ansätze der Grundlagen- und anwendungsorientierten Forschung. Dank einer heute zur Verfügung stehenden, breiten Palette effizienter Verfahren der modernen Zellbiologie, Molekularbiologie und Molekularen Medizin werden in naher Zukunft Krankheiten gezielter bekämpft werden können. Durch Einsatz evolutiver Methoden wurde es möglich, Proteinvarianten mit gewünschten Eigenschaften aus großen Sammlungen von in ausgewählten Regionen zufallsmäßig variierten Proteinen zu isolieren und damit maßgeschneiderte Werkzeuge für den Einsatz in den Biowissenschaften und der Medizin in die Hand zu bekommen. Leistungsfähigen Durchmusterungsverfahren kommt dabei eine bedeutende Rolle zu. Eine Möglichkeit, Proteine einer solchen Sammlung direkt einer Funktionsabfrage zugänglich zu machen, besteht darin, diese auf der Oberfläche von Bakterien bereitzustellen, die gleichzeitig Synthesemaschinen und präsentierende Mikropartikel sind. Durch klonale Expansion solcher Bakterien können nachfolgend neue Bindemoleküle hoher Passgenauigkeit und Bindungsstärke isoliert und identifiziert werden.

Im Rahmen dieser Arbeit wurde basierend auf dem Membranprotein EaeA (Intimin) enterohämorrhagischer Escherichia coli ein Zelloberflächenpräsentationsverfahren entwickelt und in Hinblick auf die Parameter hohe Nettoakkumulation von Passagierproteinen auf der Zelloberfläche und zelluläre Vitalität optimiert. Passagierproteine konnten durch Fusion an EaeA im Vergleich zu anderen bakteriellen Präsentationsverfahren in großer Kopienzahl auf der bakteriellen Oberfläche verankert werden. Die Vermehrungsfähigkeit der Wirtszellen wurde durch deren Expression und Exposition vergleichsweise wenig beeinträchtigt. Durch die kombinierte Regulation auf Transkriptions- und Translationsebene gelang es, die Expression und Exposition stufenlos über einen großen Bereich zu variieren. In einem Modellexperiment konnten Bakterien, die EaeA-vermittelt ein Epitop auf ihrer Oberfläche präsentierten aus einer 1:200.000 Mischung mit Kontrollzellen durch ImmunfluoreszenzMarkierung und Fluoreszenz-aktivierte Zellsortierung in wenigen Runden von Markierung und Sortierung isoliert werden. Damit ist die generelle Einsetzbarkeit dieses Expositionsverfahrens zur Durchmusterung komplexer Protein- und Peptidbibliotheken gezeigt.

Zur funktionalen Charakterisierung der Intimin-vermittelten Translokation durch die äußere Membran von Escherichia coli wurde die Zelloberflächenexposition systematisch ausgewählter Passagierdomänen untersucht. Zu den Kandidaten gehörten EETI-CK ${ }^{\text {send }}$, eine Variante des Trypsin-Inhibitors EETI-II aus Ecballium elaterium, die menschliche Immunglobulin-Domäne $R E I_{v}$, das humane Interleukin 4 (Il-4), das unter den Säugetieren hoch konservierte, Kalzium-bindende Protein Calmodulin, das $\beta$-Laktamase Inhibitor Protein BLIP aus Streptomyces clavuligerus und dessen Substrat, die TEM-1 $\beta$-Laktamase aus E. coli. Eine Exposition in hoher Kopienzahl wurde lediglich für die Domänen EETI-CK ${ }^{\text {send }}$ und $R E I_{v}$ nachgewiesen. Durch Zugabe membrandestabilisierender oder die Geschwindigkeit der Faltung der Passagierdomänen modulierender Agenzien konnte das Spektrum auf fünf der sechs untersuchten Proteine ausgeweitet werden. Es wurde experimentelle Evidenz zusammengetragen, dass Proteine nur in zumindest partiell ungefaltetem Zustand die 
Barriere der äußeren Membran passieren können. Im Falle von Calmodulin, das zur Stabilisierung seiner Faltung Kalzium-Ionen benötigt, führte der Zusatz von EDTA zu einer Zelloberflächenexposition in hoher Kopienzahl. Im Falle des $\beta$-Laktamase Inhibitor-Proteins, das im gefalteten Zustand zwei Disulfidbrücken besitzt, hatte die Zugabe von Reduktionsmitteln zum Kulturmedium einen vergleichbaren Effekt. Im Falle der TEM-1 $\beta$ Laktamase, die eine intramolekulare Disulfidbrücke besitzt, konnte auch nach Chemikalienbehandlung keine Exposition erreicht werden. Nach Durchmusterung einer Bibliothek zufallsmäßig erzeugter $\beta$-Laktamase-Varianten konnten Translokationskompetente Enzyme isoliert werden, bei denen einer der beiden Cysteinreste durch eine andere Aminosäure ersetzt und damit die Ausbildung von Disulfidbrücken unterbunden war.

Bei Beachtung der Randbedingung, dass Passagierdomänen zur Translokation durch die äußere Membran in einem ungefalteten Zustand vorliegen müssen, kann das in dieser Arbeit neu entwickelte EaeA-basierte Präsentationsverfahren als ein robustes und vielseitig einsetzbares Instrument zur Exposition von Proteindomänen auf Escherichia coli Zellen die Anreicherung von Proteinen mit neuen Funktionalitäten vereinfachen und damit neue Zugänge zu Biomolekülen mit maßgeschneiderten Eigenschaften erschließen. 


\section{Literatur}

Ambler, R. P. (1980). The structure of $\beta$-lactamases. Philos. Trans. R. Soc. Lond. B. Biol. Sci. 289(1036), 321-31.

Amstutz, P., Forrer, P., Zahnd, C. \& Plückthun, A. (2001). In vitro display technologies: novel developments and applications. Curr. Opin. Biotechnol. 12(4), 400-5.

Amzel, L. M. \& Poljak, R. J. (1979). Three-dimensional structure of immunoglobulins. Annu. Rev. Biochem. 48, 961-97.

Arkowitz, R. A., Joly, J. C. \& Wickner, W. (1993). Translocation can drive the unfolding of a preprotein domain. Embo J. 12(1), 243-53.

Babu, Y. S., Bugg, C. E. \& Cook, W. J. (1988). Structure of calmodulin refined at $2.2 \AA$ resolution. J. Mol. Biol. 204(1), 191-204.

Baddiley, J. (1989). Bacterial cell walls and membranes. Discovery of the teichoic acids. Bioessays 10(6), 207-10.

Bae, W., Mulchandani, A. \& Chen, W. (2002). Cell surface display of synthetic phytochelatins using ice nucleation protein for enhanced heavy metal bioaccumulation. J. Inorg. Biochem. 88(2), 223-7.

Bardwell, J. C., McGovern, K. \& Beckwith, J. (1991). Identification of a protein required for disulfide bond formation in vivo. Cell 67(3), 581-9.

Bass, S., Greene, R. \& Wells, J. A. (1990). Hormone phage: an enrichment method for variant proteins with altered binding properties. Proteins 8(4), 309-14.

Beebakhee, G., Louie, M., De Azavedo, J. \& Brunton, J. (1992). Cloning and nucleotide sequence of the eae gene homologue from enterohemorrhagic Escherichia coli serotype O157:H7. FEMS Microbiol. Lett. 70(1), 63-8.

Bingen, E., Bonacorsi, S., Brahimi, N., Denamur, E. \& Elion, J. (1997). Virulence patterns of Escherichia coli K1 strains associated with neonatal meningitis. J. Clin. Microbiol. 35(11), 2981-2.

Blattner, F. R., Plunkett, G., 3rd, Bloch, C. A., Perna, N. T., Burland, V., Riley, M., Collado-Vides, J., Glasner, J. D., Rode, C. K., Mayhew, G. F., Gregor, J., Davis, N. W., Kirkpatrick, H. A., Goeden, M. A., Rose, D. J., Mau, B. \& Shao, Y. (1997). The complete genome sequence of Escherichia coli K-12. Science 277(5331), 1453-74.

Blumenthal, D. K. \& Krebs, E. G. (1987). Preparation and properties of the calmodulinbinding domain of skeletal muscle myosin light chain kinase. Methods Enzymol. 139, 11526.

Blumenthal, D. K., Takio, K., Edelman, A. M., Charbonneau, H., Titani, K., Walsh, K. A. \& Krebs, E. G. (1985). Identification of the calmodulin-binding domain of skeletal muscle myosin light chain kinase. Proc. Natl. Acad. Sci. U S A 82(10), 3187-91.

Boder, E. T. \& Wittrup, K. D. (1997). Yeast surface display for screening combinatorial polypeptide libraries. Nat. Biotechnol. 15(6), 553-7.

Boder, E. T. \& Wittrup, K. D. (2000). Yeast surface display for directed evolution of protein expression, affinity, and stability. Methods Enzymol. 328, 430-44.

Bourdineaud, J. P., Fierobe, H. P., Lazdunski, C. \& Pages, J. M. (1990). Involvement of OmpF during reception and translocation steps of colicin N entry. Mol. Microbiol. 4(10), 1737-43. 
Braun, V. (1975). Covalent lipoprotein from the outer membrane of Escherichia coli. Biochim. Biophys. Acta 415(3), 335-77.

Braun, V. \& Rehn, K. (1969). Chemical characterization, spatial distribution and function of a lipoprotein (murein-lipoprotein) of the $E$. coli cell wall. The specific effect of trypsin on the membrane structure. Eur. J. Biochem. 10(3), 426-38.

Buchanan, S. K., Smith, B. S., Venkatramani, L., Xia, D., Esser, L., Palnitkar, M., Chakraborty, R., van der Helm, D. \& Deisenhofer, J. (1999). Crystal structure of the outer membrane active transporter FepA from Escherichia coli. Nat. Struct. Biol. 6(1), 56-63.

Cereghino, G. P. \& Cregg, J. M. (1999). Applications of yeast in biotechnology: protein production and genetic analysis. Curr. Opin. Biotechnol.10(5), 422-7.

Chai, T. J. \& Foulds, J. (1977). Purification of protein A, an outer membrane component missing in Escherichia coli K-12 ompA mutants. Biochim. Biophys. Acta 493(1), 210-5.

Chapman, K. B. \& Szostak, J. W. (1994). In vitro selection of catalytic RNAs. Curr. Opin. Struct. Biol. 4, 618-22.

Charbit, A., Boulain, J. C., Ryter, A. \& Hofnung, M. (1986). Probing the topology of a bacterial membrane protein by genetic insertion of a foreign epitope; expression at the cell surface. Embo J. 5(11), 3029-37.

Chattopadhyaya, R., Meador, W. E., Means, A. R. \& Quiocho, F. A. (1992). Calmodulin structure refined at $1.7 \AA$ resolution. J. Mol. Biol. 228(4), 1177-92.

Cho, G., Keefe, A. D., Liu, R., Wilson, D. S. \& Szostak, J. W. (2000). Constructing high complexity synthetic libraries of long ORFs using in vitro selection. J. Mol. Biol. 297(2), 309-19.

Christmann, A., Walter, K., Wentzel, A., Krätzner, R. \& Kolmar, H. (1999). The cystine knot of a squash-type protease inhibitor as a structural scaffold for Escherichia coli cell surface display of conformationally constrained peptides. Protein Eng. 12(9), 797806.

Christmann, A., Wentzel, A., Meyer, C., Meyers, G. \& Kolmar, H. (2001). Epitope mapping and affinity purification of monospecific antibodies by Escherichia coli cell surface display of gene-derived random peptide libraries. J. Immunol. Methods 257(1-2), 163-73.

Clackson, T. \& Wells, J. A. (1994). In vitro selection from protein and peptide libraries. Trends Biotechnol. 12(5), 173-84.

Coffman, R. L., Ohara, J., Bond, M. W., Carty, J., Zlotnik, A. \& Paul, W. E. (1986). B cell stimulatory factor-1 enhances the IgE response of lipopolysaccharide-activated $B$ cells. J. Immunol. 136(12), 4538-41.

Cohen, P. \& Klee, C. B. (1988) Calmodulin. Elsevier, Amsterdam, the Netherlands.

Coulton, J. W., Mason, P., Cameron, D. R., Carmel, G., Jean, R. \& Rode, H. N. (1986). Protein fusions of $\beta$-galactosidase to the ferrichrome-iron receptor of Escherichia coli K-12. J. Bacteriol. 165(1), 181-92.

Cowan, S. W., Schirmer, T., Rummel, G., Steiert, M., Ghosh, R., Pauptit, R. A., Jansonius, J. N. \& Rosenbusch, J. P. (1992). Crystal structures explain functional properties of two E. coli porins. Nature 358(6389), 727-33. 
Daugherty, P. S., Olsen, M. J., Iverson, B. L. \& Georgiou, G. (1999). Development of an optimized expression system for the screening of antibody libraries displayed on the Escherichia coli surface. Protein Eng. 12(7), 613-21.

Davies, J. (1994). Inactivation of antibiotics and the dissemination of resistance genes. Science 264(5157), 375-82.

Deamer, D. W. (1997). The first living systems: a bioenergetic perspective. Microbiol. Mol. Biol. Rev. 61, 230-61.

Deamer, D. W., Mahon, E. H. \& Bosco, G. (1994). Self assembly and function of primitive membrane structures. In: Early life on Earth (Bengtson, S., Hg.), S. 107-23. Columbia University Press, New York, Chichester, UK.

Dekker, N. (2000). Outer-membrane phospholipase A: known structure, unknown biological function. Mol. Microbiol. 35(4), 711-7.

Del Prete, G. (1992). Human Th1 and Th2 lymphocytes: their role in the pathophysiology of atopy. Allergy 47(5), 450-5.

Doi, N. \& Yanagawa, H. (1999). STABLE: protein-DNA fusion system for screening of combinatorial protein libraries in vitro. FEBS Lett. 457(2), 227-30.

Donnenberg, M. S. \& Kaper, J. B. (1991). Construction of an eae deletion mutant of enteropathogenic Escherichia coli by using a positive-selection suicide vector. Infect. Immun. 59(12), 4310-7.

Donnenberg, M. S. \& Kaper, J. B. (1992). Enteropathogenic Escherichia coli. Infect. Immun. 60(10), 3953-61.

Doran, J. L., Leskiw, B. K., Aippersbach, S. \& Jensen, S. E. (1990). Isolation and characterization of a $\beta$-lactamase-inhibitory protein from Streptomyces clavuligerus and cloning and analysis of the corresponding gene. J. Bacteriol. 172(9), 4909-18.

Dower, W. J., Miller, J. F. \& Ragsdale, C. W. (1988). High efficiency transformation of E. coli by high voltage electroporation. Nucleic Acids Res. 16(13), 6127-45.

Duenas, M. \& Borrebaeck, C. A. (1994). Clonal selection and amplification of phage displayed antibodies by linking antigen recognition and phage replication. Biotechnology (N Y) 12(10), 999-1002.

Echols, H., Lu, C. \& Burgers, P. M. (1983). Mutator strains of Escherichia coli, mutD and dnaO, with defective exonucleolytic editing by DNA polymerase III holoenzyme. Proc. Natl. Acad. Sci. U S A 80(8), 2189-92.

Einberger, H., Mertz, R., Hofschneider, P. H. \& Neubert, W. J. (1990). Purification, renaturation, and reconstituted protein kinase activity of the Sendai virus large (L) protein: L protein phosphorylates the NP and P proteins in vitro. J. Virol. 64(9), 4274-80.

Ekland, E. H., Szostak, J. W. \& Bartel, D. P. (1995). Structurally complex and highly active RNA ligases derived from random RNA sequences. Science 269(5222), 364-70.

Eldik, L. V. \& Watterson, D. M. (1998) Calmodulin and signal transduction (Van Eldrick, L. J. \& Watterson, D. M., Hgg.). Academic Press, New York, USA.

Ellington, A. D. \& Szostak, J. W. (1990). In vitro selection of RNA molecules that bind specific ligands. Nature 346(6287), 818-22.

Epp, O., Lattman, E. E., Schiffer, M., Huber, R. \& Palm, W. (1975). The molecular structure of a dimer composed of the variable portions of the Bence-Jones protein REI refined at 2.0- $\AA$ resolution. Biochemistry 14(22), 4943-52. 
Fath, M. J. \& Kolter, R. (1993). ABC transporters: bacterial exporters. Microbiol. Rev. 57(4), 995-1017.

Ferguson, A. D., Hofmann, E., Coulton, J. W., Diederichs, K. \& Welte, W. (1998). Siderophore-mediated iron transport: crystal structure of FhuA with bound lipopolysaccharide. Science 282(5397), 2215-20.

Fernandez-Botran, R., Sanders, V. M., Oliver, K. G., Chen, Y. W., Krammer, P. H., Uhr, J. W. \& Vitetta, E. S. (1986). Interleukin 4 mediates autocrine growth of helper T cells after antigenic stimulation. Proc. Natl. Acad. Sci. U S A 83(24), 9689-93.

Fisher, J., Belasco, J. G., Khosla, S. \& Knowles, J. R. (1980). $\beta$-Lactamase proceeds via an acyl-enzyme intermediate. Interaction of the Escherichia coli RTEM enzyme with cefoxitin. Biochemistry 19(13), 2895-901.

Fleischaker, G. R. (1990). Origins of life: an operational definition. Orig. Life Evol. Biosphere 20, 127-37.

Forst, D., Welte, W., Wacker, T. \& Diederichs, K. (1998). Structure of the sucrosespecific porin ScrY from Salmonella typhimurium and its complex with sucrose. Nat. Struct. Biol. 5(1), 37-46.

Foubister, V., Rosenshine, I., Donnenberg, M. S. \& Finlay, B. B. (1994a). The eaeB gene of enteropathogenic Escherichia coli is necessary for signal transduction in epithelial cells. Infect. Immun. 62(7), 3038-40.

Foubister, V., Rosenshine, I. \& Finlay, B. B. (1994b). A diarrheal pathogen, enteropathogenic Escherichia coli (EPEC), triggers a flux of inositol phosphates in infected epithelial cells. J. Exp. Med. 179(3), 993-8.

Foxman, B., Zhang, L., Tallman, P., Palin, K., Rode, C., Bloch, C., Gillespie, B. \& Marrs, C. F. (1995). Virulence characteristics of Escherichia coli causing first urinary tract infection predict risk of second infection. J. Infect. Dis. 172(6), 1536-41.

Francisco, J. A., Earhart, C. F. \& Georgiou, G. (1992). Transport and anchoring of $\beta$ lactamase to the external surface of Escherichia coli. Proc. Natl. Acad. Sci. U S A 89(7), 2713-7.

Frankel, G., Phillips, A. D., Rosenshine, I., Dougan, G., Kaper, J. B. \& Knutton, S. (1998). Enteropathogenic and enterohaemorrhagic Escherichia coli: more subversive elements. Mol. Microbiol. 30(5), 911-21.

Frère, J. M. (1995). $\beta$-lactamases and bacterial resistance to antibiotics. Mol. Microbiol. 16(3), 385-95.

Frère, J. M., Joris, B., Granier, B., Matagne, A., Jacob, F. \& Bourguignon-Bellefroid, C. (1991). Diversity of the mechanisms of resistance to $\beta$-lactam antibiotics. Res. Microbiol. 142(6), 705-10.

Frisch, C., Kolmar, H. \& Fritz, H. J. (1994). A soluble immunoglobulin variable domain without a disulfide bridge: construction, accumulation in the cytoplasm of E. coli, purification and physicochemical characterization. Biol. Chem. Hoppe Seyler 375(5), 3536.

Frisch, C., Kolmar, H., Schmidt, A., Kleemann, G., Reinhardt, A., Pohl, E., Usón, I., Schneider, T. R. \& Fritz, H. J. (1996). Contribution of the intramolecular disulfide bridge to the folding stability of REIv, the variable domain of a human immunoglobulin kappa light chain. Fold. Des. 1(6), 431-40. 
Galan, J. E. \& Collmer, A. (1999). Type III secretion machines: bacterial devices for protein delivery into host cells. Science 284(5418), 1322-8.

Gallagher, P. J., Herring, B. P. \& Stull, J. T. (1997). Myosin light chain kinases. J. Muscle Res. Cell Motil. 18(1), 1-16.

Garrard, L. J., Yang, M., O'Connell, M. P., Kelley, R. F. \& Henner, D. J. (1991). Fab assembly and enrichment in a monovalent phage display system. Biotechnology (N Y) 9(12), 1373-7.

Ghadessy, F. J., Ong, J. L. \& Holliger, P. (2001). Directed evolution of polymerase function by compartmentalized self-replication. Proc. Natl. Acad. Sci. U S A 98(8), 45527.

Ghoreschi, K., Thomas, P., Breit, S., Dugas, M., Mailhammer, R., van Eden, W., van der Zee, R., Biedermann, T., Prinz, J., Mack, M., Mrowietz, U., Christophers, E., Schlondorff, D., Plewig, G., Sander, C. A. \& Rocken, M. (2003). Interleukin-4 therapy of psoriasis induces Th2 responses and improves human autoimmune disease. Nat. Med. 9(1), 40-6.

Ghrayeb, J. \& Inouye, M. (1984). Nine amino acid residues at the NH2-terminal of lipoprotein are sufficient for its modification, processing, and localization in the outer membrane of Escherichia coli. J. Biol. Chem. 259(1), 463-7.

Ghuysen, J. M. (1991). Serine $\beta$-lactamases and penicillin-binding proteins. Annu. Rev. Microbiol. 45, 37-67.

Ginocchio, C. C. \& Galan, J. E. (1995). Functional conservation among members of the Salmonella typhimurium InvA family of proteins. Infect. Immun. 63(2), 729-32.

Gram, C. (1884). Ueber die isolirte Färbung der Schizomyceten in Schnitt- und Trockenpräparaten. Fortschritt der Medicin 2, 185-9.

Gramatikoff, K., Georgiev, O. \& Schaffner, W. (1994). Direct interaction rescue, a novel filamentous phage technique to study protein-protein interactions. Nucleic Acids Res. $\mathbf{2 2}(25), 5761-2$.

Griffiths, A. D., Malmqvist, M., Marks, J. D., Bye, J. M., Embleton, M. J., McCafferty, J., Baier, M., Holliger, K. P., Gorick, B. D., Hughes-Jones, N. C. \& et al. (1993). Human anti-self antibodies with high specificity from phage display libraries. Embo J. 12(2), 725-34.

Griffiths, A. D. \& Tawfik, D. S. (2000). Man-made enzymes--from design to in vitro compartmentalisation. Curr. Opin. Biotechnol. 11(4), 338-53.

Griffiths, A. D., Williams, S. C., Hartley, O., Tomlinson, I. M., Waterhouse, P., Crosby, W. L., Kontermann, R. E., Jones, P. T., Low, N. M., Allison, T. J. \& et al. (1994). Isolation of high affinity human antibodies directly from large synthetic repertoires. Embo J. 13(14), 3245-60.

Grinsted, J. \& Bennett, P. M. (1988). Methods in microbiology: plasmid technology 21, Academic Press, San Diego.

Groisman, E. A. \& Ochman, H. (1996). Pathogenicity islands: bacterial evolution in quantum leaps. Cell 87(5), 791-4.

Guillaume, G., Vanhove, M., Lamotte-Brasseur, J., Ledent, P., Jamin, M., Joris, B. \& Frère, J. M. (1997). Site-directed mutagenesis of glutamate 166 in two $\beta$-lactamases. Kinetic and molecular modeling studies. J. Biol. Chem. $272(9), 5438-44$. 
Gunneriusson, E., Samuelson, P., Uhlen, M., Nygren, P. A. \& Stahl, S. (1996). Surface display of a functional single-chain Fv antibody on staphylococci. J. Bacteriol. 178(5), 1341-6.

Hamburger, Z. A., Brown, M. S., Isberg, R. R. \& Björkman, P. J. (1999). Crystal structure of invasin: a bacterial integrin-binding protein. Science 286(5438), 291-5.

Hanahan, D. (1983). Studies on transformation of Escherichia coli with plasmids. J. Mol. Biol. 166(4), 557-80.

Hanes, J., Jermutus, L., Weber-Bornhauser, S., Bosshard, H. R. \& Plückthun, A. (1998). Ribosome display efficiently selects and evolves high-affinity antibodies in vitro from immune libraries. Proc. Natl. Acad. Sci. U S A 95(24), 14130-5.

Hanes, J. \& Plückthun, A. (1997). In vitro selection and evolution of functional proteins by using ribosome display. Proc. Natl. Acad. Sci. U S A 94(10), 4937-42.

Hanes, J., Schaffitzel, C., Knappik, A. \& Plückthun, A. (2000). Picomolar affinity antibodies from a fully synthetic naive library selected and evolved by ribosome display. Nat. Biotechnol. 18(12), 1287-92.

Hansson, M., Samuelson, P., Gunneriusson, E. \& Stahl, S. (2001). Surface display on gram positive bacteria. Comb. Chem. High Throughput Screen. 4(2), 171-84.

Hartland, E. L., Batchelor, M., Delahay, R. M., Hale, C., Matthews, S., Dougan, G., Knutton, S., Connerton, I. \& Frankel, G. (1999). Binding of intimin from enteropathogenic Escherichia coli to Tir and to host cells. Mol. Microbiol. 32(1), 151-8.

Hawkins, R. E., Russell, S. J. \& Winter, G. (1992). Selection of phage antibodies by binding affinity. Mimicking affinity maturation. J. Mol. Biol. 226(3), 889-96.

He, M., Menges, M., Groves, M. A., Corps, E., Liu, H., Bruggemann, M. \& Taussig, M. J. (1999). Selection of a human anti-progesterone antibody fragment from a transgenic mouse library by ARM ribosome display. J. Immunol. Methods 231(1-2), 10517.

He, M. \& Taussig, M. J. (1997). Antibody-ribosome-mRNA (ARM) complexes as efficient selection particles for in vitro display and evolution of antibody combining sites. Nucleic Acids Res. 25(24), 5132-4.

Heitz, A., Chiche, L., Le-Nguyen, D. \& Castro, B. (1995). Folding of the squash trypsin inhibitor EETI II. Evidence of native and non-native local structural preferences in a linear analogue. Eur. J. Biochem. 233(3), 837-46.

Henderson, I. R. \& Nataro, J. P. (2001). Virulence functions of autotransporter proteins. Infect. Immun. 69(3), 1231-43.

Henderson, I. R., Navarro-Garcia, F. \& Nataro, J. P. (1998). The great escape: structure and function of the autotransporter proteins. Trends Microbiol. 6(9), 370-8.

Hoess, R., Brinkmann, U., Handel, T. \& Pastan, I. (1993). Identification of a peptide which binds to the carbohydrate-specific monoclonal antibody B3. Gene 128(1), 43-9.

Hueck, C. J. (1998). Type III protein secretion systems in bacterial pathogens of animals and plants. Microbiol. Mol. Biol. Rev. 62(2), 379-433.

Holtje, J. V. (1998). Growth of the stress-bearing and shape-maintaining murein sacculus of Escherichia coli. Microbiol. Mol. Biol. Rev. 62(1), 181-203.

Huovinen, P., Huovinen, S. \& Jacoby, G. A. (1988). Sequence of PSE-2 $\beta$-lactamase. Antimicrob. Agents Chemother. 32(1), 134-6. 
Irving, R. A., Coia, G., Roberts, A., Nuttall, S. D. \& Hudson, P. J. (2001). Ribosome display and affinity maturation: from antibodies to single $\mathrm{V}$-domains and steps towards cancer therapeutics. J. Immunol. Methods 248(1-2), 31-45.

Ismaili, A., Philpott, D. J., Dytoc, M. T., Soni, R., Ratnam, S. \& Sherman, P. M. (1995). $\alpha$-actinin accumulation in epithelial cells infected with attaching and effacing gastrointestinal pathogens. J. Infect. Dis. 172(5), 1393-6.

Jacoby, G. A. (1994). Extrachromosomal resistance in gram-negative organisms: the evolution of $\beta$-lactamase. Trends Microbiol. 2(10), 357-60.

Janeway, C. A. jr., Travers, P. (1997). Immunologie, 2. Auflage. Spektrum Akademischer Verlag.

Jansen, J. H., Fibbe, W. E., Willemze, R. \& Kluin-Nelemans, J. C. (1990). Interleukin4. A regulatory protein. Blut $\mathbf{6 0}(5), 269-74$.

Jarvis, K. G., Giron, J. A., Jerse, A. E., McDaniel, T. K., Donnenberg, M. S. \& Kaper, J. B. (1995). Enteropathogenic Escherichia coli contains a putative type III secretion system necessary for the export of proteins involved in attaching and effacing lesion formation. Proc. Natl. Acad. Sci. U S A 92(17), 7996-8000.

Jarvis, K. G. \& Kaper, J. B. (1996). Secretion of extracellular proteins by enterohemorrhagic Escherichia coli via a putative type III secretion system. Infect. Immun. 64(11), 4826-9.

Jaurin, B. \& Grundström, T. (1981). ampC cephalosporinase of Escherichia coli K-12 has a different evolutionary origin from that of $\beta$-lactamases of the penicillinase type. Proc. Natl. Acad. Sci. U S A 78(8), 4897-901.

Javaux, E. J., Knoll, A. H. \& Walter, M. R. (2001). Morphological and ecological complexity in early eukaryotic ecosystems. Nature 412(6842), 66-9.

Jermutus, L., Honegger, A., Schwesinger, F., Hanes, J. \& Plückthun, A. (2001). Tailoring in vitro evolution for protein affinity or stability. Proc. Natl. Acad. Sci. U S A 98(1), 75-80.

Jerse, A. E., Yu, J., Tall, B. D. \& Kaper, J. B. (1990). A genetic locus of enteropathogenic Escherichia coli necessary for the production of attaching and effacing lesions on tissue culture cells. Proc. Natl. Acad. Sci. U S A 87(20), 7839-43.

Johnson, J. R., Brown, J. J., Carlino, U. B. \& Russo, T. A. (1998). Colonization with and acquisition of uropathogenic Escherichia coli as revealed by polymerase chain reaction-based detection. J. Infect. Dis. 177(4), 1120-4.

Joris, B., Ledent, P., Dideberg, O., Fonze, E., Lamotte-Brasseur, J., Kelly, J. A., Ghuysen, J. M. \& Frère, J. M. (1991). Comparison of the sequences of class A $\beta$ lactamases and of the secondary structure elements of penicillin-recognizing proteins. Antimicrob. Agents Chemother. 35(11), 2294-301.

Jung, H. C., Lebeault, J. M. \& Pan, J. G. (1998). Surface display of Zymomonas mobilis levansucrase by using the ice-nucleation protein of Pseudomonas syringae. Nat. Biotechnol. 16(6), 576-80.

Kaper, J. B. (1998). Enterohemorrhagic Escherichia coli. Curr. Opin. Microbiol. 1(1), 103-8.

Karmali, M. A. (1989). Infection by verocytotoxin-producing Escherichia coli. Clin. Microbiol. Rev. 2(1), 15-38.

Keefe, A. D. \& Szostak, J. W. (2001). Functional proteins from a random-sequence library. Nature 410(6829), 715-8. 
Keller, C. H., Olwin, B. B., LaPorte, D. C. \& Storm, D. R. (1982). Determination of the free-energy coupling for binding of calcium ions and troponin I to calmodulin. Biochemistry 21(1), 156-62.

Kenny, B., DeVinney, R., Stein, M., Reinscheid, D. J., Frey, E. A. \& Finlay, B. B. (1997). Enteropathogenic E. coli (EPEC) transfers its receptor for intimate adherence into mammalian cells. Cell 91(4), 511-20.

Kenny, B. \& Finlay, B. B. (1995). Protein secretion by enteropathogenic Escherichia coli is essential for transducing signals to epithelial cells. Proc. Natl. Acad. Sci. U S A 92(17), 7991-5.

Kieke, M. C., Cho, B. K., Boder, E. T., Kranz, D. M. \& Wittrup, K. D. (1997). Isolation of anti-T cell receptor scFv mutants by yeast surface display. Protein Eng. 10(11), 1303-10.

Kim, E. J. \& Yoo, S. K. (1999). Cell surface display of hepatitis B virus surface antigen by using Pseudomonas syringae ice nucleation protein. Lett. Appl. Microbiol. 29(5), 292-7.

Kim, Y. S., Jung, H. C. \& Pan, J. G. (2000). Bacterial cell surface display of an enzyme library for selective screening of improved cellulase variants. Appl. Environ. Microbiol. 66(2), 788-93.

Kjaergaard, K., Schembri, M. A. \& Klemm, P. (2001). Novel Zn(2+)-chelating peptides selected from a fimbria-displayed random peptide library. Appl. Environ. Microbiol. 67(12), 5467-73.

Klauser, T., Pohlner, J. \& Meyer, T. F. (1992). Selective extracellular release of cholera toxin B subunit by Escherichia coli: dissection of Neisseria Iga $\beta$-mediated outer membrane transport. Embo J. 11(6), 2327-35.

Klevit, R. E., Dalgarno, D. C., Levine, B. A. \& Williams, R. J. (1984). 1H-NMR studies of calmodulin. The nature of the $\mathrm{Ca} 2+$-dependent conformational change. Eur. J. Biochem. 139(1), 109-14.

Knutton, S., McConnell, M. M., Rowe, B. \& McNeish, A. S. (1989). Adhesion and ultrastructural properties of human enterotoxigenic Escherichia coli producing colonization factor antigens III and IV. Infect. Immun. 57(11), 3364-71.

Koch, A. L. (1996). What size should a bacterium be? A question of scale. Annu. Rev. Microbiol. 50, 317-48.

Koebnik, R., Locher, K. P. \& Van Gelder, P. (2000). Structure and function of bacterial outer membrane proteins: barrels in a nutshell. Mol. Microbiol. 37(2), 239-53.

Kolmar, H. (1991). Über die Faltungsstabilität einer variablen Immunglobulindomäne und deren Abhängigkeit von speziellen Merkmalen der Aminosäuresequenz. Dissertation an der Eberhard-Karls-Universität Tübingen.

Kolmar, H., Ferrando, E., Hennecke, F., Wippler, J. \& Fritz, H. J. (1992). General mutagenesis/gene expression procedure for the construction of variant immunoglobulin domains in Escherichia coli. Production of the Bence-Jones protein REIv via fusion to $\beta$ lactamase. J. Mol. Biol. 228(2), 359-65.

Kolmar, H., Frisch, C., Kleemann, G., Götze, K., Stevens, F. J. \& Fritz, H. J. (1994). Dimerization of Bence Jones proteins: linking the rate of transcription from an Escherichia coli promoter to the association constant of $\mathrm{REI}_{\mathrm{V}}$. Biol. Chem. Hoppe Seyler 375(1), 61-70. 
Kozloff, L. M., Turner, M. A. \& Arellano, F. (1991). Formation of bacterial membrane ice-nucleating lipoglycoprotein complexes. J. Bacteriol. 173(20), 6528-36.

Kramer, B., Kramer, W. \& Fritz, H. J. (1984). Different base/base mismatches are corrected with different efficiencies by the methyl-directed DNA mismatch-repair system of E. coli. Cell 38(3), 879-87.

Krebber, C., Spada, S., Desplancq, D. \& Plückthun, A. (1995). Co-selection of cognate antibody-antigen pairs by selectively-infective phages. FEBS Lett. 377(2), 227-31.

Kuboniwa, H., Tjandra, N., Grzesiek, S., Ren, H., Klee, C. B. \& Bax, A. (1995). Solution structure of calcium-free calmodulin. Nat. Struct. Biol. 2(9), 768-76.

Kurz, M., Gu, K. \& Lohse, P. A. (2000). Psoralen photo-crosslinked mRNA-puromycin conjugates: a novel template for the rapid and facile preparation of mRNA-protein fusions. Nucleic Acids Res. 28(18), E83.

Kwak, Y. D., Yoo, S. K. \& Kim, E. J. (1999). Cell surface display of human immunodeficiency virus type $1 \mathrm{gp} 120$ on Escherichia coli by using ice nucleation protein. Clin. Diagn. Lab. Immunol. 6(4), 499-503.

Laemmli, U. K. (1970). Cleavage of structural proteins during the assembly of the head of bacteriophage T4. Nature 227(259), 680-5.

Lambert, P. A., Hancock, I. C. \& Baddiley, J. (1977). Occurrence and function of membrane teichoic acids. Biochim. Biophys. Acta $\mathbf{4 7 2 ( 1 ) , 1 - 1 2 . ~}$

Lamotte-Brasseur, J., Dive, G., Dideberg, O., Charlier, P., Frère, J. M. \& Ghuysen, J. M. (1991). Mechanism of acyl transfer by the class A serine $\beta$-lactamase of Streptomyces albus G. Biochem. J. 279 ( Pt 1), 213-21.

Lang, H. (2000). Outer membrane proteins as surface display systems. Int. J. Med. Microbiol. $290(7), 579-85$.

Lattemann, C. T., Maurer, J., Gerland, E. \& Meyer, T. F. (2000). Autodisplay: functional display of active $\beta$-lactamase on the surface of Escherichia coli by the AIDA-I autotransporter. J. Bacteriol. 182(13), 3726-33.

Lazcano, A. (1994a). The transition from nonliving to living. In: Early life on Earth (Bengtson, S., Hg.), S. 60-9. Columbia University Press, New York, Chichester, UK.

Lazcano, A. (1994b). The RNA world, its predecessors, and its descendants. In: Early life on Earth (Bengtson, S., Hg.), S. 70-80. Columbia University Press, New York, Chichester, UK.

Lebman, D. A. \& Coffman, R. L. (1988). Interleukin 4 causes isotype switching to IgE in T cell-stimulated clonal B cell cultures. J. Exp. Med. 168(3), 853-62.

Lecompte, O., Ripp, R., Thierry, J. C., Moras, D. \& Poch, O. (2002). Comparative analysis of ribosomal proteins in complete genomes: an example of reductive evolution at the domain scale. Nucleic Acids Res. 30(24), 5382-90.

Lehtio, J., Wernerus, H., Samuelson, P., Teeri, T. T. \& Stahl, S. (2001). Directed immobilization of recombinant staphylococci on cotton fibers by functional display of a fungal cellulose-binding domain. FEMS Microbiol. Lett. 195(2), 197-204.

Le-Nguyen, D., Heitz, A., Chiche, L., el Hajji, M. \& Castro, B. (1993). Characterization and 2D NMR study of the stable [9-21, 15-27] 2 disulfide intermediate in the folding of the 3 disulfide trypsin inhibitor EETI II. Protein Sci. 2(2), 165-74. 
Liébecq, C. (1978). Biochemical nomenclature and related documents. International Union for Biochemistry. The Biochemical Society, London.

Lim, D., Park, H. U., De Castro, L., Kang, S. G., Lee, H. S., Jensen, S., Lee, K. J. \& Strynadka, N. C. (2001). Crystal structure and kinetic analysis of $\beta$-lactamase inhibitor protein-II in complex with TEM-1 $\beta$-lactamase. Nat. Struct. Biol. 8(10), 848-52.

Linse, S., Helmersson, A. \& Forsen, S. (1991). Calcium binding to calmodulin and its globular domains. J. Biol. Chem. 266(13), 8050-4.

Liu, H., Magoun, L. \& Leong, J. M. (1999a). $\beta 1$-chain integrins are not essential for intimin-mediated host cell attachment and enteropathogenic Escherichia coli-induced actin condensation. Infect. Immun. 67(4), 2045-9.

Liu, H., Magoun, L., Luperchio, S., Schauer, D. B. \& Leong, J. M. (1999b). The Tirbinding region of enterohaemorrhagic Escherichia coli intimin is sufficient to trigger actin condensation after bacterial-induced host cell signalling. Mol. Microbiol. 34(1), 67-81.

Locher, K. P., Rees, B., Koebnik, R., Mitschler, A., Moulinier, L., Rosenbusch, J. P. \& Moras, D. (1998). Transmembrane signaling across the ligand-gated FhuA receptor: crystal structures of free and ferrichrome-bound states reveal allosteric changes. Cell 95(6), 771-8.

Lorsch, J. R. \& Szostak, J. W. (1994a). In vitro evolution of new ribozymes with polynucleotide kinase activity. Nature 371(6492), 31-6.

Lorsch, J. R. \& Szostak, J. W. (1994b). In vitro selection of RNA aptamers specific for cyanocobalamin. Biochemistry 33(4), 973-82.

Louie, M., de Azavedo, J. C., Handelsman, M. Y., Clark, C. G., Ally, B., Dytoc, M., Sherman, P. \& Brunton, J. (1993). Expression and characterization of the eaeA gene product of Escherichia coli serotype O157:H7. Infect. Immun. 61(10), 4085-92.

Luckey, M. \& Nikaido, H. (1980a). Diffusion of solutes through channels produced by phage lambda receptor protein of Escherichia coli: inhibition by higher oligosaccharides of maltose series. Biochem. Biophys. Res. Commun. 93(1), 166-71.

Luckey, M. \& Nikaido, H. (1980b). Specificity of diffusion channels produced by lambda phage receptor protein of Escherichia coli. Proc. Natl. Acad. Sci. U S A 77(1), 167-71.

Luisi, P. L., Walde, P. \& Oberholzer, T. (1999). Lipid vesicles as possible intermediates in the origin of life. Curr. Opin. Colloid. Interface Sci. 4, 33-38.

Luo, Y., Frey, E. A., Pfuetzner, R. A., Creagh, A. L., Knoechel, D. G., Haynes, C. A., Finlay, B. B. \& Strynadka, N. C. (2000). Crystal structure of enteropathogenic Escherichia coli intimin-receptor complex. Nature 405(6790), 1073-7.

Lutz, R. \& Bujard, H. (1997). Independent and tight regulation of transcriptional units in Escherichia coli via the LacR/O, the TetR/O and AraC/I1-I2 regulatory elements. Nucleic Acids Res. 25(6), 1203-10.

Maldonado, J. E., Velosa, J. A., Kyle, R. A., Wagoner, R. D., Holley, K. E. \& Salassa, R. M. (1975). Fanconi syndrome in adults. A manifestation of a latent form of myeloma. Am. J. Med. 58(3), 354-64.

Mangel, W. F., Toledo, D. L., Brown, M. T., Worzalla, K., Lee, M. \& Dunn, J. J. (1994). Omptin: an Escherichia coli outer membrane proteinase that activates plasminogen. Methods Enzymol. 244, 384-99. 
Markland, W., Roberts, B. L., Saxena, M. J., Guterman, S. K. \& Ladner, R. C. (1991). Design, construction and function of a multicopy display vector using fusions to the major coat protein of bacteriophage M13. Gene 109(1), 13-9.

Marks, J. D., Ouwehand, W. H., Bye, J. M., Finnern, R., Gorick, B. D., Voak, D., Thorpe, S. J., Hughes-Jones, N. C. \& Winter, G. (1993). Human antibody fragments specific for human blood group antigens from a phage display library. Biotechnology (N Y) 11(10), 1145-9.

Martin, W. \& Russell, M. J. (2003). On the origins of cells: a hypothesis for the evolutionary transitions from abiotic geochemistry to chemoautotrophic prokaryotes, and from prokaryotes to nucleated cells. Philos. Trans. R. Soc. Lond. B. Biol. Sci. 358(1429), $59-85$

Matagne, A. \& Frère, J. M. (1995). Contribution of mutant analysis to the understanding of enzyme catalysis: the case of class A $\beta$-lactamases. Biochim. Biophys. Acta 1246(2), 109-27.

Matagne, A., Lamotte-Brasseur, J. \& Frère, J. M. (1998). Catalytic properties of class A ß-lactamases: efficiency and diversity. Biochem. J. 330 ( Pt 2), 581-98.

Mattheakis, L. C., Bhatt, R. R. \& Dower, W. J. (1994). An in vitro polysome display system for identifying ligands from very large peptide libraries. Proc. Natl. Acad. Sci. U S A 91(19), 9022-6.

Maurer, J., Jose, J. \& Meyer, T. F. (1997). Autodisplay: one-component system for efficient surface display and release of soluble recombinant proteins from Escherichia coli. J. Bacteriol. 179(3), 794-804.

McCafferty, J., Fitzgerald, K. J., Earnshaw, J., Chiswell, D. J., Link, J., Smith, R. \& Kenten, J. (1994). Selection and rapid purification of murine antibody fragments that bind a transition-state analog by phage display. Appl. Biochem. Biotechnol. 47(2-3), 157-71; discussion 171-3.

McCafferty, J., Griffiths, A. D., Winter, G. \& Chiswell, D. J. (1990). Phage antibodies: filamentous phage displaying antibody variable domains. Nature 348(6301), 552-4.

McDaniel, T. K. \& Kaper, J. B. (1997). A cloned pathogenicity island from enteropathogenic Escherichia coli confers the attaching and effacing phenotype on E. coli K-12. Mol. Microbiol. 23(2), 399-407.

Means, A. R. \& Dedman, J. R. (1980). Calmodulin--an intracellular calcium receptor. Nature 285(5760), 73-7.

Mills, D. R., Peterson, R. L. \& Spiegelman, S. (1967). An extracellular Darwinian experiment with a self-duplicating nucleic acid molecule. Proc. Natl. Acad. Sci. U S A 58(1), 217-24.

Minasov, G., Wang, X. \& Shoichet, B. K. (2002). An ultrahigh resolution structure of TEM-1 $\beta$-lactamase suggests a role for Glu166 as the general base in acylation. J. Am. Chem. Soc. 124(19), 5333-40.

Mojzsis, S. J., Arrhenius, G., McKeegan, K. D., Harrison, T. M., Nutman, A. P. \& Friend, C. R. (1996). Evidence for life on Earth before 3,800 million years ago. Nature 384(6604), 55-9.

Monnard, P. A. \& Deamer, D. W. (2002). Membrane self-assembly processes: steps toward the first cellular life. Anat. Rec. 268(3), 196-207. 
Moon, H. W., Whipp, S. C., Argenzio, R. A., Levine, M. M. \& Giannella, R. A. (1983). Attaching and effacing activities of rabbit and human enteropathogenic Escherichia coli in pig and rabbit intestines. Infect. Immun. 41(3), 1340-51.

Müller, T., Oehlenschlager, F. \& Buehner, M. (1995). Human interleukin-4 and variant R88Q: phasing X-ray diffraction data by molecular replacement using X-ray and nuclear magnetic resonance models. J. Mol. Biol. 247(2), 360-72.

Mullis, K. B. \& Faloona, F. A. (1987). Specific synthesis of DNA in vitro via a polymerasecatalyzed chain reaction. Methods Enzymol. 155, 335-50.

Nanninga, N. (1991). Cell division and peptidoglycan assembly in Escherichia coli. Mol. Microbiol. 5(4), 791-5.

Nataro, J. P. \& Kaper, J. B. (1998). Diarrheagenic Escherichia coli. Clin. Microbiol. Rev. 11(1), 142-201.

Nemoto, N., Miyamoto-Sato, E., Husimi, Y. \& Yanagawa, H. (1997). In vitro virus: bonding of mRNA bearing puromycin at the 3'-terminal end to the C-terminal end of its encoded protein on the ribosome in vitro. FEBS Lett. 414(2), 405-8.

Nielsen, J. B. \& Lampen, J. O. (1982). Membrane-bound penicillinases in Gram-positive bacteria. J. Biol. Chem. 257(8), 4490-5.

Nikaido, H. \& Vaara, M. (1985). Molecular basis of bacterial outer membrane permeability. Microbiol. Rev. 49(1), 1-32.

Nisbet, E. G. \& Sleep, N. H. (2001). The habitat and nature of early life. Nature 409(6823), 1083-91.

Noelle, R. J., Kuziel, W. A., Maliszewski, C. R., McAdams, E., Vitetta, E. S. \& Tucker, P. W. (1986). Regulation of the expression of multiple class II genes in murine B cells by B cell stimulatory factor-1 (BSF-1). J. Immunol. 137(5), 1718-23.

Overbeeke, N. \& Lugtenberg, B. (1980). Expression of outer membrane protein e of Escherichia coli K12 by phosphate limitation. FEBS Lett. 112(2), 229-32.

Pace, C. N., Vajdos, F., Fee, L., Grimsley, G. \& Gray, T. (1995). How to measure and predict the molar absorption coefficient of a protein. Protein Sci. 4(11), 2411-23.

Pallaghy, P. K., Nielsen, K. J., Craik, D. J. \& Norton, R. S. (1994). A common structural motif incorporating a cystine knot and a triple-stranded $\beta$-sheet in toxic and inhibitory polypeptides. Protein Sci. 3(10), 1833-9.

Parker, A. C. \& Smith, C. J. (1993). Genetic and biochemical analysis of a novel Ambler class A $\beta$-lactamase responsible for cefoxitin resistance in Bacteroides species. Antimicrob. Agents Chemother. 37(5), 1028-36.

Pautsch, A. \& Schulz, G. E. (1998). Structure of the outer membrane protein A transmembrane domain. Nat. Struct. Biol. 5(11), 1013-7.

Pedigo, S. \& Shea, M. A. (1995). Discontinuous equilibrium titrations of cooperative calcium binding to calmodulin monitored by 1-D 1H-nuclear magnetic resonance spectroscopy. Biochemistry 34(33), 10676-89.

Perna, N. T., Mayhew, G. F., Posfai, G., Elliott, S., Donnenberg, M. S., Kaper, J. B. \& Blattner, F. R. (1998). Molecular evolution of a pathogenicity island from enterohemorrhagic Escherichia coli O157:H7. Infect. Immun. 66(8), 3810-7. 
Persechini, A. \& Kretsinger, R. H. (1988). Toward a model of the calmodulin-myosin light-chain kinase complex: implications for calmodulin function. J. Cardiovasc. Pharmacol. 12 Suppl 5, S1-12.

Pohlner, J., Halter, R., Beyreuther, K. \& Meyer, T. F. (1987a). Gene structure and extracellular secretion of Neisseria gonorrhoeae IgA protease. Nature 325(6103), 458-62.

Pohlner, J., Halter, R. \& Meyer, T. F. (1987b). Neisseria gonorrhoeae IgA protease. Secretion and implications for pathogenesis. Antonie Van Leeuwenhoek 53(6), 479-84.

Prince, S. M., Achtman, M. \& Derrick, J. P. (2002). Crystal structure of the OpcA integral membrane adhesin from Neisseria meningitidis. Proc. Natl. Acad. Sci. U S A 99(6), 3417-21.

Pugsley, A. P. (1993). The complete general secretory pathway in Gram-negative bacteria. Microbiol. Rev. 57(1), 50-108.

Pugsley, A. P. \& Reeves, P. (1976). Iron uptake in colicin B-resistant mutants of Escherichia coli K-12. J. Bacteriol. 126(3), 1052-62.

Pugsley, A. P. \& Reeves, P. (1977). Uptake of ferrienterochelin by Escherichia coli: energy dependent stage of uptake. J. Bacteriol. 130(1), 26-36.

Randall, L. L. \& Hardy, S. J. (1986). Correlation of competence for export with lack of tertiary structure of the mature species: a study in vivo of maltose-binding protein in E. coli. Cell 46(6), 921-8.

Reeves, P. (1995). Role of O-antigen variation in the immune response. Trends Microbiol. 3(10), 381-6.

Roberts, R. W. \& Szostak, J. W. (1997). RNA-peptide fusions for the in vitro selection of peptides and proteins. Proc. Natl. Acad. Sci. U S A 94(23), 12297-302.

Rocken, M., Urban, J. \& Shevach, E. M. (1994). Antigen-specific activation, tolerization, and reactivation of the interleukin 4 pathway in vivo. J. Exp. Med. 179(6), 1885-93.

Rogers, H. J. (1974). Peptidoglycans (mucopeptides): structure, function, and variations. Ann. N. Y. Acad. Sci. 235(0), 29-51.

Rosenshine, I., Donnenberg, M. S., Kaper, J. B. \& Finlay, B. B. (1992). Signal transduction between enteropathogenic Escherichia coli (EPEC) and epithelial cells: EPEC induces tyrosine phosphorylation of host cell proteins to initiate cytoskeletal rearrangement and bacterial uptake. Embo J. 11(10), 3551-60.

Rosenshine, I., Ruschkowski, S. \& Finlay, B. B. (1996a). Expression of attaching/effacing activity by enteropathogenic Escherichia coli depends on growth phase, temperature, and protein synthesis upon contact with epithelial cells. Infect. Immun. 64(3), 966-73.

Rosenshine, I., Ruschkowski, S., Stein, M., Reinscheid, D. J., Mills, S. D. \& Finlay, B. B. (1996b). A pathogenic bacterium triggers epithelial signals to form a functional bacterial receptor that mediates actin pseudopod formation. Embo J. 15(11), 2613-24.

Rosing, M. T. (1999). 13C-Depleted carbon microparticles in >3700-Ma sea-floor sedimentary rocks from west greenland. Science 283(5402), 674-6.

Rüther, U. \& Müller-Hill, B. (1983). Easy identification of cDNA clones. Embo J. 2(10), $1791-4$.

Saffman, P. G. \& Delbrück, M. (1975). Brownian motion in biological membranes. Proc. Natl. Acad. Sci. U S A 72(8), 3111-3. 
Saiki, R. K., Gelfand, D. H., Stoffel, S., Scharf, S. J., Higuchi, R., Horn, G. T., Mullis, K. B. \& Erlich, H. A. (1988). Primer-directed enzymatic amplification of DNA with a thermostable DNA polymerase. Science 239(4839), 487-91.

Sambrook, J., Fritsch, E. F. \& Maniatis, T. (1989). Molecular cloning: a laboratory manual. Cold Spring Harbor Laboratory Press, Cold Spring Harbor, New York.

Sandkvist, M. (2001). Biology of type II secretion. Mol. Microbiol. 40(2), 271-83.

Sassanfar, M. \& Szostak, J. W. (1993). An RNA motif that binds ATP. Nature 364(6437), 550-3.

Schaffitzel, C., Hanes, J., Jermutus, L. \& Plückthun, A. (1999). Ribosome display: an in vitro method for selection and evolution of antibodies from libraries. J. Immunol. Methods 231(1-2), 119-35.

Schauer, D. B. \& Falkow, S. (1993). Attaching and effacing locus of a Citrobacter freundii biotype that causes transmissible murine colonic hyperplasia. Infect. Immun. 61(6), 248692.

Schembri, M. A., Kjaergaard, K. \& Klemm, P. (1999). Bioaccumulation of heavy metals by fimbrial designer adhesins. FEMS Microbiol. Lett. 170(2), 363-71.

Schirmer, T. (1998). General and specific porins from bacterial outer membranes. J. Struct. Biol. 121(2), 101-9.

Schirmer, T., Keller, T. A., Wang, Y. F. \& Rosenbusch, J. P. (1995). Structural basis for sugar translocation through maltoporin channels at $3.1 \AA$ resolution. Science 267(5197), $512-4$.

Schlegel, H. G. (1992). Allgemeine Mikrobiologie, 7. Auflage, Thieme Verlag, Stuttgart, New York.

Schmidt, A. (1995). Konstruktion und Charakterisierung varianter Immunglobulindomänen mit putativ faltungsstabilisierenden Aminosäureaustauschen. Diplomarbeit an der Georg-August-Universität Göttingen.

Selifonova, O., Valle, F. \& Schellenberger, V. (2001). Rapid evolution of novel traits in microorganisms. Appl. Environ. Microbiol. 67(8), 3645-9.

Shimazu, M., Mulchandani, A. \& Chen, W. (2001). Cell surface display of organophosphorus hydrolase using ice nucleation protein. Biotechnol. Prog. 17(1), 76-80.

Shusta, E. V., Kieke, M. C., Parke, E., Kranz, D. M. \& Wittrup, K. D. (1999). Yeast polypeptide fusion surface display levels predict thermal stability and soluble secretion efficiency. J. Mol. Biol. 292(5), 949-56.

Sidhu, S. S., Weiss, G. A. \& Wells, J. A. (2000). High copy display of large proteins on phage for functional selections. J. Mol. Biol. 296(2), 487-95.

Singer, S. J. \& Nicholson, G. L. (1972). The fluid mosaic model of the structure of cell membranes. Science 175: 720-31.

Skerra, A. (1994). Use of the tetracycline promoter for the tightly regulated production of a murine antibody fragment in Escherichia coli. Gene 151(1-2), 131-5.

Smith, G. P. (1985). Filamentous fusion phage: novel expression vectors that display cloned antigens on the virion surface. Science 228(4705), 1315-7.

Snapper, C. M., Finkelman, F. D. \& Paul, W. E. (1988). Differential regulation of IgG1 and IgE synthesis by interleukin 4. J. Exp. Med. 167(1), 183-96. 
Snijder, H. J., Ubarretxena-Belandia, I., Blaauw, M., Kalk, K. H., Verheij, H. M., Egmond, M. R., Dekker, N. \& Dijkstra, B. W. (1999). Structural evidence for dimerization-regulated activation of an integral membrane phospholipase. Nature 401(6754), 717-21.

Song, S., Zhang, T., Qi, W., Zhao, W., Xu, B. \& Liu, J. (1993). Transformation of Escherichia coli with foreign DNA by electroporation. Chin. J. Biotechnol. 9(3), 197-201.

Staley, T. E., Jones, E. W. \& Corley, L. D. (1969). Attachment and penetration of Escherichia coli into intestinal epithelium of the ileum in newborn pigs. Am. J. Pathol. $\mathbf{5 6}(3), 371-92$.

Sternberg, N. \& Hoess, R. H. (1995). Display of peptides and proteins on the surface of bacteriophage lambda. Proc. Natl. Acad. Sci. U S A 92(5), 1609-13.

Strynadka, N. C., Eisenstein, M., Katchalski-Katzir, E., Shoichet, B. K., Kuntz, I. D., Abagyan, R., Totrov, M., Janin, J., Cherfils, J., Zimmerman, F., Olson, A., Duncan, B., Rao, M., Jackson, R., Sternberg, M. \& James, M. N. (1996a). Molecular docking programs successfully predict the binding of a $\beta$-lactamase inhibitory protein to TEM-1 $\beta$-lactamase. Nat. Struct. Biol. 3(3), 233-9.

Strynadka, N. C., Jensen, S. E., Alzari, P. M. \& James, M. N. (1996b). A potent new mode of $\beta$-lactamase inhibition revealed by the $1.7 \mathrm{~A} X$-ray crystallographic structure of the TEM-1-BLIP complex. Nat. Struct. Biol. 3(3), 290-7.

Strynadka, N. C., Jensen, S. E., Johns, K., Blanchard, H., Page, M., Matagne, A., Frère, J. M. \& James, M. N. (1994). Structural and kinetic characterization of a $\beta$ lactamase-inhibitor protein. Nature 368(6472), 657-60.

Szostak, J. W., Bartel, D. P. \& Luisi, P. L. (2001). Synthesizing life. Nature 409(6818), 387-90.

Tanaka, T., Ohmura, T. \& Hidaka, H. (1982). Hydrophobic interaction of the Ca2+calmodulin complex with calmodulin antagonists. Naphthalenesulfonamide derivatives. Mol. Pharmacol. 22(2), 403-7.

Tawfik, D. S. \& Griffiths, A. D. (1998). Man-made cell-like compartments for molecular evolution. Nat. Biotechnol. 16(7), 652-6.

Tzipori, S., Gunzer, F., Donnenberg, M. S., de Montigny, L., Kaper, J. B. \& Donohue-Rolfe, A. (1995). The role of the eaeA gene in diarrhea and neurological complications in a gnotobiotic piglet model of enterohemorrhagic Escherichia coli infection. Infect. Immun. 63(9), 3621-7.

Ueno, Y., Yurimoto, H., Yoshioka, H., Komiya, T. \& Maruyama, S. (2002). Ion microprobe analysis of graphite from ca. 3.8 Ga metasediments, Isua crustal belt, West Greenland: relationship between metamorphism and carbon isotopic composition. Geochim. Cosmochim. Acta 66, 1257-68.

Ulshen, M. H. \& Rollo, J. L. (1980). Pathogenesis of Escherichia coli gastroenteritis in man-another mechanism. N. Engl. J. Med. 302(2), 99-101.

van Heijenoort, J. (2001). Formation of the glycan chains in the synthesis of bacterial peptidoglycan. Glycobiology 11(3), 25R-36R.

Vandeputte-Rutten, L., Kramer, R. A., Kroon, J., Dekker, N., Egmond, M. R. \& Gros, P. (2001). Crystal structure of the outer membrane protease OmpT from Escherichia coli suggests a novel catalytic site. Embo J. 20(18), 5033-9. 
Veiga, E., Sugawara, E., Nikaido, H., de Lorenzo, V. \& Fernandez, L. A. (2002). Export of autotransported proteins proceeds through an oligomeric ring shaped by Cterminal domains. Embo J. 21(9), 2122-31.

Vogt, J. \& Schulz, G. E. (1999). The structure of the outer membrane protein OmpX from Escherichia coli reveals possible mechanisms of virulence. Structure Fold. Des. 7(10), 13019.

Waley, S. G. (1988). $\beta$-lactamases: a major cause of antibiotic resistance. Sci. Prog. $\mathbf{7 2 ( 2 8 8}$ Pt 4), 579-97.

Waley, S. G. (1992). In: The Chemistry of $\beta$-Lactams (Page, M. I., Hg.), S. 198-228. Blackie, London.

Walter, K. (1999). Isolierung von Varianten des Ecballium elaterium Trypsin-Inhibitors II durch Escherichia coli Zelloberflächenpräsentation und Fluoreszenz-aktivierte Zellsortierung. Diplomarbeit an der Georg-August-Universität Göttingen.

Walter, M. (1983). Archaean stromatolites: evidence for the Earth's earliest benthos. In: Earth's earliest biosphere: it's origin and evolution (J. W. Schopf, Hg.), S. 187-213. Princeton University Press.

Waterhouse, P., Griffiths, A. D., Johnson, K. S. \& Winter, G. (1993). Combinatorial infection and in vivo recombination: a strategy for making large phage antibody repertoires. Nucleic Acids Res. 21(9), 2265-6.

Wentzel, A., Christmann, A., Adams, T. \& Kolmar, H. (2001). Display of passenger proteins on the surface of Escherichia coli $\mathrm{K}-12$ by the enterohemorrhagic E. coli intimin EaeA. J. Bacteriol. 183(24), 7273-84.

Wentzel, A., Christmann, A., Krätzner, R. \& Kolmar, H. (1999). Sequence requirements of the GPNG $\beta$-turn of the Ecballium elaterium trypsin inhibitor II explored by combinatorial library screening. J. Biol. Chem. 274(30), 21037-43.

Westerlund-Wikström, B. (2000). Peptide display on bacterial flagella: principles and applications. Int. J. Med. Microbiol. 290(3), 223-30.

Westerlund-Wikström, B., Tanskanen, J., Virkola, R., Hacker, J., Lindberg, M., Skurnik, M. \& Korhonen, T. K. (1997). Functional expression of adhesive peptides as fusions to Escherichia coli flagellin. Protein Eng. 10(11), 1319-26.

Westermeier, R. Hg. (1990). In: Elektrophorese-Praktikum, S. 53-64. VCH Verlagsgesellschaft, Weinheim.

Whittaker, R. H. \& Margulis, L. (1978). Protist classification and the kingdoms of organisms. Biosystems 10(1-2), 3-18.

Wilde, S. A., Valley, J. W., Peck, W. H. \& Graham, C. M. (2001). Evidence from detrital zircons for the existence of continental crust and oceans on the Earth 4.4 Gyr ago. Nature 409(6817), 175-8.

Willats, W. G. (2002). Phage display: practicalities and prospects. Plant Mol. Biol. 50(6), $837-54$.

Winter, G., Griffiths, A. D., Hawkins, R. E. \& Hoogenboom, H. R. (1994). Making antibodies by phage display technology. Annu. Rev. Immunol. 12, 433-55.

Woese, C. R., Kandler, O. \& Wheelis, M. L. (1990). Towards a natural system of organisms: proposal for the domains Archaea, Bacteria, and Eucarya. Proc. Natl. Acad. Sci. U S A 87(12), 4576-9. 
Woese, C. R., Magrum, L. J. \& Fox, G. E. (1978). Archaebacteria. J. Mol. Evol. 11(3), 24551.

Wolf, Y. I., Rogozin, I. B., Grishin, N. V. \& Koonin, E. V. (2002). Genome trees and the tree of life. Trends Genet. 18(9), 472-9.

Wolff, C., Nisan, I., Hanski, E., Frankel, G. \& Rosenshine, I. (1998). Protein translocation into host epithelial cells by infecting enteropathogenic Escherichia coli. Mol. Microbiol. 28(1), 143-55.

Yokota, T., Otsuka, T., Mosmann, T., Banchereau, J., DeFrance, T., Blanchard, D., De Vries, J. E., Lee, F. \& Arai, K. (1986). Isolation and characterization of a human interleukin cDNA clone, homologous to mouse B-cell stimulatory factor 1, that expresses B-cell- and T-cell-stimulating activities. Proc. Natl. Acad. Sci. U S A 83(16), 5894-8.

Yu, J. \& Kaper, J. B. (1992). Cloning and characterization of the eae gene of enterohaemorrhagic Escherichia coli O157:H7. Mol. Microbiol. 6(3), 411-7.

Zhang, L., Foxman, B., Manning, S. D., Tallman, P. \& Marrs, C. F. (2000). Molecular epidemiologic approaches to urinary tract infection gene discovery in uropathogenic Escherichia coli. Infect. Immun. 68(4), 2009-15. 


\section{Diplomarbeit:}

Wentzel, A. (1999). Über die Faltung eines Mikroproteins mit Cystin-KnotenFaltungsmotiv am Beispiel des Trypsin-Inhibitors II von Ecballium elaterium (L.) A. Rich. (EETI-II). Diplomarbeit an der Georg-August Universität Göttingen.

\section{Eigene Veröffentlichungen:}

Wentzel, A., Christmann, A., Krätzner, R. \& Kolmar, H. (1999). Sequence requirements of the GPNG $\beta$-turn of the Ecballium elaterium trypsin inhibitor II explored by combinatorial library screening. J. Biol. Chem. 274(30), 21037-43.

Christmann, A., Walter, K., Wentzel, A., Krätzner, R. \& Kolmar, H. (1999). The cystine knot of a squash-type protease inhibitor as a structural scaffold for Escherichia coli cell surface display of conformationally constrained peptides. Protein Eng. 12(9), 797-806.

\section{Eigene Veröffentlichungen im Rahmen dieser Arbeit:}

Christmann, A., Wentzel, A., Meyer, C., Meyers, G. \& Kolmar, H. (2001). Epitope mapping and affinity purification of monospecific antibodies by Escherichia coli cell surface display of gene-derived random peptide libraries. J. Immunol. Methods 257(1-2), $163-73$.

Wentzel, A., Christmann, A., Adams, T. \& Kolmar, H. (2001). Display of passenger proteins on the surface of Escherichia coli $\mathrm{K}-12$ by the enterohemorrhagic E. coli intimin EaeA. J. Bacteriol. 183(24), 7273-84.

\section{Patente:}

Kolmar, H., Wentzel, A., Christmann, A. (2002). Verfahren zur Exposition von Peptiden und Proteinen auf der Zelloberfläche von Bakterien. Anmelder: Georg-AugustUniversität Göttingen. DE 10053224 A1

Kolmar, H., Christmann, A., Wentzel, A. (2002). Method for exposing peptides and polypeptides on the cell surface of bacteria. Anmelder: Georg-August-Universität Göttingen. WO 02/34906 A2 


\section{Anhang}

\subsection{Abkürzungen}

Die verwendeten ein- und dreibuchstabigen Abkürzungen für Aminosäuren sowie alle verwendeten physikalischen Größen entsprechen der Konvention der International Union for Biochemistry (Liébecq, 1978).

$\lambda$

${ }^{\circ} \mathrm{C} \quad$ Grad Celsius

$\mu \quad$ mikro

A Adenin

Abb. Abbildung

Amp ${ }^{\mathrm{x}} \quad$ Ampicillin, $\mathrm{x} \mu \mathrm{g} / \mathrm{ml}$

APS Ammoniumperoxodisulfat

AS Aminosäure(n)

ATP Adenosintriphosphat

BCIP 5-Brom-4-Chlor-3-Indolylphosphat ( $p$-Toluidinsalz)

Bla $\quad \beta$-Laktamase

bla $\quad \beta$-Laktamase-Gen

BLIP $\quad \beta$-Laktamase Inhibitor Protein

bp Basenpaare

BSA Rinderserum-Albumin

bzw. beziehungsweise

C Cytosin

c Konzentration

ca. cirka

cat Gen für die Chloramphenicol-Acetyltransferase

$\mathrm{Cm}^{\mathrm{x}} \quad$ Chloramphenicol, $\mathrm{x} \mu \mathrm{g} / \mathrm{ml}$

C-terminal carboxyterminal

C-Terminus Carboxyterminus

d.h. das heißt

ddNTP Didesoxynukleosidtriphosphat

DMF Dimethylformamid

DMSO Dimethylsulfoxid

DNA Desoxyribonucleic Acid, Desoxyribonukleinsäure

dNTP Desoxynukleosidtriphosphat

dsDNA double stranded DNA, doppelsträngige DNA

DTT Dithiothreitol

dYT double Yeast Tryptone (-Medium)

E. coli Escherichia coli

EaeA, EaeA' Intimin enterohaemorrhagischer E. coli, Intimin' (um E2 und E3 verkürzte Varianten von EaeA)

eaeA, eaeA' EHEC Intimin-Gen, Intimin'-Gen

EDTA Ethylendiamintetraacetat

EETI-II Ecballium elaterium Trypsin-Inhibitor II

eeti-II Gen des Ecballium elaterium Trypsin-Inhibitors II

EETI-CK ${ }^{\text {send }}$ EETI-II mit dem Sendai-Epitop anstelle der Wildtyp-Inhibitorschleife 
EHEC, EPEC enterohaemorrhagische E. coli, enteropathogene E. coli

et al. et alteri (und andere)

f femto

f1 Replikationsursprung des Phagen f1

FACS Fluorescence Activated Cell Sorter (Gerät) oder Fluoreszenz-aktivierte Zellsortierung (Verfahren)

$F_{v} \quad$ variable Immunglobulin-Domäne

G Guanin

h Stunde(n)

$\mathrm{Hg}(\mathrm{g})$. Herausgeber (Plural)

Il-4 Interleukin 4

IPTG Isopropyl- $\beta$-D-thiogalactopyranosid

IR Infrarot

$\operatorname{Kan}^{\mathrm{x}} \quad$ Kanamycin, $\mathrm{x} \mu \mathrm{g} / \mathrm{ml}$

$\mathrm{kb} \quad$ Kilobasen

$K_{i} \quad$ Inhibitionskonstante in $\mathrm{M}$

$1 \quad$ Liter

lac zum E. coli Laktose-Operon gehörend (z.B. lac-Repressor, lac P/O)

M Molar

$\mathrm{mA} \quad$ Milliampère

$\min \quad$ Minute

$\mathrm{ml} \quad$ Milliliter

$M_{\mathrm{r}} \quad$ relatives Molekulargewicht, relative Molmasse

mRNA messenger RNA

n nano

NBT 4-Nitrotetrazoliumchloridblau

Nr. Nummer

nt Nukleotid(e)

$\mathrm{N}$-terminal aminoterminal

$\mathrm{N}$-Terminus Aminoterminus

O.D.x Optische Dichte bei einer Wellenlänge von $\mathrm{x} n \mathrm{~m}$

ori Replikationsursprung

p pico

p.A. proanalysi

$\mathrm{P} / \mathrm{O} \quad$ Promotor/Operator-Region

PAG Polyacrylamid-Gel

PAGE Polyacrylamid-Gelelektrophorese

PBS Phosphate Buffered Saline (-Puffer)

PBST Phosphate Buffered Saline Tween20 (-Puffer)

PCR Polymerase Chain Reaction, Polymerase-Kettenreaktion

PEG Polyethylenglycol

$\mathrm{pH} \quad$ Negativ dekadischer Logarithmus der Protonenkonzentration

RNA Ribonucleic Acid, Ribonukleinsäure

rpm rounds per minute, Umdrehungen pro Minute

RT Raumtemperatur $\left(\sim 20^{\circ} \mathrm{C}\right)$

s Sekunden

s.o. siehe oben

$s c F_{v} \quad$ single-chain $F_{v}$, Einketten- $F_{v}$-Domäne 


$\begin{array}{ll}\text { SDS } & \text { Sodiumdodecylsulfate, Natriumdodecylsulfat } \\ \text { send } & \text { Sequenz für das Sendai-Epitop (Einberger et al., 1990) } \\ \text { SSC } & \text { Saline Sodium-Citrate(-Puffer) } \\ \text { ssDNA } & \text { single stranded DNA, einzelsträngige DNA } \\ \text { T } & \text { Thymin } \\ \text { TAE } & \text { Tris-Acetate-EDTA (-Puffer) } \\ \text { TBE } & \text { Tris-Borate-EDTA (-Puffer) } \\ \text { TE } & \text { Tris-EDTA (-Puffer) } \\ \text { TEMED } & \text { N,N,N',N'-Tetramethylethylendiamin } \\ \text { Tris } & \text { Tris(hydroxymethyl)aminomethan } \\ \text { U } & \text { Uracil } \\ \text { u, U } & \text { units } \\ \text { u.a. } & \text { unter anderem/anderen } \\ \text { üN } & \text { über Nacht } \\ \text { Upm } & \text { Umdrehungen pro Minute } \\ \text { UV } & \text { Ultraviolett } \\ \text { V } & \text { Volt } \\ \text { v/v } & \text { Volumen pro Volumen } \\ \text { vgl. } & \text { vergleiche } \\ \text { Vol. } & \text { Volumen } \\ \text { W } & \text { Watt } \\ \text { W/v } & \text { Masse pro Volumen } \\ \text { X-Gal } & \text { 5-Brom-4-Chlor-3-Indolyl- } \beta \text {-D-Thiogalactopyranosid } \\ \text { z.B. } & \text { zum Beispiel } \\ & \end{array}$




\title{
8.2 Sequenzen
}

\subsection{1 pASKInt100-P}

\section{- Schematische Darstellung des Plasmids pASKInt100-P.}

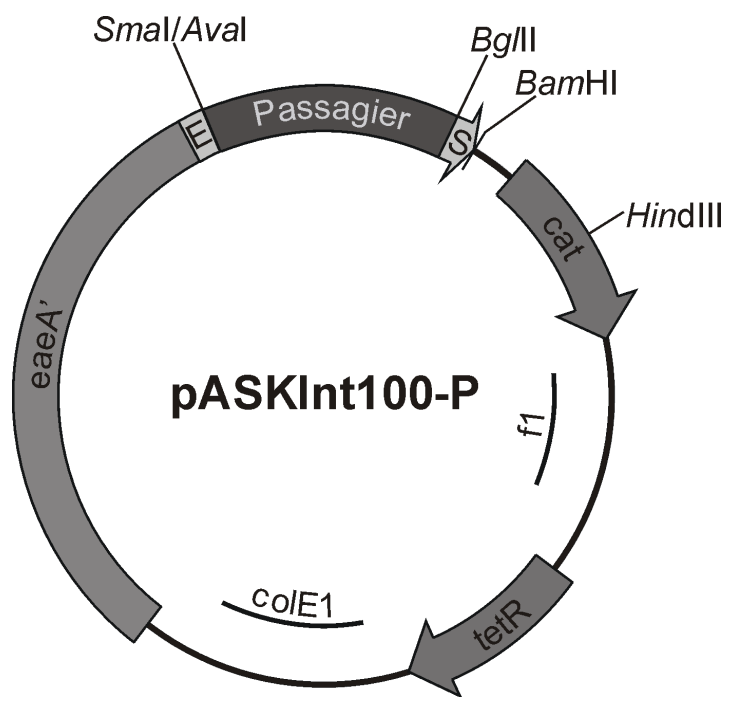

\begin{abstract}
Abbildung 28. Schematische Darstellung des Plasmids pASKInt100-P. Pfeilrichtungen geben die funktionellen Orientierungen der genetischen Elemente an. eae $A^{\prime}$ : Kodone 1 bis 659 des eaeA Gens enterohaemorrhagischer Escherichia coli (EHEC) O157:H7, E: kodierende Sequenz für das 17 Aminosäuren umfassende E-Epitop des menschlichen Gla-Proteins, Passagier: kodierende Sequenz für die jeweils verwendete Passagierdomäne P, S: kodierende Sequenz für das 13 Aminosäuren umfassende Epitop des Sendai-Virus, cat: kodierende Sequenz für das Chloramphenicol-Acetyltransferase-Gen, f1: intergenetische Region des filamentösen Phagen $f 1$ mit dem $f 1$-Replikationsursprung, tet $R$ : kodierende Sequenz für den tetA-Repressor, colE1: colE1-Replikationsursprung von E.coli. Die Expression des eaeA' Fusionsgens erfolgt unter der strikten Kontrolle der tetA-Promotor/Operator-Region. Wichtige Erkennungssequenzen für im Rahmen dieser Arbeit verwendete Restriktionsendonukleasen sind hervorgehoben.
\end{abstract}

- Nukleotidsequenz des Plasmids pASKInt100-P.

\begin{tabular}{|r|l|}
\hline $1-138$ & pASK75 (1-138) \\
\hline $139-2115$ & Kodone 1 bis 659 des EHEC O157-H7 eaeA Gens (eaeA') \\
\hline $2116-2133$ & spacer-Region (kodierte IgA-Protease Erkennungssequenz) \\
\hline $2134-2184$ & kodierende Sequenz für das E-Epitop (17 AS) \\
\hline $2185-2193$ & spacer-Region (AvaI/SmaI) \\
\hline $2194-3223$ & $\begin{array}{l}\text { kodierende Sequenz der Passagierdomäne P (unterschiedliche Länge, } \\
\text { hier 1029 bp) }\end{array}$ \\
\hline $3224-3235$ & spacer-Region (BglII) \\
\hline $3236-3274$ & kodierende Sequenz für das Sendai-Epitop (13 AS) \\
\hline $3275-3283$ & spacer-Region (BamHI) \\
\hline $3284-4152$ & $\begin{array}{l}\text { pHK5-20 mit kodierender Sequenz für die Chloramphenicol-Acetyl- } \\
\text { transferase }\end{array}$ \\
\hline $4153-4979$ & pASK75 (246-1830 unter Deletion des $\beta$-Lactamase-Gens) \\
\hline $4980-5603$ & kodierende Sequenz für den tetA-Repressor \\
\hline $5604-6412$ & pASK75 (2458-3266) \\
\hline
\end{tabular}


1 CCATCGAATg GCCAGATGAT tAATTCCTAA TTtTTGTTGA CACTCTATCA GgTAGCTTAC CGGTCTACTA ATtAAGGATT AAAAACAACT GTGAGATAGT

51 TtgAtAgAgt tAtTtTACCA CtCCCtAtCA GTGAtAgAgA AAAgtgAAAT

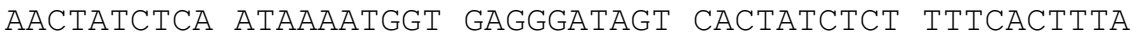

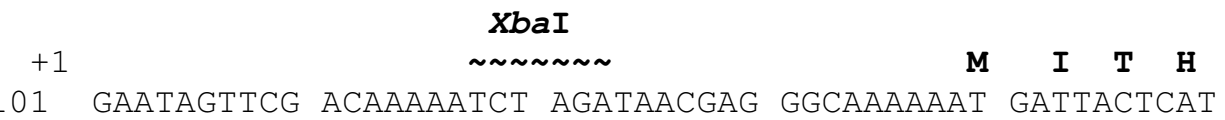
CtTAtCAAGC TGtTtTtAgA tCtAtTgCtC CCGTtTttTA CTAAtgAgtA

$\begin{array}{llllllllllllllllll}+1 & \mathbf{G} & \mathbf{C} & \mathbf{Y} & \mathbf{T} & \mathbf{R} & \mathbf{T} & \mathbf{R} & \mathbf{H} & \mathbf{K} & \mathbf{H} & \mathbf{K} & \mathbf{L} & \mathbf{K} & \mathbf{K} & \mathbf{T} & \mathbf{L} & \mathbf{I}\end{array}$ 151 GgtTgtTAtA CCCGGACCCG GCACAAGCAT AAgCTAAAAA AAACATTGAT CCAACAATAT GgGCCTGGgC CGtgtTCGtA tTCGAtTtTt tTtgtAACtA

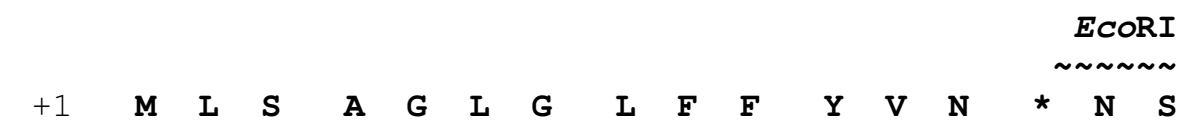

201 TATGCTTAGT GCTGgtTTAG GATTGTTTTT TTATGTTAAT TAgAATtCAT ATACGAATCA CGACCAAATC CTAACAAAAA AATACAATTA ATCTTAAGTA

$\begin{array}{llllllllllllllllll}+1 & \mathbf{F} & \mathbf{A} & \mathbf{N} & \mathbf{G} & \mathbf{E} & \mathbf{N} & \mathbf{Y} & \mathbf{F} & \mathbf{K} & \mathbf{L} & \mathbf{G} & \mathbf{S} & \mathbf{D} & \mathbf{S} & \mathbf{K} & \mathbf{L} & \mathbf{L}\end{array}$

251 TTGCAAATGg TGAAAATTAT TTTAAATTGg GTTCGGATTC AAAACTGTTA AACGTTTACC ACTTTTAATA AAATTTAACC CAAGCCTAAg TTTTGACAAT

$\begin{array}{llllllllllllllllll}+1 & \mathbf{T} & \mathbf{H} & \mathbf{D} & \mathbf{S} & \mathbf{Y} & \mathbf{Q} & \mathbf{N} & \mathbf{R} & \mathbf{L} & \mathbf{F} & \mathbf{Y} & \mathbf{T} & \mathbf{L} & \mathbf{K} & \mathbf{T} & \mathbf{G} & \mathbf{E}\end{array}$ 301 ACTCATGATA GCTATCAGAA TCGCCTTTTT TATACGTTGA AAACTGGTGA TGAgTACTAT CGATAgTCTT AgCGgAAAAA ATATGCAACT TTTGACCACT

$\begin{array}{llllllllllllllllll}+1 & \mathbf{T} & \mathbf{V} & \mathbf{A} & \mathrm{D} & \mathbf{L} & \mathbf{S} & \mathbf{K} & \mathbf{S} & \mathbf{Q} & \mathrm{D} & \mathbf{I} & \mathbf{N} & \mathbf{L} & \mathbf{S} & \mathbf{T} & \mathbf{I}\end{array}$

351 AACTGTTGCC GATCTTTCTA AAtCGCAAgA TAtTAATtTA tCGACGATTT TTGACAACGg CTAGAAAgAT TTAGCGTTCT AtAAtTAAAT AgCTGCTAAA

$\begin{array}{llllllllllllllllll}+1 & \mathbf{W} & \mathbf{S} & \mathbf{L} & \mathbf{N} & \mathbf{K} & \mathbf{H} & \mathbf{L} & \mathbf{Y} & \mathbf{S} & \mathbf{S} & \mathbf{E} & \mathbf{S} & \mathbf{E} & \mathbf{M} & \mathbf{M} & \mathbf{K} & \mathbf{A}\end{array}$

401 GgtCGTtGA tAAGCATtTA TACAgtTCTg AAAgCGAAAT GATGAAgGCC CCAGCAACTT ATtCGTAAAT ATGTCAAGAC TTtCGCTTTA CTACTTCCGG

$\begin{array}{llllllllllllllllll}+1 & \mathbf{A} & \mathbf{P} & \mathbf{G} & \mathbf{Q} & \mathbf{Q} & \mathbf{I} & \mathbf{I} & \mathbf{L} & \mathbf{P} & \mathbf{L} & \mathbf{K} & \mathbf{K} & \mathbf{L} & \mathbf{P} & \mathbf{F} & \mathbf{E} & \mathbf{Y}\end{array}$ 451 GCGCCTGGTC AgCAgAtCAT TTtgCCACTC AAAAAACTTC CCTTTGAAtA CGCGgACCAg tCGtCtAgtA AAACGgtgAg tTttitgAAg GgAAACtTAt

$\begin{array}{lllllllllllllllll}+1 & \mathbf{S} & \mathbf{A} & \mathbf{L} & \mathbf{P} & \mathbf{L} & \mathbf{L} & \mathbf{G} & \mathbf{S} & \mathbf{A} & \mathbf{P} & \mathbf{L} & \mathbf{V} & \mathbf{A} & \mathbf{A} & \mathbf{G} & \mathbf{G}\end{array}$

501 CAgTGCACTA CCACTTTTAG GTtCGgCACC TCTTGTTGCT GCAGgTGgtG GTCACGTGAT GGTGAAAATC CAAGCCGTGG AGAACAACGA CGTCCACCAC

$\begin{array}{llllllllllllllllll}+1 & \mathbf{V} & \mathbf{A} & \mathbf{G} & \mathbf{H} & \mathbf{T} & \mathbf{N} & \mathbf{K} & \mathbf{L} & \mathbf{T} & \mathbf{K} & \mathbf{M} & \mathbf{S} & \mathbf{P} & \mathbf{D} & \mathbf{V} & \mathbf{T} & \mathbf{K}\end{array}$

551 TtgCtGgtCA CACGAATAAA CTGACTAAAA TGTCCCCGGA CGTGACCAAA AACGACCAGT GTGCTTATTT GACTGATTTT ACAGGGGCCT GCACTGGTTT

$\begin{array}{llllllllllllllllll}+1 & \mathbf{S} & \mathbf{N} & \mathbf{M} & \mathbf{T} & \mathbf{D} & \mathbf{D} & \mathbf{K} & \mathbf{A} & \mathbf{L} & \mathbf{N} & \mathbf{Y} & \mathbf{A} & \mathbf{A} & \mathbf{Q} & \mathbf{Q} & \mathbf{A} & \mathbf{A}\end{array}$ 601 AgCAACATGA CCGATGACAA GgCATtAAAT TAtGCGGCAC AACAGgCGgC TCGTTGTACT GGCTACTGTT CCGTAATtTA ATACGCCGTG TTGTCCGCCG

$\begin{array}{lllllllllllllllll}+1 & \mathbf{S} & \text { L } & \mathbf{G} & \mathbf{S} & \mathbf{Q} & \mathbf{L} & \mathbf{Q} & \mathbf{S} & \mathbf{R} & \mathbf{S} & \mathrm{L} & \mathbf{N} & \mathbf{G} & \mathrm{D} & \mathbf{Y} & \mathbf{A}\end{array}$

651 GAgtCTCGgt AgCCAGCtTC AgtCGCGATC TCtgAACGgC GAttACGCGA CtCAgAgCCA tCGgtCGAAg tCAgCGCtAg AgACtTGCCG CtAAtgCGCT

$\begin{array}{llllllllllllllllll}+1 & \text { K } & \text { D } & \text { T } & \text { A } & \text { L } & \text { G } & \text { I } & \text { A } & \text { G } & \text { N } & \text { Q } & \text { A } & \text { S } & \text { S } & \text { Q } & \text { L } & \text { Q }\end{array}$ 701 AAgAtACCGC TCtTgGtAtC gCtgGtAACC AggCtTCGTC ACAgtTgCAG tTCtAtGgCG AgAACCAtAg CGACCAtTGg TCCGAAgCAG TGTCAACGTC

$\begin{array}{llllllllllllllllll}+1 & \mathbf{A} & \mathbf{W} & \text { L } & \mathbf{Q} & \text { H } & \mathbf{Y} & \mathbf{G} & \mathbf{T} & \mathbf{A} & \mathbf{E} & \mathbf{V} & \mathbf{N} & \mathbf{L} & \mathbf{Q} & \mathbf{S} & \mathbf{G} & \mathbf{D}\end{array}$ 751 GCCTGgtTAC AACATTATGg AACGgCAGAg GTTAATCTGC AgAgtggtgA CGGACCAATG TTGTAATACC TTGCCGTCTC CAATTAGACG TCTCACCACT 


\section{$\begin{array}{lllllllllllllllll}+1 & \text { N } & \mathbf{F} & \mathbf{D} & \mathbf{G} & \mathbf{S} & \mathbf{S} & \mathbf{L} & \mathbf{D} & \mathbf{F} & \text { L } & \text { L } & \mathbf{P} & \mathbf{F} & \mathbf{Y} & \mathbf{D} & \mathbf{S}\end{array}$}

801 TAACTTTGAC GGTAGTTCAC TGgACTTCTT ATTACCGTTC TATGATTCCG

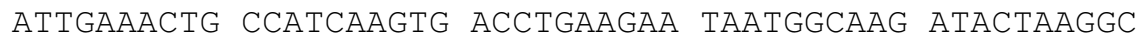

$\begin{array}{llllllllllllllllll}+1 & \mathbf{E} & \mathbf{K} & \mathbf{M} & \mathbf{L} & \mathbf{A} & \mathbf{F} & \mathbf{G} & \mathbf{Q} & \mathbf{V} & \mathbf{G} & \mathbf{A} & \mathbf{R} & \mathbf{Y} & \mathbf{I} & \mathbf{D} & \mathbf{S} & \mathbf{R}\end{array}$

851 AAAAAATGCT GGCATTTGGT CAGGTCGGAG CGCGTTACAT TGACTCCCGC TTTTTTACGA CCGTAAACCA GTCCAGCCTC GCGCAATGTA ACTGAgGgCG

$\begin{array}{llllllllllllllllll}+1 & \mathbf{F} & \mathbf{T} & \mathbf{A} & \mathbf{N} & \mathbf{L} & \mathbf{G} & \mathbf{A} & \mathbf{G} & \mathbf{Q} & \mathbf{R} & \mathbf{F} & \mathbf{F} & \mathbf{L} & \mathbf{P} & \mathbf{A} & \mathbf{N} & \mathbf{M}\end{array}$

901 TTTACGGCAA ATTTAGgTGC GgGTCAGCGT TTTTTCCTTC CTGCAAACAT AAATGCCGTT TAAATCCACG CCCAGTCGCA AAAAAgGAAG GACGTTTGTA

$\begin{array}{lllllllllllllllll}+1 & \text { L } & \mathbf{G} & \mathbf{Y} & \mathbf{N} & \mathbf{V} & \mathbf{F} & \mathbf{I} & \mathbf{D} & \mathbf{Q} & \mathbf{D} & \mathbf{F} & \mathbf{S} & \mathbf{G} & \mathrm{D} & \mathbf{N} & \mathbf{T}\end{array}$

951 GTTGGGCTAT AACGTCTTCA TTGATCAGGA TTTTTCTGGT GATAATACCC CAACCCGATA tTGCAgAAgt AACtAgtCCT AAAAAgACCA CTAtTAtgGg

$\begin{array}{llllllllllllllllll}+1 & \mathbf{R} & \mathbf{L} & \mathbf{G} & \mathbf{I} & \mathbf{G} & \mathbf{G} & \mathbf{E} & \mathbf{Y} & \mathbf{W} & \mathbf{R} & \mathbf{D} & \mathbf{Y} & \mathbf{F} & \mathbf{K} & \mathbf{S} & \mathbf{S} & \mathbf{V}\end{array}$

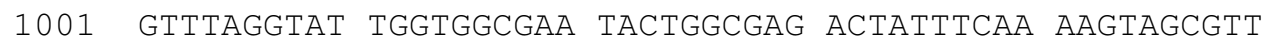
CAAATCCATA ACCACCGCTT AtgACCGCTC TGATAAAgtT TTCATCGCAA

$\begin{array}{llllllllllllllllll}+1 & \mathbf{N} & \mathbf{G} & \mathbf{Y} & \mathbf{F} & \mathbf{R} & \mathbf{M} & \mathbf{R} & \mathbf{R} & \mathbf{W} & \mathbf{H} & \mathbf{E} & \mathbf{S} & \mathbf{Y} & \mathbf{H} & \mathbf{K} & \mathbf{K} & \mathbf{D}\end{array}$ 1051 AACGgCtAtT TCCGCATGAg GCGCTGGCAt GAgtCATACC AtAAgAAAgA tTGCCGAtAA AgGCGtACtC CGCGACCGtA CtCAgtAtgG tAtTCtTtCt

$\begin{array}{llllllllllllllllll}+1 & \mathbf{Y} & \mathbf{D} & \mathbf{E} & \mathbf{R} & \mathbf{P} & \mathbf{A} & \mathbf{N} & \mathbf{G} & \mathbf{F} & \mathbf{D} & \mathbf{I} & \mathbf{R} & \mathbf{F} & \mathbf{N} & \mathbf{G} & \mathbf{Y}\end{array}$ 1101 CtATGATGA CGCCCAGCAA ATGgCtTCGA TATCCGTTTT AATGgCtATC GAtACTACTC GCGgGtCGtT TACCGAAgCT AtAgGCAAAA tTACCGAtAg

$\begin{array}{llllllllllllllllll}+1 & \mathbf{L} & \mathbf{P} & \mathbf{S} & \mathbf{Y} & \mathbf{P} & \mathbf{A} & \mathbf{L} & \mathbf{G} & \mathbf{A} & \mathbf{K} & \mathbf{L} & \mathbf{I} & \mathbf{Y} & \mathbf{E} & \mathbf{Q} & \mathbf{Y} & \mathbf{Y}\end{array}$ 1151 TACCGTCATA TCCGGCATTA GGCGCCAAGC TGATATATGA GCAGTATTAT AtgGCAgtAT AgGCCGTAAT CCGCGgtTCG ACTAtAtACT CGTCATAATA

$\begin{array}{llllllllllllllllll}+1 & \mathbf{G} & \mathbf{D} & \mathbf{N} & \mathbf{V} & \mathbf{A} & \mathbf{L} & \mathbf{F} & \mathbf{N} & \mathbf{S} & \mathbf{D} & \mathrm{K} & \mathrm{L} & \mathbf{Q} & \mathbf{S} & \mathbf{N} & \mathbf{P} & \mathbf{G}\end{array}$ 1201 GgtgAtAATG TTGCTTTGTt tAATtCTGAT AAgCTGCAGT CGAATCCTGG CCACTATTAC AACGAAACAA ATtAAGACTA TTCGACGTCA GCTTAGGACC

$\begin{array}{lllllllllllllllll}+1 & \mathbf{A} & \mathbf{A} & \mathbf{T} & \mathbf{V} & \mathbf{G} & \mathbf{V} & \mathbf{N} & \mathbf{Y} & \mathbf{T} & \mathbf{P} & \mathbf{I} & \mathbf{P} & \mathbf{L} & \mathbf{V} & \mathbf{T} & \mathbf{M}\end{array}$ 1251 TGCGGCGACC GTTGgtgtAA ACTATACTCC GATTCCTCTG GTGACGATGG ACGCCGCTGg CAACCACATt TGAtAtgAgG CtAAgGAgAC CACTGCTACC

$\begin{array}{llllllllllllllllll}+1 & \mathbf{G} & \mathbf{I} & \mathbf{D} & \mathbf{Y} & \mathbf{R} & \mathbf{H} & \mathbf{G} & \mathbf{T} & \mathbf{G} & \mathbf{N} & \mathbf{E} & \mathbf{N} & \mathbf{D} & \mathbf{L} & \mathbf{L} & \mathbf{Y} & \mathbf{S}\end{array}$

1301 GgAtCGATtA CCGTCATGgt ACGgGtAATg AAAATGATCT CCTTTACTCA CCTAGCTAAT GGCAGTACCA TGCCCATTAC TTTTACTAGA GGAAATGAGT

$\begin{array}{llllllllllllllllll}+1 & \mathbf{M} & \mathbf{Q} & \mathbf{F} & \mathbf{R} & \mathbf{Y} & \mathbf{Q} & \mathbf{F} & \mathbf{D} & \mathbf{K} & \mathbf{S} & \mathbf{W} & \mathbf{S} & \mathbf{Q} & \mathbf{Q} & \mathbf{I} & \mathbf{E} & \mathbf{P}\end{array}$

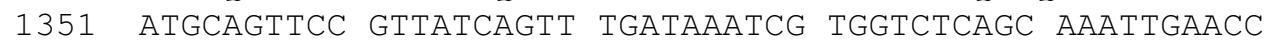
TACGTCAAgG CAAtAgtCAA ACtAtTtAgC ACCAgAgtCG tTtAACtTGg

$\begin{array}{lllllllllllllllll}+1 & \mathbf{Q} & \mathbf{Y} & \mathbf{V} & \mathbf{N} & \mathbf{E} & \mathbf{L} & \mathbf{R} & \mathbf{T} & \mathbf{L} & \mathbf{S} & \mathbf{G} & \mathbf{S} & \mathbf{R} & \mathbf{Y} & \mathbf{D} & \mathbf{L}\end{array}$ 1401 ACAGTATGTT AACGAGTTAA GAACATTATC AgGCAGCCGT TACGATCTGG

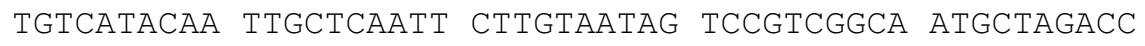

$\begin{array}{llllllllllllllllll}+1 & \mathbf{V} & \mathbf{Q} & \mathbf{R} & \mathbf{N} & \mathbf{N} & \mathbf{N} & \mathbf{I} & \mathbf{I} & \mathbf{L} & \mathbf{E} & \mathbf{Y} & \mathbf{K} & \mathbf{K} & \mathbf{Q} & \mathbf{D} & \mathbf{I} & \mathbf{L}\end{array}$ 1451 TTCAGCGTAA TAACAATATT ATtCTGGAGT ACAAGAAGCA GgATATTCTT

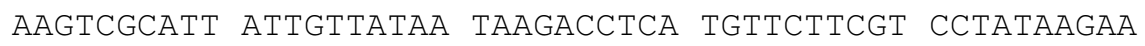

$\begin{array}{lllllllllllllllllll}+1 & \mathbf{S} & \mathbf{L} & \mathbf{N} & \mathbf{I} & \mathbf{P} & \mathbf{H} & \mathbf{D} & \mathbf{I} & \mathbf{N} & \mathbf{G} & \mathbf{T} & \mathbf{E} & \mathbf{H} & \mathbf{S} & \mathbf{T} & \mathbf{Q} & \mathbf{K}\end{array}$ 1501 TCTCTGAATA TTCCGCATGA tATtAATGgt ACTGAACACA GTACGCAGAA AgAgACtTAt AAggCGtACT AtAAtTACCA tgACtTgtgt CAtgCGtCTt

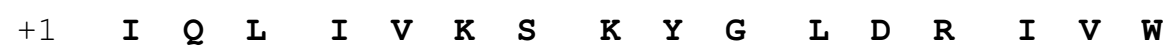
1551 GAtTCAgtTg AtCGtTAAgA gCAAAtACGg TCtgGAtCGT AtCGtCtgGg

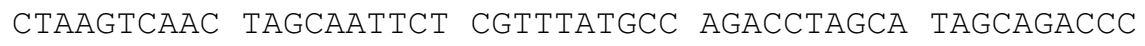

$\begin{array}{llllllllllllllllll}+1 & \mathrm{D} & \mathrm{D} & \mathbf{S} & \mathbf{A} & \mathrm{L} & \mathbf{R} & \mathbf{S} & \mathbf{Q} & \mathbf{G} & \mathbf{G} & \mathbf{Q} & \mathrm{I} & \mathbf{Q} & \mathbf{H} & \mathbf{S} & \mathbf{G} & \mathbf{S}\end{array}$ 1601 AtgAtAgtgC AttACGCAgt CAgggCggtC AgAttCAgCA TAgCGgAagC TACTATCACG TAATGCGTCA GTCCCGCCAG TCtAAgtCGT ATCGCCTTCG 
$\begin{array}{llllllllllllllllll}+1 & \mathbf{Q} & \mathbf{S} & \mathbf{A} & \mathbf{Q} & \mathrm{D} & \mathbf{Y} & \mathbf{Q} & \mathbf{A} & \mathbf{I} & \mathbf{L} & \mathbf{P} & \mathbf{A} & \mathbf{Y} & \mathbf{V} & \mathbf{Q} & \mathbf{G} & \mathbf{G}\end{array}$

1651 CAAAGCGCAC AAGACTACCA GgCTATTTTG CCTGCTTATG TGCAAGgtgG GTtTCGCGTG TTCTGAtgGT CCGAtAAAAC GGACGAATAC ACGTTCCACC

$\begin{array}{lllllllllllllllll}+1 & \mathbf{S} & \mathbf{N} & \mathbf{I} & \mathbf{Y} & \mathbf{K} & \mathbf{V} & \mathbf{T} & \mathbf{A} & \mathbf{R} & \mathbf{A} & \mathbf{Y} & \mathbf{D} & \mathbf{R} & \mathbf{N} & \mathbf{G} & \mathbf{N}\end{array}$

1701 CAgCAATATt TATAAAgtGA CGgCtCGCGC CTATGACCGT AAtgGCAATA GTCGTTATAA ATATTTCACT GCCGAgCGCG GAtACTGgCA tTACCGTTAT

$\begin{array}{llllllllllllllllll}+1 & \mathbf{S} & \mathbf{S} & \mathbf{N} & \mathbf{N} & \mathbf{V} & \mathbf{Q} & \mathbf{L} & \mathbf{T} & \mathbf{I} & \mathbf{T} & \mathbf{V} & \mathbf{L} & \mathbf{S} & \mathbf{N} & \mathbf{G} & \mathbf{Q} & \mathbf{V}\end{array}$ 1751 GCTCTAACAA TGTACAGCTT ACTATTACCG TTCTGTCGAA TGGTCAAGTT CGAGAtTGtT ACATGTCGAA tGAtAAtgGC AAGACAgCtT ACCAGTTCAA

$\begin{array}{llllllllllllllllll}+1 & \mathbf{V} & \mathbf{D} & \mathbf{Q} & \mathbf{V} & \mathbf{G} & \mathbf{V} & \mathbf{T} & \mathbf{D} & \mathbf{F} & \mathbf{T} & \mathbf{A} & \mathbf{D} & \mathbf{K} & \mathbf{T} & \mathbf{S} & \mathbf{A} & \mathbf{K}\end{array}$ 1801 GTCGACCAGG TTGgGgtAAC GgACTTTACG GCGGATAAgA CTTCGgCtAA CAgCtgGtCC AACCCCATtG CCTGAAAtgC CGCCtAttCT GAAGCCGAtT

$\begin{array}{lllllllllllllllll}+1 & \mathbf{A} & \mathbf{D} & \mathbf{N} & \mathbf{A} & \mathbf{D} & \mathbf{T} & \mathbf{I} & \mathbf{T} & \mathbf{Y} & \mathbf{T} & \mathbf{A} & \mathbf{T} & \mathbf{V} & \mathbf{K} & \mathbf{K} & \mathbf{N}\end{array}$

1851 AgCGGAtAAC GCCGATACCA TTACTTATAC CGCGACGgTG AAAAAGAATG TCGCCTATTG CGgCtATGgT AATGAAtATG GCGCTGCCAC TTtTTCtTAC

$\begin{array}{llllllllllllllllll}+1 & \mathbf{G} & \mathbf{V} & \mathbf{A} & \mathbf{Q} & \mathbf{A} & \mathbf{N} & \mathbf{V} & \mathbf{P} & \mathbf{V} & \mathbf{S} & \mathbf{F} & \mathbf{N} & \mathbf{I} & \mathbf{V} & \mathbf{S} & \mathbf{G} & \mathbf{T}\end{array}$ 1901 GgGtAgCtCA GGCTAATGTC CCTGTtTCAT TTAATATTGT TTCAgGAACT CCCATCGAgt CCGATtACAg GgACAAAgtA AAtTAtAACA AAgtCCTtGA

$\begin{array}{llllllllllllllllll}+1 & \mathbf{A} & \mathbf{T} & \mathbf{L} & \mathbf{G} & \mathbf{A} & \mathbf{N} & \mathbf{S} & \mathbf{A} & \mathbf{K} & \mathbf{T} & \mathbf{D} & \mathbf{A} & \mathbf{N} & \mathbf{G} & \mathbf{K} & \mathbf{A} & \mathbf{T}\end{array}$ 1951 GCAACTCTTG GGGCAAATAG TGCCAAAACG GATGCTAACG GTAAGGCAAC CGTtGAgAAC CCCGTtTATC ACGgtTtTGC CTACGAtTGC CAtTCCGtTG

$\begin{array}{lllllllllllllllll}+1 & \mathbf{V} & \mathbf{T} & \mathbf{L} & \mathbf{K} & \mathbf{S} & \mathbf{S} & \mathbf{T} & \mathbf{P} & \mathbf{G} & \mathbf{Q} & \mathbf{V} & \mathbf{V} & \mathbf{V} & \mathbf{S} & \mathbf{A} & \mathbf{K}\end{array}$

2001 CGTAACGTTG AAgTCGAGTA CGCCAGGACA GGTCGTCGTG TCTGCTAAAA GCATTGCAAC TTCAGCTCAT GCGgtCCTGT CCAGCAgCAC AgACGAtTtT

$\begin{array}{llllllllllllllllll}+1 & \mathbf{T} & \mathbf{A} & \mathbf{E} & \mathbf{M} & \mathbf{S} & \mathbf{S} & \mathbf{A} & \mathbf{L} & \mathbf{N} & \mathbf{A} & \mathbf{S} & \mathbf{A} & \mathbf{V} & \mathbf{I} & \mathbf{F} & \mathbf{F} & \mathbf{D}\end{array}$ 2051 CCGCGGAGAT GAGTTCAGCA CTTAATGCCA GTGCGGTTAT ATTTTTTGAT GGCGCCTCTA CTCAAGTCGT GAATTACGgT CACGCCAATA TAAAAAACTA

$\begin{array}{llllllllllllllllll}+1 & \mathbf{Q} & \mathbf{T} & \mathbf{K} & \mathbf{A} & \mathbf{S} & \mathbf{A} & \mathbf{I} & \mathbf{P} & \mathbf{P} & \mathbf{T} & \mathbf{P} & \mathbf{L} & \mathbf{G} & \mathbf{A} & \mathbf{P} & \mathbf{V} & \mathbf{P}\end{array}$ 2101 CAAACCAAGg CCAGCGCAAT TCCTCCAACG CCCCTGGGTG CGCCGgtACC

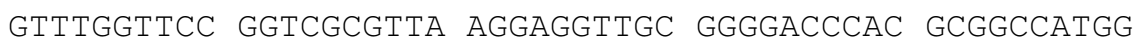

AvaI/SmaI

$\begin{array}{lllllllllllllll}+1 & \mathbf{Y} & \mathbf{P} & \mathbf{D} & \mathbf{P} & \mathbf{L} & \mathbf{E} & \mathbf{P} & \mathbf{R} & \mathbf{A} & \mathbf{A} & \mathbf{S} & \mathbf{G} & \mathbf{P} & \mathbf{G}\end{array}$

2151 GTATCCAGAT CCGCTGGAAC CGCGTGCCGC TTCTGGCCCC GGG/-----CAtAggtCtA GgCGACCTTG GCGCACGgCG AAgACCGGGG CCC/------

$\operatorname{BgIII}$

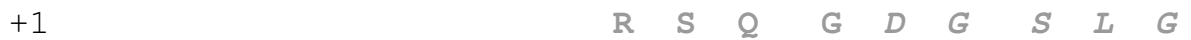

3201 -kodierende Sequenz------/AGATCTC AGGGGGATGG ATCATTAGGT -der Passagierdomäne-----/TCTAGAG TCCCCCTACC TAGTAATCCA

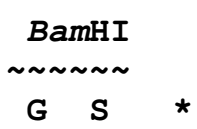

3251 GATATCGAAC CATACGATTC ATCAGGATCC TAAATACCTG TGACGGAAGA CTATAGCTTG GTATGCTAAG TAGTCCTAGG ATTTATGGAC ACTGCCTTCT

3301 TCACTTCGCA GAATAAATAA ATCCTGGTGT CCCTGTTGAT ACCGGGAAGC AgtgAAgCGT CtTAttTAtT tAgGACCACA GgGACAACtA tgGCCCtTCG

3351 CCTGgGCCAA CtTtTgGCGA AAAtgAgACG TtgAtCGgCA CGtAAgAggt GGACCCGGTT GAAAACCGCT TTTACTCTGC AACTAGCCGT GCATTCTCCA

3401 TCCAACTTTC ACCATAATGA AAtAAGATCA CTACCGgGCG TATTTTTtGA AgGtTGAAAg TGgtATtACT tTAtTCtAgt GAtGgCCCGC ATAAAAAACT 


$$
+1 \quad M \quad \mathrm{M} \quad \mathrm{K} \quad \mathrm{K} \quad \mathrm{I}
$$

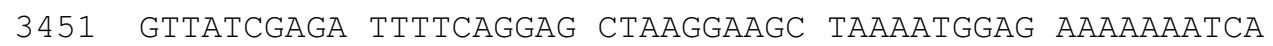
CAATAGCTCT AAAAgTCCTC GAtTCCTTCG ATtTtACCTC TTtTtTTAgt

$\begin{array}{llllllllllllllllllll}+1 & \mathrm{~T} & \mathrm{G} & \mathrm{Y} & \mathrm{T} & \mathrm{T} & \mathrm{V} & \mathrm{D} & \mathrm{I} & \mathrm{S} & \mathrm{Q} & \mathrm{W} & \mathrm{H} & \mathrm{R} & \mathrm{K} & \mathrm{E} & \mathrm{H} & \mathrm{F}\end{array}$ 3501 CTGGATATAC CACCGTtGAT AtAtCCCAAT GgCATCGTAA AgAACATtTT GACCTAtATG GTGgCAACTA TAtAgggttA CCGtAgCAtT tCTTGtAAAA

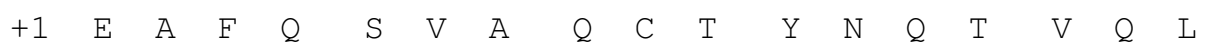
3551 GAgGCATTTC AgTCAGTTGC TCAATGTACC TATAACCAGA CCGTTCAGCT CtCCGtAAAg tCAgtCAACG AgttAcAtgG AtAttggtCt gGCAAgtCGA

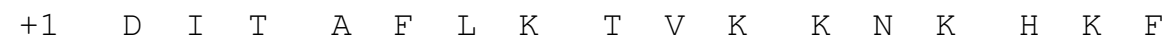
3601 GgAtATtACG GCCTTTtTAA AgACCGTAAA GAAAAATAAg CACAAgtTTt CCTATAATGC CGgAAAAAT TCtgGCATtT CTtTTTAtTC GTGTTCAAAA

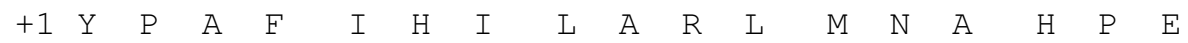
3651 ATCCGGCCTT TATTCACATt CTTGCCCGCC TGATGAATGC TCATCCGGAA tAgGCCGgAA AtAAgtgtAA GAACGgGCGg ACtACtTACG AgtAgGCCTt

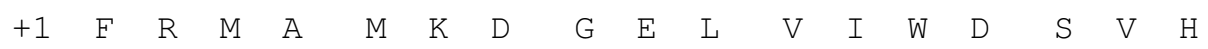
3701 Tttchtatgg CAAtgAAAgA Cggtgagctg gtgAtAtggg AtAgtgttcA AAAGCATACC GTTACTTTCT GCCACTCGAC CACTATACCC TATCACAAGT

\section{HindIII}

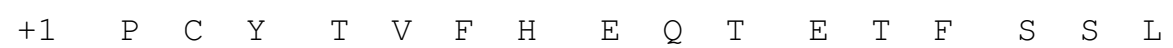
3751 CCCTTGTTAC ACCGTTTTCC AtgAgCAAAC TGAAACGTTT TCAAGCTTGT

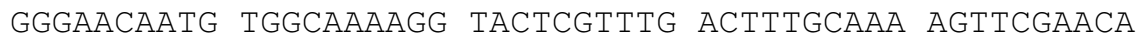

$\begin{array}{llllllllllllllllllllllllllllll}+1 & W & S & E & Y & H & D & D & F & R & Q & F & L & H & I & Y & S & Q\end{array}$ 3801 GgAgTGAATA CCACGACGAT tTCCGGCAGT TTCTACACAT ATATTCGCAA CCtCACtTAt ggtgctgCtA AAggCCGtCA AAgAtgtgtA tAtAAgCgtt

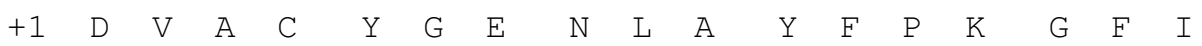
3851 GATGTGGCGT GTtACGgTGA AAACCTGGCC TATTTCCCTA AAgGgtTtAT CTACACCGCA CAATGCCACT TTTGGACCGG ATAAAgGGAT TTCCCAAATA

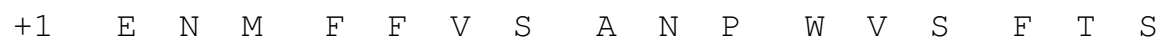

3901 TGAgAAtATG TTtTTCGTCT CAgCCAAtCC CtGgGTGAgT TTCACCAgtT ACTCTTAtAC AAAAAgCAgA GtCGgttAgG GACCCACtCA AAgtggtCAA

$\begin{array}{lllllllllllllllllll}+1 & \mathrm{~F} & \mathrm{D} & \mathrm{L} & \mathrm{N} & \mathrm{V} & \mathrm{A} & \mathrm{N} & \mathrm{M} & \mathrm{D} & \mathrm{N} & \mathrm{F} & \mathrm{F} & \mathrm{A} & \mathrm{P} & \mathrm{V} & \mathrm{F} & \mathrm{T}\end{array}$ 3951 TTGATTTAAA CGTGGCGAAT ATGGACAACT TCTTCGCCCC CGTTTTCACT AACTAAATT GCACCGCTTA TACCTGTTGA AGAAGCGGGG GCAAAAgtgA

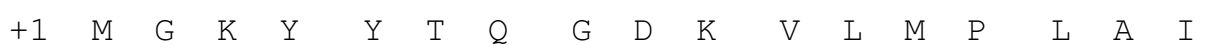
4001 ATGGGCAAA ATtATACGCA AgGCGACAAG GTGCTGATGC CGCTGGCGAT TACCCGTtTA tAATATGCGT TCCGCTGTtC CACGACtACG GCGACCGCTA

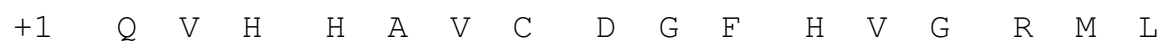
4051 TCAGgtTCAT CATGCCGTtT GTGATGgCtT CCATGTCGgC AgAAtgCtTA AgtCCAAGTA GTACGGCAAA CACTACCGAA GGTACAGCCG TCTTACGAAT

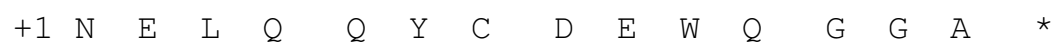

4101 AtgAAtTACA ACAgtACtgC GAtgAgtgGC AgGgCGgGgC GtAAttTtTG TACTTAATGT TGTCATGACG CTACTCACCG TCCCGCCCCG CATTAAAAAC

4151 TCGACCTGCA GGCAGCGCTT GGCGTCACCC GCAGTTCGgT GgtTAAgCtA AGCTGGACGT CCGTCGCGAA CCGCAGTGGg CGTCAAGCCA CCAATTCGAT

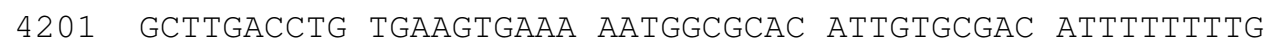
CGAACTGGAC ACTtCACTtT TtACCGCGtG tAACACGCTG TAAAAAAAAC

4251 TCtgCCGTtT ACCGCTACTG CGTCACGgAt CTCCACGCGC CCTGtAgCGg AgACGgCAAA TGgCGAtgAC GCAgtgCCtA GAgGtgCGCG GGACAtCGCC 
4301 CGCATtAAGC GCGgCGgGtg TGgtgGtTAC GCGCAGCGTG ACCGCTACAC GCGTAATTCG CGCCGCCCAC ACCACCAATG CGCGTCGCAC TGGCGATGTG

4351 TTGCCAGCGC CCTAGCGCCC GCTCCTTTCG CTTTCTTCCC TTCCTTTCTC

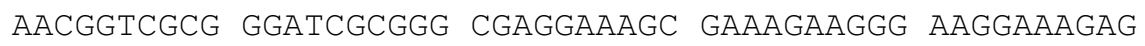

4401 GCCACGTTCG CCGGCTTTCC CCGTCAAGCT CTAAATCGgG GGCTCCCTTT CGgtgCAAGC GgCCGAAAgG GgCAgttCGA GAtTtAgCCC CCGAgGgAAA

4451 AgGgTtCCGA TTTAGTGCTT TACGGCACCT CGACCCCAAA AAACTTGATT TCCCAAGGCT AAATCACGAA ATGCCGTGGA GCTGGGGTTT TTTGAACTAA

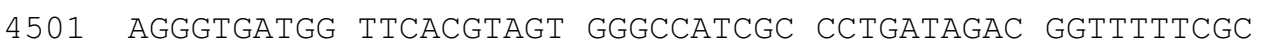
tCCCACTACC AAgtGCAtCA CCCGgtAgCG GgACtAtCtg CCAAAAAgCG

4551 CCTTTGACGT TGgAgtCCAC GTTCTTTAAT AgtgGACTCT TGTTCCAAAC GgAAACTGCA ACCTCAgGTG CAAgAAAtTA TCACCTGAgA ACAAgGtTTG

4601 TGGAACAACA CTCAACCCTA TCTCGGTCTA TTCTTTTGAT TTATAAgGgA ACCTTGTTGT GAGTTGGGAT AgAgCCAGAT AAGAAAACTA AAtATtCCCT

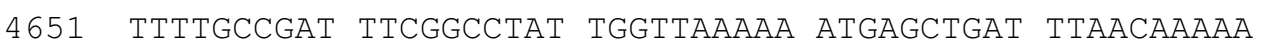
AAAACGgCtA AAgCCGgAtA ACCAAtTTtT tACTCGACTA AAtTGtTtTT

4701 tTtAACGCGA AtTtTAACAA AAtAtTAACG CTtACAAtTt CAgGtggcAC AAATTGCGCT TAAAATTGTT TTAtAATTGC GAATGTTAAA GTCCACCGTG

4751 TtTtCGgGgA AAtgtgCGCG GAACCCCTAT TTgtTTATTT TTCTAAAtAC AAAAGCCCCT TTACACGCGC CTTGGGGAtA AACAAATAAA AAGATTTATG

4801 ATtCAAATAT GTATCCGCTC AtgAgACAAT AACCCTGATA AAtgCtTCAA

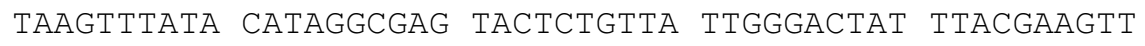

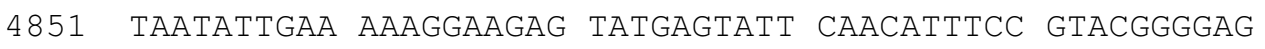

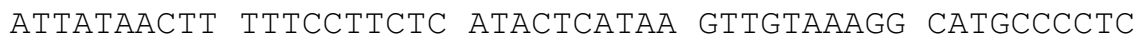

4901 TCAGgCAACT AtgGAtgAAC GAAAtAgACA GAtCGCtGAg AtAgGtgCCT AgtCCGTtGA TACCTACTTG CTtTAtCTgt CTAGCGACtC TAtCCACGgA

$\begin{array}{llllllllllllll}+2 & M & S & R & L & D & K & S\end{array}$

4951 CACTGATtAA GCAtTgGtAg GAAtTAATGA TGtCTCGTTT AgAtAAAAgt GTGACTAATT CGTAACCATC CTTAATTACT ACAGAGCAAA TCTATTTTCA

$\begin{array}{llllllllllllllllll}+2 & \mathrm{~K} & \mathrm{~V} & \mathrm{I} & \mathrm{N} & \mathrm{S} & \mathrm{A} & \mathrm{L} & \mathrm{E} & \mathrm{L} & \mathrm{L} & \mathrm{N} & \mathrm{E} & \mathrm{V} & \mathrm{G} & \mathrm{I} & \mathrm{E} & \mathrm{G}\end{array}$ 5001 AAAgTGATTA ACAGCGCATt AgAgCTGCTT AATGAgGTCG GAATCGAAGg tTtCACtAAT tgtCGCGtAA tCtCGACGAA tTACtCCAGC CTtAgCticC

$\begin{array}{lllllllllllllllllllllllllllllll}+2 & \mathrm{~L} & \mathrm{~T} & \mathrm{~T} & \mathrm{R} & \mathrm{K} & \mathrm{L} & \mathrm{A} & \mathrm{Q} & \mathrm{K} & \mathrm{L} & \mathrm{G} & \mathrm{V} & \mathrm{E} & \mathrm{Q} & \mathrm{P} & \mathrm{T}\end{array}$ 5051 TTTAACAACC CGTAAACTCG CCCAGAAgCT AgGtgtAgAg CAGCCTACAT AAAtTgtTGg GCAtTtgAgC GgGtCTtCGA TCCACAtCtC GTCGgAtGTA

$\begin{array}{llllllllllllllllll}+2 & \mathrm{~L} & \mathrm{Y} & \mathrm{W} & \mathrm{H} & \mathrm{V} & \mathrm{K} & \mathrm{N} & \mathrm{K} & \mathrm{R} & \mathrm{A} & \mathrm{L} & \mathrm{L} & \mathrm{D} & \mathrm{A} & \mathrm{L} & \mathrm{A} & \mathrm{I}\end{array}$ 5101 TGtATtgGCA TGTAAAAAAT AAgCGgGCTT TGCTCGACGC CTTAGCCATt ACATAACCGT ACATtTtTtA tTCGCCCGAA ACGAgCtgCG GAAtCGgtAA

$\begin{array}{lllllllllllllllllllllllllllllllll}2 & \mathrm{E} & \mathrm{M} & \mathrm{L} & \mathrm{D} & \mathrm{R} & \mathrm{H} & \mathrm{H} & \mathrm{T} & \mathrm{H} & \mathrm{F} & \mathrm{C} & \mathrm{P} & \mathrm{L} & \mathrm{E} & \mathrm{G} & \mathrm{E} & \mathrm{S}\end{array}$ 5151 GAgAtgttAg AtAggCACCA tActCACtTT tgCCCtTtAg AAggggAAAg CTCTACAATC tAtCCGTGgt AtgAgtgAAA ACGgGAAAtC TTCCCCTtTC

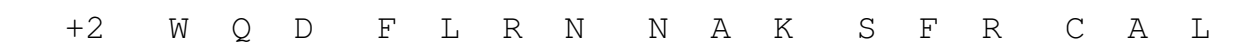
5201 CtgGCAAGAT tTtTtACGtA AtAACGCTAA AAgtTtTAgA tgtgCtTtAC GACCGTTCTA AAAAATGCAT TATTGCGATT TTCAAAATCT ACACGAAATG

$\begin{array}{llllllllllllllllllllllllllllllll}+2 & \mathrm{~L} & \mathrm{~S} & \mathrm{H} & \mathrm{R} & \mathrm{D} & \mathrm{G} & \mathrm{A} & \mathrm{K} & \mathrm{V} & \mathrm{H} & \mathrm{L} & \mathrm{G} & \mathrm{T} & \mathrm{R} & \mathrm{P} & \mathrm{T} & \mathrm{E}\end{array}$ 5251 TAAgtCATCG CGAtgGAgCA AAAgtACAtT TAgGtACACG GCCTACAgAA

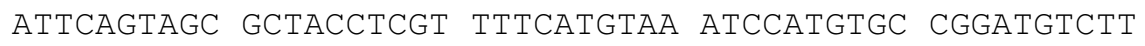




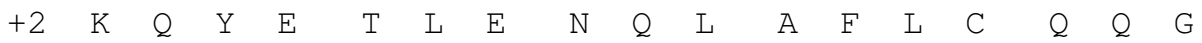
5301 AAACAgTATG AAACTCTCGA AAATCAATTA GCCTTTTTAT GCCAACAAGg

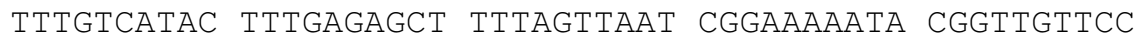

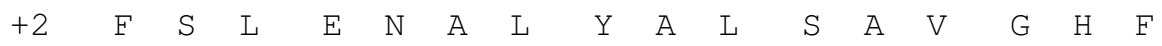
5351 TTTTTCACTA GAGAATGCAT TATATGCACT CAGCGCAGTG GGGCATtTTA AAAAAgtgAT CTCTTACGTA ATAtACGTGA GTCGCGTCAC CCCGTAAAAT

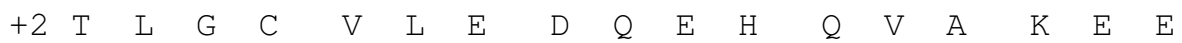
5401 Ctttaggttg CGtAttggAa gAtCAAgAgC AtCAAgtCgC TAAAgAAgAA GAAATCCAAC GCATAACCTT CTAGTTCTCG TAGTTCAGCG ATtTCTTCTT

$\begin{array}{llllllllllllllllll}+2 & \mathrm{R} & \mathrm{E} & \mathrm{T} & \mathrm{P} & \mathrm{T} & \mathrm{T} & \mathrm{D} & \mathrm{S} & \mathrm{M} & \mathrm{P} & \mathrm{P} & \mathrm{L} & \mathrm{L} & \mathrm{R} & \mathrm{Q} & \mathrm{A} & \mathrm{I}\end{array}$ 5451 AgGgAAACAC CTACTACTGA TAGTATGCCG CCATTATTAC GACAAGCTAT tCCCTtTgtg GAtgAtgACT AtCAtACGgC GgtAAtAAtg CTgtTCGAtA

$\begin{array}{llllllllllllllllllllllllllll}+2 & E & L & F & D & H & Q & G & A & E & P & A & F & L & F & G & L\end{array}$ 5501 CGAATTATTT GATCACCAAG GTGCAGAGCC AGCCTTCTTA TTCGGCCTTG GCTTAATAAA CTAGTGgTtC CACGTCtCGg TCGgAAgAAT AAgCCGgAAC

$\begin{array}{llllllllllllllllll}+2 & \mathrm{E} & \mathrm{L} & \mathrm{I} & \mathrm{I} & \mathrm{C} & \mathrm{G} & \mathrm{L} & \mathrm{E} & \mathrm{K} & \mathrm{Q} & \mathrm{L} & \mathrm{K} & \mathrm{C} & \mathrm{E} & \mathrm{S} & \mathrm{G} & \mathrm{S}\end{array}$

5551 AAtTGATCAT AtgCGgAttA GAAAAACAAC TtAAAtgtgA AAgtgggtct tTAACTAGTA tACGCCTAAT CtTtTtgttg AAtTACACT tTCACCCAgA

5601 TAAAAGCAGC AtAACCTtTT tCCGTGATgG TAACTTCACT AgtTtAAAAg AttTtCGtCG tAttggaAAA AggCACtACC AttgaAgtgA tCAAAtTtic

5651 GAtCTAgGtg AAgATCCTTT TtgAtAATCT CATGACCAAA ATCCCTTAAC CtAgAtCCAC tTCtAgGAAA AACtAttAgA gtACtggttT tAgGgAAtTG

5701 GTGAgtTTtC GTTCCACTGA GCGTCAGACC CCGTAgAAAA GATCAAAggA CACTCAAAAg CAAGgTGACT CGCAgtCTgG GgCAtCTTtT CTAGTTtCCT

5751 TCtTCtTGA AtCCTtTtTt tCtgCGCGTA AtCTGCtgCT TGCAAACAAA AGAAGAACTC TAGGAAAAAA AGACGCGCAT TAGACGACGA ACGTTTGTTT

5801 AAAACCACCG CTACCAGCGg TGgTtTGTTT GCCGGATCAA GAgCTACCAA TtTtgGtgGC GAtgGtCGCC ACCAAACAAA CGgCCtAgtT CTCGAtggtT

5851 CTCTTTTTCC GAAgGtAACT GgCTTCAGCA GAGCGCAGAT ACCAAATACT GAgAAAAgG CTTCCAtTGA CCGAAgtCGT CTCGCGtCtA tgGtTtAtgA

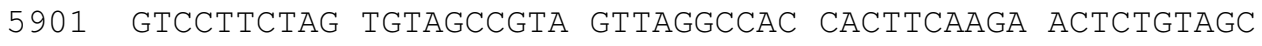
CAGGAAGATC ACATCGGCAT CAATCCGGTG GTGAAgTTCT TGAGACATCG

5951 ACCGCCTACA TACCTCGCTC TGCTAATCCT GTTACCAGTG GCTGCTGCCA tgGCGgAtgt AtgGAgCGA ACGAttAggA CAAtggtCAC CGACGACGgt

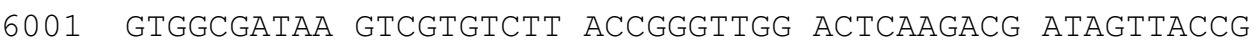
CACCGCtATt CAGCACAgAA TGgCCCAACC TGAgtTCtgC tAtCAAtgGC

6051 GAtAAgGCGC AgCGgtCGgG CtgAACGgGg GgtTCGTGCA CACAgCCCAg CTATTCCGCG TCGCCAGCCC GACTTGCCCC CCAAGCACGT GTGTCGGGTC

6101 CTTGGAGCGA ACGACCTACA CCGAACTGAG ATACCTACAg CGTGAgCtAT GAACCTCGCT TGCTGGATGT GgCTTGACTC TAtgGAtGTC GCACTCGATA

6151 GAgAAAgCGC CACGCTtCCC GAAgGgAgAA AgGCGgACAg GTAtCCGgtA CTCTTTCGCG GTGCGAAgGg CTTCCCTCTT TCCGCCTGTC CAtAgGCCAT

6201 AgCGgCAgGg tCGgAACAgG AgAgCGCACG AgggagCtTC CAgGgggAAA TCGCCGTCCC AGCCTTGTCC TCTCGCGTGC TCCCTCGAAG GTCCCCCTTT

6251 CGCCTGgtAt CtTtAtAgtC CtgtCGggtT TCGCCACCTC TGACTtGAgC GCGGACCATA GAAATACAg GACAgCCCAA AgCGgtgGA ACTGAACTCG

6301 GTCGATTTT GTGATGCTCG TCAgGgGgGC GGAGCCTATG GAAAAACGCC CAGCTAAAAA CACTACGAGC AGTCCCCCCG CCTCGGATAC CTTTTTGCGG 


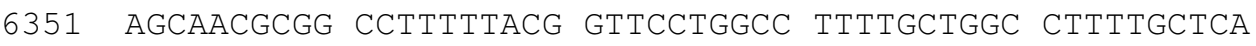
TCGTTGCGCC GGAAAAATC CAAGGACCGG AAAACGACCG GAAAACGAGT

6401 CATGACCCGA CA

GTACTGGGCT GT

\section{- Passagierdomäne EETI-CK ${ }^{\text {send }}$}

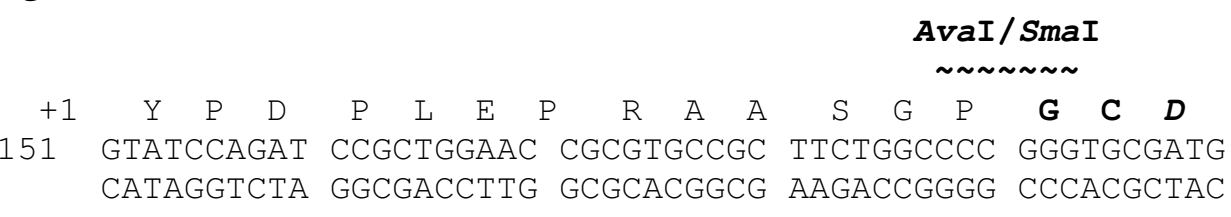

$\begin{array}{llllllllllllllllll}+1 & G & S & L & G & D & I & E & P & Y & D & S & S & C & K & Q & D & S\end{array}$

2201 GAAGCTTAgG TGATATCGAA CCATACGATt CATCATGCAA ACAgGACtCC CTTCGAATCC ACTATAGCTT GGTATGCTAA GTAGTACGTT TGTCCTGAGG

$\begin{array}{llllllllllllllllll}+1 & \mathbf{D} & \mathbf{C} & \mathrm{L} & \mathbf{A} & \mathbf{G} & \mathbf{C} & \mathbf{V} & \mathbf{C} & \mathbf{G} & \mathbf{P} & \mathbf{N} & \mathbf{G} & \mathbf{F} & \mathbf{C} & \mathbf{G} & \mathbf{S} & \text { * }\end{array}$

2251 GACTGCCTGG CTGGCTGCGT TTGCGGGCCC AACGGTTTCT GCGGATCCTA CTGACGGACC GACCGACGCA AACGCCCGgG TtgCCAAAgA CGCCTAGgAT

2301 AATACCTGTG ACGgAAgAtC ACtTCGCAGA AtAAATAAAT CCTGGTGTCC TTATGGACAC TGCCTTCTAG TGAAGCGTCT TATTtATtTA GGACCACAGG

\section{- Passagierdomäne $R E I_{v}$}

$\Delta($ SmaI/StuI $)$

$\begin{array}{llllllllllllllllll}+1 & \mathrm{Y} & \mathrm{P} & \mathrm{D} & \mathrm{P} & \mathrm{L} & \mathrm{E} & \mathrm{P} & \mathrm{R} & \mathrm{A} & \mathrm{A} & \mathrm{S} & \mathrm{G} & \mathrm{P} & \mathbf{P} & \mathbf{P} & \mathbf{T} & \ldots /\end{array}$

2151 GTATCCAGAT CCGCTGGAAC CGCGTGCCGC TTCTGGCCCC CCTCCAACG../ CAtAgGtCtA GGCGACCTTG GCGCACGGCG AAgACCGGGG GGAGgtTGC../

\section{$\operatorname{Bg} I I I$}

$\begin{array}{llllllllllllllllll}+1 & / . & \mathbf{G} & \mathbf{T} & \mathbf{K} & \mathrm{L} & \mathbf{Q} & \mathbf{I} & \mathbf{T} & \mathbf{R} & \mathbf{R} & \mathbf{S} & \mathrm{Q} & \mathbf{G} & \boldsymbol{D} & \boldsymbol{G} & \boldsymbol{S} & \boldsymbol{L}\end{array}$ 2501 /.GGTACTAA GCTTCAAATC ACTAGGAGAT CTCAGGGGGA TGGATCATTA /.CCATGATT CGAAGTTTAG TGATCCTCTA GAGTCCCCCT ACCTAGTAAT

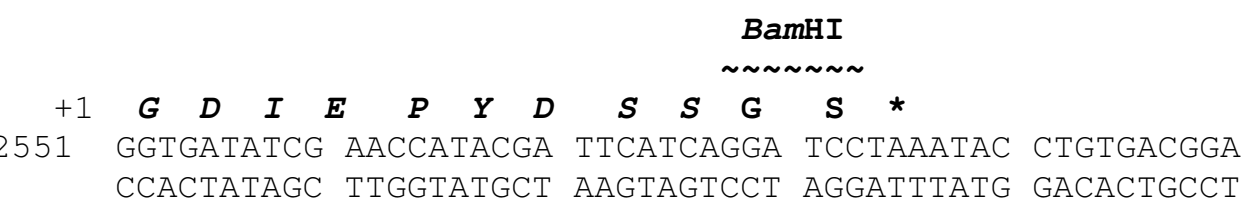

\section{- Passagierdomäne Interleukin 4}

AvaI/SmaI

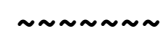

$\begin{array}{llllllllllllllllllllllll}+1 & \mathrm{Y} & \mathrm{P} & \mathrm{D} & \mathrm{P} & \mathrm{L} & \mathrm{E} & \mathrm{P} & \mathrm{R} & \mathrm{A} & \mathrm{A} & \mathrm{S} & \mathrm{G} & \mathrm{P} & \mathrm{G} & \mathrm{H} & \mathrm{K} & \ldots\end{array}$

2151 GTATCCAGAT CCGCTGGAAC CGCGTGCCGC TTCTGGCCCC GGGCACAAG../ CAtAgGtCtA GGCGACCTtG GCGCACGgCG AAgACCGgGg CCCGTGTtC..।

$\begin{array}{lllllllllllllllllll}+1 & / & \mathbf{R} & \mathbf{E} & \mathrm{K} & \mathrm{Y} & \mathbf{S} & \mathrm{K} & \mathrm{C} & \mathbf{S} & \mathbf{S} & \boldsymbol{D} & \boldsymbol{G} & \boldsymbol{S} & \boldsymbol{L} & \boldsymbol{G} & \boldsymbol{D} & \boldsymbol{I}\end{array}$ 2551 /.AGAGAGA AATATTCAAA GTGTTCGAGC GATGGATCAT TAGgtGATAT /.tCTCtCT tTAtAAgtTt CACAAGCtCG CTACCTAGTA ATCCACTATA

$\begin{array}{llllllll} & E & P & Y & D & S & S \quad & \begin{array}{r}\text { BamHI } \\ \sim \sim \sim \sim \sim\end{array}\end{array}$

2601 CGAACCATAC GATTCATCAT AAGGATCCTA AATACCTGTG ACGGAAGATC

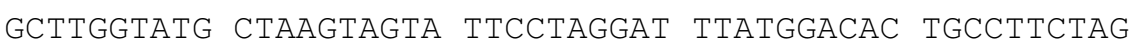


- Passagierdomäne Calmodulin

AvaI/SmaI

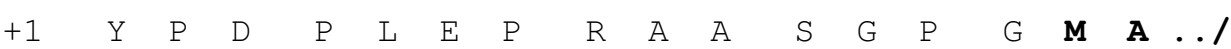

2151 GTATCCAGAT CCGCTGGAAC CGCGTGCCGC TTCTGGCCCC GGGATGGCT../ CAtAgGtCtA GgCGACCTtg GCGCACGgCG AAgACCGGGg CCCTACCGA..।

BglII

$\begin{array}{lllllllllllllllll}+1 & / \ldots & \mathbf{N} & \mathbf{Y} & \mathbf{E} & \mathbf{E} & \mathbf{F} & \mathbf{V} & \mathbf{Q} & \mathbf{M} & \mathbf{M} & \mathbf{T} & \mathbf{A} & \mathbf{K} & \mathbf{R} & \mathbf{S} & \mathbf{Q}\end{array}$

$2601 / \ldots$...ATTAT GAAGAGTTTG TACAGATGAT GACTGCAAAG AGATCTCAGG /...tTAAtA CTtCtCAAAC AtgtCtActa ctgacgttTC tCtAgAgtCC

$\begin{array}{llllllllllllllllll}+1 & G & D & G & S & L & G & D & I & E & P & \boldsymbol{Y} & D & \boldsymbol{S} & \boldsymbol{S} & \mathbf{G} & \mathbf{S} & \text { * }\end{array}$

2651 GgGAtgGATC AtTAggtgAt AtCGAACCAT ACGATTCATC AgGATCCTAA CCCTACCTAG tAATCCACtA tAgCtTGgtA tgCtAagtag tCCtAggAtT

- Passagierdomäne $\beta$-Laktamase Inhibitor Protein (BLIP)

AvaI / SmaI

$\begin{array}{llllllllllllllllllllll}1 & Y & P & D & P & L & E & P & R & A & A & S & G & P & G & A & G & \ldots\end{array}$

2151 GtATCCAGAt CCGCTGgAAC CGCGTGCCGC TtCTGGCCCC GGgGCGgGg../

CAtAggtCTA GGCGACCTTG GCGCACGgCG AAgACCGGGg CCCCGCCCC...

$\begin{array}{llllllllllllllllll}+1 & / & \text { G } & \text { V } & \text { L } & \text { Q } & \text { G } & \text { K } & \text { R } & \mathbf{Q} & \text { W } & \text { D } & \text { L } & \text { V } & D & G & S & L\end{array}$

2651 /.gGgGtGCT TCAGGgCAAG CGGCAGTGGG ACCTTGTAGA TGGATCATtA /. CCCCACGA AgTCCCGTTC GCCGTCACCC TGGAACATCT ACCTAGtAAT

$+1 G \quad D \quad I \quad E \quad P \quad Y \quad D \quad S \quad S *$ BamHI

2701 GgTGATATCG AACCATACGA TTCATCATAA GgATCCTAAA TACCTGTGAC

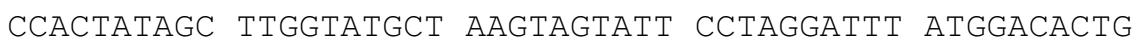

- Passagierdomäne TEM-1 $\beta$-Laktamase

AvaI/SmaI

$\sim \sim \sim \sim \sim \sim$

$\begin{array}{llllllllllllllllllllll}+1 & \mathrm{Y} & \mathrm{P} & \mathrm{D} & \mathrm{P} & \mathrm{L} & \mathrm{E} & \mathrm{P} & \mathrm{R} & \mathrm{A} & \mathrm{A} & \mathrm{S} & \mathrm{G} & \mathrm{P} & \mathrm{G} & \mathrm{H} & \mathrm{P} & \ldots\end{array}$

2151 GTATCCAGAT CCGCTGGAAC CGCGTGCCGC TTCTGGCCCC GGGCACCCA../

CAtAgGtCTA GGCGACCTTG GCGCACGgCG AAgACCGgGg CCCGTGGgt../

$\operatorname{BglII}$

$\begin{array}{llllllllllllllllll}+1 & / \ldots & \mathbf{P} & \mathbf{T} & \mathbf{P} & \mathrm{D} & \mathbf{I} & \mathbf{G} & \mathbf{T} & \mathbf{E} & \mathbf{F} & \mathbf{I} & \mathbf{D} & \mathbf{R} & \mathbf{S} & \mathbf{Q} & \mathbf{G} & \mathbf{D}\end{array}$

$3001 / .$. CCAACGC CTGATATCGG TACCGAATTC ATCGATAGAT CTCAGGgGgA /..gGtTGCG GACTATAGCC ATGGCtTAAg TAGCTATCTA GAgtCCCCCT

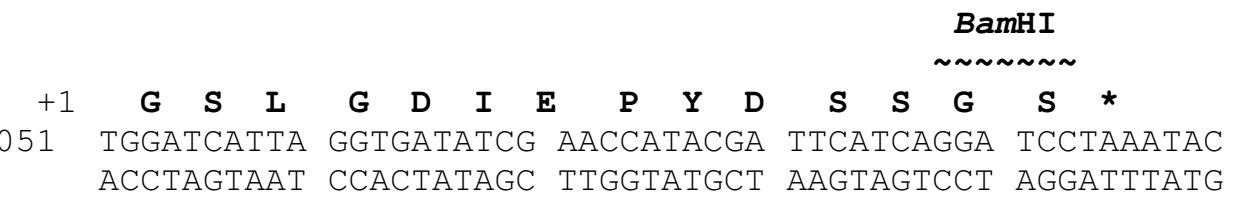




\subsection{2 pREP4-supE}

- Schematische Darstellung des Plasmids pREP4-supE.

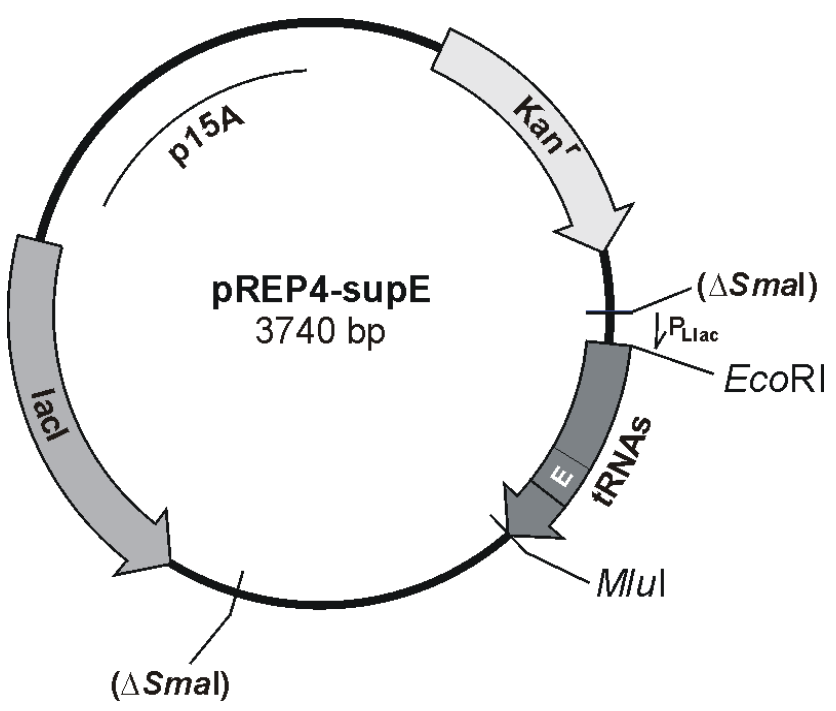

Abbildung 29. Schematische Darstellung des Plasmids pREP4-supE. Pfeilrichtungen geben die funktionellen Orientierungen der genetischen Elemente an. tRNAs: kodierende Sequenz für die tRNA ${ }^{\mathrm{Gln}(\mathrm{CAA})}$, die tRNA ${ }^{\mathrm{Gln}(\mathrm{CCU})}$, die tRNA ${ }^{\mathrm{Met}}$, die supE tRNA (E) und die tRNA ${ }^{\mathrm{Gln}(\mathrm{AAU})}$, $\mathrm{Kan}^{r}$ : kodierende Sequenz für das Kanamycin-Resistenz-Gen, lacI des Transposons 5, kodierende Sequenz für den lac-Repressor, p15A: p15A-Replikationsursprung von E. coli. Die Transkription des tRNA-Clusters erfolgt unter der Kontrolle der $P_{\text {Llac }}$-Promotor/OperatorRegion $\left(P_{\text {Llac }}\right)$. Wichtige Erkennungssequenzen für im Rahmen dieser Arbeit verwendete Restriktionsendonukleasen sowie die beiden Hälften der durch die Klonierung der tRNAGene deletierten SmaI Schnittstelle ( $\Delta$ SmaI) sind hervorgehoben.

- Ausschnitt aus der Nukleotidsequenz des Plasmids pREP4-supE.

\begin{tabular}{|r|l|}
\hline $1356-1419$ & Promotor-Region aus pZA22-MCS1 \\
\hline $1420-2061$ & $\begin{array}{l}\text { Ausschnitt aus dem supB-E tRNA gene cluster von E. coli, kloniert } \\
\text { über die Restriktionsschnittstellen EcoRI und } M l u I, \text { darin }\end{array}$ \\
\hline $1431-1514$ & kodierende Sequenz für die tRNA Gln(CAA) $^{\text {Gln(CCU) }}$ \\
\hline $1549-1623$ & kodierende Sequenz für die tRNA ${ }^{\text {Met }}$ \\
\hline $1639-1715$ & kodierende Sequenz für die tRNA ${ }^{\text {Met }}$ \\
\hline $1763-1837$ & kodierende Sequenz für die supE tRNA \\
\hline $1875-1945$ & kodierende Sequenz für die tRNA \\
\hline $2062-$ & Bereich aus pZA22-MCS1 \\
\hline
\end{tabular}


1451 CAAGCGGTAA GGCACCGGTT TTTGATACCG GCATTCCCTG GTTCGAATCC GTTCGCCATT CCGTGGCCAA AAACTATGGC CGTAAGGGAC CAAGCTTAGG

1501 AgGTACCCCA GCCATCTTCT TCGAGTAAGC GGTTCACCGC CCGGTTATTG TCCATGgGgt CGgtAgAAGA AgCTCATTCG CCAAGTGGCG GGCCAATAAC

1551 GGGTATCGCC AAGCGGTAAG GCACCGGTTT TTGATACCGG CATTCCCTGG CCCATAGCGG TTCGCCATTC CGTGGCCAAA AACTATGGCC GTAAGGGACC

1601 TTCGAATCCA GGTACCCCAg CCATCGAAGA AACAATCTGg CTACGTAGCT AAGCTTAGGT CCATGGGGTC GGTAGCTTCT TTGTTAGACC GATGCATCGA

1651 CAGTTGGTTA GAGCACATCA CTCATAATGA TGGGGTCACA GGTTCGAATC GTCAACCAAT CTCGTGTAGT GAGTATTACT ACCCCAGTGT CCAAGCTTAG

1701 CCGTCGTAGC CACCAAATTC TGAATGTATC GAATATGTTC GGCAAATTCA GGCAGCATCG GTGGTTTAAG ACTTACATAG CTTATACAAG CCGTTTAAGT

1751 AAACCAATT GTTGGGGTAT CGCCAAGCGG TAAGGCACCG GATTCTGATT TTTGGTTAAA CAACCCCATA GCGGTTCGCC ATTCCGTGGC CTAAGACTAA

1801 CCGGCATTCC GAGGTTCGAA TCCTCGTACC CCAGCCAATT TATTCAAGAC GGCCGTAAGG CTCCAAGCTT AGGAGCATGG GGTCGgTTAA ATAAGTTCTG

1851 GCTTACCTTG TAAGTGCACC CAGTTGGgGt ATCGCCAAGC GGTAAGGCAC CGAATGGAAC ATTCACGTGG GTCAACCCCA TAGCGGTTCG CCATTCCGTG

1901 CGGATTCTGA TTCCGGCATT CCGAGGTTCG AATCCTCGTA CCCCAGCCAC GCCTAAGACT AAGGCCGTAA GGCTCCAAGC TTAGGAGCAT GGGGTCGGTG

1951 ATtAAAAAA CTCGCTTCGg CGAGCTTTTT GCTTTTCTGC GTTCATTCAA TAATtTtTTC GAGCGAAGCC GCTCGAAAAA CGAAAAGACG CAAGTAAgtT

2001 TGtCGAAtgC GAtgtTGACA CGTCtTAtCC tTCAAtgtCG GAtgCGACGC ACAGCTTACG CTACAACTGT GCAGAAtAgG AAgtTACAGC CTACGCTGCG

MluI 

2051 TGCCGCGTCT TACGCGTGCT AgAgGCATCA AAtAAAACGA AAgGC.... ACGGCGCAGA ATGCGCACGA TCTCCGTAGT TTATTTTGCT TTCCG.... 


\subsection{Danksagung}

Die vorliegende Arbeit wurde in der Abteilung für Molekulare Genetik und Präparative Molekularbiologie des Instituts für Mikrobiologie und Genetik der Georg-August-Universität Göttingen angefertigt und durch den Sonderforschungsbereich 416 "Chemische und biologische Synthese und Transformation von Naturstoffen und Naturstoff-Analoga" sowie das Graduiertenkolleg „Chemische Aktivitäten von Mikroorganismen“ unterstützt.

An erster Stelle möchte ich Harald Kolmar für die langjährige, kollegiale und fruchtbare Zusammenarbeit an der Universität Göttingen und darüber hinaus danken. Die stets vorhandene Bereitschaft zu wissenschaftlicher Diskussion und Hilfestellung gepaart mit dem mir entgegengebrachten Vertrauen in Sachen Planung und Durchführung von Experimenten sowie die unterstützende Mitarbeit in vielen Bereichen dieser Arbeit hatten einen entscheidenden Anteil an deren Gelingen.

Prof. Hans-Joachim Fritz danke ich recht herzlich für die Möglichkeit, in seiner Abteilung diese Arbeit anfertigen und alle zur Verfügung stehenden Ressourcen nutzen zu können sowie für eine Vielzahl wertvoller Anregungen und Diskussionen im Rahmen der Arbeitsberichte und Seminare.

Den Gruppenleitern Wilfried Kramer, Susanne Behrens, Reinhard Sterner und Andreas Schwienhorst danke ich für viele hilfreiche Lösungsvorschläge in Sachen Wissenschaft. Wilfried Kramer danke ich darüber hinaus für die Übernahme des Korreferats.

Marita Kalck, Rainer Merkl, Olaf Waase und Patrick Regin danke ich für ihre stete, ideenreiche Hilfsbereitschaft in Fragen der Bürokratie, bei Problemen mit Soft- und Hardware sowie in allen sonstigen technischen Angelegenheiten. Weiter gilt ein Dank Elisabeth Schafflik, Marlies Bartels und Angelika Löffers für die reibungslose Ver- und Entsorgung.

Meinen jetzigen und ehemaligen Mitstreitern Andreas Christmann, Thorsten Adams, Ulli Schmoldt, Bettina Hucke, Kerstin Walter, Dirk Ponsel, Gerrit Hennecke, Martina HennSax, Anke Schürer, Christian Rudolph, Birgit Zeike, Jürgen Scheller, Martin Laging, Eva Kansy, Julia Wittmann, Stina Schiller, Rüdiger Dietrich, Milena Ninkovic, Gülden Aral, Dennis Wegener, Christian Hildmann, Christian Klug, Frank Wirsching, René Hempel und allen, die ich unbeabsichtigt in der Aufzählung unterschlagen habe, gilt ein großer Dank für die angenehme Arbeitsatmosphäre auf der Etage über die gesamte Zeit. Thorsten Adams danke ich hierbei besonders für die Mithilfe bei der Klonierung des BLIP-Gens.

Der Belegschaft des Göttingen Genomics Laboratory $\left(\mathrm{G}_{2} \mathrm{~L}\right)$ gilt der Dank für eine Vielzahl gut auswertbarer Sequenzen. Ralph Pries aus der Abteilung für Molekulare Mikrobiologie von Prof. Braus danke ich für die Unterstützung in Sachen fluoreszenzmikroskopische Fotografie.

Der Arbeitsgruppe von Prof. Dr. J. Hacker, Universität Würzburg, danke ich für die Bereitstellung von abgetöteten EHEC Zellen, Dr. Karlheinz Friedrich, Universität Jena, für die Bereitstellung des Plasmids pRPR9IL-4FD sowie Dr. N. C. J. Strynadka, University of British Columbia, Vancouver, für die Überlassung eines für BLIP kodierenden Plasmids.

Besonders möchte ich meinen Eltern danken, die mich stets in meinen Zielen bestärkt und die mich die gesamte Zeit meines Studiums über nach Kräften unterstützt haben. Sie haben auf diese Weise einen entscheidenden Anteil an dieser Arbeit.

Mein größter Dank gilt meiner Verlobten Heike,... für Ihre Geduld. 


\subsection{Lebenslauf}

Name: $\quad$ Alexander Wentzel

Geburtsdatum: 25. Februar 1973

Geburtsort: $\quad$ Freie und Hansestadt Hamburg

Staatsangehörigkeit: deutsch

Familienstand: $\quad$ ledig

Eltern: Wolfgang Wentzel und Hannelore Wentzel, geb. Ehmann

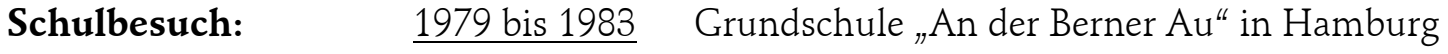

1983 bis 1984 Gymnasium Meiendorf in Hamburg

1985 bis 1992 Johann-Rist-Gymnasium in Wedel/Holstein

1992 Abitur am Johann-Rist-Gymnasium in Wedel/Holstein

Zivildienst: $\quad 1992$ bis 1993 Mobiler Sozialer Hilfsdienst bei der Arbeiterwohlfahrt, Kreisverband Pinneberg

Studium der Biologie: 1993 bis 1997 an der Georg-August-Universität zu Göttingen

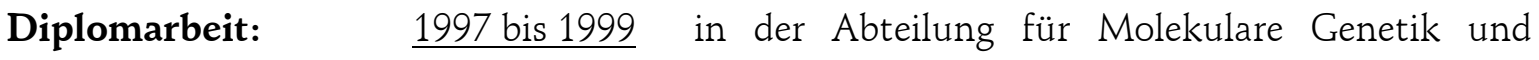
Präparative Molekularbiologie des Instituts für Mikrobiologie und Genetik der Georg-August-Universität zu Göttingen.

Titel: „Über die Faltung eines Mikroproteins mit Cystin-KnotenFaltungsmotiv am Beispiel des Trypsin-Inhibitors II von Ecballium elaterium (L.) A. Rich. (EETI-II)“, Gesamtnote: „Mit Auszeichnung“

Doktorarbeit: $\quad$ seit April 1999 in der Abteilung für Molekulare Genetik und Präparative Molekularbiologie des Instituts für Mikrobiologie und Genetik der Georg-August-Universität zu Göttingen. Unterstützt durch den SFB416 "Chemische und biologische Synthese und Transformation von Naturstoffen und Naturstoffanaloga" sowie durch das Graduiertenkolleg "Chemische Aktivitäten von Mikroorganismen" der Georg-August-Universität zu Göttingen.

Sonstiges:

Gründungsgesellschafter der im Juli 2001 in Göttingen gegründeten Selecore $\mathrm{GmbH}$.

seit Juli 2002 Projektleiter "Technologieentwicklung" bei der Selecore GmbH Göttingen. 